NBSIR 80-1627

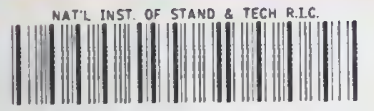

A】l】04 52941己

\title{
MATERIALS STUDIES FOR MAGNETIC FUSION ENERGY APPLICATIONS AT LOW TEMPERATURES - III
}
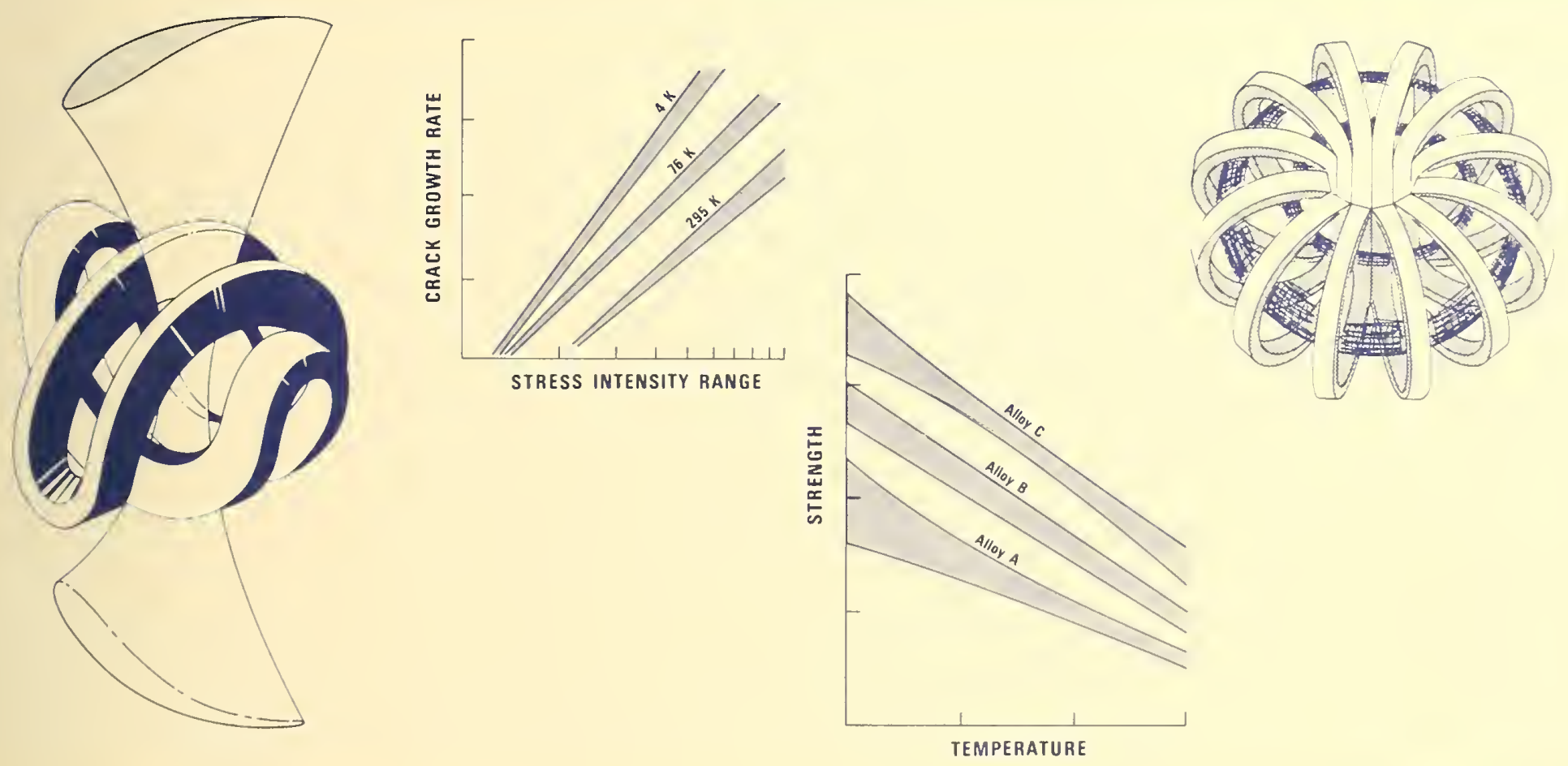

TO

DEPARTMENT OF ENERGY OFFICE OF FUSION ENERGY WASHINGTON, D.C. 20545

$-Q C$

100

.456

$80-1627$

1980
TECHNICAL REPORTS

TEMPERATURE
BY

FRACTURE AND DEFORMATION DIVISION NATIONAL BUREAU OF STANDARDS BOULDER, CO 80303 



\section{TECHNICAL REPORTS}

\section{MATERIALS STUDIES FOR MAGNETIC FUSION ENERGY \\ APPLICATIONS AT LOW TEMPERATURES - III}

\section{Edited By}

R.P. Reed

Fracture and Deformation Division

National Bureau of Standards

Boulder, CO 80303

June 1980

Sponsored By

Department of Energy

Office of Fusion Energy

Washington, D.C. 20545

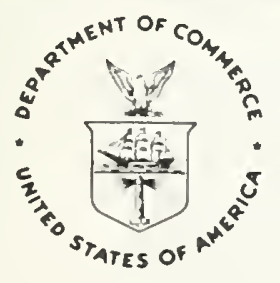

U.S. DEPARTMENT OF COMMERCE, Philip M. Klutznick, Secretary

Luther H. Hodges, Jr., Deputy Secretary

Jordan J. Baruch, Assistant Secretary for Productivity, Technology and Innovation

NATIONAL BUREAU OF STANDARDS, Ernest Ambler, Director 

SUMMARY

SUMH

INTRODUCTION

Interstitial Carbon and Nitrogen Effects on the Tensile and Fracture Parameters of AISI 304 Stainless Steels

Temperature Dependence of Yielding in Austenitic Stainless Steels

Anomalous Low-Temperature Elastic-Constant Behavior in $\mathrm{Fe}-13 \mathrm{Cr}-19 \mathrm{Mn}$

Room-temperature Elastic Constants and Low-Temperature Sound Velocities for Six Nitrogen-Strengthened Stainless Steels

Sound Velocities and Elastic Constants of Austenitic Steels 304, 310, and 316

Elastic Constants of Stainless Steels 304, 310, 316 between 4 and $295 \mathrm{~K}$

Young's Modulus of a Copper-Stabilized

Niobium-Titanium Superconductive Wire

WELDING

Weldments for Liquid Hel ium Service

Fracture Behavior of Ferrite-Free Stainless Steel welds in Liquid Helium

Weld Process Study for 316L Stainless Steel Weld Metal at Cryogenic Temperatures

The Computer-Aided J-Integral Test Facility at NBS

Tensile and Notch Tensile Properties at Room Temperature and $4 \mathrm{~K}$ of Welds in Aluminum Alloy 5083-0 Plate

Note on a Simple Test Method for Estimating $\mathrm{J}_{\mathrm{IC}}$

NONMETALLICS

Nonmetallics for Magnet Systems

Cryogenic Properties of Filamentary-Reinforced Composites: An Update

Mechanical Properties of G-10CR and G-11CR

Mechanical, Electrical, and Thermal Characterization of G-10CR and G-11CR Glass/Cloth Epoxy Laminates Between Room Temperature and $4 \mathrm{~K}$

Temperature Dependence of Young's Modulus and Internal

Friction of G-lOCR and G-1TCR Epoxy Resins

Directional Variation of Young's Modulus and Internal

Friction in Two Fiberglass-Cloth-Epoxy Composites

Thermal Conductivity of G-10CR and G-11CR Industrial

Laminates at Low-Temperatures (Part II)

Thermal Expansion of Cryogenic-Grade Glass-Epoxy Laminates 405

TECHNOLOGY TRANSFER

Structures, Insulators and Conductors for Large

VAIL WORKSHOP Superconducting Magnets 

The reports presented here summarize the work of the low temperature materials research project for the third year of the program. The various projects are outlined and the research results are presented. The major thrust of the measurements has been the evaluation of the low temperature mechanical and physical properties of stainless steel base metal and welds, with particular emphasis on the nitrogen-strengthened stainless steels. Aluminum alloys have received some consideration also. Work has also been done on the production and standardization of nonmetallics, primarily industrial laminates, for low temperature applications and on the measurement of their properties at cryogenic temperatures. A brief description of the third NBS/DoE Vail workshop, held in October 1979, is given.

Note: Certain commercial equipment, instruments, or materials are identified in this paper to adequately specify the experimental procedure. In no case does such identification imply recommendation or endorsement by the National Bureau of Standards, nor does it imply that the material or equipment identified is necessarily the best available for the purpose. Papers by non-NBS authors have not been reviewed or edited by NBS. Therefore, the National Bureau of Standards accepts no responsibility for comments or recommendations contained therein. 

INTRODUCTION

This report contains results of a research program to produce materials properties data to facilitate design and development of cryogenic structures for superconducting magnets required for plasma confinement in magnetic fusion energy power plants and prototypes. The program was conceived and developed jointly by the staffs of the National Bureau of Standards and the Office of Fusion Energy of the Department of Energy. This program, sponsored by DoE, is managed by NBS. Research is conducted at NBS and at various other laboratories through subcontracts with NBS. 

Highlights of Results 

We present here a brief description of outstanding results from the project reports, which follow in the next section. Alloys for Low Temperature Service

The effects on $4 \mathrm{~K}$ strength and toughness of carbon and nitrogen additions to an AISI 304L base alloy were examined. Amounts of carbon between 0.03 and 0.09 weight percent and of nitrogen between 0.03 and 0.22 weight percent were used. Three-fold increases of yield strength were obtained at $4 \mathrm{~K}$. The strength was found proportional to carbon plus nitrogen additions. The dependence of flow strength on carbon and nitrogen concentration is more pronounced at lower temperatures. Although toughness decreases and fatigue crack growth rates increase with carbon and nitrogen additions, adequate toughness and crack growth rates are maintained at $4 k$ in the alloys with high concentrations.

The temperature dependence of the flow strength of AISI 316 was measured at about ten different temperatures between 4 and $300 \mathrm{~K}$. Unlike AISI 304L, no anomalous decreases of flow strength at lower temperatures were observed. Using the Oak Ridge National Laboratory high temperature data for the same alloy heat, equations predicting the temperature dependence of alloys were assessed. The best low temperature fit to our data relates flow stress to the reciprocal of temperature. The relationship of this temperature dependence to physical factors affecting strength is being examined.

Physical Properties of Stainless Steels

This report contains brief descriptions of four experimental studies on the elastic properties of 300 -series austenitic stainless steels: 
1. Room-temperature sound velocities and elastic constants of austenitic stainless steels 304,310 , and 316 . This study extends our previously reported effort on the elastic-constant variability in stainless steel 304. For all three steels, for all elastic constants, variabilities are less than two percent.

2. Elastic constants of stainless steels 304, 310, and 316 between 4 and $295 \mathrm{~K}$. A11 three steels show low-temperature elastic-constant anomalies related to magnetic transitions. Stainless-steel 310 behaves differently in this regard than 304 and 316.

3. Room-temperature elastic constants and low-temperature sound velocities in six nitrogen-strengthened austenitic stainless steels. Despite large composition differences, room-temperature elastic constants vary only slightly in these alloys. At low temperatures, elastic constants, affected by magnetic transitions, show qualitatively similar, but quantitatively different, behavior.

4. Anomalous low-temperature elastic-constant behavior in $\mathrm{Fe}-13 \mathrm{Cr}-$ 19Mn. This Soviet stainless steel, containing high manganese, but no nickel, exhibits large elastic-constant anomalies upon cooling to about 290 K.

Welding

Tensile and fracture toughness tests were conducted on stainless steel welds at $4 \mathrm{~K}$ in support of the Large Coil Project (LCP) and Magnetic Fusion Test Facility programs. Welds were provided by LCP contractors and Lawrence Livermore Laboratory (LLL). Notable results at $4 \mathrm{~K}$ are summarized below. Peening the weld after each pass improved the toughness of the LCP $316 \mathrm{~L}$ welds. Annealing the LCP $316 \mathrm{~L}$ welds resulted in a substantial improvement in toughness. The 316L SMA welds supplied by LLL had satisfactory 
strength and toughness at $4 \mathrm{~K}$. An open-arc flux-cored $308 \mathrm{~L}$ weld exhibited brittle behavior in the $4 \mathrm{~K}$ toughness tests; this was attributed to nitrogen pickup during welding. Experimental weld compositions supplied by filler metal producers were evaluated at $4 \mathrm{~K}$. The $18 \mathrm{Cr}-16 \mathrm{Ni}-9 \mathrm{Mn}$ alloy had a yield strength of $1030 \mathrm{MPa}$ and a toughness of $121 \mathrm{MPa} \sqrt{\mathrm{m}}$ at $4 \mathrm{~K}$. The $16 \mathrm{Cr}-16 \mathrm{Ni}-2 \mathrm{Mo}$ alloy deposited by the FCAW process had a toughness of 239 . MPa $\sqrt{m}$ and a yield strength of $607 \mathrm{MPa}$ at $4 \mathrm{~K}$.

Alcoa conducted an evaluation of $51 \mathrm{~mm}$ thick 5083-0 aluminum weldments provided by several fabricators. All welds were made using 5183 electrodes and the gas metal-arc process. The tensile and notch tensile properties were determined at room temperature and $4 \mathrm{~K}$. The same test plates will be fracture toughness tested by NBS in FY80 to extend to $4 \mathrm{~K}$ the correlation between notch-yield ratio and fracture toughness, which is currently valid at room temperature and $77 \mathrm{~K}$.

Teledyne-McKay prepared a series of six test weldments on AISI 304 stainless steel base plate using three welding processes: GTA, GMA, and SAW. Each of the weldments was tested to measure the tensile properties at room temperature, the Charpy impact toughness at $77 \mathrm{~K}$, and the microfissuring tendencies. NBS will evaluate the tensile properties and fracture toughness at $4 \mathrm{~K}$ during FY80. The Charpy values indicate that the GTA and GMA welds meet ASME requirements at $77 \mathrm{~K}$, but the SA welds are brittle.

Nonmetallics for Magnet Structures

The initial static mechanical property characterization of the G-10CR and G-11CR cryogenic grades of industrial glass-epoxy laminates have been completed. Additionally, the CR-grade products produced by a 
second manufacturer have been evaluated and the performance of these grades fabricated with boron-free type E glass fabric has been assessed. No statistically significant differences in cryogenic tensile or compression strength or in tensile modulus was observed in the tested products. The $\mathrm{CR}$ grades have proven to have excellent low temperature properties and have been accepted by a variety of fabricators for use in superconducting magnet technology.

Material representing all CR-grade production has been sent to ORNL for assessment of neutron radiation performance at $76 \mathrm{~K}$.

NBS has worked closely with the Owens-Corning Fiberglas Corporation to systematize the available data on glass-mat reinforced epoxy laminates for use at cryogenic temperatures. These materials provide an alternative to fabric-reinforced products where somewhat lower mechanical properties can be tolerated at a substantially lower laminate cost.

Assessment of the magnitudes and sources of variability in cryogenic properties of the CR-grade laminates will continue in FY80. We shall begin a program to assess the level of variability and the lower bounds on cryogenic properties of cotton fabric/phenolic products of NEMA $L$ and LE types. We shall begin a literature search to define the present state of knowledge on the cryogenic performance of nonmetallic insulating films of interest to the MFE community.

Technology Transfer

The annual NBS/DoE Workshop on Materials at Low Temperatures was attended by about seventy representatives of the materials and magnet design communities at Vail, Colorado in October 1979. Again, the meeting was viewed constructively; it served as a focal point to identify and discuss magnet construction or design problems related to materials. For a few who have become recently involved in cryogenic applications, the workshof served an educational role. 
Structural Alloys 

INTERSTITIAL CARBON AND NITROGEN EFFECTS ON THE

TENSILE AND FRACTURE PARAMETERS OF AISI 304

STAINLESS STEELS

National Bureau of Standards 

INTERSTITIAL CARBON ANO NITROGEN EFFECTS ON THE TENSILE AND FRACTURE PARAMETERS OF AISI 304 STAINLESS STEELS

R. L. Tobler and R. P. Reed National Bureau of Standards

Boulder, Colorado 


\section{ABSTRACT}

This study was conducted to determine the effects of carbon and nitrogen on the mechanical properties of an Fe-18Cr-loivi austenitic stainless steel having a base composition corresponding to AISI 304. Nine steels having carbon plus nitrogen $(C+N)$ contents between 0.067 and 0.325 wt.\% were tensile tested at 295, 195, 76, and $4 \mathrm{~K}$. J-integral fracture toughness and fatigue crack growth rate tests using $25-\mathrm{mm}$ thick, compact specimens (TL orientation) were also performed at $4 \mathrm{~K}$. At $295 \mathrm{~K}$, the yield stress was linearly dependent on $\mathrm{C}+\mathrm{N}$ content, with values ranging from 222 to $358 \mathrm{MPa}$. At cryogenic temperatures, the interstitial strengthening effects were magnified, so that the yield stress values ranged from 329 to $1177 \mathrm{MPa}$. The fatigue crack growth resistance and fracture toughness decreased with increasing $\mathrm{C}+\mathrm{N}$ content. The $\mathrm{K}_{\mathrm{Ic}}$ estimates obtained at $4 \mathrm{~K}$ ranged from 337 to $123 \mathrm{MPa} \cdot \mathrm{m}{ }^{1 / 2}$, exhibiting an inverse dependence on yield. Measurements of ultimate stress, elongation, and reduction of area are reported, and the role of martensite transformation in these steels is discussed.

\section{INTRODUCTION}

The AISI 300 series stainless steels are austenitic $\mathrm{Fe}-\mathrm{Cr}-\mathrm{Ni}$ alloys, offering relatively low strength but excellent cryogenic ductility and toughness [1]. By virtue of favorable mechanical properties, service history, and availability, AISI 304 is perhaps the most widely used cryogenic alloy in the world. But nitrogen-strengthened grades, such as AISI $304 \mathrm{~N}$ or AISI 304 LN, have attracted attention as possible substitutes for AISI 304 in applications demanding higher strength. 
Witrogen is a relatively inexpensive and effective strengthener.

Nitrogen also stabilizes the austenitic structure and reduces the probability of martensite transformation. Carbon has similar effects, but carbon contents in austenitic stainless steels must be held to low levels to prevent sensitization during thermal excursions.

Nitrogen-strengthened austenitic stainless steels are gaining popularity, but some applications are hindered by limited availability, limited service experience, lower fracture toughness, and a lack of cryogenic design data[2]. Several mechanical property studies were conducted on these steels $[2-16]$, but most papers are concerned only with room temperature behavior. The present study was undertaken to describe cryogenic behavior in greater detail. Yield stress, ultimate stress, elongation, and reduction of area measurements for nine heats of an Fe-18Cr-101/i stainless steel are reported at 295, 195, 76, and $4 \mathrm{~K}$. The carbon and nitrogen contents of the nine heats were varied to enable a systematic study of interstitial concentration on mechanical property trends. The results can be used to predict the properties of commercial alloys of known compositions or to tailor the properties for a particular application by appropriate specification of the steel composition.

\section{MATERIALS}

Nine stainless steel plates were purchased from a commercial steel manufacturer. These plates had a nominal base composition falling within the limits set by ASTM specification A240 for AISI 304 stainless steel: Fe-18Cr-10Ni-1.5Mn-0.02P-0.02S-0.55Si-0.2Mo-0.2Cu. The carbon and nitrogen levels varied however, with carbon at 0.03 , 
0.06 , or 0.09 wt. $\%$, and nitrogen at $0.04,0.12,0.24$ wt.\%. The mill chemical analyses are listed in Table I. The nine plates were produced from three $136-\mathrm{kg}$ (300-1b) vacuum-induction-melted heats, split with respect to carbon level, and teemed into $76-\mathrm{cm} \times 200 \mathrm{~cm} \times 360-\mathrm{cm}$ hottopped cast-iron ingot molds. The ingots were then reheated and soaked at $1561 \mathrm{~K}\left(2350^{\circ} \mathrm{F}\right)$, hot-rolled to $25.4-\mathrm{mm}$ thick plates, and air cooled. The plates were finally annealed at $1332 \pm 7 \mathrm{~K}\left(1937 \pm 13^{\circ} \mathrm{F}\right)$ for $1 \mathrm{~h}$ and water quenched. The hardness and grain size measurements are listed in Table I.

\section{EXPERIMENTAL PROCEDURE}

Tensile

Tensile tests were conducted using the cryostat described by Reed $^{[17]}$. Low temperatures were achieved by immersing the specimen and cryostat in alcohol and dry ice at $195 \mathrm{~K}$, liquid nitrogen at $76 \mathrm{~K}$, and liquid helium at $4 \mathrm{~K}$. The specimen geometry is shown in in Fig. 1. The load-vs-deflection curves were recorded using the outputs from a commercial load cell and strain gage extensometer. The specimen yield stress at $0.2 \%$ plastic strain, ultimate tensile stress, elongation, and reduction of area were measured.

\section{Fatigue Crack Growth Rates}

Fatigue and fracture toughness tests were performed using the 100-kN machine and cryostat described by Fowlkes and Tobler [18]. These tests used compact specimens in the TL orentation, as defined by ASTM Method E-399-74[19]. The specimen geometry is shown in Fig. 1; specimen width, w, was $50.8 \mathrm{~mm}$, and thickness, B, was $24.5 \mathrm{~mm}$. These specimens 
were precracked at $77 \mathrm{~K}$, using a maximum load of $23 \mathrm{kil}$. Fatigue crack growth rates were then measured at $4 \mathrm{~K}$. The load ratio was 0.1 and the load cycle was sinusoidal at a frequency of $25 \mathrm{~Hz}$. The compliance method of crack growth rate. measurement was used, as described previously[18]. Data were obtained from one or two specimens per heat of steel.

\section{Fracture Toughness}

J-integral tests were necessary because these austenitic stainless steels fail in a ductile (elastic-plastic) mode with gradual crack extension at $4 \mathrm{~K}$. Therefore, single-specimen J-integral tests were used to measure fracture toughness. The technique was a variant of the unloading compliance method $[2,20]$ modified by incorporating a computer to enable digital data acquisition and J-resistance curve plotting during the tests.

The fracture specimens were fatigue cracked at $4 \mathrm{~K}$ to a crack length, $a$, between 28.8 and $36 \mathrm{~mm}\left(\frac{a}{W} \simeq 0.57\right.$ to 0.71$)$. The specimens were then loaded in displacement control at the rate of about $50 \mathrm{~mm} / \mathrm{s}$. As the load increased, partial unloadings were performed periodically. The load reduction during unloading was never greater than $10 \%$ of the maximum 1oad. Using the crack-length-vs-compliance correlation, the crack length at each unloading was inferred and used to obtain the crack extension increment $(\Delta \mathrm{a})$ from the difference of the initial precrack length. The $J$ value at each unloading point was calculated using expression:

$$
J=\frac{\lambda A}{B b}
$$


where

$\lambda$ is the Merkle-Corten factor [21]

$A$ is the area under the load-vs-defection curve at the unloading point, and

$b$ is the specimen ligament $(b=W-a)$.

$\mathrm{J}$-resistance curves consisting of many sets of $\mathrm{J}$ and $\Delta \mathrm{a}$ points were generated, as shown by the example in Fig. 2 .

The $J_{\text {Ic }}$ value for each steel was taken at the intersection of the J-resistance curve with the blunting line. The blunting line is given by $J=2 \sigma_{f} \Delta_{a}$ where $\sigma_{f}$ is the flow stress, which is equal to the average of the yield and ultimate tensile stresses. As shown in Fig. 2, there is an artificial offset of the data from the theoretical blunting line, so a blunting line parallel to the theoretical blunting line but passing through the data was used. After the test, the $\Delta a$ values inferred from the compliance data agreed within 10\% with those found by direct measurement from the fracture surface. Scatter in the J-resistance curves lead to uncertainties of $\pm 12 \%$ in the values of $\mathrm{J}_{\mathrm{IC}}$.

The validity of $J_{I c}$ results was determined by the size criterion which requires that ${ }^{[22]}$

$$
B, b, a \geq \frac{25 J_{I c}}{\sigma_{f}}
$$

Previous results have shown that valid results at $295 \mathrm{~K}$ are impossible for annealed austenitic stainless steels of 24.5- $\mathrm{mm}$ thickness, so a complete temperature dependence of J Ic was not attempted. Only $4 \mathrm{~K}$ values are reported. 


\section{Phase Transformation}

In all low temperature tensile, fatigue, and fracture tests, partial transformation of the paramagnetic austenite to ferromagnetic $\alpha^{\prime}$ (bcc) martensite was observed. The extent of $\alpha^{\prime}$ transformation was estimated using a bar-magnet device described previousty [23]. Small amounts of $\varepsilon$ (hcp) martensite may also have formed, but this was not measured.

\section{RESULTS AND DISCUSSION}

The tensile properties of the steels tested in this study are listed in Table II and plotted in Figs. 3-6. As shown in Fig. 3, the yield stress at $0.2 \%$ plastic strain is a 1 inear function of interstitial $\mathrm{C}+\mathrm{N}$ content at $295 \mathrm{~K}$, where the yield stresses vary from 222 to $358 \mathrm{MPa}$. With greater data scatter, linear dependences are also observed at cryogenic temperatures, but the effectiveness of interstitial strengthening progressively increases as temperature is reduced. Thus, the $4 \mathrm{~K}$ yield stresses have greatly increased, to values ranging from 329 to $1177 \mathrm{MPa}$.

As shown in Fig. 3, there are departures from the linear trends at low temperatures for $\mathrm{C}+\boldsymbol{N}$ contents of $0.128 \mathrm{wt} . \%$ or less. These breaks from otherwise linear dependences are attributed to deformation mode changes, possibly in association with austenite instability. It is known that partial phase transformations to $\alpha^{\prime}$ (bcc) or $\varepsilon$ (hcp) martensite phases can occur in AISI 304 alloys having low interstitial contents [24]. Such transformations are not probable at $295 \mathrm{~K}$, but low temperatures tend to promote transformations. An x-ray examination of selected specimens after only $0.2 \%$ plastic strain would be necessary to test this interpretation. 
In Fig. 4 the yield stress data are plotted versus temperature using a semilog scale. Previous work showed that many stable austenitic stainless steels exhibit a linear trend when their $\sigma_{y}$ values are plotted in this way[25], whereas less stable alloys, such as AISI 304L, exhibit less regular behavior. The AISI $30 \AA_{i} \mathrm{~L}$ behavior is marked by anomalous decreases of strength in the temperature range between 200 and $100 k^{[4]}$. The trends in Fig. 4, therefore, suggest that alloys having $\mathrm{C}+\mathrm{N}$ contents less than 0.128 wt.\% behave similarly to AISI $304 \mathrm{~L}$, since their yield stresses below $200 \mathrm{~K}$ are lower than expected. The same effect is responsible for the break from the 1 inear dependences at 195, 76, and $4 \mathrm{~K}$ in Fig. 3 for alloys having less than 0.128 wt.\% carbon plus nitrogen.

Figure 5 shows that the ultimate tensile strengths for the steels tested fall in the ranges 596 to $740 \mathrm{MPa}$ at $295 \mathrm{~K}$, and 1454 to $1735 \mathrm{i} \cdot \mathrm{Pa}$ at $4 \mathrm{~K}$. The ultimate tensile strength increases slightly with increasing interstitial content, but the effect is minor compared to the effects of interstitials on yield stress, or compared to the effect of cryogenic temperatures on yield and ultimate stresses. All of the tensile tests at $4 \mathrm{~K}$ produced serrated stress-vs-strain curves, such as described by Read and Reed ${ }^{[5]}$. This phenomenon Basinski[26,27] originally attributed to adiabatic heating. In the present study, the load drops were observed to vary from 1.11 to $4.45 \mathrm{kN}$ (250 to $1000 \mathrm{lbs}$ ), increasing with alloy yield stress.

As shown in Fig. 6, the elongation and reduction of area measurements for all nine steels fall in the ranges 45 to $72 \%$ at $295 \mathrm{~K}$ and 30 to $48 \%$ at $4 \mathrm{~K}$. These values are typical for commercial stainless steels of similar composition. As listed in Table II, some of the steels of 
this study show a progressive decrease of ductility at temperatures between 295 and $4 \mathrm{~K}$, whereas others exhibit an initial increase of ductility between 295 and $200 \mathrm{~K}$, followed by the decrease. In any case, the level of ductility for the interstitially strengthened steels remains useful at temperatures as low as $4 \mathrm{~K}$.

\section{Fatigue}

Fatigue resistance at ${ }^{-}$cryogenic temperatures decreases with increasing $\mathrm{C}+\mathrm{N}$ content. As shown in $\mathrm{Fig}$. 7 , the resistance to crack initiation at $77 \mathrm{~K}$ is reduced by about a factor of 4 for the conditions chosen in these tests. The fatigue crack growth rates shown in Fig. 8 also demonstrate that the $d a / d N$ values at $4 K$ and at a given $\Delta K$ value generally increase with increasing $\mathrm{C}+\mathrm{N}$ content. The results agree with existing trends for commercial AISI 304 L, AISI 304, and AISI 304 is stainless steels, which show that the fatigue crack growth rates increase with increasing nitrogen content.

Fracture Toughness

$J_{\text {Ic }}$ results were obtained for seven of the austenitic stainless steels tested, but the data for the two lower-strength heats with $\mathrm{C}+\mathrm{N}$ contents of 0.067 and 0.097 wt.\% were invalid. The maximum $J$ values in these tests exceeded the allowable limits for 24.5-mm thick specimens, the resistance curves deviated from the blunting line at exceptionally low $\mathrm{J}$ values, and the curves could not be analyzed according to conventional techniques because there was no obvious intersection point at the blunting line-resistance curve intersection. The $J_{I C}$ data for the seven other alloys tested at $4 \mathrm{~K}$ are listed in Table III, and the corresponding $K_{I c}$ estimates are plotted in Figs. 9 and 10. 
The $K_{\text {Ic }}$ estimates from J-integral data were obtained from the relationship:

$$
K_{I C}^{2}=\frac{J_{I C} E}{\left(1-v^{2}\right)}
$$

where $E$ is Young's modulus and $\nu$ is Poisson's ratio.

The elastic constants for the stainless steels at $4 \mathrm{~K}$ were estimated at $E=206.8 \mathrm{GPa}$ and $v=0.30$. The values of $K_{I c}$ estimates ranged from 337 to $123 \mathrm{MPa} \cdot \mathrm{m}^{1 / 2}$ for carbon plus nitrogen contents between 0.128 and 0.325 wt.\%. As shown in Fig. 9, the $K_{\text {Ic }}$ estimates decreased linearly with interstitial concentration. In Fig. 10, the $K_{I c}$ estimates are also shown to be inversely related to yield stress. The expression governing the relationship between fracture toughness and yield stress is:

$$
K_{\text {Ic }}=500-0.3 \sigma_{y}
$$

This expression gives $K_{I C}$ to within $\pm 20 \mathrm{MPa} \cdot \mathrm{m}^{1 / 2}$. The fracture toughness results compare well with existing data, some of which are shown for comparison in Fig. 10. Nitronic (Fe-Cr-Ni-Mn-N) alloys tend to have higher nitrogen contents, which results in higher $4 \mathrm{~K}$ strength and lower toughness compared with the AISI 304 alloys ${ }^{[3]}$. The AISI $304 \mathrm{~N}$ data of Read and Reed ${ }^{[2]}$ fall slightly below the present data trend, reflecting differences owing to material variability or measurement uncertainty. 


\section{Martensitic Transformations}

The approximate amount of $\alpha^{\prime}$ (bcc) martensite formed during fatigue and fracture at $4 \mathrm{~K}$ is plotted as a function of interstitial content in Fig. 11. These results provide only an approximate indication of the extent of phase transformation, because the measurements were taken directly from the compact specimen fracture surfaces, which are rough and unmachined. Some $\varepsilon$ (hcp) martensite is known to form in addition to $\alpha^{\prime}$ phase, but this was not measured. Nevertheless, it is clear from Fig. 11 that the stability of the austenite is significantly increased by carbon and nitrogen additions, but some martensite forms in all of the alloys when fatigued or fractured at $4 \mathrm{~K}$. The amount of martensite formed increases with the plastic zone size, so more $\alpha^{\prime}$ is detected on fracture surfaces compared with fatigue surfaces, and more martensite forms in the low-strength grades. The role of martensite transformation and its effect on mechanical property results needs to be further investigated.

\section{SUMMARY AND CONCLUSIONS}

1. Fatigue crack growth and fracture toughness measurements at $4 \mathrm{~K}$ and conventional tensile properties at 295, 195, 76, and $4 \mathrm{~K}$ are reported for $\mathrm{Fe}-18 \mathrm{Cr}-10 \mathrm{Ni}$ austenitic stainless steels having $\mathrm{C}+\mathrm{N}$ contents ranging from 0.067 to 0.325 wt $\%$

2. Carbon and nitrogen both increase the yield stress, but nitrogen additions are much more effective. The yield stress for the alloys tested increased from $222-358 \mathrm{MPa}$ at room temperature to $329-1177 \mathrm{MPa}$ at $4 \mathrm{~K}$. At room temperature the yịeld stress increased linearly with carbon plus nitrogen content. At low temperatures, the 
yield stress also increased linearly for $C+N$ contents greater than $0.128 w t . \%$

2. Fatigue crack growth resistance at $4 \mathrm{~K}$ decreased with increasing $\mathrm{C}+\mathrm{N}$ content.

4. Fracture toughness tests were performed using the single specimen J-integral unloading compliance technique and 24.5-mm thick compact specimens of the TL orientation. The tests yielded $J_{\text {Ic }}$ results and $K_{I C}$ estimates for seven of the alloys at $4 \mathrm{~K}$. The fracture toughness decreased linearly with increasing $C+N$ content, and the $\mathrm{K}_{\mathrm{Ic}}$ estimates at $4 \mathrm{~K}$ were inversely related to yield stress at $4 \mathrm{~K}$, with values ranging from 123 to $336 \mathrm{MPa} \cdot \mathrm{m}^{1 / 2}$.

5. The mechanical properties of austenitic stainless steels vary predictably with $\mathrm{C}+\mathrm{N}$ content so that the $4 \mathrm{~K}$ properties can be tailor-made by adjusting the interstitial element concentration.

\section{ACKNOWLEDGMENTS}

D. T. Read of NBS assembled the computer-aided, J-integral test apparatus. D. T. Read, T. A. Whipple, A. C. Castille, D. S. Burkhalter, and D. H. Beekman assisted in performing the tensile and fracture tests. The stainless steel plates were supplied by the United States Steel Corporation. 


\section{REFERENCES}

1. R. P. Reed, F. R. Fickett, M. B. Kasen, and H. I. McHenry, "Magnetic Fusion Energy Low Temperature Materials Program: A Survey," in: Materials Studies for Magnetic Fusion Energy Applications at Low Temperatures-I, NBSIR 78-884, F. R. Fickett and R. P. Reed, Eds, National Bureau of Standards, Boulder, CO, April 1978, pp. 245-335.

2. D. T. Read and R. P. Reed, "Fracture and Strength Properties of Selected Austenitic Stainless Steels at Cryogenic Temperatures," in: Materials Studies for Magnetic Fusion Energy Applications at Low Temperatures-II, NBSIR 79-1609, F. R. Fickett and R. P. Reed, Eds, National Bureau of Standards, Boulder, C0, June 1979, pp. 81-122.

3. D. T. Read and R. P. Reed, "Toughness, Fatigue Crack Growth, and Tensile Properties of Three Nitrogen-Strengthened Stainless Steels at Cryogenic Temperatures," in: Materials Studies for Magnetic Fusion Energy Applications at Low Temperatures-I, NBSIR 78-884, F. R. Fickett and R. P. Reed, Eds, National Bureau of Standards, Boulder, C0, April 1978, pp. 91-154.

4. D. T. Read, R. P. Reed, and R. E. Schramm, "Low Temperature Deformation of Fe-18Cr-8Ni Steels," in: Materials Studies for Magnetic Fusion Energy Applications at Low Temperatures-II, NBSIR 79-1609, F. R. Fickett and R. P. Reed, Eds, National Bureau of Standards, Boulder, C0, June 1979, pp. 151-172.

5. D. T. Read and R. P. Reed, "Heating and Strain Rate Effects in AISI 304L Stainless Steel at $4 \mathrm{~K}, "$ in: Materials Studies for Magnetic Fusion Energy Applications at Low Temperatures-II, NBSIR 791609, F. R. Fickett and R. P. Reed, Eds, National Bureau of Standards, Boulder, C0, June 1979, pp. 125-147. 
6. R. L. Tobler and R. P. Reed, "Tensile and Fracture Behavior of Nitrogen-Strengthened, Chromium-Nickel-llanganese Stainless Steel at Cryogenic Temperatures," Symposium on Elastic-Plastic Fracture, American Society for Testing and Materials, Atlanta, GA, Nov. 1977.

7. P. P. Dessau, "LN 2 and $L_{2}$ Fracture Toughness of Armco Alloy 22-13-5," Report No. TID/SNA-2083, Aerojet Nuclear Systems Co, Sacramento, CA 1971.

8. D. C. Larbalestier and D. Evans, "High Strength Austenitic Stainless Steels for Cryogenic Use," Proceedings of Sixth International Cryogenic Engineering Conference, Grenoble, France (1976), IPC

Science and Technology Press, Guildford, Surrey, England, pp. 345-347.

9. R. B. Gunia and G. R. Woodrow, "Nitrogen Improves Engineering Properties of Chromium-Nickel Stainless Steels," J. Mater., J!ILSA, 5, June 1970, pp. 413-430.

10. R. Voyer and L. Weil, "Tensile and Creep Properties of a High Nitrogen Content 18/10 (AISI 304L) Stainless Steel at Cryogenic Temperatures," Adv. Cryo. Eng. 11, 1965, pp. 447-452.

11. L. $-\AA$. Norström, "The Influence of Nitrogen and Grain Size on Yield Strength in Type AISI 316L Austenitic Stainless Stee1, "Met. Sci. 11, 1977, pp. 208-212.

12. M. K. Booker and V. K. Sikka, "Effects of Composition Variables on the Tensile Properties of Type 304 Stainless Steel, "ORNL-5353, Oak Ridge National Laboratory, Oak Ridge, TN, 1977, pp. 38.

13. P. Soo and W. H. Horton, "The Effect of Carbon and Nitrogen on the Short-term Tensile Behavior of Types 304 and 316 Stainless Steels," llard NA 3045-2, Westinghouse Electric Corp., Madison, PA, pp. 48.

14. K. J. Irvine, D. T. Lewellyn, and F. B. Pickering, "High Strength Austenitic Stainless Steels," J. Iron Steel Inst. 199, Oct. 1961 , pp. 153-175. 
15. K. J. Irvine, T. Gladman, and F. B. Pickering, "The Strength of Austenitic Stainless Steels," J. Iron Steel Inst., 207, July 1969, pp. 1017-1028.

16. C. E. Spaeder, Jr., and W. F. Domis, "Cryogenic and ElevatedTemperature Mechanical Properties of a High-Nitrogen Type 304 Stainless Steel," Report No. 44(012)-062-2, United States Steel Corporation, Pittsburgh, PA, 1969.

17. R. P. Reed, "A Cryostat for Tensile Tests in the Temperature Range 300 to $4 \mathrm{~K}, "$ Adv. Cryo. Eng. 71961 , pp. 448-454.

18. C. H. Fowlkes and R. L. Tobler, "Fracture Testing and Results for a Ti-6Al-4V Alloy at Liquid Helium Temperature," Eng. Frac. Mech. 8 1976, pp. 487-500.

19. Standard Method of Test for Plane Strain Fracture Toughness of Metallic laterials (Designation E399-74), 1974 Annual Book of ASTM Standards, Part 10, 1974, pp. 432-451.

20. G. A. Clarke, H. R. Andrews, P. C. Paris, and D. W. Schnidt, "Single Specimen Tests for J Ic Determination," in: Mechanics of Crack Growth, ASTM STP 590, American Society for Testing and Materials, Philadelphia, PA, 1976, pp. 27-42.

21. J. G. Merkle and H. T. Corten, "A J-Integral Analysis for the Compact Specimen, Considering Axial Force as Well as Bending Effects," ‥ Pressure Vessel Tech., Trans ASME, $\underline{6}$, 1974, pp. 1-7.

22. J. D. Landes and J. A. Begley, "Test Results from J-Integral Studies: An Attempt to Establish a J Ic Testing Procedure," in: Fracture Analysis, ASTM STP 560, American Society for Testing and Materials, Philadelphia, PA, 1974, pp. 170-186. 
23. R. P. Reed and R. P. Ilikesell, "The Stability of Austenitic Stainless Steels at Low Temperatures as Determined by Magnetic Measurements," Adv. Cryo. Eng. 4 1960, pp. 84-100.

24. R. P. Reed and C. J. Guntner, "Stress-Induced Martensitic Transformations in 18Cr-Ni Steel," Trans. Met. Soc. AIME 230, 1964, pp. $1713-1720$.

25. R. L. Tobler, R. P. Reed, and D. S. Burkhalter, "Temperature Dependence of Yielding in Austenitic Stainless Steels," in this volume.

26. Z. S. Basinski, "The Instability of Plastic Flow of Metals at Very Low Temperatures," Proc. Roy. Soc. A240, 1957, pp. 229-242.

27. Z. S. Basinski, The Instability of Plastic Flow of Metals at Very Low Temperatures," Aust. ‥ Phys. 13, 1260, pp. 354-353. 
Table Mo.

I. Stainless steel compositions (wt.\%), hardnesses, and grain sizes.

II. Tensile property results (one test per temperature).

III. J-integral toughness results at $4 \mathrm{~K}$. 


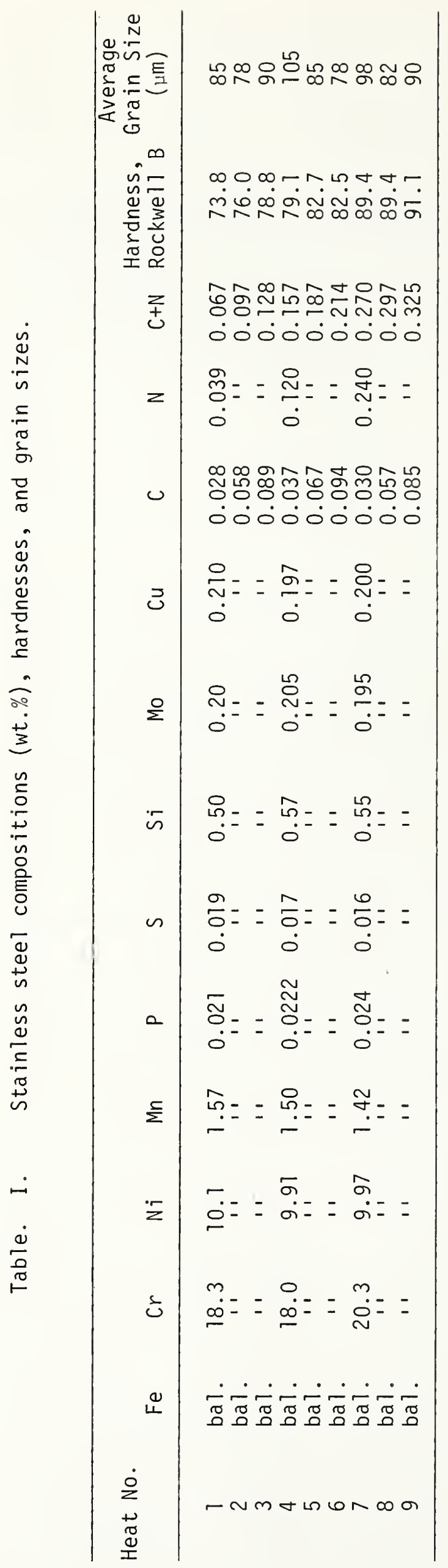




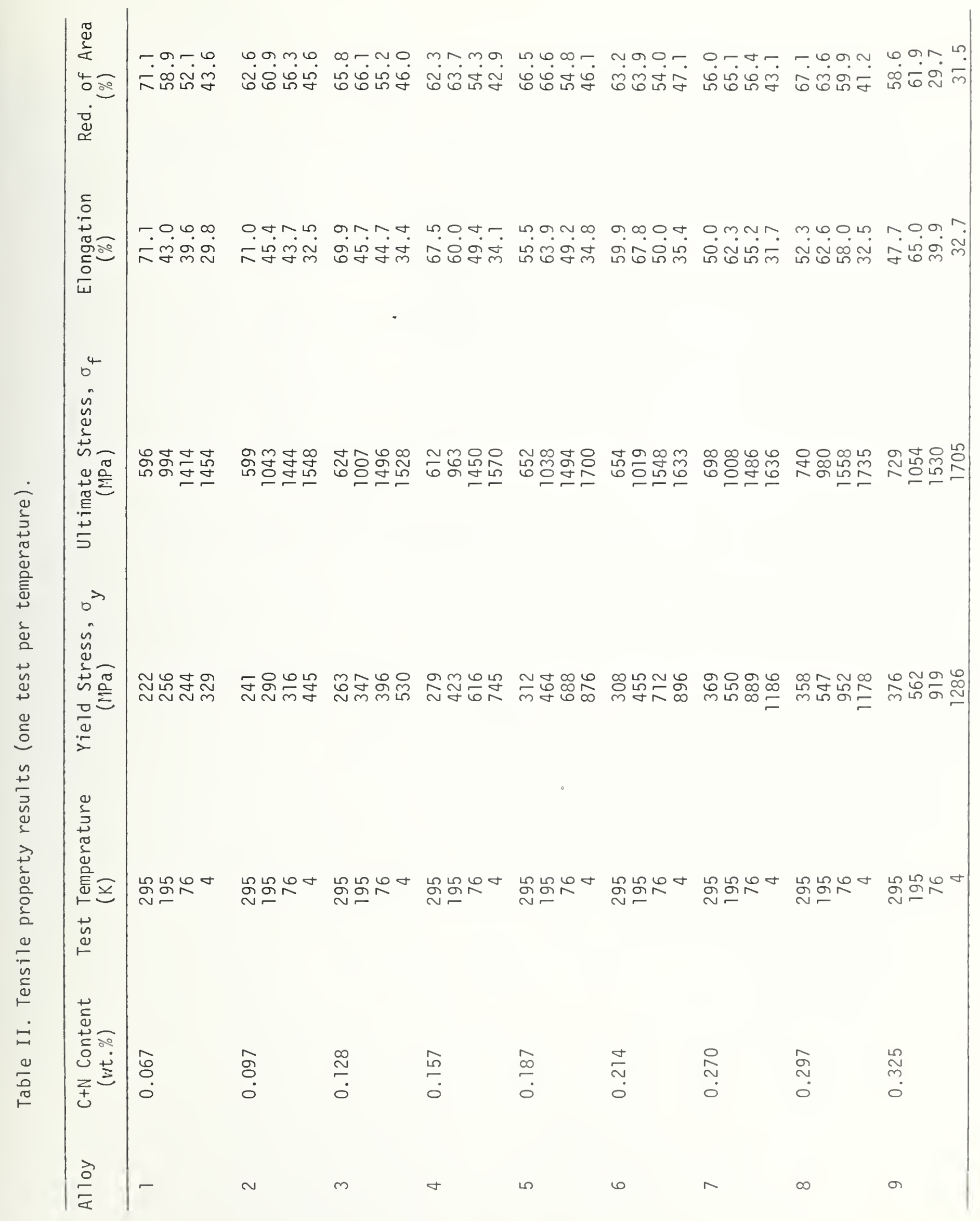


Table III. Yield stress and J-Integral toughness results at $4 \mathrm{~K}$.

\begin{tabular}{|c|c|c|c|c|c|c|}
\hline Specimen & $\begin{array}{c}C+N \text { Content } \\
(w t . \%)\end{array}$ & $\begin{array}{c}\text { Yield Stress, } \sigma_{y} \\
(\mathrm{MPa})\end{array}$ & $\begin{array}{c}\text { Flow Stress, } \sigma_{f} \\
(M P a)\end{array}$ & $\frac{25 \mathrm{~J}_{\mathrm{Ic}}}{\sigma \mathrm{f}}$ & $\begin{array}{c}{ }^{\mathrm{J}} \mathrm{IC} \\
\left(\mathrm{kJ} / \mathrm{m}^{2}\right)\end{array}$ & $\begin{array}{c}\text { KIC Estimates* } \\
\left(\mathrm{MPa} \cdot \mathrm{m}^{1 / 2}\right)\end{array}$ \\
\hline $\begin{array}{l}1 \\
2 \\
3 \\
4 \\
5 \\
6-A \\
6-B \\
7 \\
8-A \\
8-B \\
9\end{array}$ & $\begin{array}{l}0.067 \\
0.097 \\
0.28 \\
0.157 \\
0.187 \\
0.214 \\
0.214 \\
0.270 \\
0.297 \\
0.297 \\
0.325\end{array}$ & $\begin{array}{r}329 \\
445 \\
530 \\
745 \\
876 \\
896 \\
896 \\
1186 \\
1178 \\
1178 \\
1286\end{array}$ & $\begin{array}{r}892 \\
996 \\
1029 \\
1158 \\
1288 \\
1264 \\
1264 \\
1411 \\
1456 \\
1456 \\
1496\end{array}$ & $\begin{array}{r}\text { NA } \\
\text { NA } \\
12.2 \\
6.6 \\
4.6 \\
4.3 \\
5.3 \\
11.9 \\
1.5 \\
1.3 \\
1.1\end{array}$ & $\begin{array}{l}\text { NA } \\
\text { NA } \\
499 \\
312 \\
230 \\
218 \\
272 \\
67 \\
88 \\
78 \\
63\end{array}$ & $\begin{array}{l}\text { NA } \\
\text { NA } \\
337 \\
266 \\
230 \\
222 \\
249 \\
124 \\
141 \\
133 \\
124\end{array}$ \\
\hline
\end{tabular}

*Calculated from the expression $K_{I C}^{2}=J_{I C} \cdot E /\left(1-v^{2}\right)$, where it is assumed that $E=206.8 \mathrm{GPa}$ and $v=0.30$ at $T=4 \mathrm{~K}$. 
Figure No.

1. Specimen geometries used for conventional tensile and fracture mechanics tests.

2. Typical J-resistance curve for an austenitic stainless steel tested at $4 \mathrm{~K}$.

3. Dependence of yield stress on carbon and nitrogen level, with temperature as a parameter.

4. Temperature dependence of yield stress. Numbers refer to heat numbers, Table I.

5. Dependence of ultimate tensile stress on carbon and nitrogen, with temperature as a parameter.

6. Temperature dependence of elongation and reduction of area.

7. Fatigue crack initiation resistance at $77 \mathrm{~K}$.

8. Dependence of fatigue crack growth rates at $4 \mathrm{~K}$ on carbon and nitrogen content.

9. Dependence of $K_{I C}$ at $4 K$ on carbon and nitrogen content.

10. Inverse relationship between fracture toughness and yield stress for austenitic stainless steels at $4 \mathrm{~K}$.

11. Relative amounts of $\alpha^{\prime}$ (bcc) martensite formed during tests of compact specimens at $4 \mathrm{~K}$. 


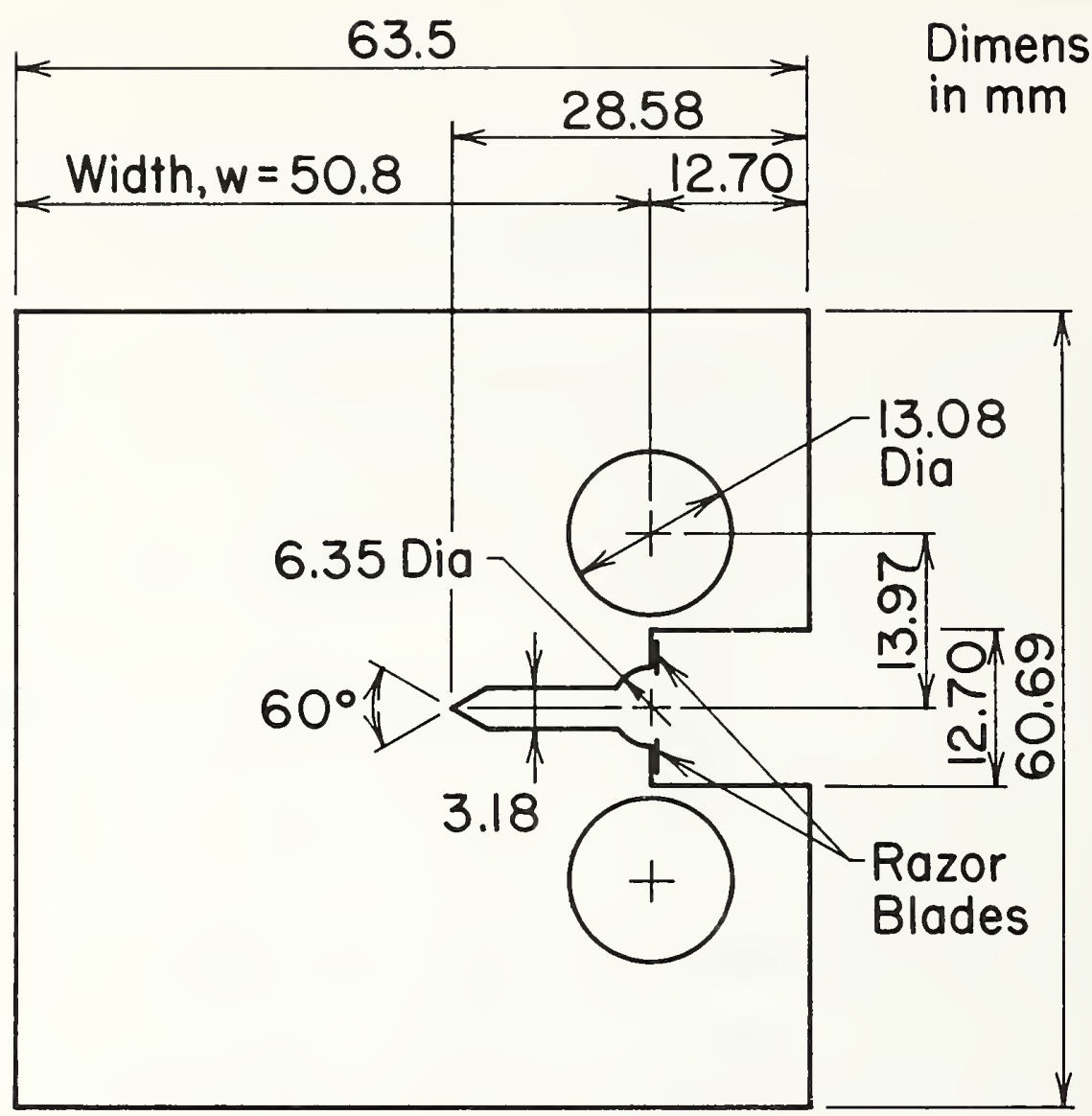

COMPACT SPECIMEN

Thickness $=24.4 \mathrm{~mm}$

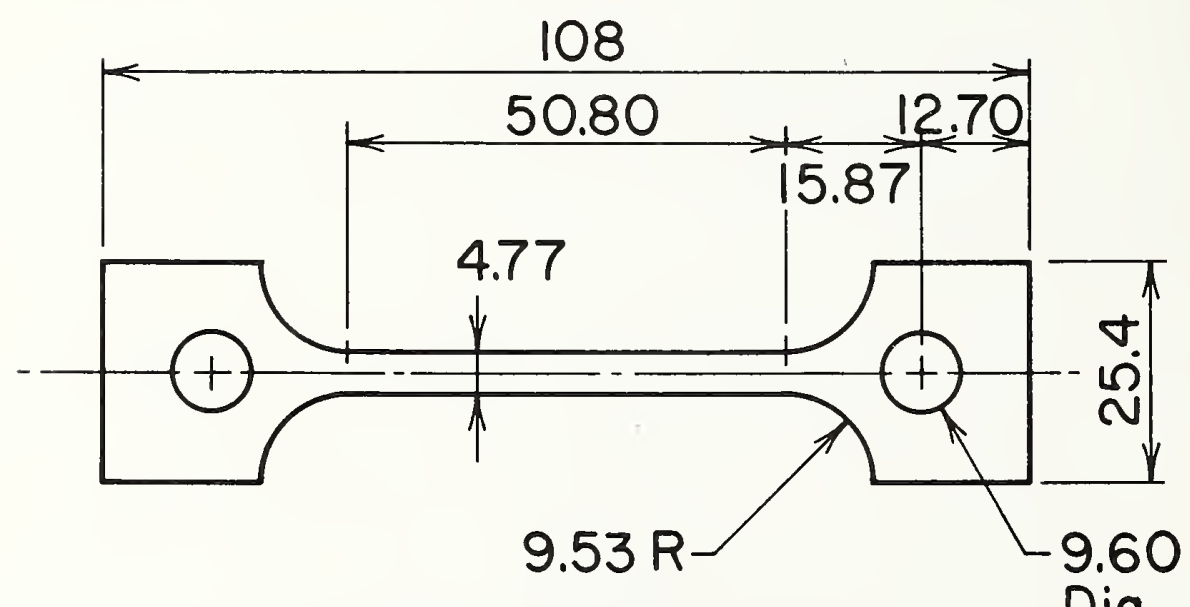

TENSILE SPECIMEN

Dia

\section{Thickness $=2.54 \mathrm{~mm}$}

Figure 1. Specimen geometries used for conventional tensile and fracture mechanics tests. 


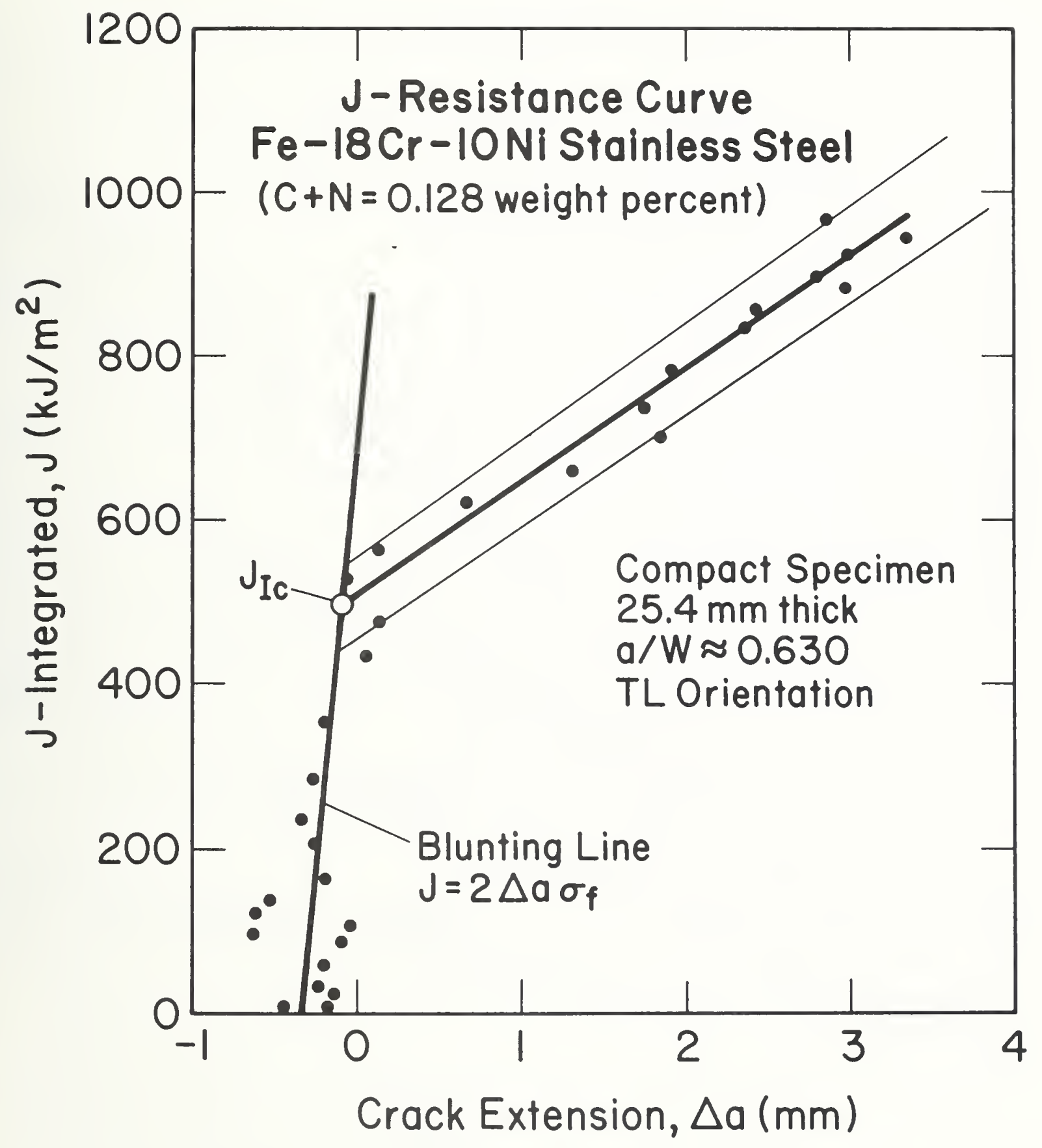

Figure 2. Typical J-resistance curve for an austenitic stainless steel tested at $4 \mathrm{~K}$. 


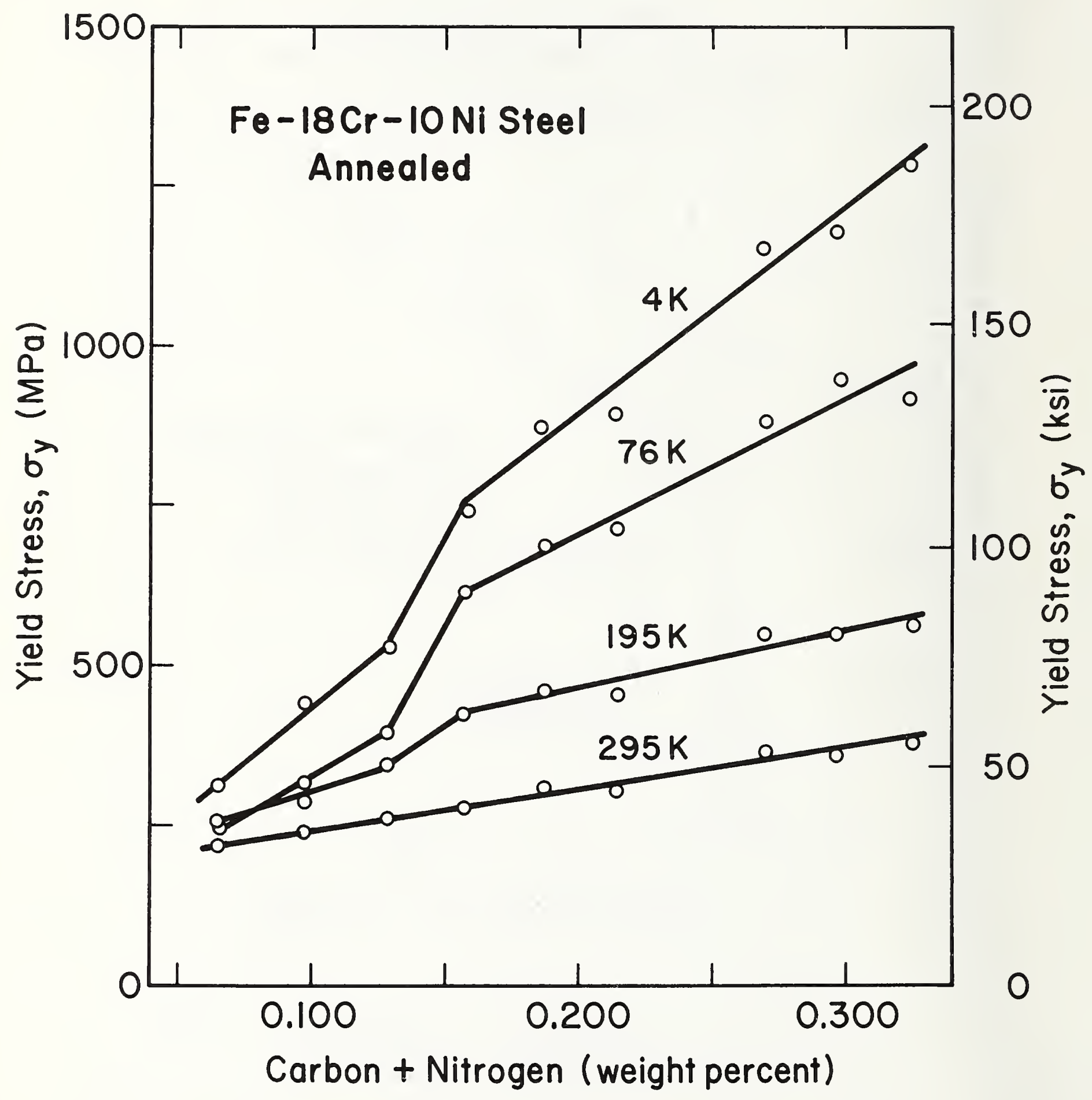

Figure 3. Dependence of yield stress on carbon and nitrogen level, with temperature as a parameter. 


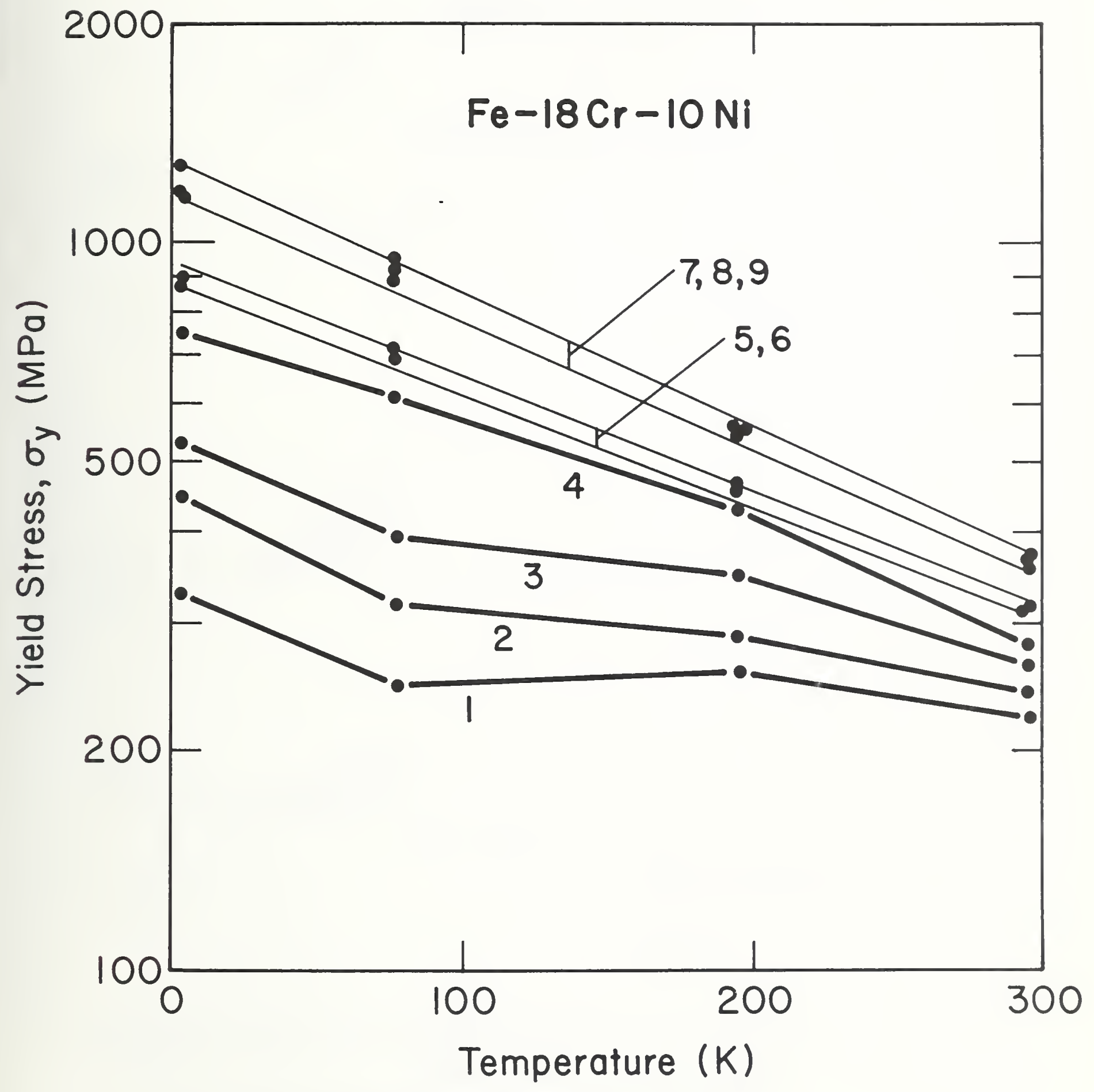

Figure 4. Temperature dependence of yield stress. Numbers refer to heat numbers, Table I. 


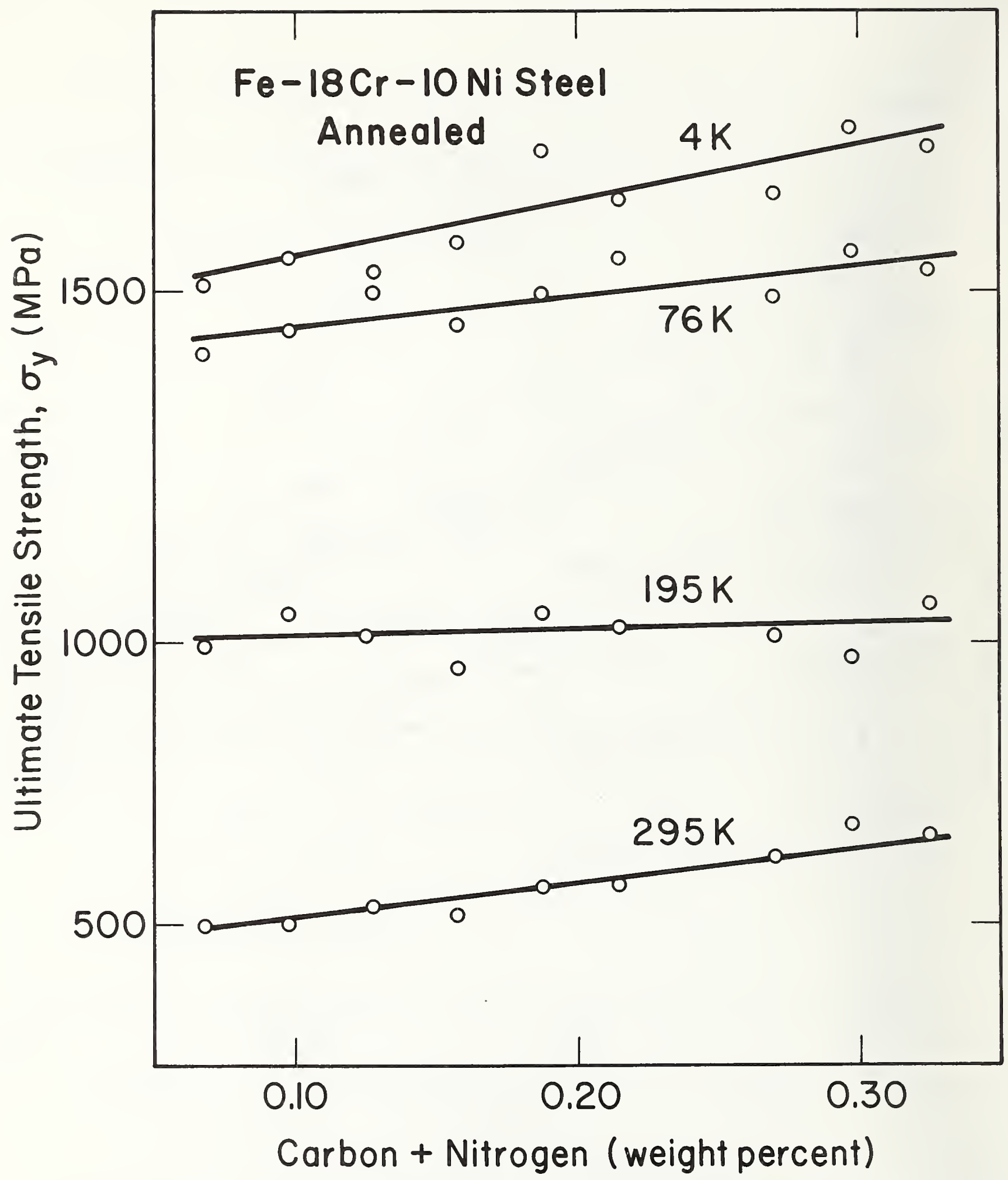

Figure 5. Dependence of ultimate tensile stress on carbon and nitrogen, with temperature as a parameter. 


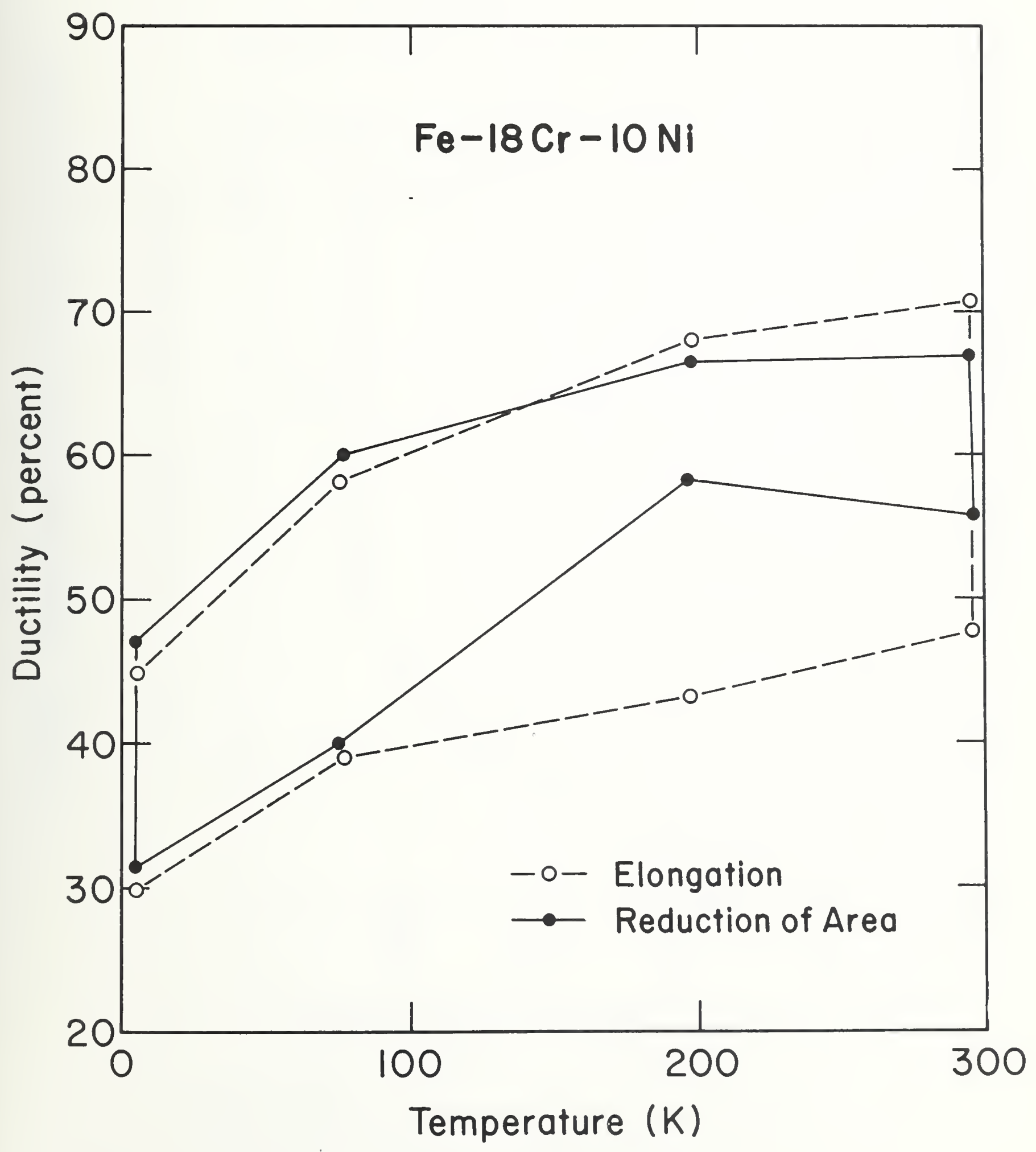

Figure 6. Temperature dependence of elongation and reduction of area. 


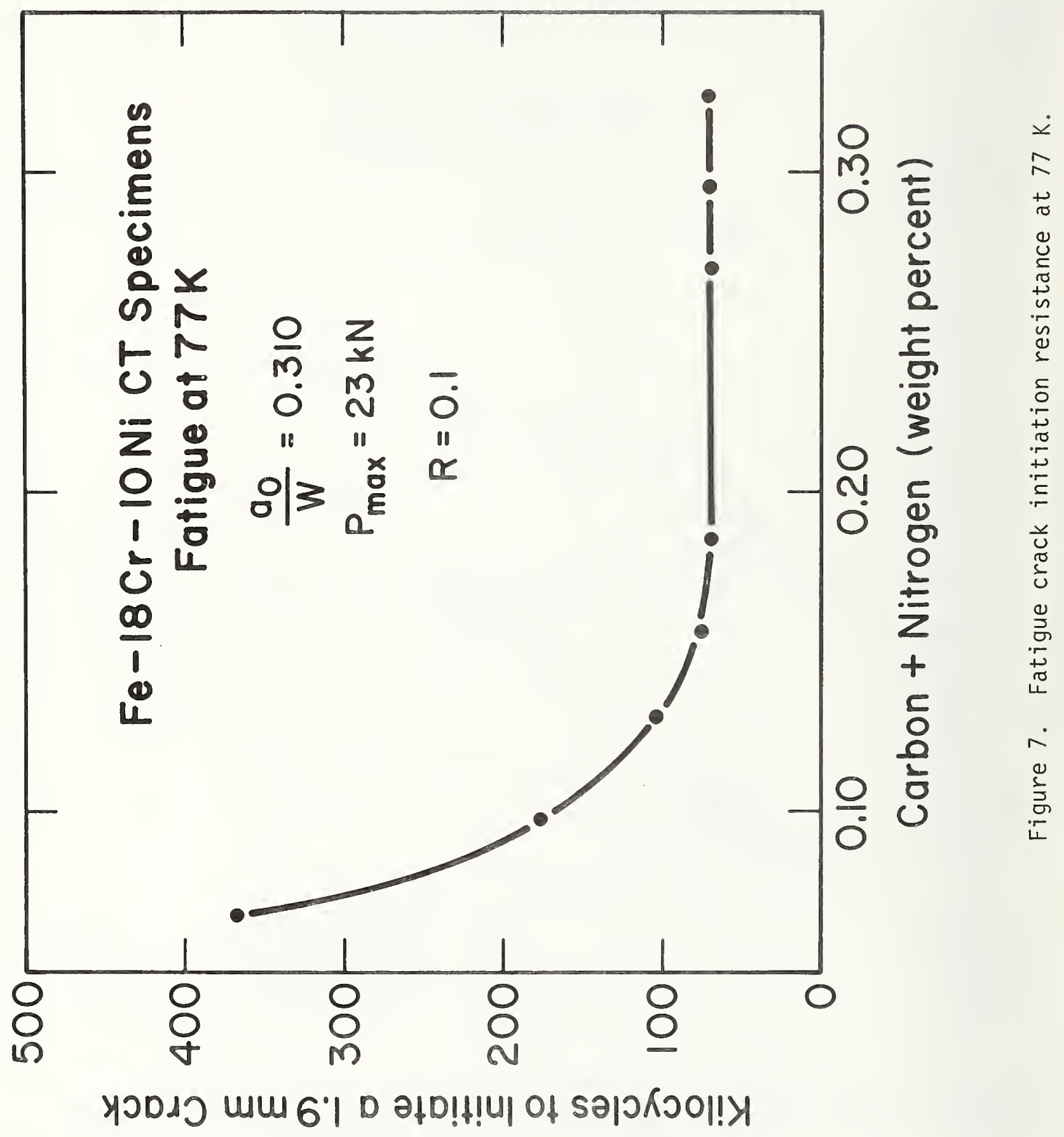




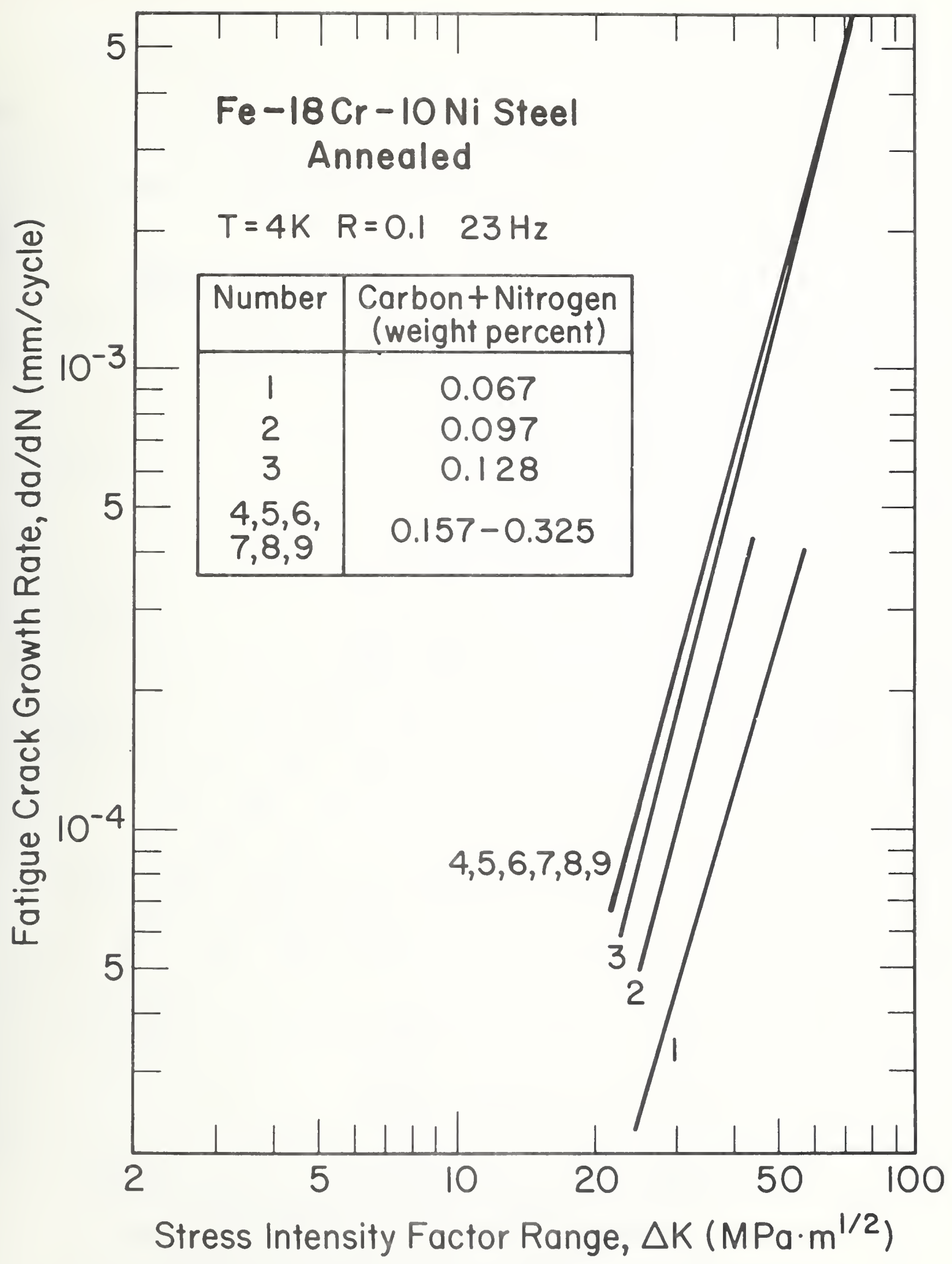

Figure 3. Dependence of fatigue crack growth rates at $4 \mathrm{~K}$ on carbon and nitrogen content. 


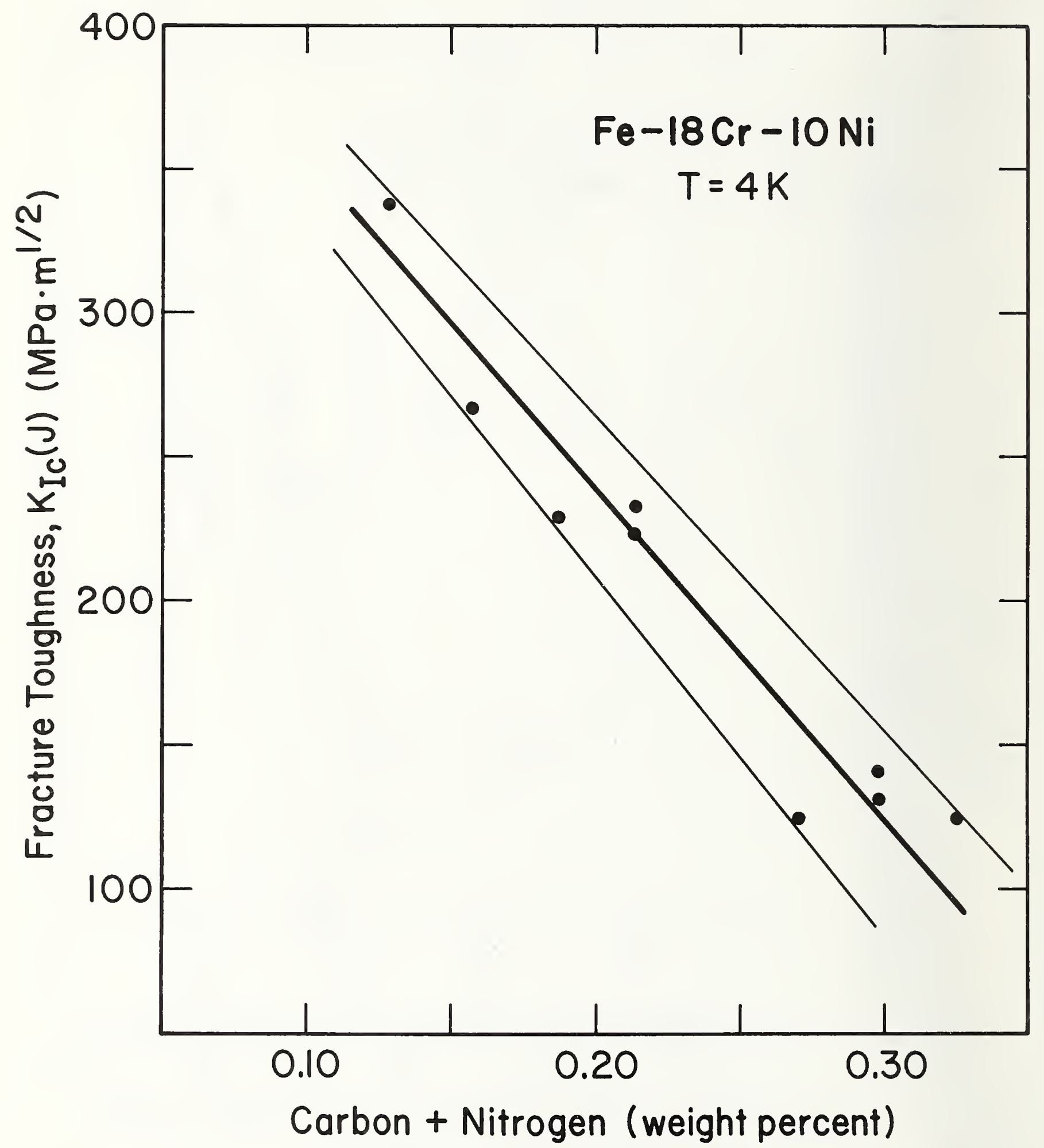

Figure 9. Dependence of $K_{I C}$ at $4 K$ on carbon and nitrogen content. 


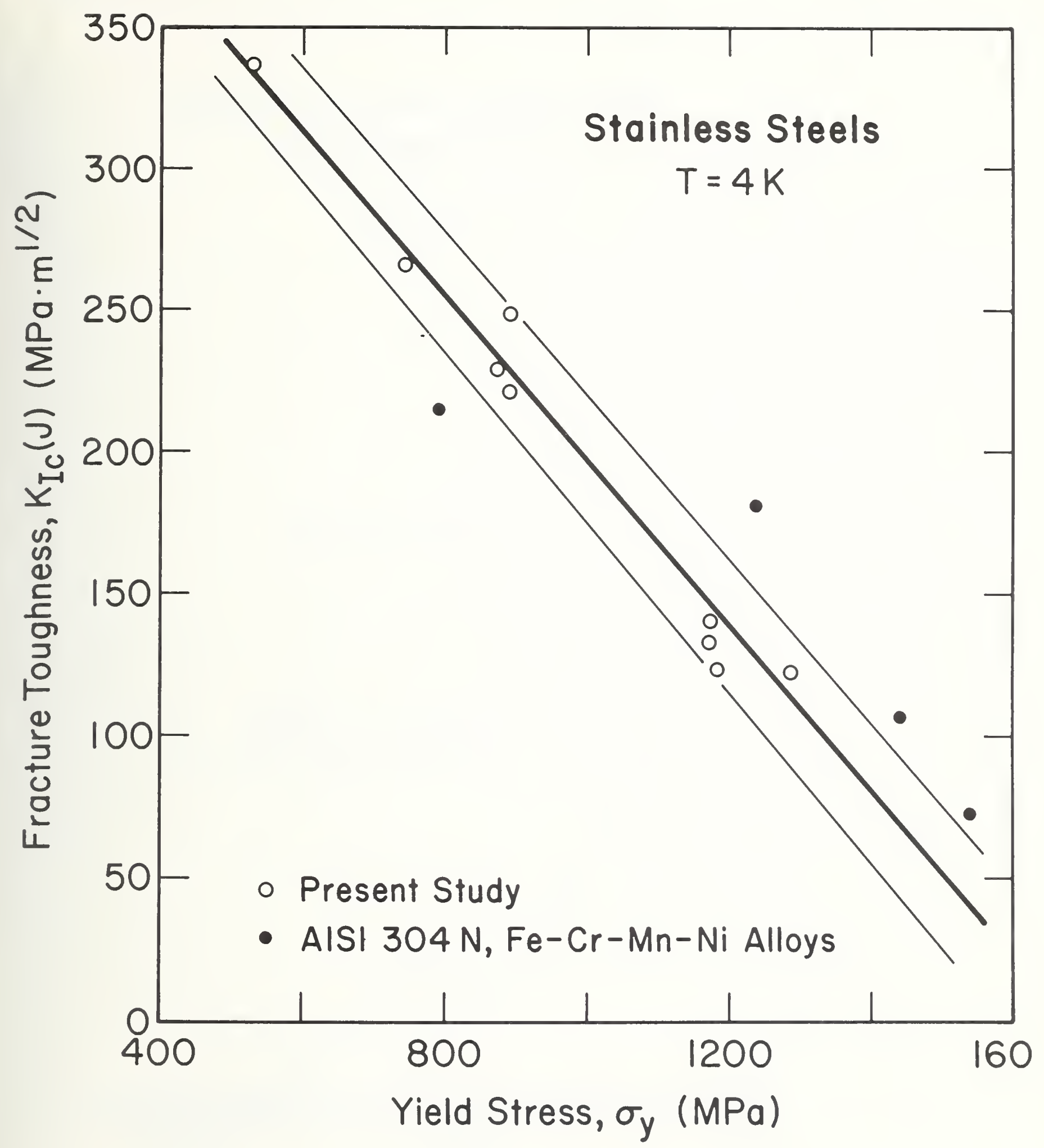

Figure 10. Inverse relationship between fracture toughness and yield stress for austenitic stainless steels at $4 \mathrm{~K}$. 


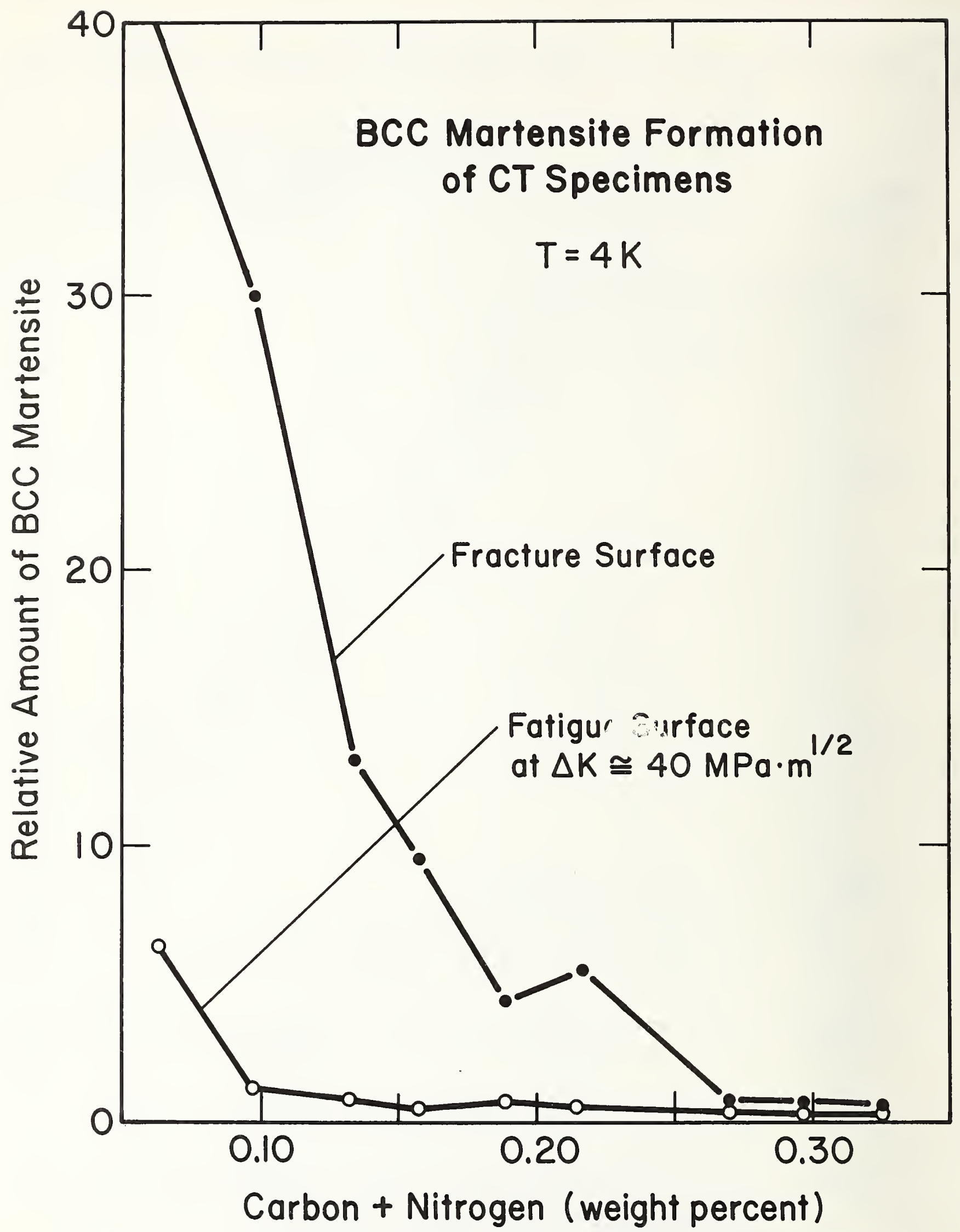

Figure 11. Relative amounts of $\alpha^{\prime}(\mathrm{bcc})$ martensite formed during tests of compact specimens at $4 k$. 
TEMPERATURE DEPENDENCE OF YIELDING IN

AUSTENITIC STAINLESS STEELS

National Bureau of Standards 

R. L. Tobler, R. P. Reed, and D. S. Burkhalter

National Bureau of Standards

Boulder, Colorado

\section{ABSTRACT}

The temperature dependence of yielding is discussed with specific reference to austenitic stainless steels. Tensile yield stress $\left(\sigma_{y}\right)$ measurements at $0.2 \%$ plastic strain, a strain rate of $0.02 \mathrm{~mm} / \mathrm{s}$, and temperatures between 4 and $295 \mathrm{~K}$ are reported for a heat of AISI 316 stainless steel. The results are compared with previously published data for the same heat at elevated temperatures, and the yield stress is observed to decrease from $660 \mathrm{MPa}$ at $4 \mathrm{~K}$ to $102 \mathrm{MPa}$ at $922 \mathrm{~K}$. The decrease is regular, with no obvious anomalies, and apparently no low temperature martensitic transformations at $0.2 \%$ strain. The merits and 1 imitations of various expressions for describing the temperature dependence of the yield stress are then evaluated, and an excellent data fit is obtained using the expression;

$$
\sigma_{y}=\sigma_{A}+\left(\sigma_{0}-\sigma_{A}\right) \exp \left(-C_{7} T\right)
$$

where $\sigma_{A}$ is an athermal stress, $\sigma_{0}$ is the yield stress at absolute zero, and $C_{7}$ is a constant related to thermodynamic parameters for therma $11 y$ activated plastic flow.

Key Hords: cryogenic properties of materials; iron alloys; low temperature mechanical properties; plastic deformation; temperature effects; stainless steel alloys; yield stress.

\footnotetext{
*Supported by the Office of Fusion Energy, U.S. Department of Energy.
} 
The tensile properties of stable austenitic stainless steels, such as AISI 310 (Fe-25Cr-20Ni-2Mn-0.08C), have a regular temperature dependence with trends similar to the classical behavior expected for metals and alloys having the face-centered cubic structure [1]. The classical behavior consists of a smooth, monotonic increase of yield stress as temperature is lowered to about $60 \mathrm{~K}$. In contrast, metastable stainless steels, such as AISI 304L (Fe-18Cr-9Ni-2Mn-0.03C), have yield-stress-( $\left.\sigma_{y}\right)$ vs.-temperature anomalies that are believed to be associated with low temperature martensitic transformations to body-centered cubic $\left(\alpha^{\prime}\right)$ and hexagonal close-packed $(\varepsilon)$ phases [2]. It has been suggested that such transformations may lower the $0.2 \%$ yield stress [2]. In addition, both the stable and metastable alloys are capable of anomalous behavior at extreme cryogenic temperatures (below $60 \mathrm{~K}$ ) owing to deformation mode changes associated with dislocation tunneling or magnetic transitions [3].

The metastable stainless steel AISI 316 (Fe-18Cr-13Ni-2Mn-2Mo$0.06 \mathrm{C}$ ) remains austenitic after cooling to cryogenic temperatures but transforms to approximately $50 \% \alpha^{\prime}$ martensite when strained to fracture at $4 \mathrm{~K}$ [4]. Since AISI 316 is an important candidate for superconducting machinery and magnetic fusion, its temperature dependence of yielding was investigated. As described below, anomalous effects on the $\sigma_{y}$-vs.temperature relationship owing to the possible formation of martensite at $0.2 \%$ strain proved negligible in our tests. Therefore the data are used to appraise various analytical expressions for describing the temperature dependence of $\sigma_{y}$ for AISI 316 and related alloys including AISI 310. 
Oak Ridge National Laboratory donated the AISI 316 stainless steel that Sikka $\Gamma 5\rceil$ had tested previously at elevated temperatures. This material was a $25.4-\mathrm{mm}$ thick plate with the following composition in wt. \%: Fe-17.25Cr-13.48Ni-1.86Mn-2.84Mo-0.02P-0.019S-0.58Si-0.057C-0.030N.

Twenty flat, pin-loaded tensile test specimens in the transverse orientation were machined from stock. The specimens had a $2.5-\mathrm{mm}$ by 4-mm rectangular reduced cross section and a 25-mm gauge 1ength. After machining, the specimens were annealed at $1289 \mathrm{~K}$ in a vacuum tube furnace. After $1 \mathrm{~h}$, the tube was removed from the furnace, the vacuum was broken, and the specimens were cooled in air. Following this treatment, the average grain diameter was $67 \mu \mathrm{m}$ (ASTM grain size No. 4.9), and the hardness was Rockwel1 B 75.

Tensile tests used the screw-driven machine and the cryostat described by Read, Reed, and Schramm [2]. The strain rate was $0.02 \mathrm{~mm} / \mathrm{s}$. The specimens were instrumented with a double-beam strain gauge extensometer, as well as platinum or carbon resistance thermometers. Tests at 4 and $77 \mathrm{~K}$ were performed by direct immersion in liquid helium or liquid nitrogen. Other temperatures were achieved by controlled thermal conduction using liquid helium or nitrogen reservoirs and heating wires attached to the specimen grips and load train. Current to the heating wires was varied until thermal equilibrium was reached at the desired test temperature. Load-vs.-deflection curves were recorded using commercial load cell and extensometer outputs, and the yield stress at $0.2 \%$ plastic strain was calculated in the conventional manner. Two or three specimens were tested at 295, 76, and $4 \mathrm{~K}$. Individual measurements did 
not deviate more than $\pm 6 \%$ from the average values at these temperatures. The specimens were plastically strained only $0.2 \%$; they were then unloaded and examined using a torsion bar magnet device [2] to check for the presence of ferromagnetism and, hence, $\alpha^{\prime}$ martensite at this small deformation.

\section{RESULTS AND DISCUSSION}

Seventeen yield stress measurements were obtained at 13 temperatures between 4 and $295 \mathrm{~K}$. These measurements are 1isted in Table I, along with Sikka's elevated temperature data for the same heat. The combined results represent the most extensive yield stress data available for a single heat of austenitic stainless steel. The two data sets are in good agreement at room temperature where they overlap: Sikka's yield stress of $216 \mathrm{MPa}$ at $298 \mathrm{~K}$ is only $5 \%$ higher than the average value of $205 \mathrm{MPa}$ at $295 \mathrm{~K}$ from this study. The yield stress vs temperature plot for this heat of AISI 316 (shown in Fig. 1) indicates a regular monotonic decrease of $\sigma_{y}$ from 660 to $102 \mathrm{MPa}$ as temperature is raised from 4 to $922 \mathrm{~K}$. The decrease is most dramatic between 4 and $295 \mathrm{~K}$, amounting to a factor of 3.2. Selected specimens from this temperature range were examined at room temperature using torsion bar magnet and metallographic techniques, but measurable amounts $10.1 \%$ or greater) of the ferromagnetic $\alpha^{\prime}$ phase could not be detected after plastic strains of $0.2 \%$. This search for martensite was cursory, and an $x$-ray inspection would be necessary to confirm whether small amounts of $\alpha^{\prime}$ or $\varepsilon$ phases had formed; but the absence of any obvious yield stress anomalies implied that the martensitic transformation had a negligible effect on $\sigma_{y}$ in this heat of AISI 316 stainless steel. 
Sanderson and Llewellyn's data for AISI 310 and AISI 316 stainless steels [6] are also plotted for comparison in Fig. 1. The trend for AISI $310(77 \leq T \leq 800 \mathrm{~K})$ resembles the trend for the AISI 316 al1oy of this study. This is significant because AISI 310 is highly alloyed and completely stable with respect to low temperature martensitic transformations. Thus, neither in the AISI 310 of Sanderson and Llewel1yn's study nor in the AISI 316 of this study are there any indications of anomalous yield stress decreases at temperatures between 200 and $100 \mathrm{~K}$, such as those observed in AISI 304L where strain-induced martensitic transformations occur.

On the other hand, the Sanderson and Llewellyn data for AISI 316 begin to deviate from the present results at temperatures below $176 \mathrm{~K}$, and the difference increases at still lower temperatures amounting to $100 \mathrm{MPa}$ at $77 \mathrm{~K}$. Sanderson and Llewel1yn's heat (Fe-16.72Cr-11.27Ni$1.52 \mathrm{Mn}-2.58 \mathrm{Mo}-0.32 \mathrm{Si}-0.05 \mathrm{C}$ ) had a lower alloy content than the one 0 . this study (Fe-17.25Cr-13.48Ni-1.86Mn-2.34Mo-0.58Si-0.057C-0.03N), which may explain the lower yield stress, since low-temperature martensitic transformations are believed to lower the yield stress, and such transformations would be more probable for their heat. This suggests the possibility that measurements at strains higher than $0.2 \%$, where martensite products are formed, might reveal flow-stress-vs.-temperature anomalies in the heat of AISI 316 of this study. This possibility will be investigated in future tests.

\section{CURVE-FITTING TECHNIQUES}

Various expressions have been proposed to specify the temperature dependence of yielding for alloys exhibiting regular behavior. To 
evaluate their merits and limitations, data spanning a broad temperature range are needed. Table I fills this need for AISI 316 stainless steel. In the following analysis, yield stress, $\sigma_{y}$, is in MPa and temperature T, is in kelvin.

\section{Polynomials}

The most common engineering expressions for general curve-fitting purposes are polynomials of the form:

$$
\sigma_{y}=c_{0}+c_{1} T+c_{2} T^{2}+c_{3} T^{3}+c_{4} T^{4}+\ldots
$$

The number of terms used may vary, but by mathematical regression it is possible to determine the coefficients $\left(C_{0}, C_{1}, C_{2}, \ldots\right)$, thereby fitting practically any data, regardless of alloy or temperature range. For AISI 316 , the following four-term solution was obtained:

$$
\sigma_{y}=680.5-2.468 T+3.534 \times 10^{-3} T^{2}-1.670 \times 10^{-6} T^{3}
$$

which predicts $\sigma_{y}$ to within $8 \%$ of the measured values for the temperatures listed in Table I. Polynomials are a useful design tool because of their wide applicability. To their disadvantage, however, polynomials contain terms that have no physical significance or theoretical basis, and extrapolations of polynomials beyond the actual data accumulation range are not accurate.

Yang's Expression

Based on empirical data and some theoretical support, Yang [7] proposed the expression:

$$
\sigma_{y}=C_{5}{ }^{C_{6}}
$$


where $C_{5}$ and $C_{6}$ are constants for a given alloy. If this expression is valid, data in agreement with it should exhibit a linear trend when plotted as $\log \sigma_{y}$ vs. $\log T$. Yang claimed satisfactory results when using this equation to describe his yield stress measurements for highstrength iron, nickel, aluminum, and titanium alloys at temperatures between 20 and $300 \mathrm{~K}$. But the data of annealed AISI 316 do not fit Eq. (3) (Fig. 2). Poor fits are also found using annealed AISI 310 data $[6,8]$, thus, Eq. (3) is inapplicable to annealed austenitic stainless steel data.

Zener and Hollomon's Expression

Building on Becker's thermally activated plastic-flow theory [9], Zener and Hollomon [10] proposed the following expression for a pearlitic steel between 293 and $77 \mathrm{~K}$ :

$$
\sigma_{y}=\sigma \exp (r Q / R T)
$$

where $\sigma$ and $r$ are constants, $Q$ is a heat of activation, and $R$ is the universal gas constant $(R=8.31 \mathrm{~J} / \mathrm{mol} \mathrm{K})$. According to this expression, a plot of $\log \sigma_{y}$ vs. T/T should be linear, and it is for pearlitic steel [10], molybdenum [11], and tungsten [12]. As indicated in Fig. 3, the Zener and Hollomon expression also holds for AISI 316 and AISI 310 stainless steels, but only at elevated temperatures. The governing equation for AISI 316 between 300 and $922 \mathrm{~K}$ is:

$$
\sigma_{y}=72.9 \exp (2560 / R T)
$$


Elevated temperature data for AISI 304 and 310 stainless steels $[6,13]$ fit similar expressions, but the $r$ and $Q$ parameters cannot be evaluated separately unless variable strain rate tests are performed. Another obvious disadvantage of the Zener and Hollomon expression is that it fails for austenitic stainless steels at cryogenic temperatures, as shown clearly in Fig. 1 .

Yaroshevich and Ryvkina's Expression

A very successful expression stems from classical theory which relates the yield stress to two terms [14]:

$$
\sigma_{y}=\sigma_{A}+\sigma_{T}
$$

Here $\sigma_{A}$ is an athermal (temperature independent) stress determined by metallurgical structure, and $\sigma_{T}$ is a thermal stress controlled by lattice vibrations and thermally-activated rate processes. From thermodynamic and thermally activated plastic flow theories, Yaroshevich and Ryvkina [15] developed the following expression for $\sigma_{T}$ :

$$
\sigma_{T}=\left(\sigma_{0}-\sigma_{A}\right) \exp \left(-C_{7} T\right)
$$

In this expression, $\sigma_{0}$ is the extrapolated yield stress at absolute zero, $\sigma_{0}-\sigma_{A}$ is the value of $\sigma_{T}$ at absolute zero, and $C_{7}$ is a physically significant material constant related to activation energy, entropy, and strain rate [15]. A complete expression for the yield stress then follows:

$$
\sigma_{y}=\sigma_{A}+\left(\sigma_{0}-\sigma_{A}\right) \exp \left(-C_{7} T\right)
$$


or:

$$
\log \left(\sigma_{y}-\sigma_{A}\right)=\log \left(\sigma_{0}-\sigma_{A}\right)-C_{7} T
$$

where $\sigma_{A}$ is a constant that can be estimated from the $\sigma_{y}$-vs-temperature plot for a given alloy.

If Eq. (9) holds, a plot of $\log \left(\sigma_{y}-\sigma_{A}\right)$ vs. T should be linear, and it is for AISI 316 in Fig. 4. From such a plot, $\sigma_{0}-\sigma_{A}$ is the ordinate intercept at $T=0$, and $C_{7}$ is the slope. From Fig. $1, \sigma_{A}$ for AISI 316 is approximately $100 \mathrm{MPa}$. Thus, the following solution is obtained for AISI 316:

$$
\sigma_{y}=100+676 \exp \left(-6.16 \times 10^{-3} \mathrm{~T}\right)
$$

Between 922 and $30 \mathrm{~K}$, Eq. (10) predicts the data of Table I to within $20 \mathrm{MPa}$. Below $30 \mathrm{~K}$, the fit is less accurate, and the measured $\sigma_{y}$ values fall below Eq. (10) predictions by as much as $115 \mathrm{MPa}$. This deviation at extreme cryogenic temperatures may be a subtle manifestation of paramagnetic-to-antiferromagnetic transformations and dislocation tunneling effects, which represent departures from the assumptions underlying Eqq. (8), (9), and (10). Magnetic transition (near $60 \mathrm{~K}$ and below) and dislocation tunneling (near $4 \mathrm{~K}$ ) are both expected to reduce the yield stress, according to Skibina's [3] work on similar steels. Moreover, Ledbetter's elastic property measurements for the AISI 376 of this study confirm that Young's modulus is anomalous below $60 \mathrm{~K}$, and therefore, the magnetic transition probably occurs in this alloy [16]. 
The Yaroshevich and Ryvkina expression also works well for AISI 310 at temperatures between 77 and $800 \mathrm{~K}$. In terms of Eq. (8), the strength difference between AISI 316 and 310, as 117 ustrated in Fig. 1, may be ascribed primarily to the difference in $\sigma_{A}$. From Fig. 1 the $\sigma_{A}$ values for AISI 310 and 316 are 183 and $100 \mathrm{MPa}$, respectively, whereas Fig. 4 shows that the $\sigma_{T}$ terms are nearly identical. This result implies that the thermally activated flow processes for these two congeneric alloys are similar.

Although the Yaroshevich and Ryvkina expression is successful for austenitic stainless steels, some practical difficulties remain. A large data base, including elevated temperatures, is necessary to determine parameters such as $\sigma_{A}$ accurately. Rarely are elevated temperature data available for cryogenic alloys, and rarely are cryogenic data available for elevated temperature alloys.

\section{A Simplified Cryogenic Expression}

It was discovered that the AISI 316 data of this study between 4 and $295 \mathrm{~K}$ have a linear relationship when $\log \sigma_{y}$ is plotted vs. T. Using this format, the data for AISI 316 and 310 are compared in Fig. 5. Below 295 and $250 \mathrm{~K}$, respectively, the data for both alloys obey an equation of the form:

$$
\sigma_{y}=\sigma_{0} \exp \left(-C_{8} T\right)
$$

Here $\sigma_{0}$ is the extrapolated yield stress at absolute zero, and $C_{8}$ is an empirical constant without theoretical significance corresponding to the slope of the straight line in Fig. 5. Solving these parameters for AISI 316 gives: 


$$
\sigma_{y}=697 \exp \left(-4.08 \times 10^{-3} \mathrm{~T}\right)
$$

The fit between 4 and $295 \mathrm{~K}$ is such that none of the experimental data vary by more than $7 \%$ from the Eq. (12) predictions, and most data agree to within $4 \%$, which is the order of specimen-to-specimen variability.

A practical use of Eq. (11) is illustrated in Fig. 6, where selected data for other austenitic stainless steels also fit the proposed format of Eq. (11). The data shown for AISI $310[8,17,18]$, Fe-21Cr-6Ni-9Mn [19], Fe-18Cr-3Ni-13Mn [20], and a110y A-286[21] suggest the possibility of predicting the $4 \mathrm{~K}$ yield stress from only 77 and $295 \mathrm{~K}$ data. This is reasonable for stainless steels that are known to remain austenitic after $0.2 \%$ plastic strain at cryogenic temperatures, but broader applicability is questionable. For example, other yield stress data [6] for AISI 316 at $0.2 \%$ plastic strain are not 1 inear when plotted as $\log \sigma_{y}$ vs. T, and Eq. (11) should not be expected to hold if a change in deformation mechanism occurs at cryogenic temperatures.

The latter point is emphasized in Fig. 7, where $\sigma_{y}$ values at $0.2 \%$ plastic strain for AISI 310 and $304 \mathrm{~L}$ are compared on a $\log \sigma_{y}$ vs. T scale. Warren and Reed's data [8] for the stable AISI 310 indicate a trend similar to the present results for AISI 316, closely fitting Eq. (11). But AISI 304L has a lower austenite stability compared with AISI 316 or 310 , so spontaneous or stress-induced martensitic phase transformations are expected for AISI 304L. The data of Read et al. [2] for AISI 304L show the typical strengthening between 300 and $200 \mathrm{~K}$, but anomalous behavior is observed between 200 and $100 \mathrm{~K}$ where $\sigma_{\mathrm{y}}$ decreases. 
Below $100 \mathrm{~K}, \sigma_{y}$ increases again, following an exponential function similar to Eq. (11). This anomaly could be directly associated with a partial phase transformation to $\varepsilon$ martensite, as remarked elsewhere in this paper.

Figures 5 to 7 indicate that Eq. (11) is a good approximation of stable austenitic stainless-steel data in the cryogenic range, opening prospects of a parametric analysis whereby mechanical and metallurgical effects might be characterized in terms of the parameters $\sigma_{0}$ and $C_{8}$. For example, the effects of cold work on the behavior of AISI 310 [18] are illustrated in Fig. 8 As cold work increases, $\sigma_{0}$ increases and $\mathrm{C}_{8}$ decreases. Eq. (8) could also be used for parametric analysis, but Eq. (11) is simpler. The disadvantages of Eq. (11) compared with Eq. (8) are that Eq. (11) is restricted to low temperatures and the parameter $C_{8}$ lacks the physical significance attached to $C_{7}$.

\section{SUMMARY AND CONCLUSIONS}

The yield stress was measured for one heat of AISI 316 stainless steel at $0.2 \%$ plastic strain and at temperatures between 4 and $295 \mathrm{~K}$. Comparison with elevated-temperature data showed that the yield stress decreased rapidiy from $660 \mathrm{MPa}$ at $4 \mathrm{~K}$ to $102 \mathrm{MPa}$ at $922 \mathrm{~K}$. The decrease was regular and monotonic, with no obvious anomaly, and no measurable amount of $\alpha^{\prime}$ martensite was detected after $0.2 \%$ plastic strain. But it is suspected that anomalies in the yield or flow stress temperature dependences may occur in heats of AISI 316 at lower alloy contents or at higher strains.

Since the yield-stress-temperature relationship for the AISI 316 steel of this study was regular, a number of curve-fitting techniques 
were evaluated. Various expressions describing the temperature denendence of $\sigma_{y}$ for AISI 316 and other stainless steels that remain austenitic at $0.2 \%$ strain are summarized in Table II. The most satisfactory expression (Eq. 7) for the 922-degree-temperature-range considered is derived from thermodynamic and thermally activated plastic-flow theories: $\sigma_{y}=\sigma_{A}+\left(\sigma_{0}-\sigma_{A}\right) \exp \left(-C_{7} T\right)$; where $\sigma_{A}$ and $C_{7}$ are material constants and $\sigma_{0}$ is the extrapolated yield stress at absolute zero. For AISI 316 , the experimental agreement with this expression is excellent, except for subtle deviations below $30 \mathrm{~K}$ that may be attributable to maqnetic transition and dislocation tunnelling effects that moderately reduce $\sigma_{y}$ below expected values.

\section{ACKNOWLEDGMENT}

D. Baxter of the National Bureau of Standards, Boulder, Colorado contributed by performing tensile tests and data reduction. Her assistance is gratefully acknowledged. 
NOTATION

Roman Symbols

$C_{0}, C_{1}, C_{2}=$ coefficients or exponents used in expressions for the temperature dependence of vield stress.

$Q=$ heat of activation

$r=$ constant used in Eq. $4 . R=$ universal qas constant.

$T=$ temperature in degrees Kelvin.

Greek Symbols

$\sigma=$ constant used in Eq. 4, having units of stress.

$\sigma_{A}=$ the athermal component of yield stress.

$\sigma_{0}=$ the yield stress at absolute zero, obtained by extrapolation.

$\sigma_{T}=$ the thermal component of yield stress.

$\sigma_{y}=$ the yield stress at $0.2 \%$ plastic strain. 


\section{REFERENCES}

1. K. G. Brickner and J. D. Defilippi, in Handbook of Stainless Steels,

(D. Peckner and I. M. Bernstein, eds.), McGraw-Hill Book Company, New York (1977), p. 20-1.

2. D. T Read, R. P. Reed, and R. E. Schramm, in Materials Studies for Magnetic Fusion Energy Applications at Low Temperatures - II,

NBSIR 79-1609, National Bureau of Standards, Boulder, Colorado (June 1979), p. 151

3. L. V. Skibina, Prob. Prochn. 2:71 (1976).

4. D. C. Larbalestier and H. W. King, Cryogenics 13:160 (1973).

5. V. K. Sikka, "Product Form Characterization of Reference Heat of Type 316 Stainless Steel," Report No. ORNL-5384, Oak Ridge National Laboratory, Oak Ridge, Tennessee, (1978).

6. G. P. Sanderson and D. T. Llewellyn, J. Iron Steel Inst. 207:1129 (1969).

7. C. T. Yang, J. Eng. Ind. 88:117 (1966).

8. K. A. Warren and R. P. Reed, "Tensile and Impact Properties of Selected Materials from 20 to $300^{\circ} \mathrm{K}$," NBS Monograph 63, National Bureau of Standards, Boulder, Colorado, (1963).

9. R. Becker, Z. Tech. Phys. 7:547 (1926).

10. C. Zener and J. H. Hollomon, J. Appl. Phys. 15:22 (1944).

11. J. H. Bechtold, J. Mets., 5:1469 (1953).

12. J. H. Bechtold and P. G. Shewmon, Trans. Am. Soc. Met. 46:397 (1954).

13. M. K. Booker and V. K. Sikka, "Effects of Composition Variables on the Tensile Properties of Type 304 Stainless Steel," ORNL-5353, Oak Ridge National Laboratory, Oak Ridge, Tennessee (1977).

14. H. Conrad, in High Strength Materials (V. F. Zackey, ed.) John Wiley \& Sons, Inc., New York (1964), p. 436.

15. V. D. Yaroshevich and D. G. Ryvkina (1970). Sov. Phys.-Solid State (Engl. Trans 1.) 12(2) (1970). 
16. H. M. Ledbetter, National Bureau of Standards, Boulder, Colorado, unpublished data.

17. J. M. Wells, R. Kossowsky, W. A. Logsdon, and M. R. Daniel, in "Materials Research for Superconducting Machinery - III," NBS/ARPA, Semi-Annual Technical Report ADA012365 (1975), p. 1.

18. J. L. Christian, J. D. Gruner, and L. D. Girton, Trans. Am. Soc. Met. 57:199 (1964).

19. R. L. Tobler and R. P. Reed, in Elastic-Plastic Fracture, ASTM STP 668, American Society for Testing and Materials, Philadelphia (1979), p. 537.

20. D. T. Read and R. P. Reed, in Materials Studies for Magnetic Fusion Energy Applications at Low Temperatures - I, NBSIR 78-884, National Bureau of Standards, Boulder, Colorado (April 1978), p. 91.

21. R. P. Reed, R. L. Tobler, and R. P. Mikese11, in Advances in Cryogenic Engineering. Vol. 22, Plenum Press, New York (1977), p. 68. 


\section{LIST OF TABLES}

Table 1. Yield stress versus temperature data for annealed AISI 316 plate.

Table 2. Summary of expressions for the temperature dependence of yield stress, based on attempted data fits for AISI 316 and related stainless steels. 
Table I. Yield Stress vs. Temperature Data for Annealed AISI 316 Stainless Steel

\begin{tabular}{cccc}
\hline Temperature, $K$ & $\begin{array}{c}0.2 \% \text { Yield stress, } \\
\text { MPa }\end{array}$ & Temperature, $K$ & $\begin{array}{c}0.2 \% \text { Yield stress, } \\
\text { MPa }\end{array}$ \\
\hline 4 & 663 & 298 & 216 \\
4 & 656 & 366 & 174 \\
30 & 599 & 477 & 135 \\
54 & 578 & 589 & 119 \\
76 & 512 & 700 & 115 \\
76 & 516 & 811 & 103 \\
95 & 493 & 922 & \\
123 & 440 & & \\
153 & 390 & & \\
193 & 317 & & \\
214 & 299 & & \\
218 & 292 & & \\
242 & 266 & & \\
250 & 248 & & \\
295 & 213 & & \\
295 & 193 & & \\
295 & 209 & & \\
\hline
\end{tabular}

*Data from this study.

Data from Sikka [5]. 


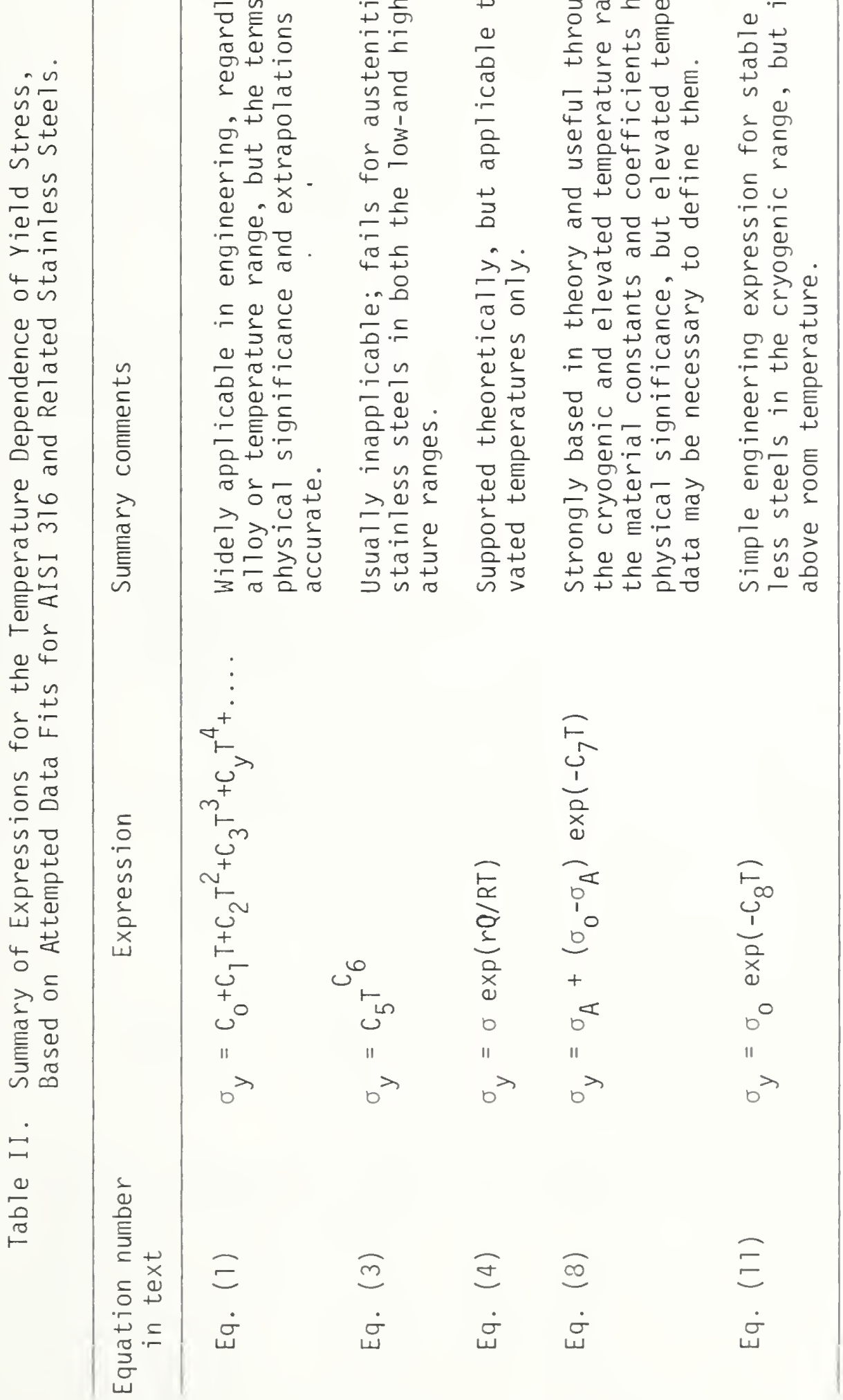


Figure 1. Effect of temperature on the yield stress of annealed AISI 316 plate, with literature data for comnarison.

Figure 2. Plot of $\log \sigma_{y}$ vs. $\log T$ for AISI 316 , illustrating the unsatisfactory fit to Eq. (3).

Figure 3. Plot of $\log \sigma_{y}$ vs. 1/T, illustrating the applicability of Eq. (4) for AISI 316 and 310 alloys at elevated temperatures.

Figure 4. Plot of $\log \left(\sigma_{y}-\sigma_{A}\right)$ vs. T, illustrating the apnlicability of Eq. (7) for AISI 316 and 310 stainless steels.

Figure 5. Plot of $\log \sigma_{y}$ vs. T, illustrating the applicability of Eq. (11) for 316 and 310 stainless steels at cryogenic temperatures.

Figure 6. Plot of $\log \sigma_{y}$ vs. T, illustrating the apnlicability of Eq. (11) to data for various austenitic stainless steels at cryogenic temperatures.

Figure 7. Plot of $\log \sigma_{y}$ vs. T, illustrating the anomalous behavior of AISI 304L compared with the more heavily alloyed and more stable AISI 316 and 310.

Figure 8. Effect of cold work on the yielding of AISI 310, using the format of Eq. (11). 


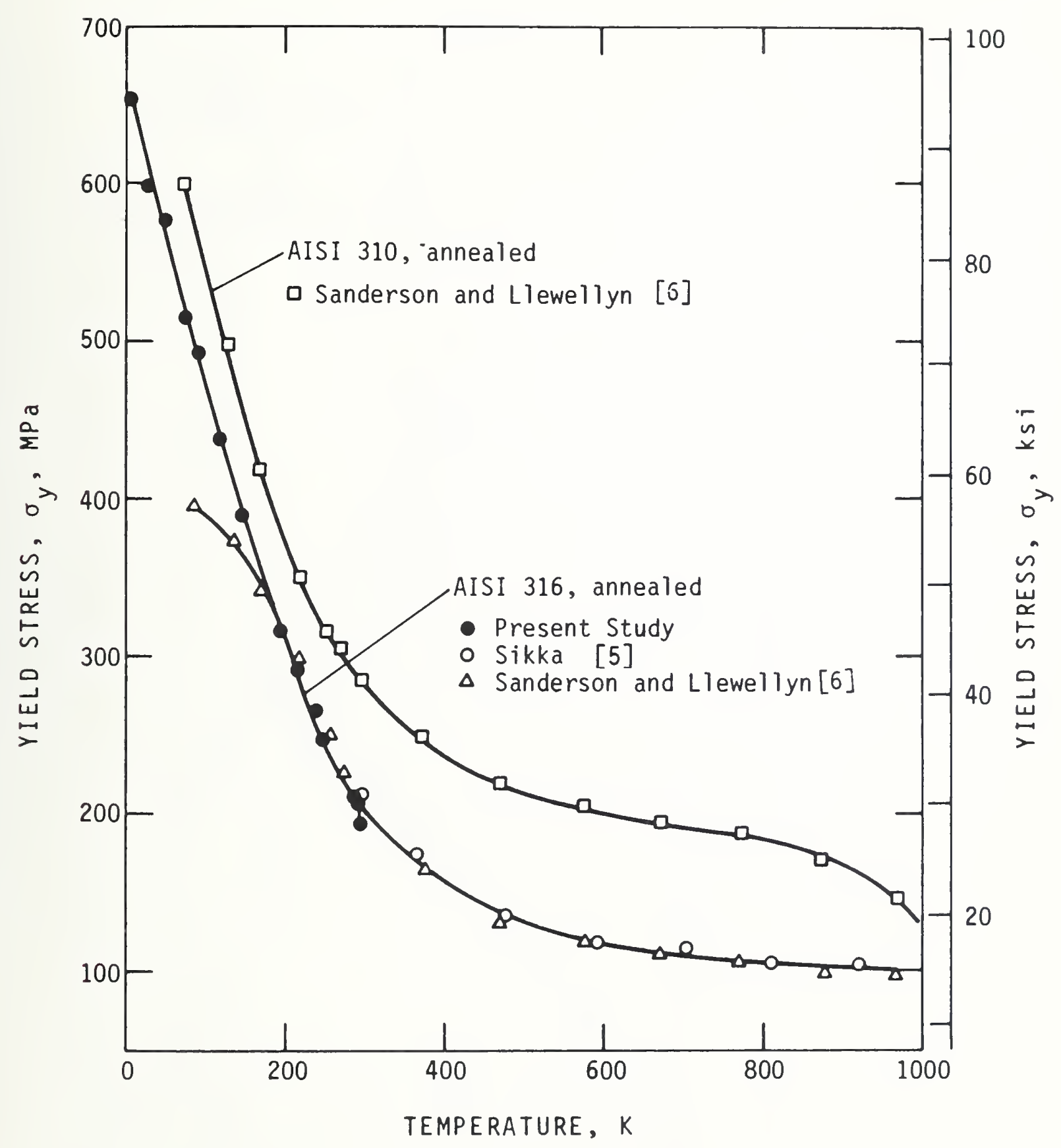

Figure 1. Effect of temperature on the yield stress of annealed AISI 376 plate, with literature data for comparison. 


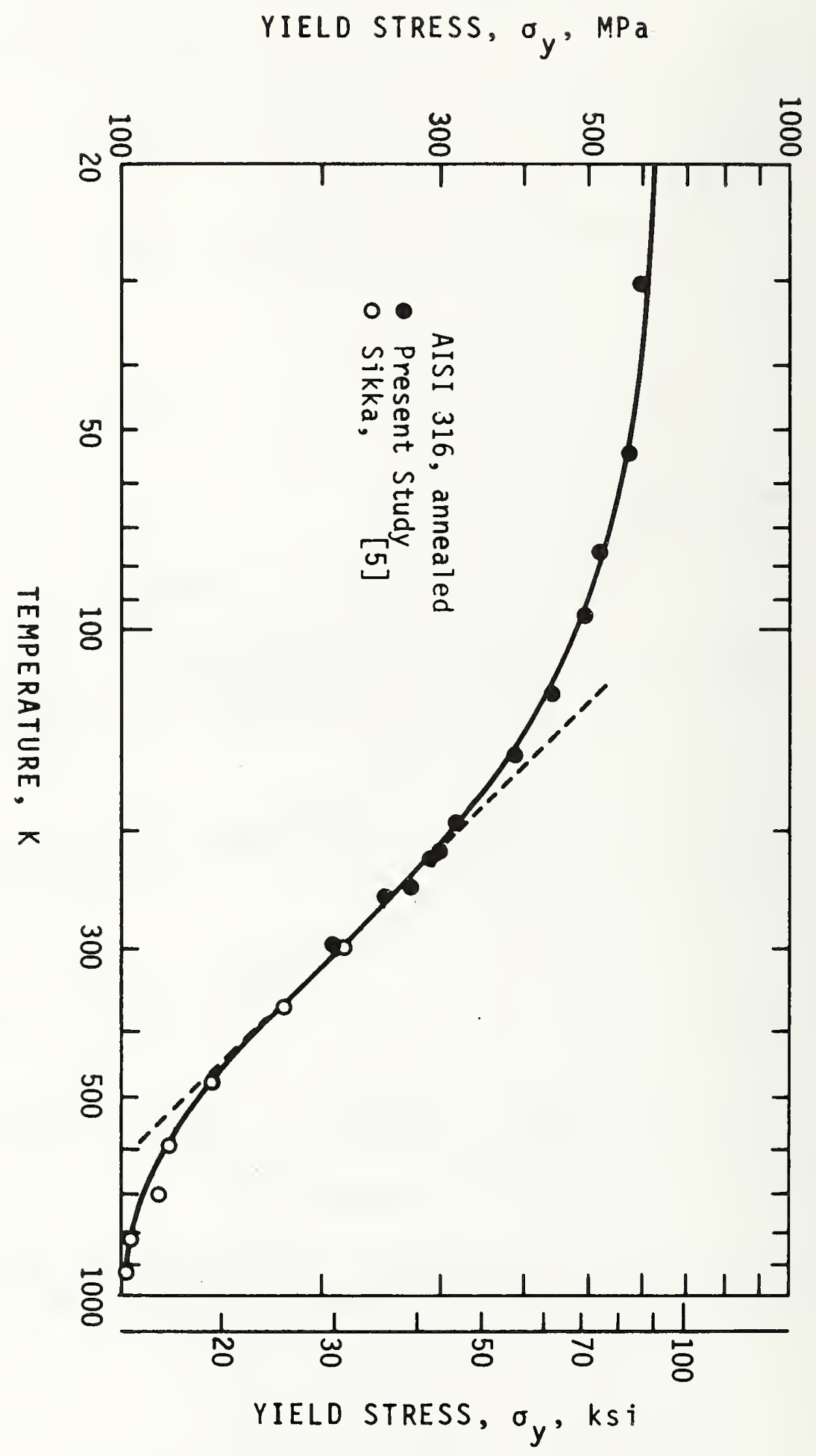

Figure 2. Plot of $\log \sigma_{\text {vs. }}$ vs. $\log T$ for AISI 316, i1lustrating the unsatisfactory $¥$ it to Eq. (3). 
TEMPERATURE, $K$

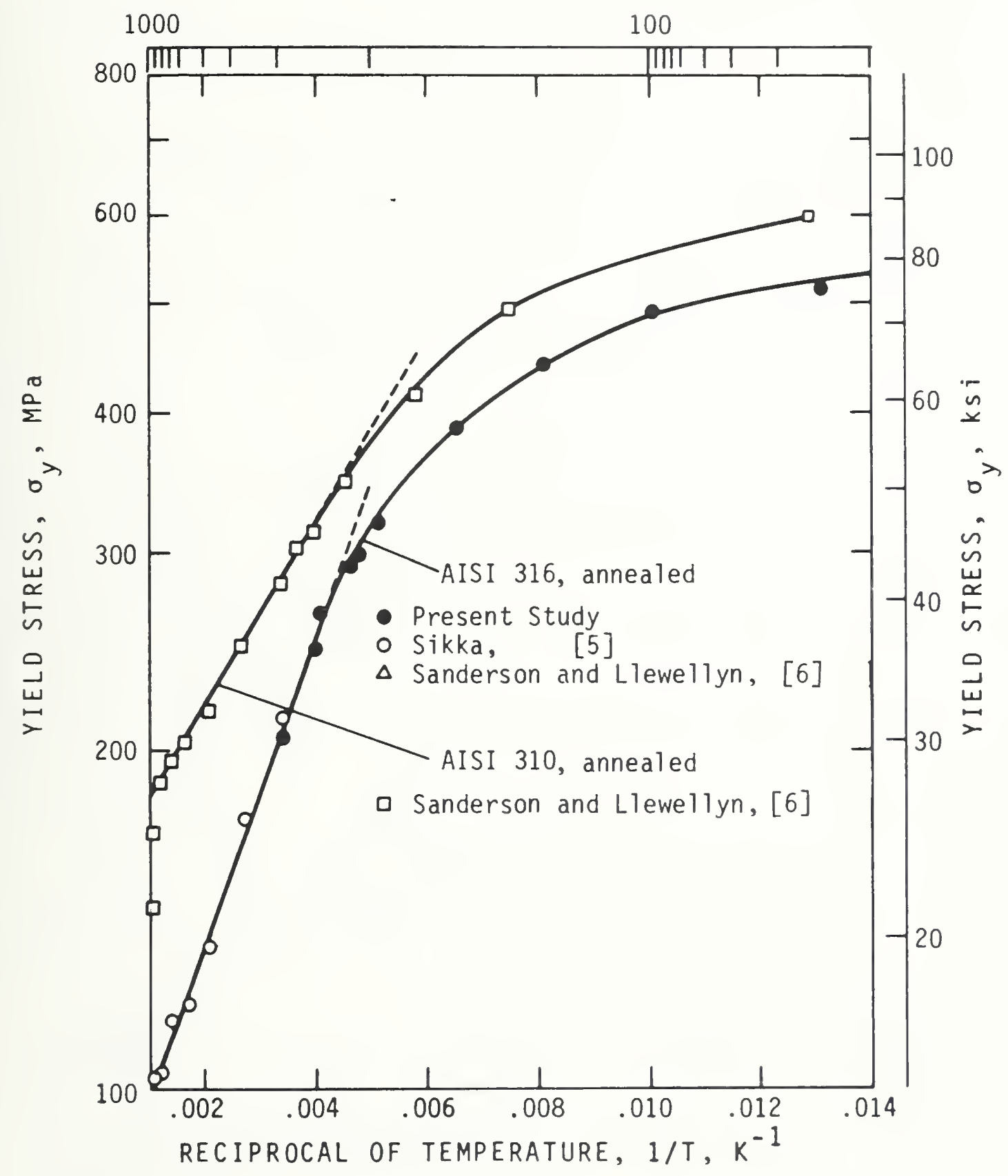

Figure 3. Plot of $\log \sigma$ vs. $1 / T$, illustrating the applicability of Eq. (4) for AISI 316 and 310 alloys at elevated temperatures. 


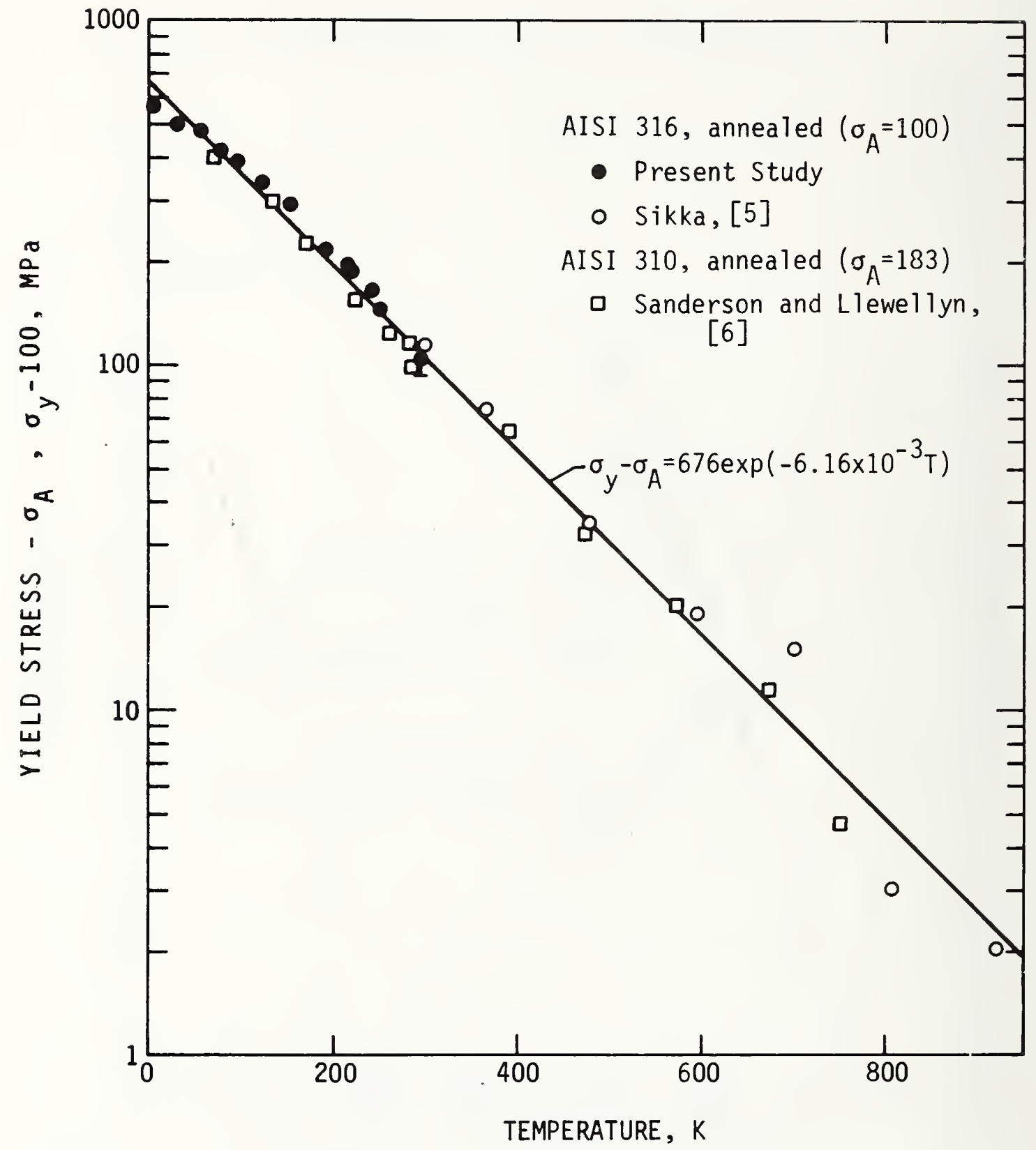

Figure 4. Plot of $\log \left(\sigma_{-}-\sigma_{A}\right)$ vs. T, illustrating the applicability of Eq. (7) for AISI 316 and 310 stainless steels. 


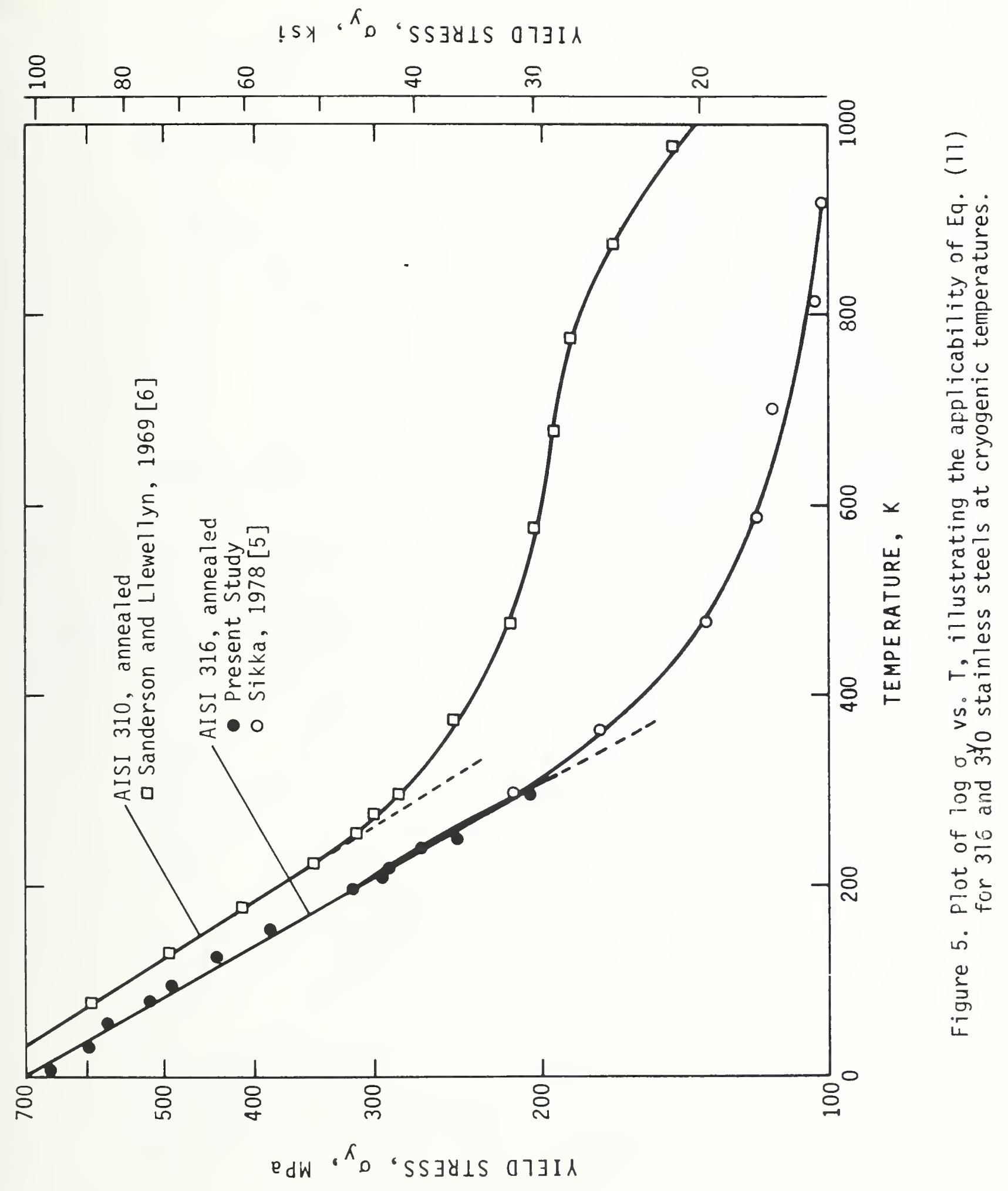




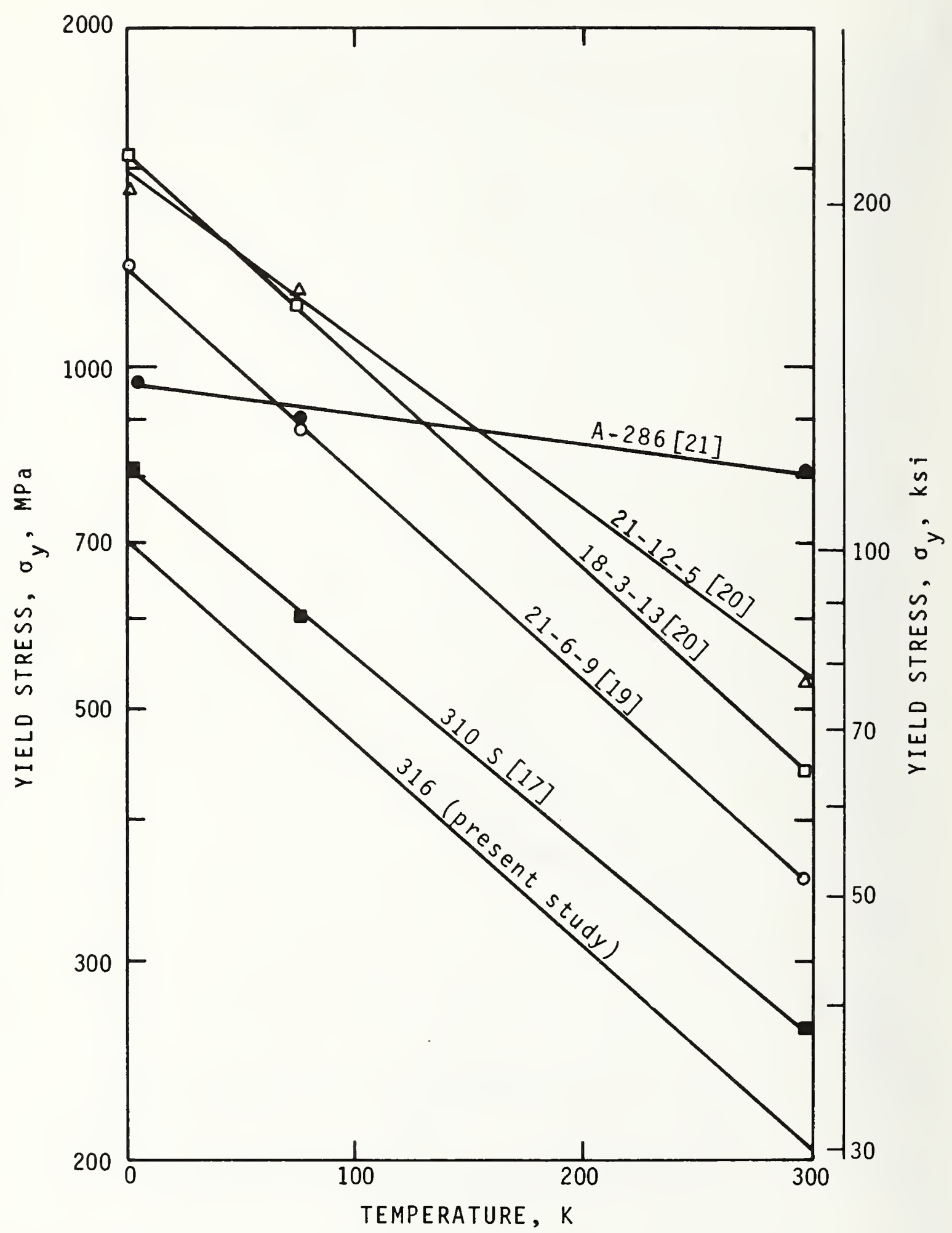

Figure 6. Plot of $\log \sigma_{\text {vs. }}$ v, illustrating the applicability of Eq. (11) to data for various austenitic stainless steels at cryogenic temperatures. 


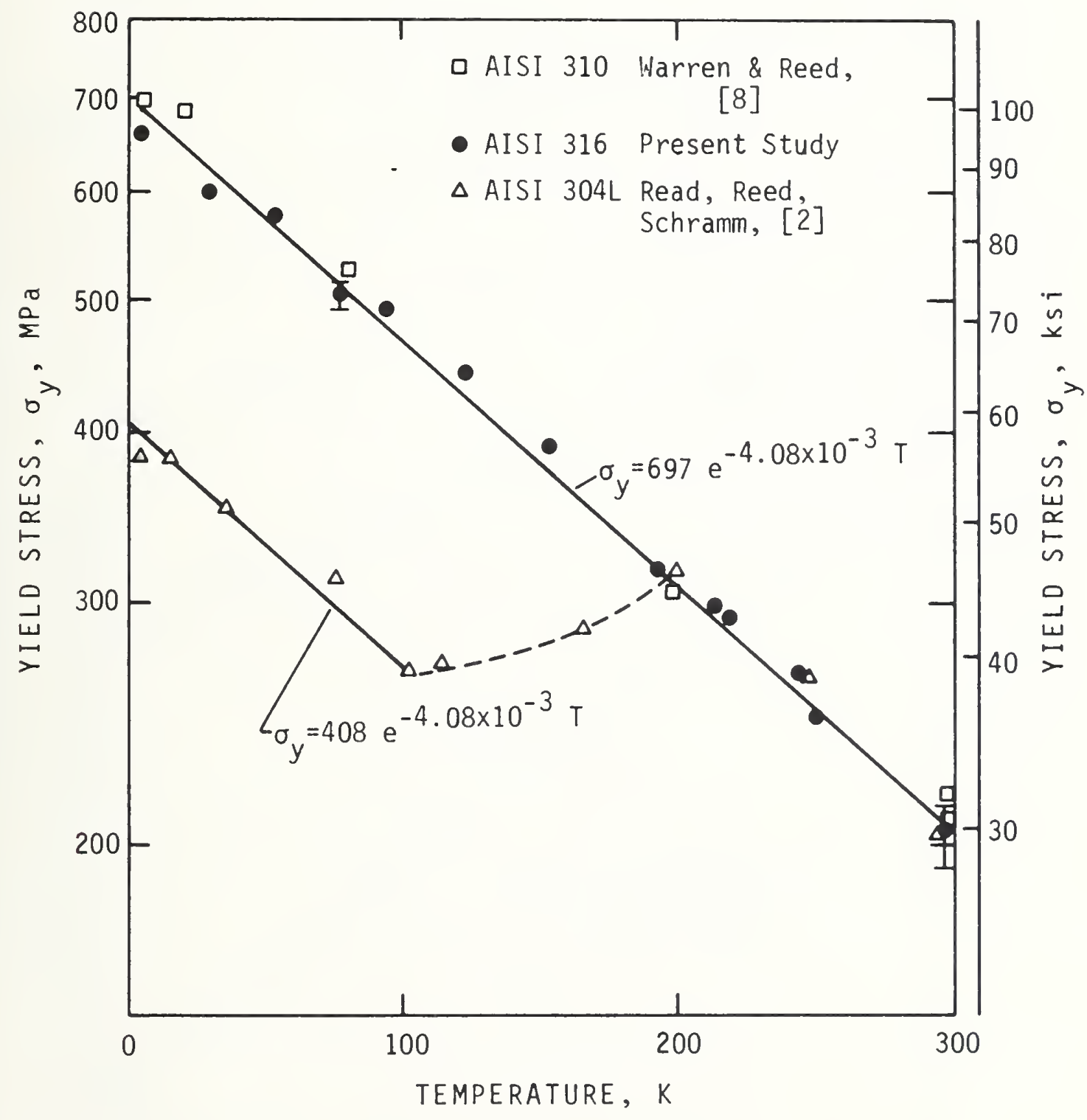

Figure 7. Plot of log $\sigma_{y}$ vs. T, illustrating the anomalous behavior of AISI $304 L$ compared with the more heavily alloyed and more stable AISI 316 and 310 . 


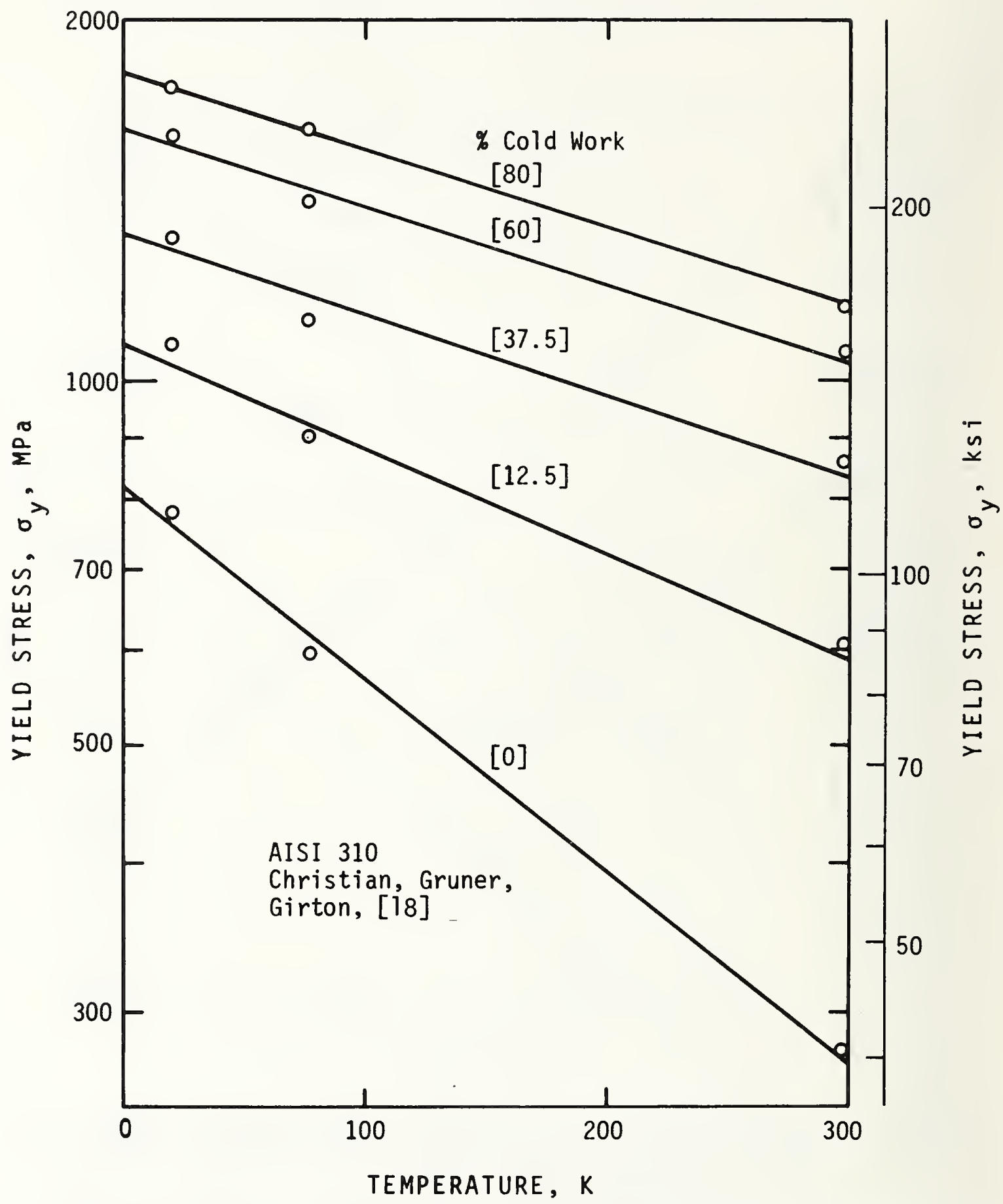

Figure 8. Effect of cold work on the yielding of AISI 310, using the format of Eq. (11). 


\section{ANOMALOUS LOW-TEMPERATURE ELASTIC-CONSTANT BEHAVIOR}

IN Fe-13Cr-19!:In

National Bureau of Standards 

ANOMALOUS LOW-TEMPERATURE ELASTIC-CONSTANT BEHAVIOR IN Fe-13Cr-19Mn* H. M. Ledbetter, Research Metallurgist

Fracture and Deformation Division, National Bureau of Standards, Boulder, Colorado 80303

Elastic constants determined by sound-vẻlocity measurements in an Fe-13Cr-19Mn steel show anomalous temperature behavior around $274 \mathrm{~K}$, indicating a paramagnetic-antiferromagnetic transition.

Key Words: Elastic constants; iron alloy; Neel transition; stainless steel. 
Recent studies $^{1-3}$ show that austenitic stainless steels with Mn and $\mathrm{N}$ substituted for $\mathrm{Ni}$ show anomalous physical-property/temperature behavior. Ledbetter ${ }^{1}$ observed that Fe-21 Cr-6Ni-9Mn exhibits elastic-constant anomalies when cooled to about $130 \mathrm{~K}$, and conjectured that a paramagneticantiferromagnetic (Neel) transition caused the anomalies. Collings and Ledbetter ${ }^{2}$ verified the Neel transition explanation in studying the elastic constants and magnetic susceptibility of a similar alloy, Fe$18 \mathrm{Cr}-3 \mathrm{Ni}-13 \mathrm{Mn}$, which behaves anomalously upon cooling to about $190 \mathrm{~K}$. Neel-transition-induced anomalies occur also in $\mathrm{Fe}-22 \mathrm{Cr}-13 \mathrm{Ni}-5 \mathrm{Mn}{ }^{3}$ at temperatures near $33 \mathrm{~K}$.

Primarily, Mn content controls the anomalous behavior ${ }^{3}$. Higher $M n$ means a higher Neel transition temperature, $T_{N}$, and larger elasticconstant changes at $T_{N}$.

Studying the limiting case -- Mn and $\mathrm{N}$ substituted completely for $\mathrm{Ni}$-- becomes of considerable interest. Such an alloy should show a high $T_{N}$ and a large, anomalous elastic-constant change.

A Soviet steel -- Fe-13Cr-19Mn -- approximates this limiting case and therefore was studied. The actual chemical composition, by weight percent, is: $13.40 \mathrm{cr}, 19.0 \mathrm{Mn}, 0.82 \mathrm{Ni}, 0.16 \mathrm{~N}, 0.055 \mathrm{C}, 0.38 \mathrm{Si}, 0.07$ $\mathrm{Cu}, 0.020 \mathrm{P}, 0.011 \mathrm{~S}, 0.10 \mathrm{~V}, 0.01 \mathrm{Mo},<0.01 \mathrm{Ti}, 0.0005 \mathrm{~B}$, balance Fe. Besides its scientific importance, this steel has technological applications. Intended for liquefied-natural-gas tankage, it shows good lowtemperature fracture-mechanics parameters ${ }^{4}$. The present communication represents perhaps the first study of its physical properties.

Elastic constants were determined by measuring ultrasonic velocities between $300 \mathrm{~K}$ and $76 \mathrm{~K}$ using equipment and procedures described elsewhere ${ }^{5}$. 
The key experimental parameters include: orthogonal-prism specimen $1.3 \mathrm{~cm}$ by $1.3 \mathrm{~cm}$ by $1.6 \mathrm{~cm}$; opposite faces flat and parallel within $3 \mu \mathrm{m}$; quartz transducers $1-\mathrm{cm}$ diameter, $x$-cut and ac-cut, rough polished, gold electroplated two sides, 6 to $8 \mathrm{MHz}$ fundamental frequencies; bonding agent phenyl salicylate at room temperature, stopcock grease at lower temperatures. Mass density determined pycnometrically was 7.81 $\mathrm{g} / \mathrm{cm}^{3}$. The raw material was a $2.0-\mathrm{cm}$ plate austenitized at $1050^{\circ} \mathrm{C}$ for $\mathrm{l} \mathrm{h}$ and air cooled.

Table I gives for selected temperatures the longitudinal and transverse sound velocities, $v_{\ell}$ and $v_{t}$, which Figs. 1 and 2 show as longitudinal and shear moduli

$$
c_{\ell}=\rho v_{\ell}^{2}
$$

and

$$
c_{t}=\rho v_{t}^{2}
$$

where $\rho$ denotes mass density. Table I and Fig. 3 give four derived elastic constants ${ }^{6}$ :

Shear modulus $=G=C_{t}$

$$
\text { Bulk modulus }=B=C_{\ell}-\frac{4}{3} G
$$

$$
\text { Young's modulus }=E=9 G B /(G+3 B)
$$

and

$$
\text { Poisson's ratio }=v=(E / 2 G)-1
$$


Maximum experimental uncertainties are believed to be 1 percent for $G$ and $E$ and 1.5 percent for $B$ and $v$.

All the elastic constants of this steel are anomalous near $274 \mathrm{~K}$, which corresponds presumably to its Neel temperature, considerably higher than $T_{N}=215 \mathrm{~K}$ predicted by an empirical relationship developed for $\mathrm{Fe}-\mathrm{Cr}-\mathrm{Ni}$ alloys ${ }^{7}$. Magnitudes of the elastic-constant changes agree with previous results ${ }^{1}$. The overall results closely resemble those reported for the highest-Mn alloy studied previously, $\mathrm{Fe}-18 \mathrm{Cr}-3 \mathrm{Ni}-13 \mathrm{Mn}$, with a Neel temperature of $191 \mathrm{~K}$.

This steel fits the elastic-constant/temperature behavior pattern established for Fe-Cr-Ni-Mn alloys ${ }^{3}$. Reflecting its high Mn content, its Neel temperature is the highest found thus far for these alloys.

The author acknowledges the technical assistance of M. Austin. This study was supported in part by the National Science Foundation and in part by the DoE Office of Fusion Energy. 
1. H. M. Ledbetter: Mater. Sci. Eng., 1977, vol. 29, p. 255-260.

2. E. W. Collings and H. M. Ledbetter: Phys. Lett., 1979, vol. 72A, p. 53-56.

3. H. M. Ledbetter and E.W. Collings: in Metal Science of Stainless Stee1s, TMS-AIME, New York, 1979.

4. R. L. Tobler, H. I. McHenry, and R. P. Reed: in Advances in Cryogenic Engineering, Volume 24, Plenum, New York, 1978, p. 560-572.

5. H. M. Ledbetter and D. T. Read: Meta11. Trans. A, 1977, vo1. 8A, p. 1805-1808.

6. L. D. Landau and E. M. Lifshitz: Theory of Elasticity, Pergamon, London, 1959 , p. 13, p. 99.

7. L. A. A. Warnes and H. W. King: Cryogenics, 1976, vol. 16, p. 659-667. 
Table I. Dynamic elastic properties of Fe-13Cr-19Mn steel at selected temperatures. $v_{\ell}=$ longitudinal sound velocity, $v_{t}=$ transverse sound velocity, $E=$ Young's modulus, $G=$ shear modulus, $B=$ bulk modulus, and $\nu=$ Poisson's ratio.

\begin{tabular}{|c|c|c|c|c|c|c|}
\hline $\begin{array}{c}\mathrm{T} \\
(\mathrm{K})\end{array}$ & $\begin{array}{l}v_{\ell} \\
\left(10^{6}\right.\end{array}$ & $(\mathrm{cm} / \mathrm{s})^{v_{t}}$ & $E$ & $\left(10^{11} \mathrm{G} / \mathrm{m}^{2}\right)$ & B & $v$ \\
\hline 300 & .5554 & .3152 & 1.959 & .779 & 1.374 & .263 \\
\hline 290 & .5554 & .3155 & 1.961 & .777 & 1.373 & .262 \\
\hline 280 & .5546 & .3149 & 1.954 & .774 & 1.369 & .262 \\
\hline 270 & .5495 & .3098 & 1.899 & .749 & 1.359 & .267 \\
\hline 260 & .5478 & .3086 & 1.885 & .744 & 1.352 & .268 \\
\hline 250 & .5483 & .3089 & 1.889 & .745 & 1.354 & .268 \\
\hline 240 & .5488 & .3093 & 1.893 & .747 & 1.356 & .267 \\
\hline 230 & .5495 & .3099 & 1.900 & .750 & 1.358 & .267 \\
\hline 220 & .5501 & .3104 & 1.905 & .752 & 1.360 & .267 \\
\hline 210 & .5508 & .3108 & 1.911 & .755 & 1.363 & .266 \\
\hline 200 & .5514 & .3113 & 1.916 & .757 & 1.365 & .266 \\
\hline 190 & .5520 & .3117 & 1.921 & .759 & 1.368 & .266 \\
\hline 180 & .5527 & .3121 & 1.926 & .761 & 1.371 & .266 \\
\hline 170 & .5533 & .3126 & 1.931 & .763 & 1.373 & .266 \\
\hline 160 & .5539 & .3130 & 1.937 & .765 & 1.375 & .265 \\
\hline 150 & .5545 & .3135 & 1.942 & .767 & 1.378 & .265 \\
\hline 140 & .5551 & .3139 & 1.947 & .770 & 1.380 & .265 \\
\hline 130 & .5556 & .3744 & 1.952 & .772 & 1.381 & .265 \\
\hline 120 & .5562 & .3148 & 1.957 & .774 & 1.384 & .264 \\
\hline 110 & .5567 & .3153 & 1.962 & .776 & 1.385 & .264 \\
\hline 100 & .5572 & .3156 & 1.966 & .778 & 1.387 & .264 \\
\hline 90 & .5576 & .3159 & 1.969 & .779 & 1.389 & .264 \\
\hline 80 & .5579 & .3160 & 1.971 & .780 & 1.391 & .264 \\
\hline
\end{tabular}




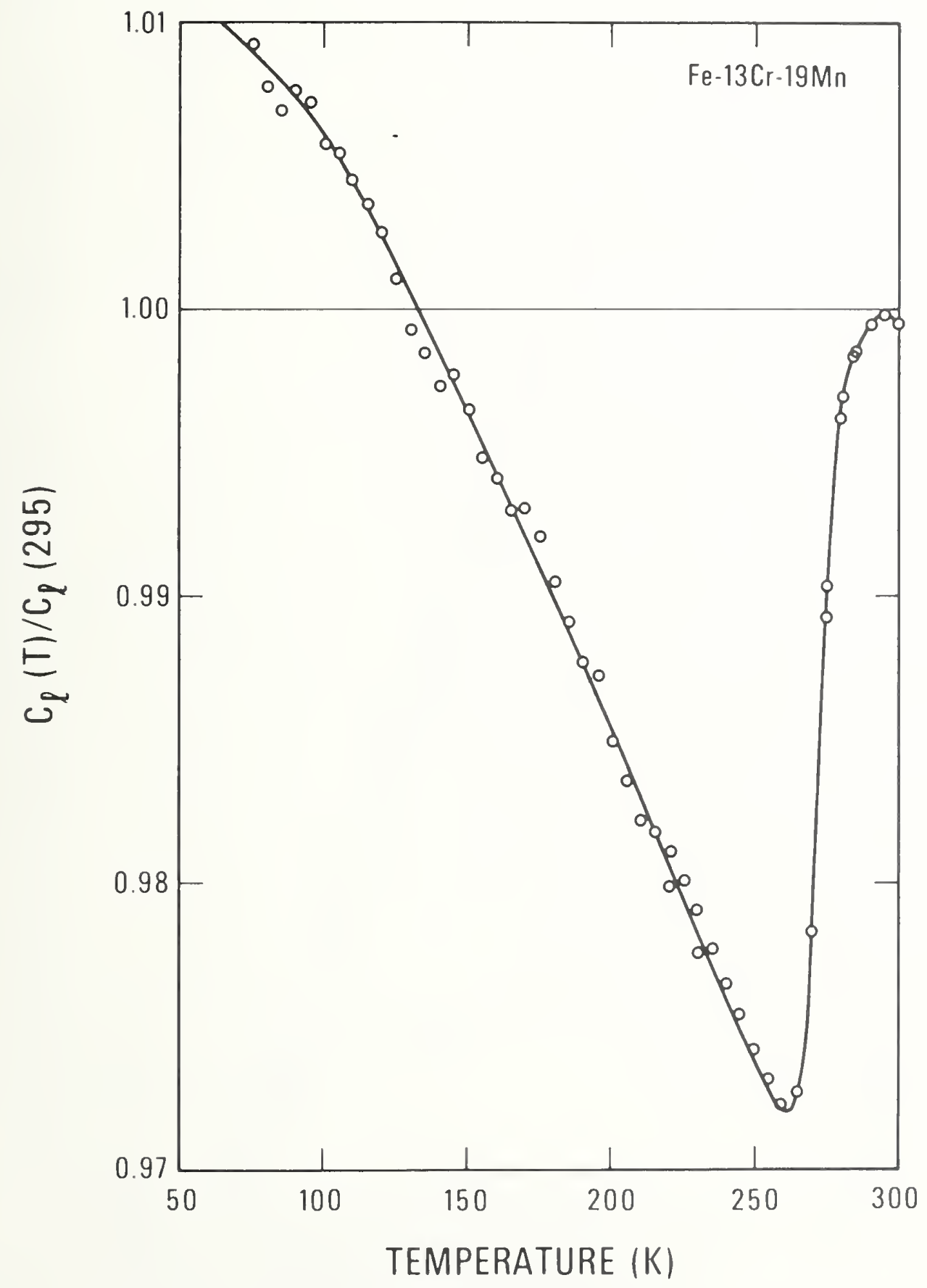

Fig. 1. Temperature dependence of the longitudinal modulus $C_{l}=\rho v_{l}^{2}$ for Fe-13Cr-19Mn. As described in the text, the anomalous behavior is caused by a Néel (paramagnetic-antiferromagnetic) transition. 


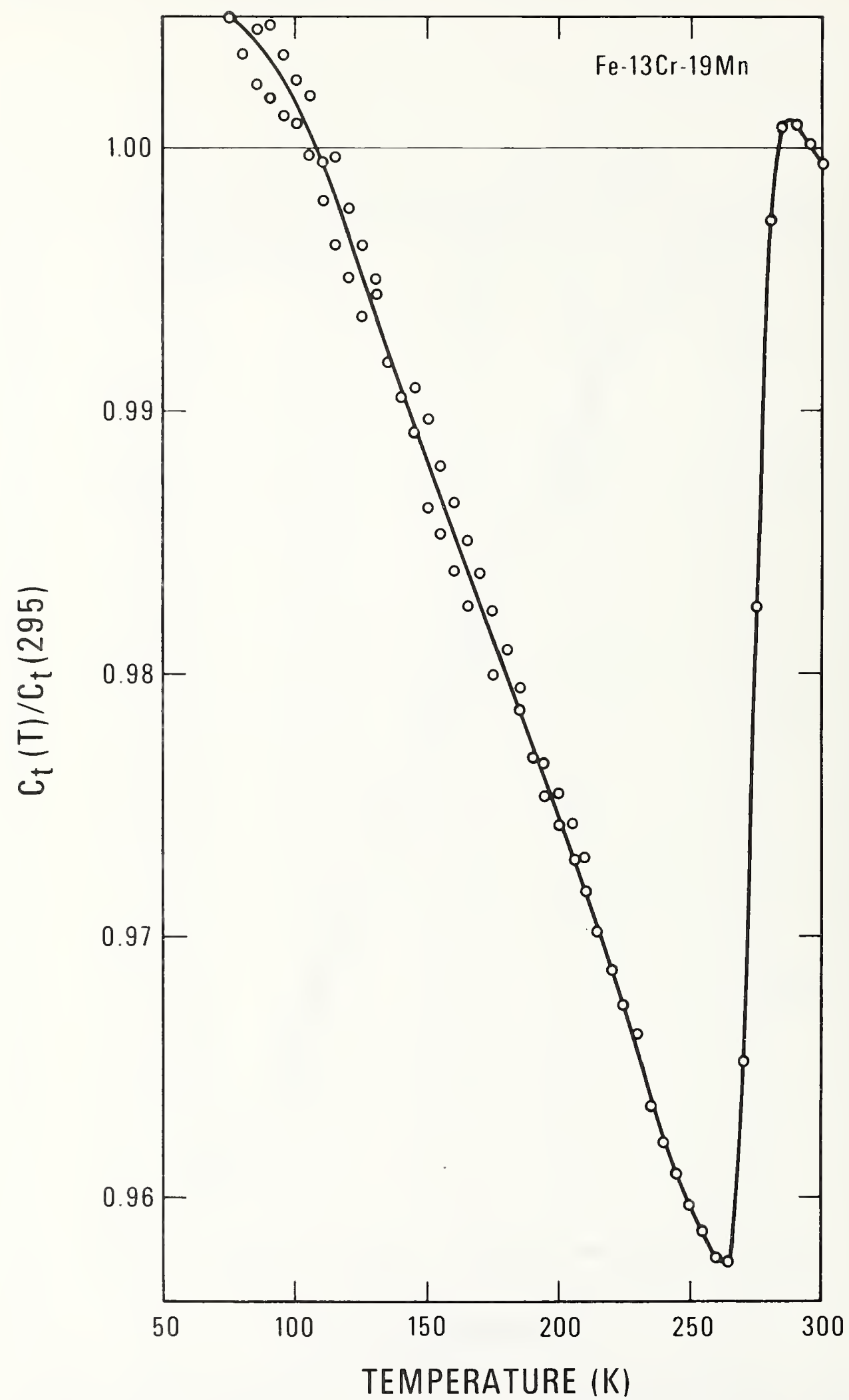

Fig. 2. Temperature dependence of the shear modulus $G=\rho v_{t}^{2}$ for Fe-13Cr-19Mn. 


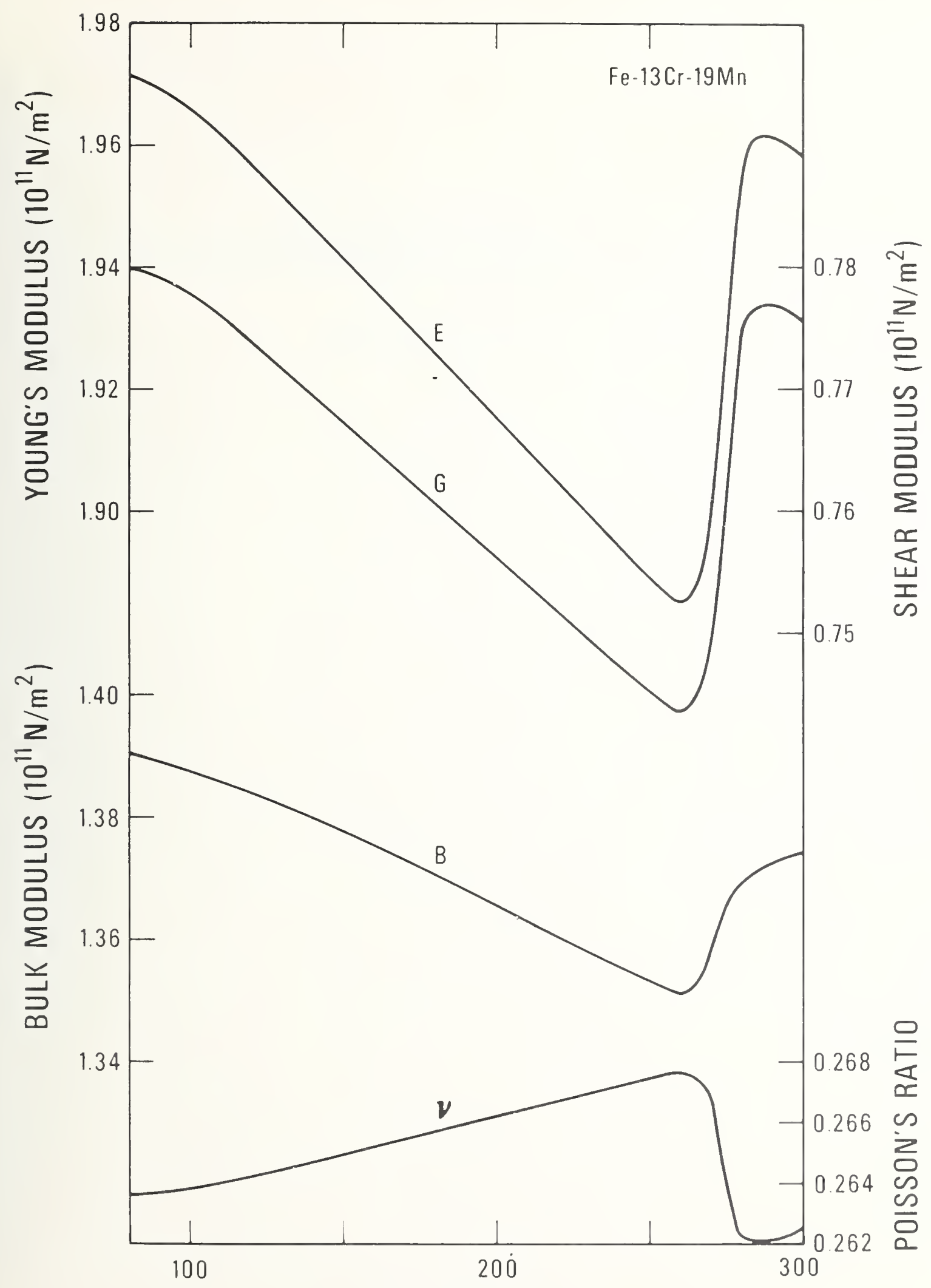

TEMPERATURE (K)

Fig. 3. Smoothed temperature dependence of the four elastic constants of Fe-13Cr-19/1n: $E$ = Young's moduTus, $G=$ shear modulus, $B=$ butk modulus (reciprocal compressibility), $v=$ Poisson's ratio. 

ROO:-TEMPERATURE ELASTIC CONSTANTS AND

LOW-TEMPERATURE SOUND VELOCITIES FOR SIX NITROGEN-STRENGTHENED

AUSTENITIC STAINLESS STEELS

National Bureau of Standards 

ROOM-TEMPERATURE ELASTIC CONSTANTS AND LOW-TEMPERATURE SOUND VELOCITIES FOR SIX NITROGEN-STRENGTHENED AUSTENITIC STAINLESS STEELS

H. M. Ledbetter

Fracture and Deformation Division

National Bureau of Standards

Boulder, Colorado 80303

Despite large chemical-composition differences, six nitrogen-alloyed stainless steels show only slight differences in their room-temperature elastic constants, determined by ultrasonic-velocity measurements. At low temperatures, magnetic transitions cause anomalous elastic-constant behavior and significant differences in elastic constants. Nitrogen content seems not to affect the elastic constants.

Key Words: Elastic constants; iron alloys; low temperatures; magnetic transitions; sound velocities; stainless steels. 
Metallurgists began studying nitrogen-alloyed stainless steels in 1925. 1 Renewed interest in these alloys results from two causes: concern over diminishing supplies of alloying elements such as nickel and the unfulfilled dream of a high-strength face-centered-cubic steel.

Research on these alloys has been largely empirical and without theoretical guidance. These studies, which focused mainly on mechanicalstrength properties have been reviewed by several authors. 1-3

One small but important step toward a basic understanding of a material is knowledge of its elastic constants, which are among the most fundamental mechanical properties. Effects of nitrogen on the elastic constants of these alloys remain unstudied. Nor have such effects been investigated for the relevant binary systems. Furthermore, the effects of $\mathrm{Cr}, \mathrm{Ni}$, and $\mathrm{Mn}$ contents on the elastic constants of these stainless steels remains unresolved. Another uncertainty is the occurrence of low-temperature magnetic transitions, or possibly even structural transitions, that manifest themselves as elastic-constant anomalies.

The presently reported study does not resolve these questions, but contributes significantly toward their solution by providing accurate measurements of basic properties of several alloys. The complete set of elastic constants -- Young's modulus, shear modulus, bulk modulus, and Poisson's ratio -- were determined at ambient temperature for six nitrogen-alloyed stainless steels representing a wide range of chemical compositions. One of the elastic constants, the longitudinal modulus, was determined during cooling to either liquid-nitrogen or liquid-helium temperature.

Ledbetter and collings ${ }^{4}$ recently reported elastic constants of three nitrogen-alloyed steels - - Fe-18Cr-3Ni-12Mn, Fe-21Cr-6ili-9Mn, and 
Fe-22Cr-13Ni-5Mn - - between room temperature and liquid-nitrogen temperature. All these alloys undergo Néel (paramagnetic-antiferromagnetic) transitions at a below-ambient temperature, $T_{N}$, that depends mainly on the Mn content. All the elastic constants -- Young's modulus, shear modulus, bulk modulus, Poisson's ratio, etc. -- behave anomalously at temperatures near $T_{N}$. Higher $M n$ content causes a higher $T_{N}$ and a larger elastic-constant change at $T_{N}$.

This communication reports results for three additional nitrogenalloyed steels - Fe-18Cr-2Ni-13Mn, Fe-17Cr-9ivi-8Mn, and Fe-18Cr-8Ni (AISI 304N), whose chemical compositions are given in Table I and metallurgical characterizations in Table II. Note that all six steels were in a solution-treated-and-quenched state; thus, most or all nitrogen was presumably in interstitial solid solution and not in precipitates. References 4 and references therein describe the experimental equipment and methods.

Table III gives the room-temperature sound-velocity and elasticconstant results. Excluding the Fe-17Cr-9Ni-8Mn alloy, Young's modulus varies least $( \pm 1.3$ percent) and the bulk modulus varies most $( \pm 2.4$ percent). Considering the chemical-composition differences among the alloys, these are surprisingly small variations. The slower shear-wave velocity for Fe-17Cr-9Ni-8Mn, which results in lower Young's and shear moduli and in higher bulk modulus and Poisson's ratio, is not understood. Strong texture resulting in higher elastic anisotropy may explain this result. But elastic anisotropy measured in Fe-18Cr-3Ni$12 \mathrm{Mn}$ amounted to only 0.16 and 0.32 percent for the longitudinal and shear velocities measured in three orthogonal directions. 5 This alloy's 
high Si content may cause its relatively low shear modulus, but apparently such factors remain unevaluated.

Longitudina1-modulus-versus-temperature curves shown in Fig. 1 reveal qualitatively similar behavior for all six alloys: a normal linear increase upon cooling below room temperature, an anomalous decrease through a minimum, and an increase to the zero-temperature value. The longitudinal modulus reflects changes that occur either in the bulk modulus or in the shear modulus. Néel (paramagneticantiferromagnetic) transition temperatures Measured previously ${ }^{4}$ for three alloys and computed empirically ${ }^{6}$ for one alloy are also indicated as dashed vertical lines in Fig. 1. Clearly, the elastic-constant anomalies relate to the magnetic transitions. Based on the elastic data, Néel temperatures are approximately $171 \mathrm{~K}$ for $\mathrm{Fe}-18 \mathrm{Cr}-2 \mathrm{Ni}-13 \mathrm{Mn}$ and $43 \mathrm{~K}$ for $\mathrm{Fe}-77 \mathrm{Cr}-9 \mathrm{Ni}-8 \mathrm{Mn}$.

In summary, six nitrogen-alloyed austenitic stainless steels, with one exception, show similar room-temperature elastic constants. During cooling all six steels undergo Héel (paramagnetic-antiferromagnetic) transitions accompanied by anomalous elastic-constant/temperature behavior. The transition temperature relates strongly to the Mn content. While further studies, with systematic nitrogen-content variations, are required, solid-solution nitrogen content seems not to influence the elastic constants of these alloys. The Fe-18Cr-3Ni-12Mn alloy was studied also in an annealed-and-furnace-cooled condition. The elastic constants were: Young's modulus $=1.965 \cdot 10^{11} \mathrm{~N} / \mathrm{m}^{2}$, shear modulus $=0.768 \cdot 10^{11} \mathrm{~N} / \mathrm{m}^{2}$, bulk modulus $=1.489 \cdot 10^{11} \mathrm{~N} / \mathrm{m}^{2}$, and Poisson's ratio $=0.282$. Thus, precipitation of nitrogen causes a one to three percent lowering of both the dilatation-type and shear-type elastic constants. 
The author acknowledges the contribution of alloy samples by Armco Steel Corporation and experimental assistance by M. Austin. These results emerged from a study sponsored by DoE Office of Fusion Energy. 


\section{REFERENCES}

1. B. Gunia and G. R. Woodrow: J. Mater, 1970, Vol. 5, p. 413-430.

2. K. J. Irvine, T. Gladman, and F. B. Pickering: J. Iron Steel Inst., 1969, Vol. 207, p. 1017-1028.

3. A. Randak, W. Wessling, H. E. Beck, H. Steinmauer, and L. Faust: Stahl und Eisen, 1971, Vol. 91, p. 1255-1270.

4. H. M. Ledbetter and E. W. Collings: in Metal Science of Stainless Steels, TMS-AIME, New York, 1979, p. 22-40.

5. H. M. Ledbetter and E.W. Collings: to be published.

6. L. A. A. Warnes and H. W. King: Cryogenics, 1976, Vo1. 16, p. 659-667. 


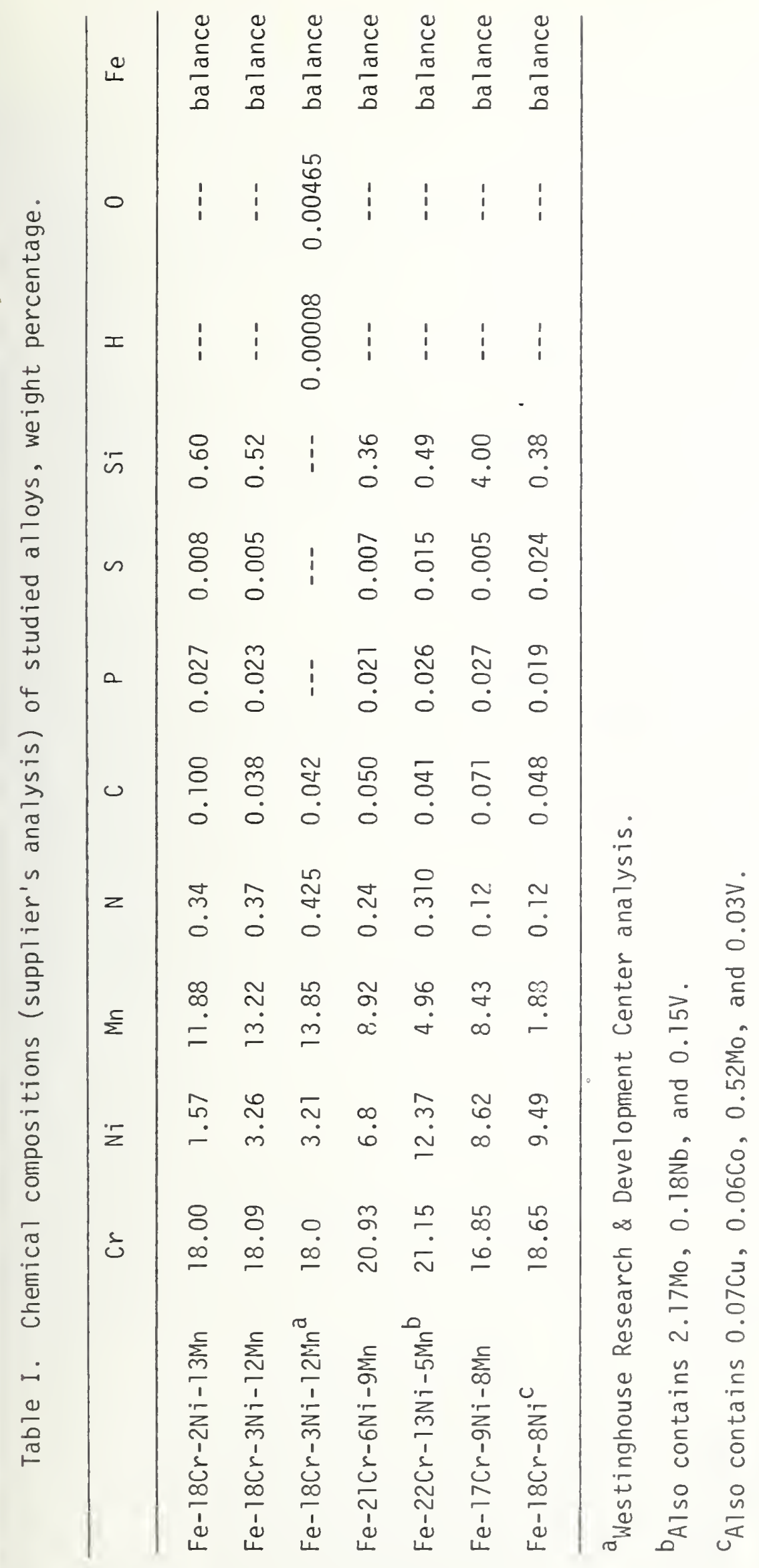




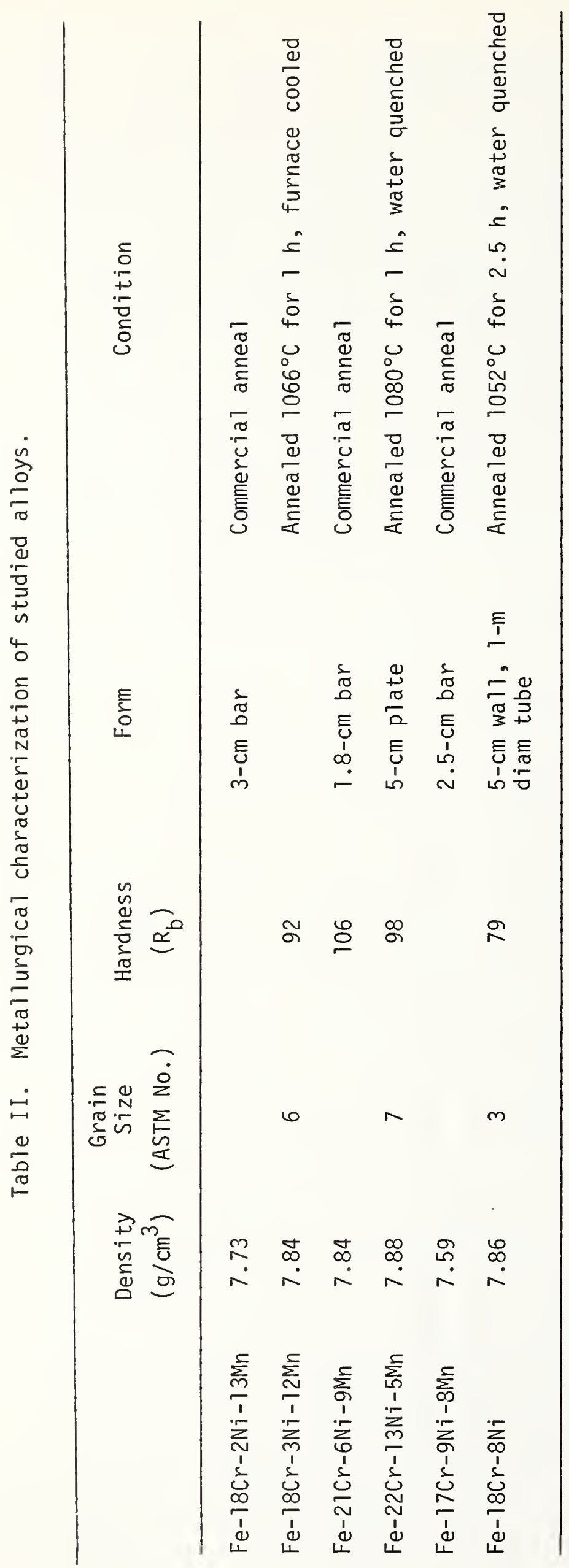




\section{FIGURE CAPTION}

Fig. 1. Temperature dependence of the longitudinal modulus $\rho v_{\ell}^{2}$ for six nitrogen-alloyed stainless steels. As described in the text, the anomalies are due to Néel (paramagneticantiferromagnetic) transitions. 


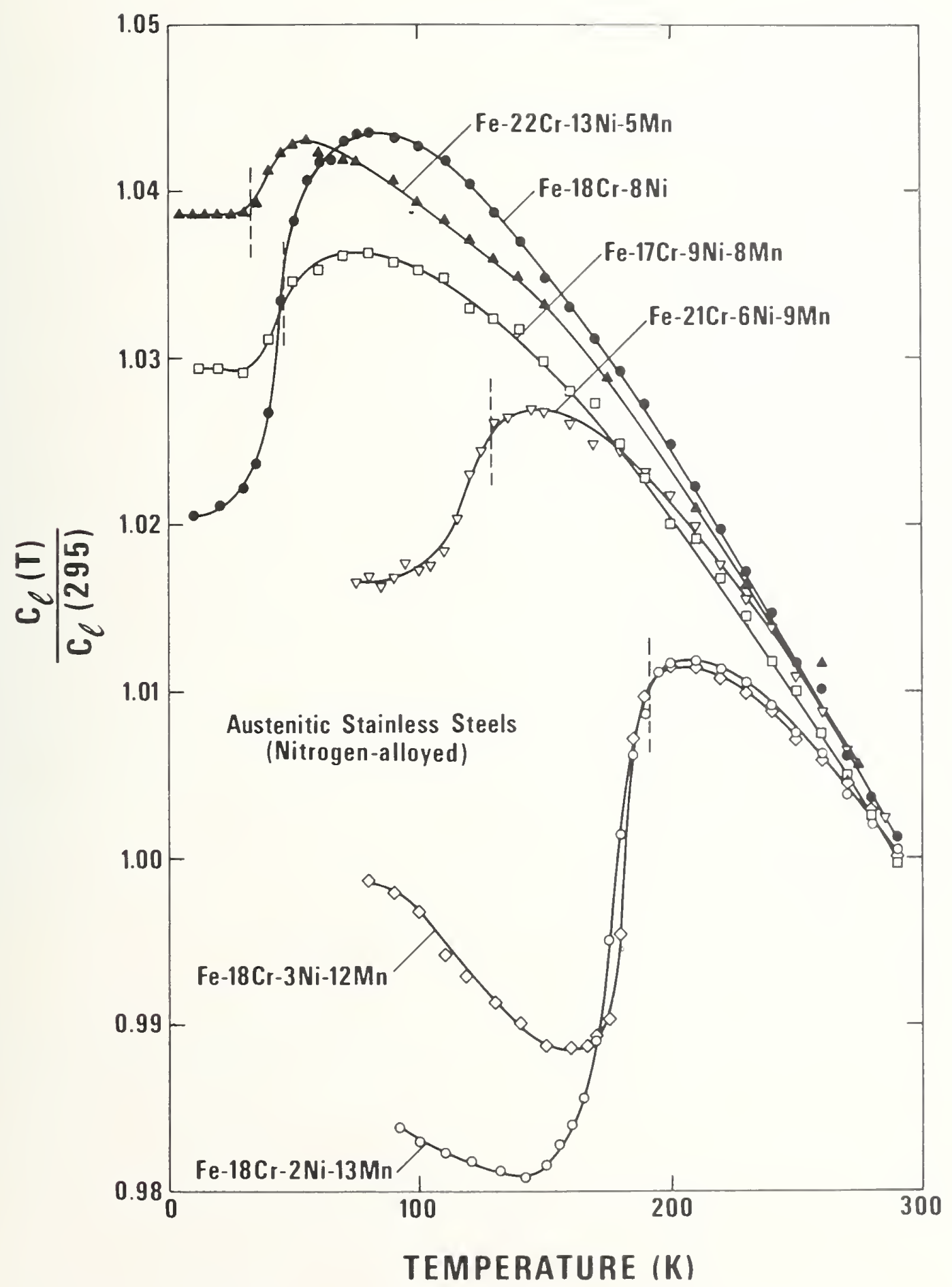

Fig. 1. Temperature dependence of the longitudinal modulus $\rho v^{2}$ for six nitrogen-alloyed stainless steels. As described in the text, the anomalies are due to Méel (paramagneticantiferromagnetic) transitions. 

SOUND VELOCITIES AND ELASTIC CONSTANTS

OF AUSTENITIC STAINLESS STEELS 304, 310, AND 316

National Bureau of Standards 

Sound velocities and elastic constants of austenitic stainiess steels 304,310 , and 316

H. M. Ledbetter

Fracture and Deformation Division

National Bureau of Standards

Boulder, Colorado 80303

Room-temperature ultrasonic velocities, longitudinal and transverse, were measured in three AISI 300-series austenitic stainless steels. Elastic constants computed from these velocities show small but significant variations with composition.

Key Words: Bulk modulus; elastic constants; Poisson's ratio; shear modulus; sound velocity; stainless steel; Young's modulus. 
Recently the author ${ }^{1}$ collaborated in studying the elastic-constant variability in stainless steel 304. Twenty samples acquired randomly were measured ultrasonically within an experimental uncertainty of 0.2 percent in the sound velocities. Results showed surprisingly small elastic-constant variations: about 1 percent in the Young's and shear moduli and about 1.5 percent in the bulk modulus and Poisson's ratio. This included all possible variation sources: chemical composition, thermomechanical processing, sample anisotropy, and experimental error.

This report describes a less-ambitious related study on two similar materials: stainless steels 310 and 316 (three samples of each). Experimentally, this study proceeded exactly as the previously reported study $^{1}$ on stainless-steel 304. On the basis of that study, several possible sources of variation could be neglected: anisotropy; sampleto-sample, within 1ot; repeated measurements; measurement frequency. Table 1 contains characterizations of the studied alloys.

Stainless steel 310 differs from 304 principally in containing considerably more nickel (by a factor of 2.5) and chromium (by a factor of 1.3) to stabilize the alloy against low-temperature strain-induced phase transformations.

Stainless steel 316 differs from 304 principally in containing an additional two percent molybdenum to improve both corrosion resistance and high-temperature mechanical properties. Also, it contains more nickel by a factor of about 1.5, to compensate for the molybdenum, which is a ferrite stabilizer.

Tables 2 and 3 show the results for stainless steels 310 and 316 . For comparison, Table 4 summarizes results 1 of the stainless-steel- 
304 study. In these tables, $v_{\ell}$ and $v_{t}$ denote the measured longitudinal and transverse ultrasonic velocities, and $\rho$ denotes the mass density. Elastic constants relate to sound velocities through well-known relationships:

$$
\begin{aligned}
& \text { longitudinal modulus }=C_{l}=\rho v_{l}^{2} \\
& \text { shear modulus }=G=\rho v_{t}^{2} \\
& \text { bulk modulus }=B=\rho\left(v_{l}^{2}=\frac{4}{3} v_{t}^{2}\right) \\
& \text { Young's modulus }=E=3 \rho v_{t}^{2}\left(v_{l}^{2}-\frac{4}{3} v_{t}^{2}\right) /\left(v_{l}^{2}-v_{t}^{2}\right) \\
& \text { Poisson's ratio }=v=\frac{1}{2}\left(v_{l}^{2}-2 v_{t}^{2}\right) /\left(v_{l}^{2}-v_{t}^{2}\right)
\end{aligned}
$$

Since these three alloys consist principally of iron, chromium, and nickel, some interesting observations arise concerning the relative effects of chromium and nickel on the elastic constants. Contrary to alloying effects in dilute alloys ${ }^{2}$ where increasing solute usually decreases the elastic stiffnesses, in these alloys, chromium increases all the elastic stiffnesses: B, E, and G. Nickel decreases both $E$ and $G$, as expected, but leaves B unaffected or slightly increased. Chromium has little effect on Poisson's ratio, but nickel increases it because

$$
\frac{d v}{v} \approx \frac{4}{9}\left(\frac{d B}{B}-\frac{d G}{G}\right)
$$

and the usual cancellation of the two terms does not occur.

The author is unaware of any systematic elastic-constant/composition studies of the basic $\mathrm{Fe}-18 \mathrm{Cr}-8 \mathrm{Ni}$ composition. Several binary body-centered-cubic iron alloys, studied by Speich, Schwoeble, and Leslie ${ }^{3}$ showed that chromium increased both $B$ and $G$, while nickel decreased both. Following previous studies, these authors factored the 
observed alloying effects into electronic and volume contributions; they concluded that $\mathrm{Fe}-\mathrm{Cr}-\mathrm{Ni}$ alloys show negligible electronic-term changes.

Further systematic studies of the elastic constants of alloys would be useful in several ways: (1) effects of various alloying elements-$\mathrm{Cr}, \mathrm{Ni}, \mathrm{Mo}, \mathrm{Mn}$-could be determined; (2) relationships of elastic constants to theories of solid-solution strengthening and plastic deformation could be assessed; (3) fundamental properties would be provided for testing various electron-theory models of transition metals; (4) the important, unsolved problem of face-centered-cubic iron's elastic constants might be elucidated.

\section{ACKNOWLEDGMENT}

This study was supported by the DoE Office of Fusion Energy and the NBS Office of Standard Reference Data. 


\section{REFERENCES}

1. H. M. Ledbetter, N. V. Frederick, and M. W. Austin: Elasticconstant variability in stainless steel 304, J. Appl. Phys., 1980, January issue.

2. C. Zener: Relation between residual strain energy and elastic moduli, Acta Crystallogr., 1949, 2, 163-166.

3. G. R. Speich, A. J. Schwoeble, and W. C. Leslie: Elastic constants of binary iron-base alloys, Meta 11. Trans., 1973, Vol. 3, pp. 2031-2037. 


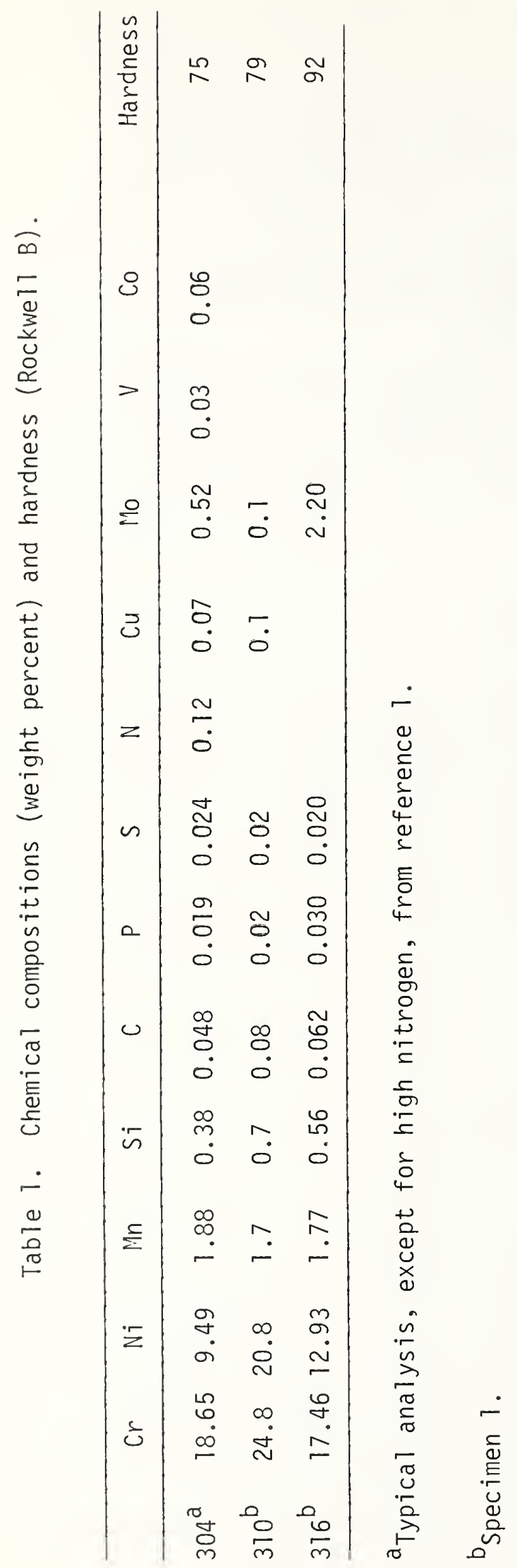


Table 2. Sound velocities and elastic constants of stainless steel 310 at $T=295 \mathrm{~K}$.

\begin{tabular}{|c|c|c|c|c|c|c|}
\hline & 1 & $\underset{2}{\text { Sample }}$ & 3 & Mean & $\begin{array}{l}\text { Std. } \\
\text { Dev. }\end{array}$ & $\begin{array}{l}\text { Coeff. } \\
\text { of Var. }\end{array}$ \\
\hline$v_{\ell}(\mathrm{cm} / \mu \mathrm{s})$ & 0.5765 & 0.5775 & 0.5749 & 0.5763 & 0.0013 & 0.2 \\
\hline$v_{t}(\mathrm{~cm} / \mu \mathrm{s})$ & 0.3035 & 0.3049 & 0.3068 & 0.3051 & 0.0017 & 0.5 \\
\hline$\rho\left(\mathrm{g} / \mathrm{cm}^{3}\right)$ & & & & 7.850 & & \\
\hline$C_{\ell}(\mathrm{GPa})$ & 260.9 & 261.8 & 259.5 & 260.7 & 1.2 & 0.4 \\
\hline $\mathrm{G}(\mathrm{GPa})$ & 72.3 & 73.0 & 73.9 & 73.1 & 0.8 & 1.1 \\
\hline $\mathrm{B}(\mathrm{GPa})$ & 164.5 & 164.5 & 160.9 & 163.3 & 2.1 & 1.3 \\
\hline$E(G P a)$ & 189.2 & 190.7 & 192.2 & 190.8 & 1.5 & 0.8 \\
\hline v & 0.308 & 0.307 & 0.301 & 0.305 & 0.004 & 1.2 \\
\hline
\end{tabular}


Table 3. Sound velocities and elastic constants of stainless steel 316 at $T=295 \mathrm{~K}$.

\begin{tabular}{lcccccc}
\hline & 1 & $\begin{array}{c}\text { Sample } \\
2\end{array}$ & 3 & Mean & $\begin{array}{l}\text { Std. } \\
\text { Dev. }\end{array}$ & $\begin{array}{l}\text { Coeff. } \\
\text { of Var. }\end{array}$ \\
\hline$v_{\ell}(\mathrm{cm} / \mathrm{\mu S})$ & 0.5712 & 0.5714 & 0.5648 & 0.5691 & 0.0038 & 0.7 \\
$v_{t}(\mathrm{~cm} / \mathrm{\mu S})$ & 0.3085 & 0.3100 & 0.3038 & 0.3074 & 0.0032 & 1.0 \\
$\rho\left(\mathrm{g} / \mathrm{cm}^{3}\right)$ & 7.965 & 7.949 & 7.961 & 7.958 & 0.008 & 0.1 \\
$C_{\ell}(\mathrm{GPa})$ & 259.9 & 259.5 & 254.0 & 257.7 & 3.3 & 1.3 \\
$\mathrm{G}(\mathrm{GPa})$ & 75.8 & 76.4 & 73.5 & 75.2 & 1.5 & 2.1 \\
$\mathrm{~B}(\mathrm{GPa})$ & 158.8 & 157.7 & 156.0 & 157.5 & 1.4 & 0.9 \\
$\mathrm{E}(\mathrm{GPa})$ & 196.2 & 197.3 & 190.5 & 194.6 & 3.7 & 1.9 \\
$\nu$ & 0.294 & 0.291 & 0.296 & 0.294 & 0.003 & 0.9 \\
\hline
\end{tabular}


Table 4. Sound velocities and elastic constants of stainless steel 304 at $T=295 \mathrm{~K}$.

\begin{tabular}{lccc}
\hline & Mean & Std. Dev. & Coeff. of Var. \\
\hline$v_{\ell}(\mathrm{cm} / \mu \mathrm{s})$ & 0.5759 & 0.0015 & 0.3 \\
$v_{t}(\mathrm{~cm} / \mu \mathrm{s})$ & 0.3134 & 0.0018 & 0.6 \\
$\rho\left(\mathrm{g} / \mathrm{cm}^{3}\right)$ & 7.880 & 0.045 & 0.6 \\
$C_{\ell}(\mathrm{GPa})$ & 261.3 & 2.0 & 0.8 \\
$G(\mathrm{GPa})$ & 77.4 & 0.009 & 1.1 \\
$\mathrm{~B}(\mathrm{GPa})$ & 158.2 & 0.022 & 1.4 \\
$E(\mathrm{GPa})$ & 99.6 & 0.017 & 0.9 \\
$\nu$ & 0.290 & 0.004 & 1.4 \\
\hline
\end{tabular}



ELASTIC CONSTANTS OF STAINLESS STEELS 304, 310, AND 316 BETWEEN 4 AND $295 \mathrm{~K}$

National Bureau of Standards 

H. M. Ledbetter

Fracture and Deformation Division

National Bureau of Standards

Boulder, Colorado 80303

For stainless steels 304, 310, and 316, longitudinal and transverse ultrasonic velocities were measured by a pulse-echo method between 295 and $4 \mathrm{~K}$. From these velocities were computed five elastic constants:

longitudinal modulus, shear modulus, Young's modulus, bulk modulus, and Poisson's ratio. All three steels show low-temperature elastic-constant anomalies.

Key Words: Bulk modulus; elastic constants; low-temperature; physical properties; Poisson's ratio; shear modulus; sound velocity; stainless steel; Young's modulus. 
Several years ago ${ }^{1}$ the author collaborated in studying the lowtemperature elastic constants of four austenitic stainless steels: 304 , 310, 316, and A286. That study indicated that all four steels show lowtemperature anomalies in dilatation-type elastic constants. But the sheartype elastic constants showed no measurable anomalies.

The study reported here, based on an improved measurement system, ${ }^{2}$ reveals that the shear-type elastic constants are also anomalous at low temperatures in two steels, 304 and 316. Steel 310 shows no anomaly in its shear modulus. Besides better temperature sensitivity, the measurements reported here have lower absolute uncertainty and represent averages of several sources of samples, which were previously unavailable. The improved elastic-constant/temperature resolution elucidates the nature of the relationship between elastic constants and low-temperature magnetic phase transitions. Thus, the present study replaces that reported previously.

For brevity, experimental details are omitted here. Equipment and techniques are described elsewhere. ${ }^{2}$ And the characterization of the alloys are given in a companion publication. 3

Figures 1-5 show the elastic-constant/temperature results. And elastic-constant values at selected temperatures are given in Table 1.

At temperatures exceeding about $100 \mathrm{~K}$, all elastic constants of all three alloys behave regularly: with increasing temperature, increasing negative slope approaching linearity at higher temperatures.

With the exception of the shear modulus in stainless 310 , all elastic constants in a 11 three alloys are anomalous at low temperatures. However, in stainless 310 , the anomalies in Young's modulus and Poisson's ratio are relatively small. 
The shear-modulus anomaly occurs at the highest temperature in stainless 304 . The smaller, bulk-modulus anomaly occurs at the highest temperature in stainless 310, where it occurs less abruptly over a wider temperature region.

The "explanation" of these results lies in the magnetic transitions in these alloys. As shown by Collings and Hart, ${ }^{4,5}$ steels 304 and 316 undergo magnetic transitions near $50 \mathrm{~K}$ and $30 \mathrm{~K}$, respectively; but steel 310 shows no such transition, at least down to $5 \mathrm{~K}$. Relationships between magnetic transitions and elastic constants were reviewed by Ledbetter and Collings. 6

It should not escape attention that the elastic-constant changes and magnetic transitions relate also to the crystal-structural stability of the face-centered-cubic phase. Because of higher nickel content, steel 316 is more stable austenitically than steel 304. Steel 310 contains still higher nickel, which is a strong austenite stabilizer, so that it resists transition to the body-centered-cubic phase, caused either by cooling or by mechanical deformation.

Since steel 310 shows no cooling-induced magnetic transition, the shear-modulus and bulk-modulus anomalies must be related to separate internal changes within the alloy. The paramagnetic-antiferromagnetic transition, manifested as a peak in the magnetic-susceptibility/temperature curve, ${ }^{4}$ is accompanied by a shear-modulus anomaly. The bulk-modulus anomaly relates to another internal change at a higher temperature. This different behavior of the shear and bulk elastic constants occurs in several stainless-steel alloys ${ }^{6}$ and in invar alloys. 7

Comparing the present results with recent specific-heat studies ${ }^{6-9}$ leads to a surprising conclusion. No specific-heat anomalies occur at 
temperatures where the elastic constants change abruptly. Such anomalies would be expected because the elastic constants determine the Debye temperature, which determines the lattice specific heat. This phenomenon was discussed recently by Collings and Ledbetter ${ }^{10}$ for an Fe-21Cr-6Ni-9inn alloy, which exhibits a paramagnetic/spin-glass transition.

The low-temperature Young's moduli of two steels, $18 \mathrm{Cr}-8 \mathrm{Ni}$ and $18 \mathrm{Cr}-25 \mathrm{Ni}$, were reported recently by Verkin, Ilichev, and Klimenko. 11 Their results seem consistent with those of this study, although they invoke formation of epsilon phase to partly explain the Young's-modulus/temperature behavior of the less stable alloys. The reversibility of our results on cooling and heating suggests that epsilon phase is not a factor. Also, contrary to the conclusions of Verkin et al., we find no low-temperature anomalous decrease in the Young's modulus of stable alloys.

This study was supported by the NBS Office of Standard Reference Data and by the DoE Office of Fusion Energy. 
1. H. M. Ledbetter, W. F. Weston, and E. R. Naimon, Low-temperature elastic properties of four austenitic stainless steels, J. Appl. Phys. 46, 3855-3860 (1975).

2. H. M. Ledbetter, N. V. Frederick, and M. W. Austin, J. Appl. Phys., (January 1980), forthcoming.

3. H. M. Ledbetter, Room-temperature sound velocities and elastic constants of austenitic stainless steels 304,310 , and 316 , to be pub1 ished.

4. E. W. Collings and S. C. Hart, Low-temperature magnetic-susceptibility and magnetization studies of some commercial austenitic stainless steels, Cryogenics 19, 521-530 (1979).

5. E. W. Collings and S. C. Hart, The magnetic character of austenitic stainless steels, in Advances in Cryogenic Engineering, Volume 26 (Plenum, New York, 1980), forthcoming.

6. H. M. Ledbetter and E. W. Collings, Low-temperature magnetically induced elastic-constant anomalies in three manganese stainless steels, in Metal Science of Stainless Steels (Met. Soc. AIME, New York, 1979).

7. G. Hausch, E. Torok, T. Mohri, and Y. Nakamura, Thermal expansion, elastic properties, and the Mössbauer effect of stainless invar, J. Mag. Magnetic Mater. 10, 157-162 (1979).

8. J. M. Corsan and N. I. Mitchem, The specific heat of stainless steels between $4 \mathrm{~K}$ and $300 \mathrm{~K}$, in Froceedings of the Sixth International Cryogenic Conference (IPC Science and Technology Press, Surrey, 1976), pp. 342-344.

9. E.W. Collings, F. J. Jelenik, J. C. Ho, and M. P. Mathur, Magnetic and thermal properties of stainless steel and inconel at cryogenic temperatures, in Advances in Cryogenic Engineering, Volume 22, (Plenum, New York, 1977), pp. 159-173. 
10. J. C. Ho, G. B. King, and F. R. Fickett, Low temperature specific heat of two stainless steels, cryogenics 18, 296-298 (1978).

11. J. M. Corsan and N. I. Mitchem, The specific heat of fifteen stainless steels in the temperature range $4 \mathrm{~K}-30 \mathrm{~K}$, Cryogenics 19 , $11-16(1979)$.

12. E. H. Collings and H. M. Ledbetter, Sound-velocity anomalies near the spin-glass transition in an austenitic stainless-steel alloy, Phys. Lett. 72A, 53-56 (1979).

13. B. I. Verkin, V. Ya. II ichev, and I. N. KIimenko, The low-temperature change of magnetic structure and plastic properties of $\mathrm{Fe}-\mathrm{Cr}-\mathrm{Ni}$ alloys, in Advances in Cryogenic Engineering, Volume 26 (Plenum, New York, 1980), forthcoming. 
List of Figures

Fig. 1. Longitudinal modulus, $C_{\ell}$, of three stainless steels. $C_{l}=$ $\rho v_{\ell}^{2}$, where $\rho$ denotes mass density and $v_{\ell}$ denotes longitudina? wave velocity.

Fig. 2. Shear modulus, $G$, of three stainless steels. $G_{x}=\rho v_{t}^{2}$, where $\rho$ denotes mass density and $v_{t}$ denotes transverse, or shear, wave velocity.

Fig. 3. Bulk modulus, $B$, of three stainless steels. $B=C_{\ell}-\frac{4}{3} G$, where $C_{\ell}$ denotes longitudinal modulus and $G$ denotes shear modulus.

Fig. 4. Younq's modulus, $E$, of three stainless steels. $E=9 r_{\mathrm{r}} B /(3 B+G)$, where $B$ and $G$ denote bulk and shear moduli.

Fig. 5. Poisson's ratio, $\nu$, of three stainless steeis. $\nu=(E / 2 G)-7$, where $E$ and $G$ denote Young's and shear moduli. 


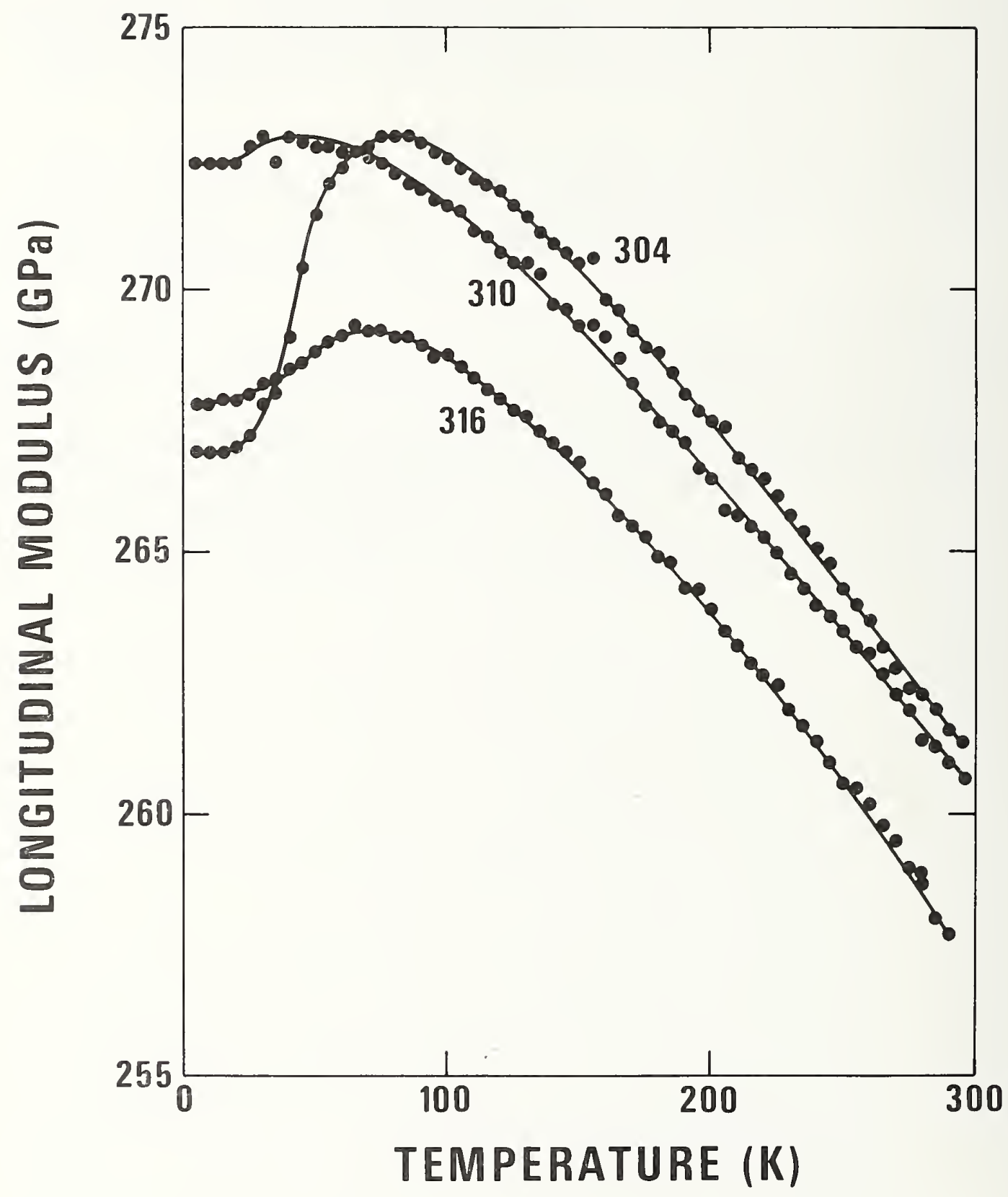

Fig. 1. Longitudinal modulus, $C_{\ell}$, of three stainless steels. $C_{\ell}=$ $\rho v_{\ell}^{2}$, where $\rho$ denotes mass density and $v_{\ell}$ denotes longitudinal wave velocity. 


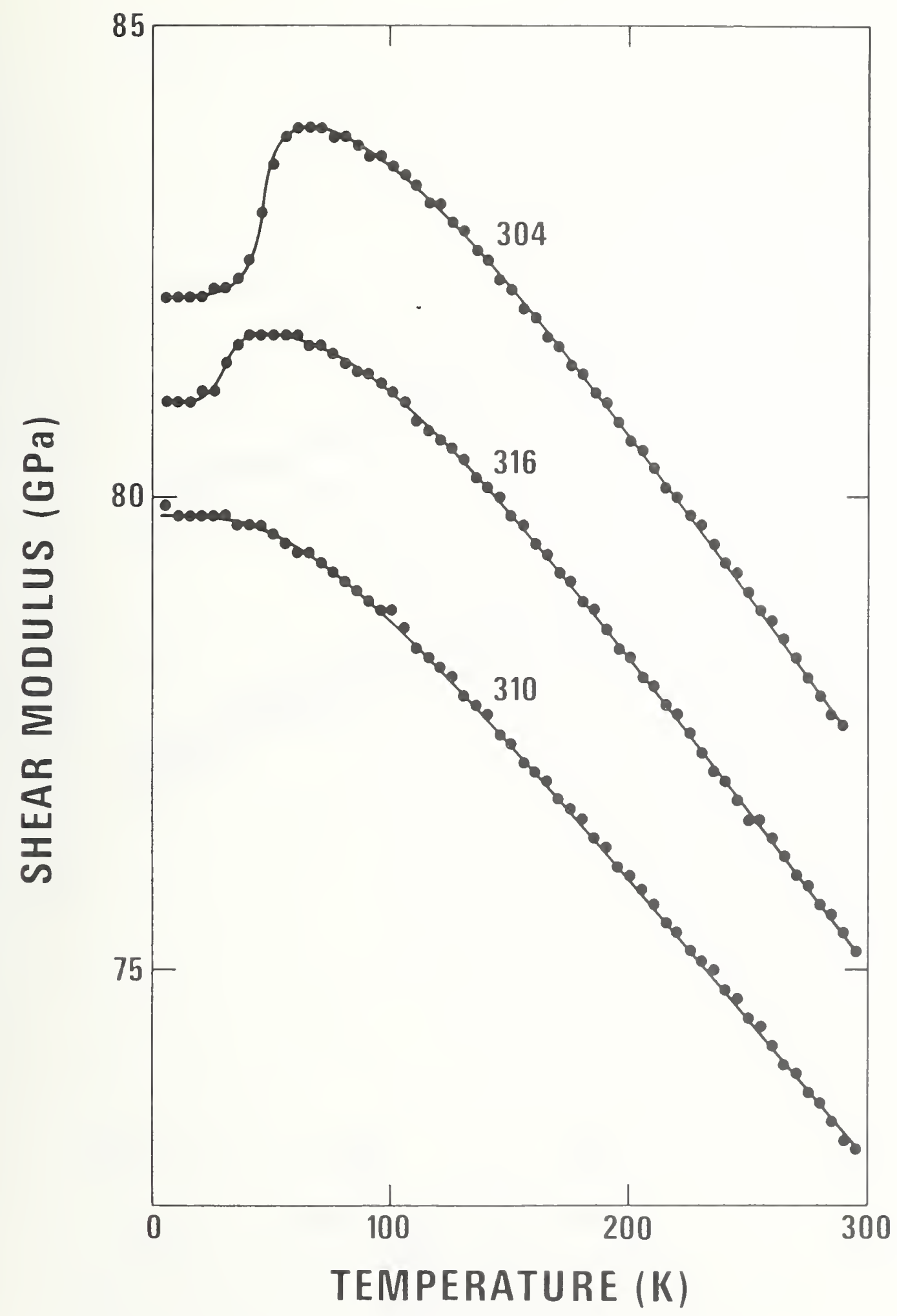

Fig. 2. Shear modulus, $G$, of three stainless steels. $G=\rho v_{t}^{2}$, where $\rho$ denotes mass density and $v_{t}$ denotes transverse, or shear, wave velocity. 


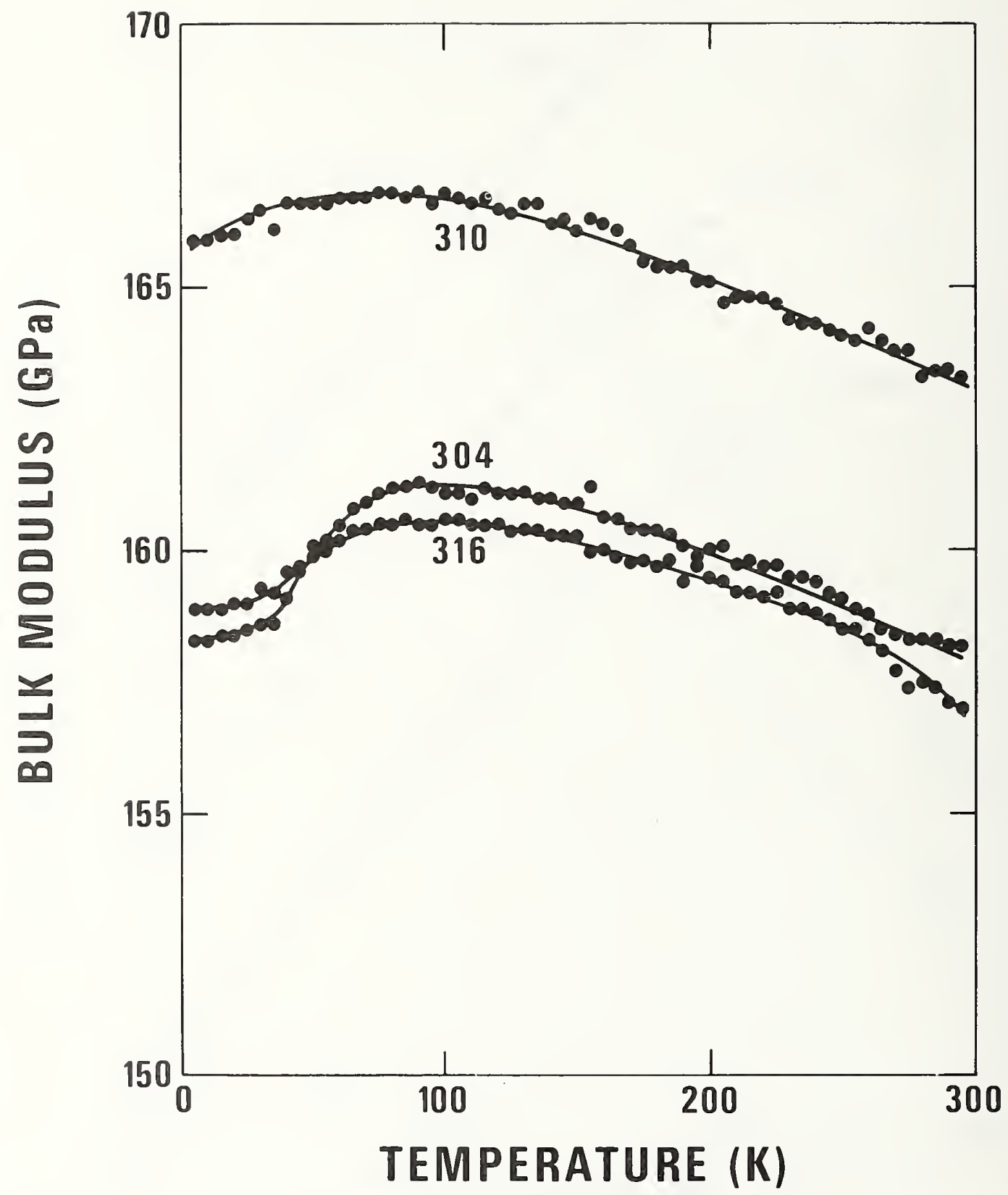

Fig. 3. Bulk modulus, $B$, of three stainless steels. $B=C_{\ell}-\frac{4}{3} G$, where $C_{\ell}$ denotes longitudinal modulus and $G$ denotes shear modulus. 


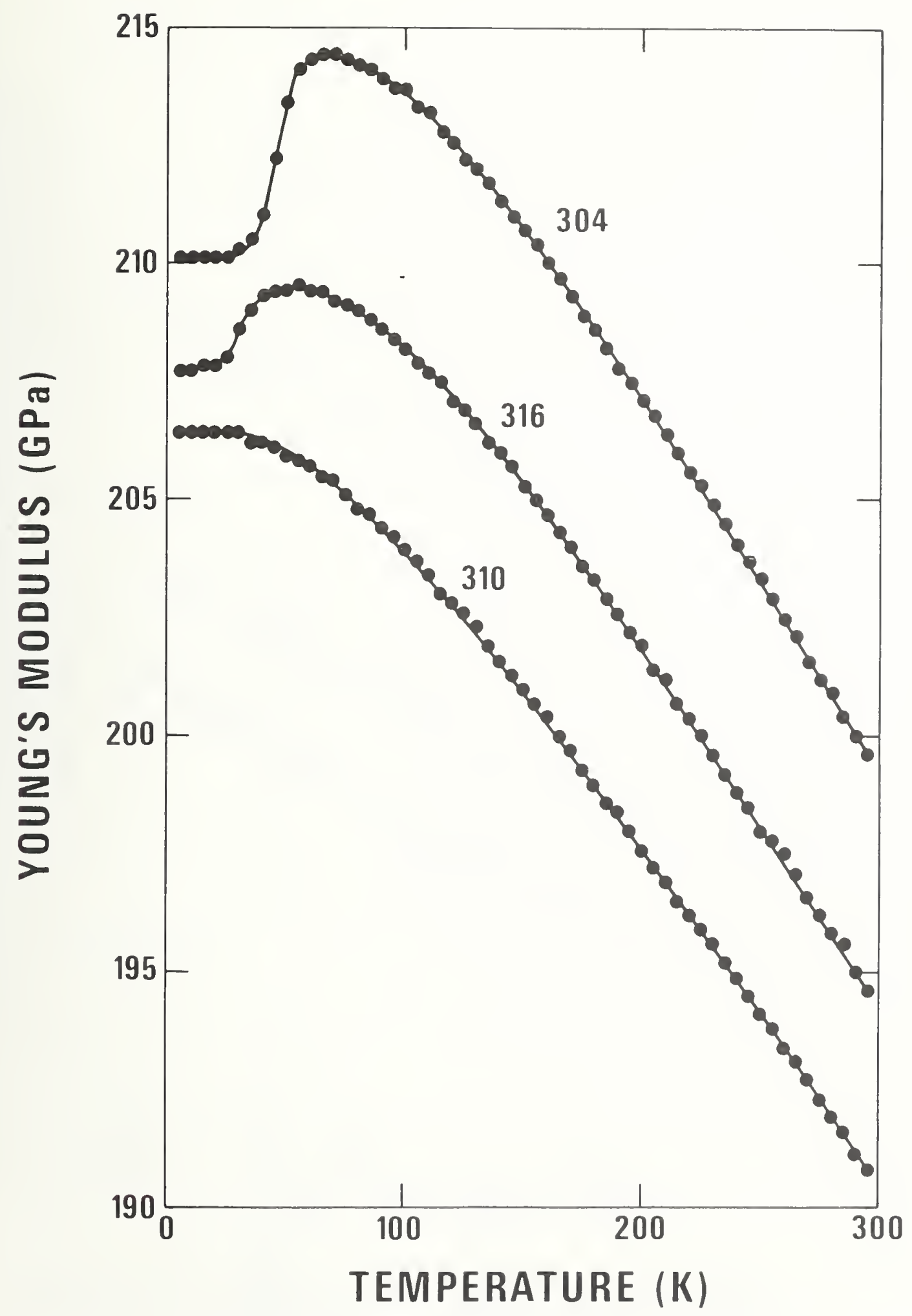

Fig. 4. Young's modulus, $E$, of three stainless steels. $E=9 G B /(3 B+G)$, where $B$ and $G$ denote bulk and shear moduli. 


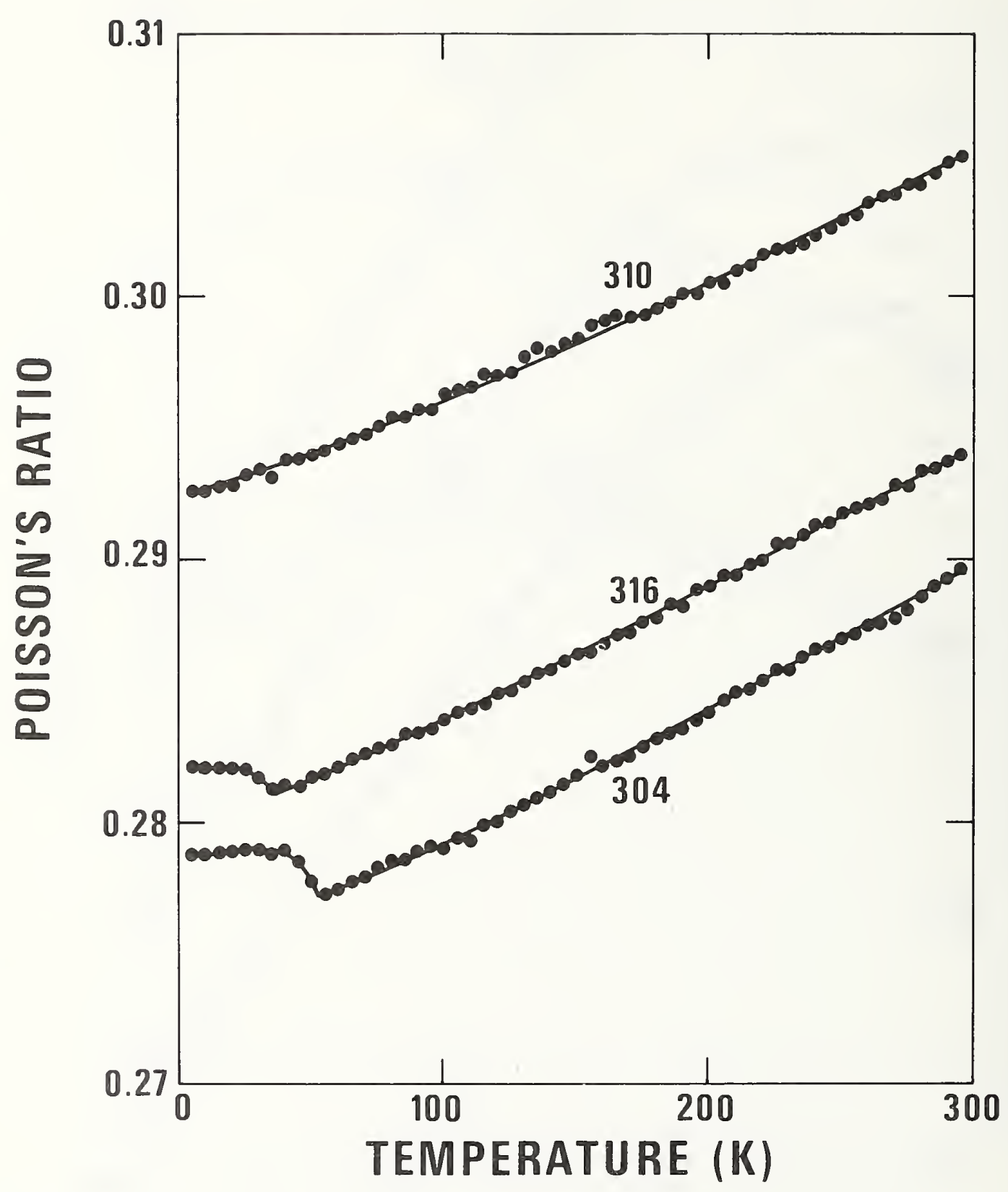

Fig. 5. Poisson's ratio, $\nu$, of three stainless steels. $\nu=(E / 2 G)-1$, where $E$ and $G$ denote Young's and shear moduli. 
G

B

v

(K)

(GPa)

$(\mathrm{GPa})$

(GPa)

\section{Stainless 304}

$\begin{array}{rrrrr}295 & 199.6 & 77.4 & 158.2 & 0.290 \\ 280 & 200.9 & 77.9 & 158.3 & 0.289 \\ 260 & 202.5 & 78.7 & 158.8 & 0.288 \\ 240 & 204.1 & 79.3 & 159.4 & 0.287 \\ 220 & 205.6 & 80.0 & 159.7 & 0.285 \\ 200 & 207.1 & 80.6 & 160.0 & 0.284 \\ 180 & 208.6 & 81.3 & 160.4 & 0.283 \\ 160 & 210.0 & 81.9 & 160.6 & 0.282 \\ 140 & 211.3 & 82.5 & 161.0 & 0.281 \\ 120 & 212.6 & 83.1 & 161.1 & 0.279 \\ 100 & 213.7 & 83.5 & 161.1 & 0.279 \\ 80 & 214.2 & 83.8 & 161.2 & 0.278 \\ 60 & 214.3 & 83.9 & 160.5 & 0.279 \\ 40 & 211.0 & 82.5 & 159.1 & 0.279 \\ 20 & 210.7 & 82.1 & 158.4 & 0.279 \\ 5 & 210.1 & 82.1 & 158.3 & \end{array}$

Stainless 310

295
280
260
240
220
200
180
160
140
120
100
80
60
40
20
5

Stainless 316
190.8

191.9

193.4

194.9

196.2

197.6

199.0

200.4

201.6

202.8

203.9

204.8

205.7

206.2

206.4

206.4

194.6

195.8

197.5

198.8

200.4

201.9

203.3

204.7

206.0

207.1

208.2

209.0

209.4

209.3

207.8

207.7
73.1

73.6

74.2

74.8

75.4

76.0

76.6

77.1

77.7

78.2

78.8

79.1

79.4

79.7

79.8

79.9

75.2
75.7
76.4
77.0
77.7
78.3
78.9
79.5
80.1
80.6
81.7
81.4
81.7
81.7
81.1
81.0
163.3

163.3

164.2

164.3

164.8

165.1

165.4

166.2

166.2

166.5

166.8

166.8

166.7

166.6

166.0

165.9

0.305

0.304

0.304

0.302

0.302

0.301

0.300

0.299

0.298

0.297

0.296

0.295

0.294

0.294

0.293

0.293
157.5

153.0

158.3

158.8

159.1

159.5

159.7

160.0

160.3

160.5

160.6

160.5

160.2

159.6

159.0

158.9
0.294

0.293

0.292

0.291

0.290

0.289

0.288

0.287

0.286

0.285

0.284

0.283

0.282

0.281

0.282

0.282 

YOUNG'S MODULUS OF A COPPER-STABILIZED

NIOBIUM-TITANIUM SUPERCONDUCTIVE MIRE

National Bureau of Standards 

YOUNG'S MODULUS OF A COPPER-STABILIZED NIOBIUM-TITANIUM SUPERCONDUCTIVE WIRE

\author{
H. i. Ledbetter \\ Fracture and Deformation Division \\ National Bureau of Standards \\ Boulder, Colorado 80303 \\ J. C. Moulder \\ Thermophysical Properties Division \\ National Bureau of Standards \\ Boulder, Colorado 80303 \\ M. W. Austin \\ Fracture and Deformation Division \\ National Bureau of Standards \\ Boulder, Colorado 80303
}

\title{
$\underline{\text { ABSTRACT }}$
}

Young's modulus was determined for a 0.6-mm-diameter niobium-titanium superconductive wire. Two methods were used: continuous-wave-resonance and laser-pulse-excitation. Young's moduli were also determined for the components -- copper and $\mathrm{Nb}-\mathrm{Ti}$-- in both wire and bulk forms. Some mechanical-deformation effects on Young's modulus were also measured. From the components' elastic moduli, that of the composite was predicted accurately by a simple rule-of-mixtures relationship.

Key words: Copper; elastic constants; niobium-titanium; rule of mixtures; sound velocity; superconductor; wire; Young's modulus 


\section{INTRODUCTION}

Most existing technological superconductors are wires. For example, in evaluating $\mathrm{Nb}_{3} \mathrm{Sn}$ 's superconducting performance, Blum, Gregory, and Coffey ${ }^{1}$ emphasized that its use depends on its "ability to be handled and wound into superconducting devices... through proper design and the use of rectangular wire..." Dew-Hughes ${ }^{2}$ reviewed practical superconductive materials and concluded that "a superconductor is of no use unless it can be manufactured as a continuous, flexible conductor... this means the production of wire..." Several authors have discussed the manufacture and nature of wire superconductors. ${ }^{3-5}$

Elastic constants relate to several practical aspects of superconductive wire behavior in magnets and other devices -- load-deflection behavior, thermoelastic stress, winding tension, prestress, magnetomechanical strain, residual stress -- as well as to other physical properties. Elastic constants relate in general to any stress-coupled force. Depending on the symmetry of the stress and strain tensors, various elastic constants -- for example, Young's modulus, shear modulus, bulk modulus, Poisson's ratio, etc. -- become appropriate to a particular application.

Composite superconductive wires present particular difficulties to the experimentalist measuring their elastic constants. In static methods, stress must be low enough so that both matrix and fibers deform coherently and elastically. High-frequency ultrasonic methods may give an apparent modulus too low because of dispersion or because of the diameterto-wavelength ratio. U/trasonic pulse methods often become difficult in wires because of mode conversion caused by reflection of elastic waves from the wire's surface. A composite-oscillator technique is impractical 
because of the wire's small mass and small cross-sectional area. Thus, as described below, unconventional experimental methods are required.

Especially for wires, Young's modulus, E, is the simplest, bestknown, and most useful elastic constant. Its utility arises from the uniaxial stress, $\sigma_{z}$, that occurs along the wire axis, $z$. The axial strain is $\varepsilon_{x}=\sigma_{z} / E$. For uniaxial stress the transverse strain is $\varepsilon_{x}=-v \sigma_{z} / E$, where $\nu$ denotes Poisson's ratio; when $\nu$ is not isotropic, the second transverse strain, $\varepsilon_{y}$, differs from $\varepsilon_{x}$. In bending deformation, $\varepsilon_{z}=\sigma_{z} / E=x / r$, where $x$ denotes a co-ordinate in the bending direction perpendicular to $z$, and $r$ denotes the radius of curvature of the neutral surface near the origin. Velocities of extensionalcompressional waves in rods and wires are given by $v_{e}=(E / \rho)^{1 / 2}$, where $\rho$ denotes mass density. As described below, this relationship provides a simple, convenient, accurate method for measuring $E$.

The study reported here focused on Young's modulus of a single superconductive composite wire: copper-stabilized $\mathrm{Nb}-\mathrm{Ti}$. The study had three principal objectives: (1) determine the wire's Young's modulus, which was uncertain; (2) determine the Young's moduli of the wire's components in both their annealed and deformed states, in both wire and bulk forms; (3) evaluate critically the rule-of-mixtures relationship between component and composite Young's moduli. 


\section{EXPERIMENT}

\section{A. MATERIALS}

\section{Superconductor Wire}

The composite superconductor wire (Fig. 1), obtained from a commercial source, had $180 \mathrm{NbTi}$ filaments in a high-conductivity, oxygen-free copper matrix with final cross-sectional dimensions of 0.58 by $0.68 \mathrm{~mm}$. The filaments, $0.0322 \mathrm{~mm}$ diameter, were twisted 0.8 turns $/ \mathrm{cm}$. Their chemical composition was 55 wt.pct. $\mathrm{Nb}$ and 45 wt.pct. Ti (38.7 at.pct. Nb, 61.3 at.pct. Ti). Based on a 1.8:1 Cu:NbTi volume ratio, computed mass density was $7.921 \mathrm{~g} / \mathrm{cm}^{3}$ based on 8.930 for copper and 6.104 for $\mathrm{NbTi}$, values measured hydrostatically on bulk samples. The wire was coated with formvar insulation, a polyvinyl formal resin. Diamond-pyramid hardness for a $2-g$ load was $98 \pm 20$; presumably this represents the outer copper layer of the conductor. Residual resistance ratio was 70 and copper grain size was $0.02 \mathrm{~mm}$. Being proprietary, the wire's thermomechanical treatment remains uncertain. But it should closely resemble the treatment specified in the next paragraph for copper wire with the addition of a final, large, cold reduction.

Copper Wire

High-conductivity, oxygen-free copper wire was obtained with the following thermomechanical treatment: hot rolled at $1123 \mathrm{~K}$ to $0.6-\mathrm{cm}-$ diameter rod, annealed at $1123 \mathrm{~K}$ for $0.5 \mathrm{~h}$, water quenched, cold drawn to $0.2-\mathrm{cm}$ wire, annealed at $773 \mathrm{~K}$ for $0.5 \mathrm{~h}$, water quenched, cold drawn to $0.07-\mathrm{cm}$ wire, annealed at $573 \mathrm{~K}$ for $1 \mathrm{~h}$. Diamond-pyramid hardness was $70 \pm 10$ for a $2-\mathrm{g}$ load, residual-resistance ratio was 146 , and average grain diameter was $0.011 \mathrm{~mm}$. 
Four-centimeter-diameter ND-45Ti rod obtained commercially was recrystallized at $1073 \mathrm{~K}$ and water quenched. Its oxygen content was low, less than $1000 \mathrm{ppm}$. Mass density was $6.124 \mathrm{~g} / \mathrm{cm}^{3}$, room-temperature electrical resistivity was $71 \mu \Omega \cdot \mathrm{cm}$, diamond-pyramid hardness was $152 \pm 6$, and grain size was $0.04 \mathrm{~mm}$ and equiaxed.

The Nb-45Ti alloy was also given a thermomechanical treatment resembling that of the superconductive wire: extrude from $4 \mathrm{~cm}$ to $1.55 \mathrm{~cm}$ diameter, anneal at $648 \mathrm{~K}$ for $48 \mathrm{~h}$, draw to a final $1.0-\mathrm{cm}$ diameter. Hardness increased to $192 \pm 5$ in the deformed alloy, and density decreased to 6.104. Most other properties remained unchanged, although grain shape and grain size could not be determined unambiguously. Further properties of this alloy, particularly mechanical, were reported by Read, 6 who detected a $\{110\}$ extrusion texture typical of body-centered-cubic alloys.

\section{B. Methods}

Two methods were used to determine Young's modulus of the wires: continuous-wave-resonance and laser-pulse-excitation. While these methods have not been applied extensively to wires, the principles are simple and the description here is brief. Young's modulus of bulk materials was determined by either a pulse-echo-overlap method or by a Marx-oscillator method.

\section{Continuous-wave-resonance}

A length of wire between 5 and $10 \mathrm{~cm}$ was cemented between identical PZT piezoelectric transducers $1.27-\mathrm{cm}$ in diameter, whose fundamental resonance frequencies were $200 \mathrm{kHz}$ for longitudinal vibration. 
Standing waves were established by sweeping the frequency of one transducer until a maximum voltage across the second transducer was detected on an oscilloscope. Resonance corresponds to an integral number, $n$, of half wavelengths in the wire. Thus, the velocity was obtained by:

$$
v_{e}=f \lambda=2 f \ell / n
$$

where $f$ denotes frequency, $\lambda$ wavelength, and $\&$ specimen length. For the superconductor wire in resonance at $200 \mathrm{kHz}, 10$ half wavelengths equalled a 9.55-cm specimen length. Thus, $n$ and $v_{e}$ were determined with little difficulty by measuring, around the transducer's fundamental frequency, several resonance frequencies of the wire, which were typically measurable to 1 part in $10^{5}$ or better. Further details of this method are described by other authors. ${ }^{7-8}$

\section{Laser-pulse-excitation}

Hide-spectrum acoustic pulses were launched in wire specimens 3- to $5-\mathrm{cm}$ long, by focusing the output of a Q-switched Nd-glass laser on one end of the wire. The arrival of the acoustic pulse at the specimen's opposite end was detected with an X-cut, $10 \mathrm{MHz}$-fundamenta 7 -frequency quartz transducer, $0.32 \mathrm{~cm}$ in diameter, glued to the wire with phenyl salicylate. The ends of the wires were ground flat by hand. The 14-ns laser pulses were monitored with a portion of the beam reflected onto a silicon photodiode; its output was summed electronically with the quartz transducer output in the vertical amplifier of a storage oscilloscope, triggered slightly before laser-firing by the Q-switch controller. This produced an oscilloscope trace of two short pulses, one representing the pulse launch time and one the pulse detection time. Transit times were determined from photographs of the oscilloscope traces, which were calibrated independently for each measurement with a time-mark generator. Transit times determined using this technique were routinely reproducible 
to within \pm 1 percent; the overall accuracy in determining the extensiona? velocity (calculated from the experimental velocity corrected for dispersion) was determined by $\ell / t$ inaccuracy, where $\ell$ denotes wire length and $t$ one-way transit time, is estimated to be \pm 3 percent, owing to the uncertainties associated with detecting the first motion of the back surface and a smaller uncertainty in specimen length.

\section{Pulse-echo-overlap}

A quartz piezoelectric crystal with a fundamental frequency near 10 MHz was glued with phenyl salicylate onto an approximately $1 \mathrm{~cm}$-cube specimen with flat and parallel surfaces. A 1-2 cycle acoustic pulse was introduced into the specimen through the quartz transducer. The pulse-echo train was detected by the same transducer and displayed on an oscilloscope equipped with sweep delay and time-interval microprocessor. Sound velocities were determined by $2 \ell / t$, where $\ell$ denotes specimen thickness and $t$ round-trip transit time (time between echoes). Young's modulus was computed from longitudinal and transverse sound velocities combined with the mass density.

Marx oscillator

Cylindrical-rod specimens, 4.76-mm diameter, were cemented to a matched pair of $Y$-cut, X-plated rectangular-rod quartz crystals with 50$\mathrm{kHz}$ fundamental frequencies. Using suitable electronics, this threecomponent (Marx) composite oscillator was swept in frequency until halfwave resonance occurred, which was detected by oscilloscope and measured by frequency meter. The specimen's Young's modulus was determined from the realtionship:

$$
E=4 \rho f^{2} \ell^{2}
$$

where $\rho=$ mass density, $f=$ specimen frequency, and $\ell=$ specimen 1 enqth . 


\section{RESULTS AND DISCUSSION}

Table 1 gives results for sound velocities and Young's moduli in the various materials. For wires, the extensional velocity, $v_{e}$, is obtained, which, when combined with the mass density, $\rho$, gives Young's modulus:

$$
E=\rho v_{e}^{2}
$$

For bulk specimens, longitudinal and transverse sound velocities, $v_{\ell}$ and $v_{t}$, were obtained, which give the extensional velocity by

$$
v_{e}^{2}=3 v_{t}^{2}\left(v_{l}^{2}-\frac{4}{3} v_{t}^{2}\right) /\left(v_{l}^{2}-v_{t}^{2}\right)
$$

\section{A. NbTi bulk alloy}

Young's modulus, $84.3 \mathrm{GPa}$ for the annealed bulk NbTi alloy, agrees approximately with previous studies. For example, from the resonance study of Fedotov and Belousov ${ }^{9}$ one obtains an interpolated value of 79.3 GPa. Koch and Easton ${ }^{10}$ cite several other studies that give a similar value for alloys with similar compositions. The compositional variation of Young's modulus will be described extensively in a forthcoming publication by Ledbetter and Collings. As expected (since mechanical deformation usually lowers elastic stiffness), the deformed alloy showed a lower Young's modulus, 79.2 GPa. The combined pulse-echo and Marxoscillator results for the deformed alloy show a significant texture, amounting to stiffening along the rod axis, consistent with Read's 6 finding of a $\{110\}$ rod texture.

\section{B. Bulk copper}

Copper's Young's modulus was determined recently in our laboratory by both pulse and resonance techniques. These results, together with several other results reported in the literature, were described recently by Ledbetter, 11 who concluded that Young's modulus for annealed copper is $128.7 \pm 1.4 \mathrm{GPa}$. 


\section{NBTi Wire}

Thus far, NBTi wire has not been measured in our laboratory. However, Schmidt ${ }^{12}$ reported a static stress-strain Young's modulus for Nb50 wt.pct.Ti wire, $0.26 \mathrm{~mm}$ in diameter, measured at liquid-helium temperature. Corrected for temperature and for composition, Schmidt's result becomes 79.1 GPa. Based on the single-crystal studies of Reid, Routbort, and Maynard ${ }^{13}$ for a NB-43.6 wt.pct.Ti alloy, elastic anisotropy is moderate for NBTi; the Zener anisotropy, $A=2 C_{44} /\left(C_{11}-C_{12}\right)$, is 1.76 . Compared with an isotropic Young's modulus of $87.4 \mathrm{GPa}$, this alloy has a Young's modulus of 63.6 along [100], 91.8 along [110], 92.9 along [111]. Thus, only a $\{100\}$ wire texture would lower Young's modulus. Read's ${ }^{6} x$-ray diffraction studies suggest a $\{110\}$ texture, which would slightly increase Young's modulus compared with the zero-texture case; Schmidt's result supports Read's finding of a $\{110\}$ rod texture. As for bulk NDTi, mechanical deformation lowers the Young's modulus of the wire by about six percent. This lowering could arise entirely from deformationinduced defects, and texture need not necessarily be a factor.

\section{Copper wire}

For annealed copper wire a Young's modulus of 126.2 GPa was obtained by cw-resonance ultrasonic-pulse ${ }^{14^{\circ}}$ methods at $200 \mathrm{kHz}$ and a value of $125.8 \mathrm{GPa}$ by the laser-excitation method, giving a mean value of 126.0 GPa. This differs only one percent from the bulk-annealed-copper value. As calculated from copper's single-crystal elastic constants, Young's modulus would be $66.6 \mathrm{GPa}$ for $\{100\}$ texture, $76.8 \mathrm{GPa}$ for $\{110\}$, 191.4 GPa for $\{111\}$, and $128.7 \mathrm{GPa}$ for the untextured, quasi-isotropic case. Thus, the copper wire must be nearly, if not completely, texture free. 


\section{E. NbTi:Cu wire}

For the composite superconductor wire, a Young's modulus of 107.8 GPa was determined by $\mathrm{cw}$-resonance $\mathrm{ultrasonic}$ pulse ${ }^{14}$ methods at $200 \mathrm{kHz}$ and $109.4 \mathrm{GPa}$ by laser-pulse excitation; the mean value is $108.6 \pm 1.1$ $\mathrm{GPa}$.

\section{F. Rule-of-mixture-predictions}

If the strain along the fiber direction is the same in the fibers and the matrix forming a composite, then it is simple to derive a ruleof-mixtures relationship for the effective Young's modulus in the fiber direction:

$$
E=x_{f} E_{f}+\left(1-x_{f}\right) E_{m}
$$

where $f$ and $m$ denote fiber and matrix and $x$ denotes volume fraction. This simple linear relationship is predicted by most elementary theories that relate component and composite elastic properties. Actually, Eq. (5) represents an upper bound; the lower bound being given by a similar average for the elastic compliance, $1 / E$, rather than the elastic stiffness, E. This lower bound represents the Young's modulus perpendicular to the fibers, where stress, not strain, is the same.

Using the bulk, annealed component values in Table I, Eq. (5) predicts for the composite wire a Young's modulus of $109.3 \mathrm{GPa}$, within one percent of the observed value. Using the component wire values changes this prediction only slightly. Thus, in this case, a theory more sophisticated than the rule-of-mixtures is not required to relate the longitudinal Young's modulus to component Young's moduli. 
IV. CONCLUDING REMARKS

From this study the following principal results and conclusions emerge:

1. Copper wire processed thermomechanically to resemble the superconductor matrix has the same Young's modulus as bulk, annealed copper.

2. Deformed niobium-titanium wire has the same Young's modulus as bulk, deformed niobium-titanium.

3. Young's modulus of an NbTi:Cu wire superconductor can be measured by various methods: ultrasonic-pulse, continuouswave-resonance, or laser-pulse-excitation. For this particular wire, Young's modulus was found to be $108.6 \mathrm{GPa}$.

4. Young's modulus for the composite superconductor wire can be predicted reliably at room temperature using for the Young's moduli of the components either bulk annealed values or deformed-wire values. The predicted Young's modulus was $109.3 \mathrm{GPa}$.

\section{FUTURE STUDIES}

Further studies should focus on the following problems:

1. Wires with other NbTi:Cu volume ratios and the applicability of the rule-of-mixtures to those wires.

2. Young's modulus perpendicular to the wire axis, either experimentally or theoretically.

3. Changes of Young's modulus of both components and superconductor with decreasing temperature. Applicability of ruleof-mixtures, especially at liquid-helium temperature.

4. Improved experimental methods for measuring a wire's elastic properties. 
5. Frequency spectrum of the detected acoustic signal for laserpulse excitation. The effect of diameter-to-wavelength ratio for composite wires.

6. Component-composite elastic-property relationship for other elastic constants such as the shear modulus and Poisson's ratio.

7. Measurements of torsional modulus to provide a complete set of elastic constants and to provide information on texture.

\section{ACKNOMLEDGMENTS}

This study was encouraged by Dr. J. W. Ekin of NBS, who supplied the wires. Financial support was provided by the U.S. Naval Ship Research and Development Center and by the DoE Office of Fusion Energy. Dr. D. T. Read of NBS permitted use of his preliminary unpublished studies of ultrasonic velocities in copper and superconducting wires, Gary Maerz made several of the experimental measurements.

\section{REFERENCES}

1. P. Blum, E. Gregory, and D. L. Coffey, in Advances in Cryogenic Engineering, Vol. 22 (Plenum, New York, 1977), pp. 362369.

2. D. Dew-Hughes, in Superconducting Machines and Devices (Plenum, New York, 1974), pp. 87-130.

3. D. Dew-Hughes, Mater. Sci. Eng. 1, 2-29 (1966).

4. D. Dew-Hughes, Rep. Prog. Phys. 34, 821-73 (1971).

5. J. D. Livingston and H. W. Schadler, in Progress in Materials Science, Vol. 12, (Pergamon, 0xford, 1964), pp. 183. 
6. D. T. Read, Cryogenics 18, 579-84 (1978).

7. D. I. Bolef and M. Menes, J. App1. Phys. 31, 1010-17, (1960).

8. D. I. Bolef and J. deKlerk, IEEE Trans. Ultrason. Eng. 10, 19-26 (1963).

9. S. G. Fedotov and P. K. Belousov, Fiz. Metal Metalloved 17732 (1964).

10. C. C. Koch and D. S. Easton, Cryogenics 17, 391-413 (1977).

11. H. M. Ledbetter, J. Phys. D, forthcoming.

12. C. Schmidt, Appl. Phys. Lett. 28, 463-5 (1976).

13. C. N. Reid, J. L. Routbort, and R. A. Maynard, J. Appl. Phys. 44, 1398-9 (1973).

14. D. T. Read, Fracture and Deformation Division, NBS, Boulder, Colorado, personal communication. 
Table I. Sound velocities and Young's moduli for a superconducting wire and its components

\section{Material}

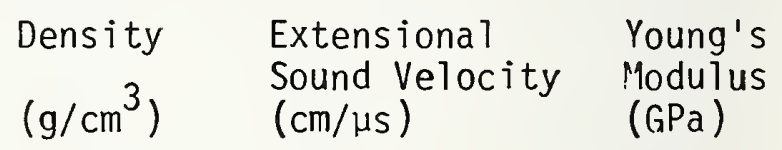

Cu, bulk, annealed

Cu, wire, annealed ${ }^{\mathrm{a}}$

NBTi:Cu, wire, deformed ${ }^{a}$

NBTi:Cu, wire, rule-of-mixtures

NBTi, wire, deformed ${ }^{b}$

NbTi, bulk, annealed

NbTi, bulk, deformed
8.93

0.380

8.93

0.376

7.92

0.370

7.92

0.371

6.10

0.360

6.12

0.371

6.10

0.360
128.7

126.0

108.6

109.3

79.1

84.3

79.2

ancludes unpublished pulse-echo results. 14

bxtrapolated from results in Ref. 12. 


\section{FIGURE CAPTION}

Fig. 1. Photomicrograph of transverse section of superconducting wire. NbTi filaments, 180 in number, constitute $5 / 14$ of the volume. The wire's dimensions are 0.58 by $0.68 \mathrm{~mm}$. 


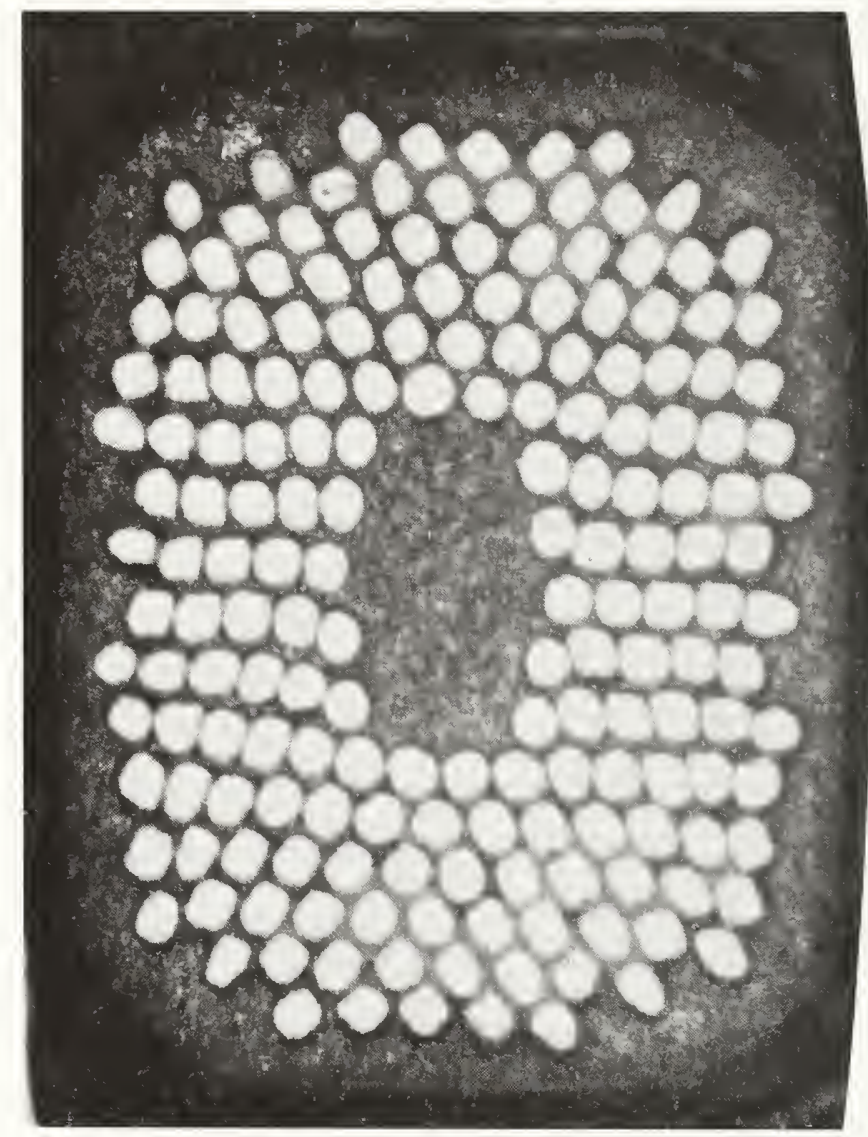

Fig. 1. Photomicrograph of transverse section of Nb-Ti superconductive wire. NbTi filaments, 180 in number, constitute $5 / 14$ of the volume. The wire's dimensions are 0.58 by $0.68 \mathrm{~mm}$. 
Welding 

WELDMENTS FOR LIOUUID HELIUM SERVICE

National Büreau of Standards 

WELDMENTS FOR LIQUID HELIUM SERVICE

H. I. HcHenry and T. A. Whipple

National Bureau of Standards

Boulder, Colorado 80303

The program to evaluate weldments for structural applications in superconducting magnet systems $[1,2]$ was continued in FY79. The objectives for the program are:

1. To investigate the metallurgical factors which affect the toughness of stainless steel weld metals at cryogenic temperatures.

2. To contribute to the development of improved filler metals for welding stainless steels for liquid helium service.

3. To evaluate the strength and toughness of stainless steel and aluminum weldments at $4 \mathrm{~K}$.

During the three years of the program, the first objective has remained unchanged, and objectives 2 and 3 have been generalized to cover the expanding scope of the program. Research started this year on the evaluation of promising filler metals for improved-toughness stainless steel weldments (but not improved strength), on the evaluation of aluminum alloy weldments, and in the development of improved procedures for measuring fracture toughness at $4 \mathrm{~K}$. Work continued on metallurgical investigations and toughness tests on stainless steel weldments supplied by various contributers to the DoE/OFE superconducting magnet programs. This report summarizes the results obtained in FY79 and briefly outlines the plans for FY80.

Stainless Steel Weldments

Previous work $[1,2]$ has identified ferrite content, nitrogen content, and sensitization as causes for toughness deterioration in stainless steel weldments at cryogenic temperatures. Most of the investigations were done on AWS $316 \mathrm{~L}$ welds deposited by the shielded 
metal-arc (SMA) process in 25.4-mm thick plates. This year, numerous toughness tests were conducted on $316 \mathrm{~L}$ SMA welds which were ferritefree, and contained low levels of $\mathrm{N}$ and $\mathrm{C}$. The welds were supplied by participants in the Large Coil Project and the Mirror Fusion Test Facility Project. The results, presented later in this report by Whipple, McHenry, and Read, indicate that wide variations in fracture toughness occur at $4 \mathrm{~K}$ even when ferrite is absent, nitrogen is constant, and sensitization is nil. The toughness at $4 \mathrm{~K}$ correlates well with grain size, indicating that process variables and welding procedures can have a marked influence on toughness.

A series of $308 \mathrm{~L}$ weldments were supplied for liquid helium testing in support of the LCP magnet design. Welds were deposited by the SMA, gas metal arc (GMA), and flux core metal-arc (FCMA) welding processes. The welds contained between 3 and $8 \%$ ferrite. The strength and fracture toughness values measured at $4 \mathrm{~K}$ are summarized in Tables 1 and 2 . Brittle behavior was observed in the FCMA welds where the fracture toughness was measured to be $50 \mathrm{MPa} \sqrt{\mathrm{m}}$ using valid plane strain procedures per ASTM E 399. The low toughness was attributed to high nitrogen in the welds; the FCMA welding process is self-shielded (i.e., no inert gas coverage is used) and tends to pick up nitrogen from the atmosphere. A welding process study for $316 \mathrm{~L}$ stainless steel weld metal was conducted by Kotecki. The results of this investigation are summarized later in this report. The purpose of this investigation was to assess the effect of welding process and, to a lesser extent, welding parameters on the cryogenic toughness of AWS $316 \mathrm{~L}$ weld metal at two nominal ferrite levels, 0 and 5\%. Welds were deposited in 25.4-mm thick plate 
by the gas tungsten-arc (GTA), GMA, and submerged arc (SA) processes.

Fissure bend tests, room temperature tensile tests, and Charpy tests at 77 to $173 \mathrm{~K}$ were conducted, and test plates for evaluation at $4 \mathrm{~K}$ were provided to NBS. The results indicate that GTA and GMA welds have acceptable toughness at $77 \mathrm{~K}$ by ASME standards, but the SA welds have unacceptable toughness. Further tests using the J-integral method will be conducted by NBS in FY80.

Two experimental stainless steel weld metals were evaluated at $4 \mathrm{~K}$. The properties are summarized in Tables 3 and 4 . A 16Cr-16Ni-2Mo alloy was deposited by the FCMA process. The weld metal had relatively low strength, $606 \mathrm{MPa}$, and excellent fracture toughness, $239 \mathrm{MPa} \sqrt{\mathrm{m}}$. The flux core wire used to deposit the $16 \mathrm{Cr}-16 \mathrm{Ni}-2 \mathrm{Mo}$ weld contained a special flux formulated to result in a low nitrogen deposit under open-arc conditions (i.e., without inert gas coverage). The outstanding toughness of this alloy combined with the improved deposition rates possible with the FCMA process makes this alloy an excellent candidate for further developmental work. The second experimental alloy was the $18 \mathrm{Cr}$ $16 \mathrm{Ni}-9 \mathrm{Mn}$ alloy, which was previously evaluated at $77 \mathrm{~K}[2]$. The $18 \mathrm{Cr}-$ 16Ni-9Mn weld deposited by the GMA process had relatively high tensile strength, $1076 \mathrm{MPa}$, but marginal fracture toughness, $120 \mathrm{MPa} \sqrt{\mathrm{m}}$. At the present time, no further work is planned on this alloy because of the low fracture toughness and the excessive microfissuring, which lead to an almost totally intergranular fracture.

Two SA weldments have been evaluated at $4 \mathrm{~K}$. The results are given in Tables 5 and 6 . The SA weldments were supplied by the MHD project being conducted by MIT. The two weldments contained 4.7 and $8.0 \%$ ferrite and had fracture toughness values of 136 and $99 \mathrm{MPa} \sqrt{\mathrm{m}}$, respectively. 
A program to evaluate the tensile and notched tensile properties of several aluminum alloy 5083 welds at $4 \mathrm{~K}$ was conducted by Kelsey and lifueller[3]. The idea was to have several fabricators and suppliers prepare test welds in 5-cm thick 5083-0 plate using 5183 filler wire. The equipment, procedures, and filler wire source were selected by each of the six participating companies. All welds were deposited by the GMA process. The welded plates were tested to determine the variability of weld properties at $4 \mathrm{~K}$. The results of this program are presented later in this report by Kelsey. Portions of each test weldment will be sent to NBS for J-integral fracture toughness testing at $4 \mathrm{~K}$. The results will be correlated with the notched tensile test results to determine if the empirical correlations used for aluminum alloys at room temperature and $77 \mathrm{~K}$ are valid at $4 \mathrm{~K}$.

\section{Test-Method Development}

Fracture toughness testing is the principal method for evaluating weldments at $4 \mathrm{~K}$. The $\mathrm{J}$-integral test procedure used is expensive, time consuming, and difficult. A simplified procedure is needed for research purposes and also for weld qualification testing by fabricators and independent laboratories. Two test-method-development activities are discussed later in this report. A computer-interactive J-integral test procedure was developed to improve the efficiency of $\mathrm{J}$-integral testing at NBS-Boulder. This method is described by Read, Tobler, and Reed [4]. A simple test method for estimating $J_{\text {Ic }}$ was developed at NBS by Begley and evaluated for liquid helium service by Whipple and McHenry. The method appears to be suitable to base metals, but further testing, scheduled for FY80, is needed to determine its applicability to weldments. 


\section{Future Work}

The main emphasis in the FY80 program will be to start work on the development of materials and procedures to improve the toughness of stainless steel welds deposited by high deposition rate processes. Initial work will be directed toward defining the metallurgical characteristics necessary for good toughness in large-grain-size welds.

Fracture toughness testing of stainless steel weldments will continue in support of the LCP program, the weld process selection study, the $16 \mathrm{Cr}$ 16Ni-2Mo filler metal development, and a cooperative program with an Austrian filler metal supplier on ferrite free SMA welds. In addition, work will continue on the evaluation of the 5083 aluminum alloy weldments and on development of the $J_{I c}$ estimation procedure.

\section{REFERENCES}

1. H. I. McHenry, "Evaluation of Stainless Steel Weld Metals at Cryogenic Temperatures," in Materials Studies for Magnetic Fusion Energy Applications at Low Temperatures-I, NBSIR 78-884 (1978), pp. 159166.

2. H. I. McHenry, D. T. Read, and P. A. Steinmeyer, "Evaluation of Stainless Steel Weld Metals at Cryogenic Temperatures," in Materials Studies for Magnetic Fusion Energy Applications at Low Temperatures-II, NBSIR 79-1609 (1979), pp. 299-308.

3. R. A. Kelsey and L. N. Mueller, "Tensile and Notch-Tensile Properties at Room Temperature and $4 \mathrm{~K}$ of WeTds in Aluminum A7loy 5083-0 Plate," in Material Studies for Magnetic Fusion Energy Applications at Low Temperatures-II, NBSIR 80-1627 (1980), pp.

4. D. T. Read, R. L. Tobler, and R. P. Reed, "J-Integral Methods and Measurements for AISI 304 Stainless Steels at Low Temperatures" submitted for publication (1980). 


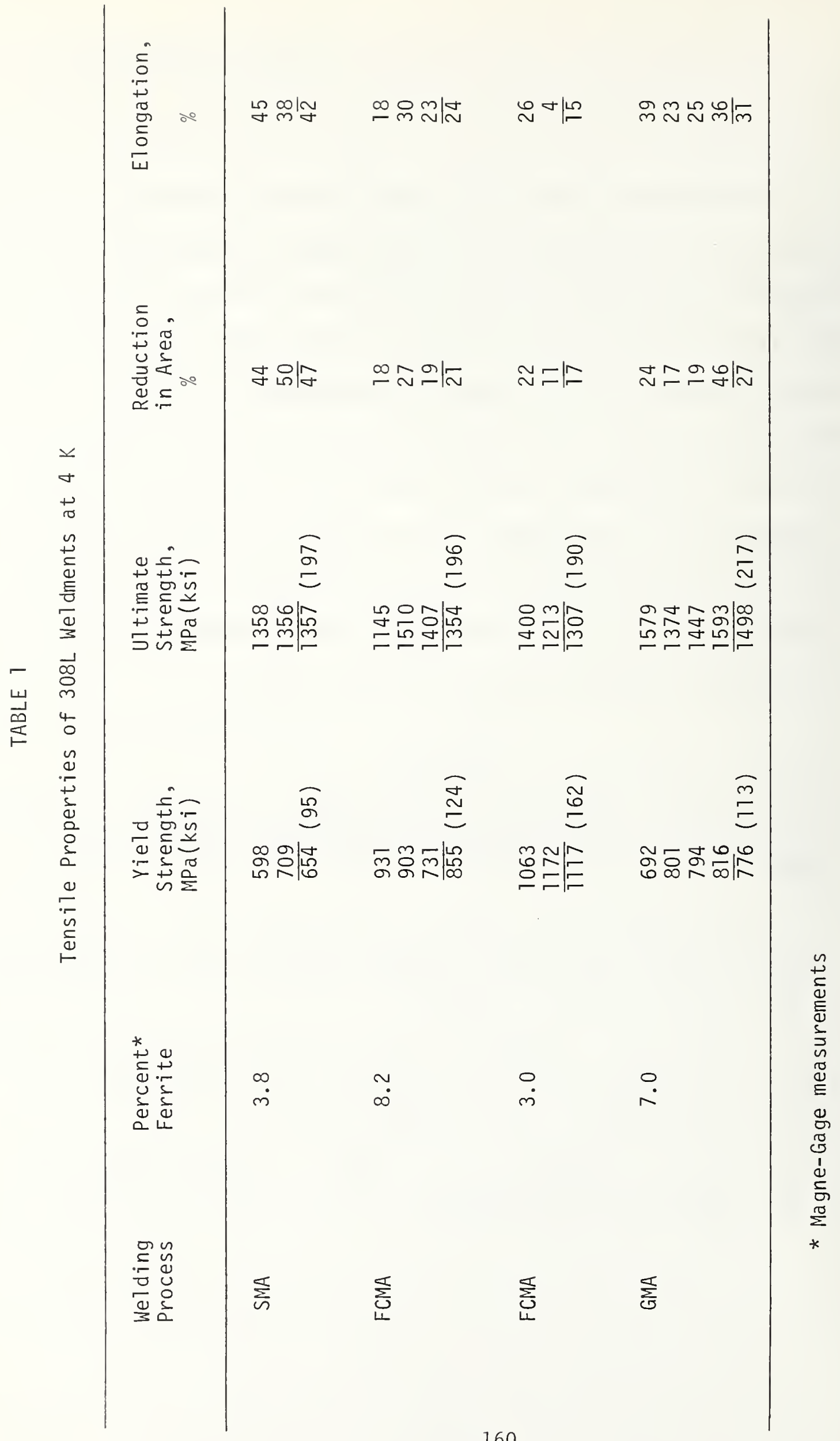




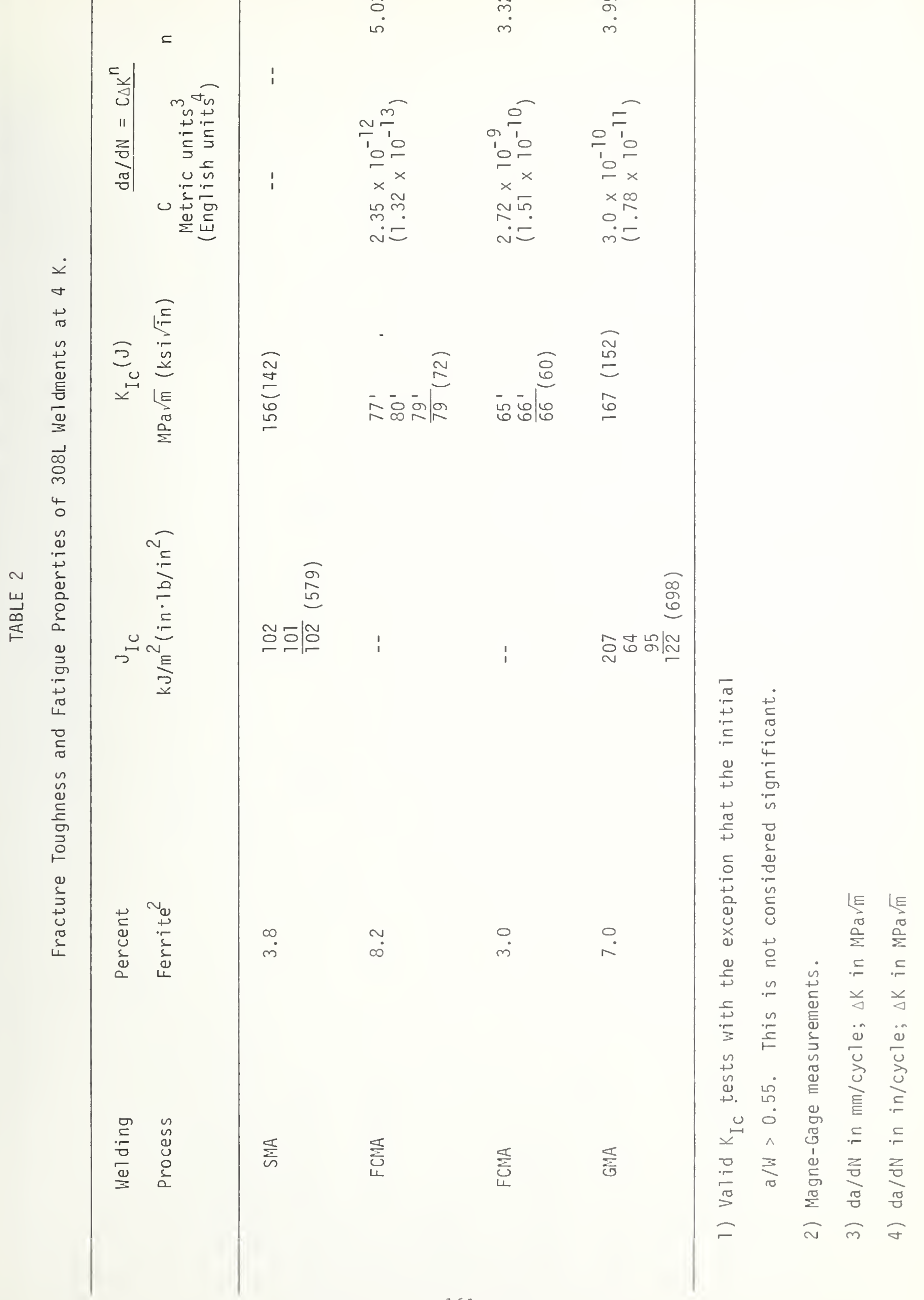




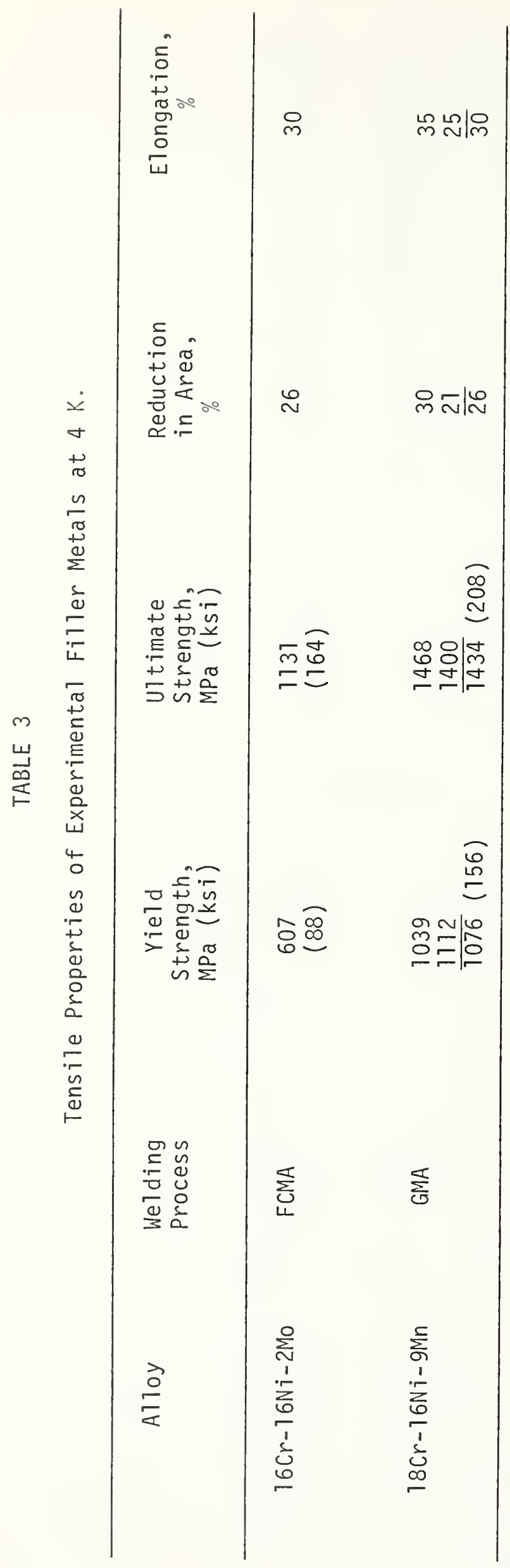




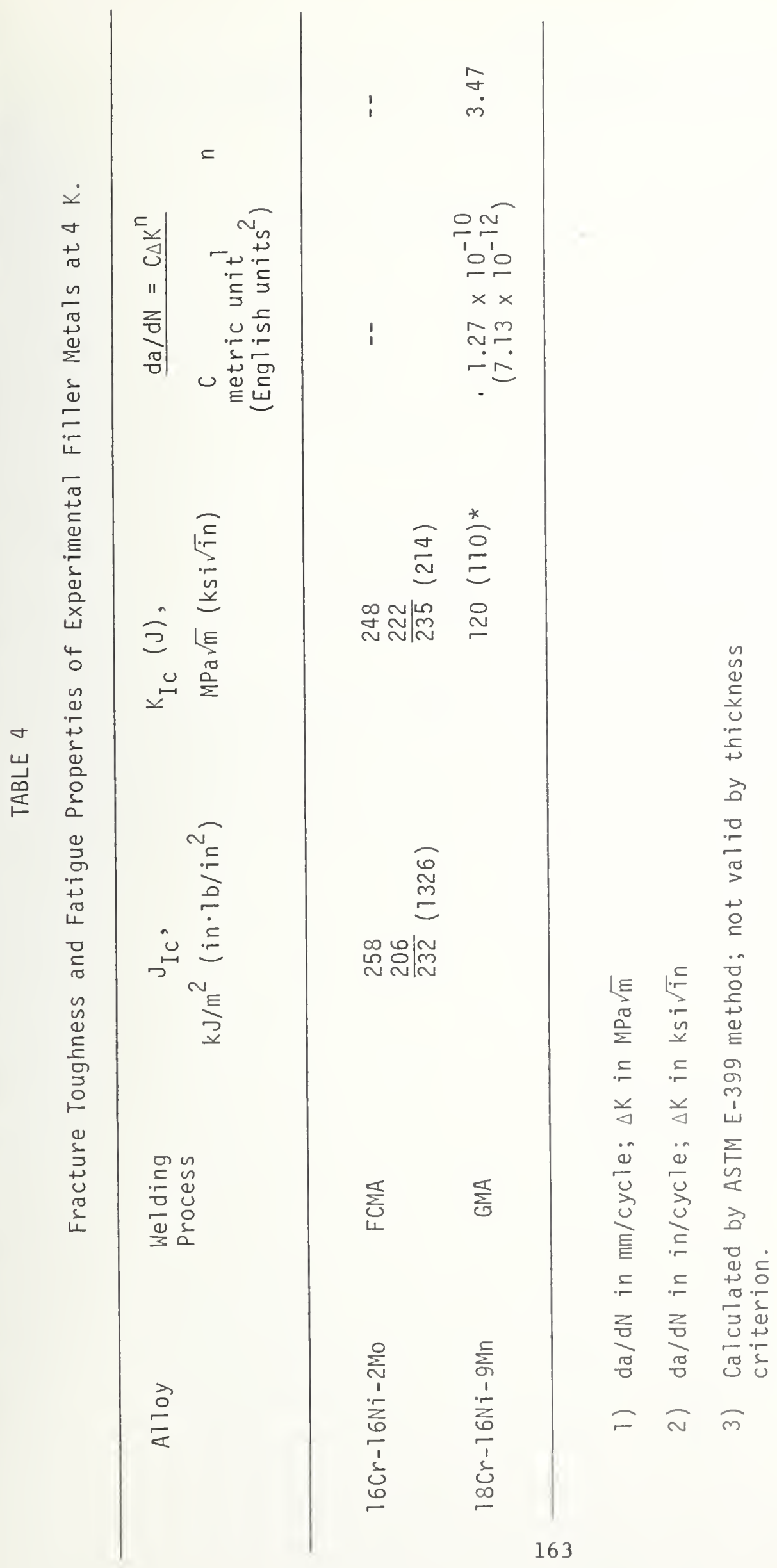




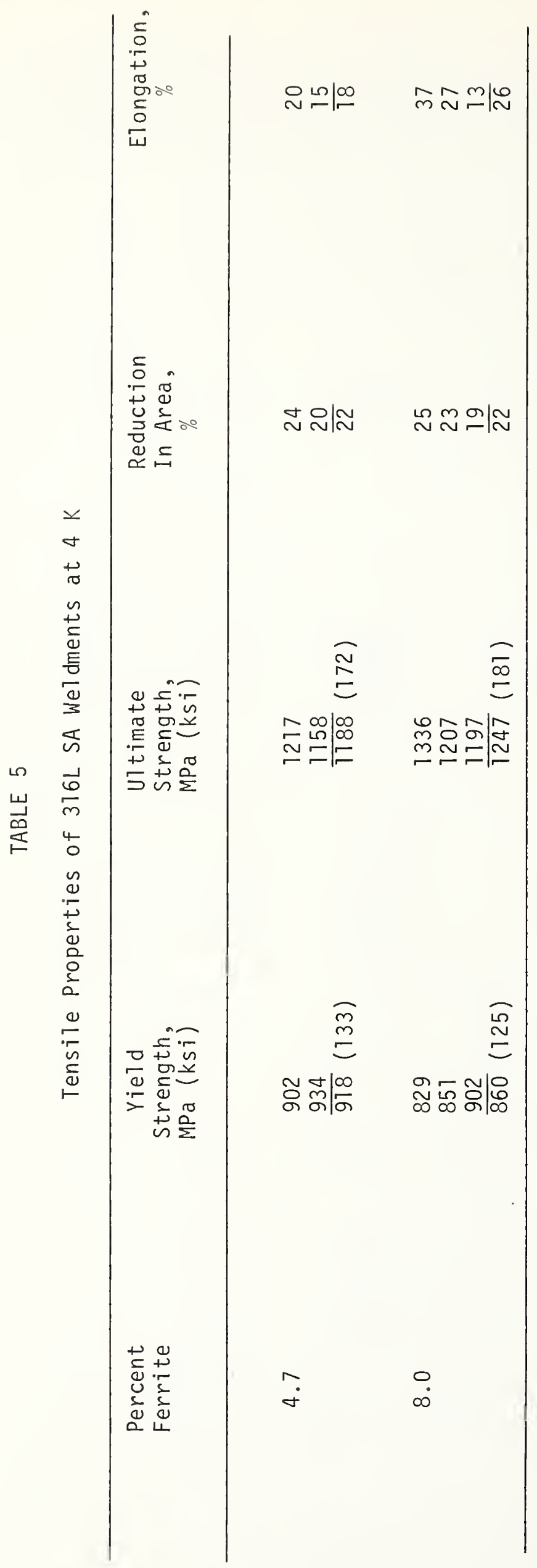


TABLE 6

Fracture Toughness and Fatigue Properties of $316 \mathrm{~L}$ SA Weldments at $4 \mathrm{~K}$

Percent

Ferrite

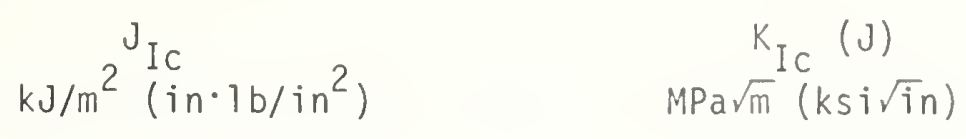
$d a / d N=C \Delta K^{n}$ C metric units ${ }^{2}$ (English units ${ }^{3}$ )
4.7
84
$\frac{71}{78}(443)$
138
$\frac{126}{132}$
8.0

47
43
$\frac{40}{43}(247)$
103

1) Magne-Gage measurements

2) $\mathrm{da} / \mathrm{dN}$ in $\mathrm{mm} / \mathrm{cycle} ; \Delta K$ in $\mathrm{MPa} \sqrt{\mathrm{m}}$

3) da/dn in in/cycle; $\Delta K$ in $k s i \sqrt{i n}$ 

FRACTURE BEHAVIOR OF FERRITE-FREE

STAINLESS STEEL WELDS IN LIQUID HELIUM*

T. A. Whipple, H. I. McHenry, and D. T. Read

National Bureau of Standards

Boulder, CO 80303

Work supported by the U.S. Department of Energy, Office of Fusion Energy. 

Most research to date concerning the cryogenic toughness of stainless steel weldments has concentrated on the effects of delta-ferrite content and nitrogen concentration. It has been shown that an increase in either of these leads to reduced cryogenic toughness. This paper reports that a wide variation in fracture toughness occurs in $316 \mathrm{~L}$ weldments that contain no delta ferrite and only small differences in nitrogen concentration. Therefore, welding parameters and minor compositional variability must also have significant influences. Optical microscopy revealed a strong correlation between cryogenic fracture toughness and fusion-zone grain width, which is controlled by welding parameters and weld-metal composition. An increase in grain size reduces the toughness. Microfissuring, which is a problem in low-ferrite welds, did not have an effect on the measured fracture toughness, but in one case it severely reduced the tensile ductility. Fatigue crack growth rate tests showed little variation in the fatigue properties of $316 \mathrm{~L}$ weldments, regardless of the variations in other properties. 
The fabrication of the load-bearing members of large superconducting magnet support structures requires the welding of thick sections. These weldments must be capable of withstanding high stresses at liquid helium temperatures. Current welding practice yields stainless steel weldments with sufficient strength; however, the high stresses, thick sections, and low temperatures increase the possibility of brittie fracture [1]. Therefore, the fracture toughness and fatigue crack growth rate of the weldments are important design parameters. Previous work on the cryogenic toughness of austenitic stainless steel weldments has generally centered on the effects of two important variables: delta ferrite content and nitrogen concentration $[2,3,4]$.

Read, McHenry, Steinmeyer, and Thomas [2] showed that large decreases in both fracture toughness and Charpy impact energy were related to increasing delta-ferrite content at $76 \mathrm{~K}$. At $4 \mathrm{~K}$, a strong decrease in fracture toughness with increasing delta-ferrite content was also observed. As the delta-ferrite content was increased from $0.13 \%$ to $10.1 \%$, the Charpy impact energy decreased from 35 to $12 \mathrm{~J}$, and the $\mathrm{J}_{\mathrm{Ic}}$ decreased from 135 to $41 \mathrm{~kJ} / \mathrm{m}^{2}$ at $4 \mathrm{~K}$. These results demonstrate convincingly the strong detrimental effect of delta ferrite on low temperature fracture toughness.

Szumachowski and Reid have also investigated the role of ferrite in reducing the low temperature toughness of stainless steel weldments [3]. Using $77 \mathrm{~K}$ Charpy impact tests, they found that the toughness not only increased with a decrease in the actual ferrite content, but continued to increase as the calculated ferrite number became negative. Also, lowcarbon content and the use of lime-coated electrodes improved the low 
temperature toughness of stainless steel weldments. In a continuation of this study, Szumachowski and Reid found that an increase in the nitrogen content of the weldment led to a decrease in the $77 \mathrm{~K}$ Charpy impact energy [4]. This is consistent with the results of Tobler and Reed [5], who reported that nitrogen was an extremely effective strengthening agent for 304 stainless steel base metals at cryogenic temperatures, but the increase in strength with increasing nitrogen led to a decrease in the toughness.

In this paper, recent data on the tensile and fracture properties of stainless steel weldments at $4 \mathrm{~K}$ are presented, and factors other than ferrite and nitrogen that appear to affect these properties are discussed.

\section{MATERIALS}

The data reported here have, for the most part, been obtained from weldments that were produced as part of a test program or are qualification weldments associated with large superconducting magnet programs sponsored by the Department of Energy. The magnet programs include the Large Coil Project (LCP) at Oak Ridge National Laboratory and the Mirror Fusion Test Facility (MFTF) at Lawrence Livermore Laboratory. The weldments discussed here are shielded-metal-arc (SMA) weldments made with special low-ferrite AWS E316L-15 electrodes. These weldments contain $0 \%$ delta ferrite (by Magne-Gage measurements) and were, with the exception of one vertical weld, produced in the flat position.

\section{PROCEDURES}

The weldments were evaluated using tensile, fatigue crack growth rate and fracture toughness tests. All tests were conducted in liquid helium at $4 \mathrm{~K}$. 


\section{Tensile Tests}

Tensile tests were conducted at $4 \mathrm{~K}$ using $2.5-\mathrm{cm}(1-i n)$ gage length and $0.64-\mathrm{cm}(0.25-\mathrm{in})$ diameter specimens. The specimens were oriented along the length of the weldment such that the entire sample was welded metal. The test procedures and the cryostat for the low temperature tests have been described by Reed [6].

Fracture Toughness Tests

Fracture toughness tests were conducted at $4 \mathrm{~K}$ using the ASTM E399 compact specimen with a $5.1-\mathrm{cm}(2-\mathrm{in})$ width and $2.5-\mathrm{cm}\left(1-\mathrm{in}_{\text {n }}\right)$ thickness. The specimens were generally oriented such that loading was perpendicular to the weldment, and crack extension was along the weldment centerline. The single-specimen J-integral procedure [7] was used to determine $\mathrm{J}_{\mathrm{IC}}$, the value of $\mathrm{J}$ at the onset of crack extension. The plane strain fracture toughness, $K_{I C}(J)$, was determined from $J_{I c}$ using the relationship proposed by Begley and Landes [8]:

$$
K_{I C}(J)=\left(\frac{J_{I C} E}{1-v^{2}}\right)^{T / 2}
$$

where $E$ is Young's modulus and $\nu$ is Poisson's ratio. Tests were conducted in an electrohydraulic fatigue machine equipped with the cryostat described by Fowlkes and Tobler [9].

In the single-specimen $\mathrm{J}$-integral technique, the specimen is precracked in tension-tension fatigue to a crack length of $3 \mathrm{~cm}(1.2 \mathrm{in})$. Subsequentry, the specimen is loaded monotonically at a load-linedisplacement rate of $50 \mathrm{um} / \mathrm{s}$ or less under displacement control to a point within the elastic region. The curve of load vs. load-line displacement is recorded on a second $x-y$ plotter with appropriate amplification and signal conditioning. 
A signal proportional to the change in load is electronically substracted from the signal; the proportionality factor is adjusted so that the unloading compliance before crack extension is displayed as a vertical line on the graph of load change against load-line displacement change. The specimen is incrementally extended, with several stops for recording the unloading compliance.

Typically, ten to twenty unloading compliances are recorded. The magnitude of the decrease in load during the unloadings is restricted to $10 \%$ of the total load. J-integral values are calculated from the load vs. load-line displacement recorded at each unloading point using the Merkle-Corten relation [10]. Crack extension values $\Delta a$, are calculated from all unloading compliance curves except the first one, which is used to evaluate the compliance at $\Delta a=0$. The ( $\mathrm{v} v, \Delta \mathrm{a}$ ) data are then plotted, and $\mathrm{J}_{\mathrm{Ic}}$ is evaluated graphically as the intersection of a curve through the data, with the theoretical blunting line given by $\mathrm{J}=$ $20 \Delta \mathrm{a}$, where $\sigma$ is the arithmetic mean of the yield strength and the ultimate tensile strength.

This method evolved into the following procedure, which was also used in this study: Load and displacement signals are converted to digital form, and a laboratory minicomputer processes the data and plots each $(\Delta a, J)$ datum point immediately after the associated unloading is completed [11]. The $\Delta a$ values obtained from the compliance data generally agreed within 10\% of those measured after the test. Scatter in the J-resistance curves led to uncertainties of about $\pm 12 \%$ in the J Ic values. 
Fatigue crack growth rate tests were conducted at $4 \mathrm{~K}$ on compact specimens identical to those used for fracture toughness testing. The tests were conducted in the same testing machine and cryostat described above. The specimens were sinusoidally loaded in tension with an amplitude of $90 \%$ of the peak load and at a cyclic rate of $20 \mathrm{~Hz}$. At regular intervals, the compliance of the specimen was measured on an $x-y$ plotter. The intervals between compliance measurements were shortened as the crack growth rate increased so that roughly the same amount of crack extention occurred between each compliance measurements were shortened growth per cycle, da/div, was calculated from the compliance measurements, and the stress intensity change, $\Delta K$, was calcualted from the crack length and loads. These data are plotted according to the relationship:

$$
d a / d N=C \Delta K^{n}
$$

where $\mathrm{C}$ and $\mathrm{n}$ are constants.

\section{RESULTS AND DISCUSSION}

Tables 1 and 2 contain a summary of the data obtained during this investigation on 316L SMA weldments, which contained no delta ferrite. Fracture Toughness Properties

The results of Read et al. [2] showed that, in a controlled series of $316 \mathrm{~L}$ SMA weldments, an increase in the delta-ferrite content resulted in a decrease in the fracture toughness. In that series of weldments, the chromium and nickel contents were varied while the compositions of minor alloying elements and the welding parameters were held constant. This approach resulted in a very good description of the effect of 
delta-ferrite content. In the present study, a number of different $316 \mathrm{~L}$ SMA weldments with $0 \%$ ferrite and similar nitrogen contents were tested. Although all these weldments had a similar composition, they were produced with different welding parameters and in different plate thicknesses. Figure 1 shows the $K_{I c}(J)$ data of Read et al. along with the fracture toughness data for $316 \mathrm{~L}$ SMA weldments obtained during this study. There is a larger variation in fracture toughness for weldments that contain no ferrite than that obtained for the controlled series of weldments containing 0 to $10 \%$ ferrite. Therefore, the fracture toughness is not only a function of the ferrite and nitrogen contents, but is also strongly dependent on other factors, such as welding parameters and other compositional variations.

Attempts to correlate the variation in fracture toughness with other mechanical properties, such as tensile properties or Charpy VNotch (CVN) toughness, have been unsuccessful. The range of yield strengths for the $0 \%$ ferrite $316 \mathrm{~L}$ weldments is only 772 to $882 \mathrm{MPa}$ (112 to $128 \mathrm{ksi}$ ); this small variation in yield strengths can not account for the large difference in fracture toughness values of 95 to $200 \mathrm{MPa} \sqrt{\mathrm{m}}$ (86 to $182 \mathrm{ksi} \sqrt{\mathrm{in}}$ ). Also, $77 \mathrm{~K}$ CVN toughness does not vary greatly within this group of weldments and does not correlate with the fracture toughness. Figure 2 shows the strong correlation found between the fracture toughness, $K_{I C}(J)$, and the grain size of the fusion zone. The fusion zone of stainless steel weldments consists of large columnar grains that display epitaxial growth, that is, the grains are continuous between passes (see Figure 3, a three-dimensional micrograph of the weldment structure). When a compact tension specimen is loaded, the plane that experiences the highest strain is the plane parallel to the 
plate surface. The structure of this plane is essentially equiaxed; therefore, the important grain size for deformation is the columnar grain width, this is the grain size plotted in Figure 2.

This dependence of the toughness on the grain size leads to some interesting possibilities concerning the effects of specimen orientation on the mechanical properties of the weldment. For example, for cracks propagating in the through-thickness direction, the columnar grains are oriented with the length direction in the direction of crack propagation. This has the effect of increasing the average grain size in the plane of highest strain. One weldment, No. 7, was tested in both orientations, the crack propagating down the centerline and in the through-thickness direction. The results are shown in Table 1. Although the load-deflection curve of the through-thickness sample was still characteristic of a tough material, the $\mathrm{K}_{\mathrm{Ic}}(\mathrm{J})$ value was only $107 \mathrm{MPa} \sqrt{\mathrm{m}}(97 \mathrm{ksi} \sqrt{\mathrm{in}})$ compared with $200 \mathrm{MPa} \sqrt{\mathrm{m}}(183 \mathrm{ksi} \sqrt{\mathrm{in}})$ for the standard orientation. This is only the result of one test and is not conclusive. However, it does point out that a design assumption of isotropic weldment properties may not be valid, and with regard to normal stress states, a crack propagating in the through-thickness direction is usually very important. This aspect of weldment properties deserves further investigation.

It has also been observed that there is a directional dependence to the plastic deformation of stainless steel weldments. An example of the directional dependence is seen in the necked down section of round, longitudinal tensile specimens, in which the fracture surface is always elliptical in shape. The long axes of the grains are aligned with the short axis of the ellipse, showing that plastic deformation occurs more 
easily in that direction. An example of the deformation following the columnar grains in a compact tension specimen is shown in Figure 4. This specimen is oriented such that the crack is propagated in the through-thickness direction. Notice that the deformed region is not symmetric around the crack tip as it would be in an equiaxed structure, but follows the length of the columnar grains.

\section{Effect of Microfissures}

Given consistent welding conditions, a decrease in the deltaferrite content of the weldment results in an increased cryogenic fracture toughness [2]. However, the production of very low ferrite or fully austenitic weldments can be difficult because these weldments are apt to form microfissures. The subject of microfissuring has been extensively studied [12-16], particularly with regard to the effects of delta-ferrite content and chemical composition. It is generally agreed that microfissuring is the result of a liquation process, where a lowmelting temperature grain-boundary constituent is remelted by the subsequent welding pass. The thermal stresses cause the fissure to open.

The exact cause of microfissuring is not yet well established; nevertheless, it is well known that microfissuring can be eliminated by adjusting the composition to obtain 5 to $10 \%$ delta ferrite. The amount of delta-ferrite necessary depends on the chemical composition and the welding process and parameters used. To date, the technology to produce consistently microfissure-free, fully austenitic weldments is not available. Therefore, the effect of these defects on mechanical properties must be considered. 
From their studies of the effects of microfissures on mechanical properties, Honeycombe and Gooch [13] concluded that microfissures are unlikely to have a significant effect on the tensile or charpy impact properties of the weldment. It was observed that microfissures may extend by ductile tearing, but have no propensity for unstable failure. They did find that microfissures can have an effect on the fatigue life, if the microfissures are the most significant defects present (i.e., if the weldment reinforcement is removed and there are no other defects). In this study, no apparent effect of microfissures on the fracture toughness was found. For weldment No. 8 which contained significant microfissuring, the fracture toughness value was consistent with other similar weldments that did not contain microfissures. This observation is not surprising, considering the orientation of the microfissures with respect to the crack plane. The microfissures, being perpendicular to the crack, act as obstacles to crack propagation and cause the crack to branch or change plane.

In weldment No. 8, the microfissures were generally oriented transverse to the welding direction, that is, they were perpendicular to the tensile axis of all weld-metal tensile samples. In this orientation, microfissures reduce the load-bearing area of tensile samples. This did not appear to affect the yield strength, but it did severely reduce the ultimate strength and ductility measurements. The total elongation values for the three tensile samples tested were $2.2,8.6$, and $13.8 \%$. This variation in total elongation appears to relate directly to the size of the microfissures on the fracture surface -- the largest microfissure was observed on the sample with the lowest elongation. The magnitude of this effect is related to the area of the microfissure 
relative to the entire cross-sectional area, and since the size of the microfissures is generally small, a larger sample size should reduce the effect. Therefore, if the entire cross section of the weld is considered, the effect of microfissures on tensile ductility will probably be small. They, will only be significant if the loading is in the longitudiual direction of the weld.

Figures 5 and 6 are scanning electron microscope (SEM) fractographs of the fracture surface of weidment No. 8. Figure 5 shows a grain boundary that was completely open prior to testing; note that the liquated surface shows no evidence of deformation. Although the microfissure appears to have opened up during testing, it does not appear to have propagated. Figure 6 is an example of a microfissure in which the grain boundary did not separate completely during welding. It is evident that there were small ligaments of solid material left in the grain boundary; these ligaments failed in a ductile manner during the test.

Fatigue crack growth rate tests were also conducted on the weldment with microfissures. Wo effect of microfissures was observed; this is probably also due to the orientation of the microfissures with respect to the crack plane, as discussed above.

\section{Fatigue Crack Growth}

The results of the fatigue crack growth rate tests are given in Table 2 and shown graphically in Figure 7 for the low-ferrite 316L SMA weldments. Figure 8 combines the data for all the weldments tested and shows only minor variations in the fatigue crack growth rate, in spite of the fact that these weldments represent fracture toughness variations from 132 to $200 \mathrm{MPa} \sqrt{\mathrm{m}}$ (120 to $182 \mathrm{ksi} \sqrt{\mathrm{in}})$. In all cases, the fatigue crack growth rate properties of the weld metal are better than those for 
304 N stainless steel base metal [17], which is representative of the base metals used for magnet casings.

\section{SUMMARY}

The tensile fracture toughness and fatigue crack growth properties of eight $316 \mathrm{~L}$ stainless steel SMA weldments were evaluated in liquid helium at $4 \mathrm{~K}$. The tensile strength and fatigue crack growth rates were similar for all eight weldments. However, the fracture toughness varied from 95 to $200 \mathrm{MPa} \sqrt{\mathrm{m}}$. The toughness increased with decreasing fusion-zone grain width. Microfissuring was observed in several weldments but with one exception, did not appear to influence the properties measured. In the excepted weldment, the tensile strength and ductility were reduced due to microfissures in the test section. 
1. H. I. McHenry and R. P. Reed, "Structural Alloys for Superconducting Magnets in Fusion Energy System," Nucl. Eng. Des., forthcoming.

2. D. T. Read, H. I. McHenry, P. A. Steinmeyer, and R. D. Thomas, Jr., "Metallurgical Factors Affecting the Toughness of 316L SMA Weldments at Cryogenic Temperatures," Material Studies for Magentic Fusion Energy Applications at Low Temperatures-II, NBSIR 79-1609, National Bureau of Standards, Boulder, C0, pp. 313-352.

3. E. R. Szumachowski and H. F. Reid, "Cryogenic Toughness of SMA Austenitic Stainless Steel Weld Metals: Part I - Role of Ferrite," Weld. J., Weld. Res. Suppl. 57, 325-s-333-s (1978).

4. E. R. Szumachowski and H. F. Reid, "Cryogenic Toughenss of SMA Austenitic Stainless Steel Weld Metals: Part II - Role of Nitrogen," Weld. J., Weld. Res. Suppl. 58, 34-s-44-s (1979).

5. R. L. Tobler and R. P. Reed, "Interstitual Carbon and Nitrogen Effects on the Tensile Properties and Fracture Mechanics Parameters of an AISI 304 Type Austenitic Stainless Steel", Material Studies for Magnetic Fusion Energy Applications at Low Temperatures-III., NBSIR 80-1627, National Bureau of Standards, Boulder, Co, pp. 15-48.

6. R. P. Reed, "A Cryostat for Tensile Tests in the Temperature Range 300 to $4 \mathrm{~K}$," in Advances in Cryogenic Engineering, Vol. 7, Plenum Press, New York (1962) pp. 448-454.

7. G. A. Clarke, W. R. Andrews, P. C. Paris, and D. W. Schmidt, in Mechanics of Crack Growth, Proceedings of the 1974 National Symposium on Fracture Mechanics, ASTM STP 590, American Society for Testing and Materials, Philadelphia, PA (1976), pp. 27-42. 
8. J. A. Begley and J. D. Landes, in Fracture Toughness, Proceedings of the 1971 National Symposium on Fracture Mechanics, Part II, ASTM STP, 514 American Society for Testing and llaterials, Philadelphia, PA (1972), pp. 1-20.

9. C. W. Fowlkes and R. L. Tobler, "Fracture Testing and Results for a Ti 6Al-4V Alloy at Liquid Helium Temperatures," Eng. Fract. Mech., 8, 487-500 (1976).

10. J. G. Merkle and H. T. Corten, "A J-Integral Analysis for the Compact Specimen, Considering Axial Force as well as Bending Effects," Journal of Pressure Vessel Technology, Trans. ASME, 96, 1-7 (1974).

11. J. A. Joyce and J. P. Gudas, Computer Interactive J Ic Testing of ilaval Alloys ASTM STP 668, American Society of Testing and Materials, Philadelphia, PA (1979) pp. 451-468.

12. C. D. Lundin and D. F. Spond, "The Nature and Morphology of Fissures in Austenitic Stainless Steel Weld Metals," Weld. J. Weld. Res. Suppl. 55, 356-s-367-s (1976).

13. J. Honeycombe and T. G. Gooch, "The Effect of Microcracks upon the Mechanical Properties of Austenitic Stainless Steel Weld Metals," Report Ho. M/69/72, The Welding Institute, Cambridge, MA (1972).

14. S. Kanazawa, K. Yamato, T. Tekeda, and K. Hashimoto, "Study of Reheat Cracking in Weldment (Report I)," Trans. Jpn. Weld. Soc., 7, No. 1, 49-57 (1976).

15. J. Honeycombe and T. G. Gooch, "The Effect of Compositional and Process Variables on Microcracking in Fully Austenitic Stainless Steel and Weld Meta1," Report No. M/74/73, The Welding Institute, Cambridge, MA (1973). 
16. J. A. Brooks and F. J. Lambert Jr., "The Effects of Phosphorus, Sulfur and Ferrite Content on Weld Cracking of Type 309 Stainless Steel," Weld. ․ Weld. Res. Suppl. 57, 139-s-143-s (1978).

17. D. T. Read and R. P. Reed, "Toughness, Fatigue Crack Growth, and Tensile Properties of Three Nitrogen-Strengthened Stainless Steels at Cryogenic Temperatures," Materials Studies for Magnetic Fusion Energy Applications at Low Temperatures-I, NBSIR 78-884, National Bureau of Standards, Boulder, C0, (1978), pp. 91-154. 


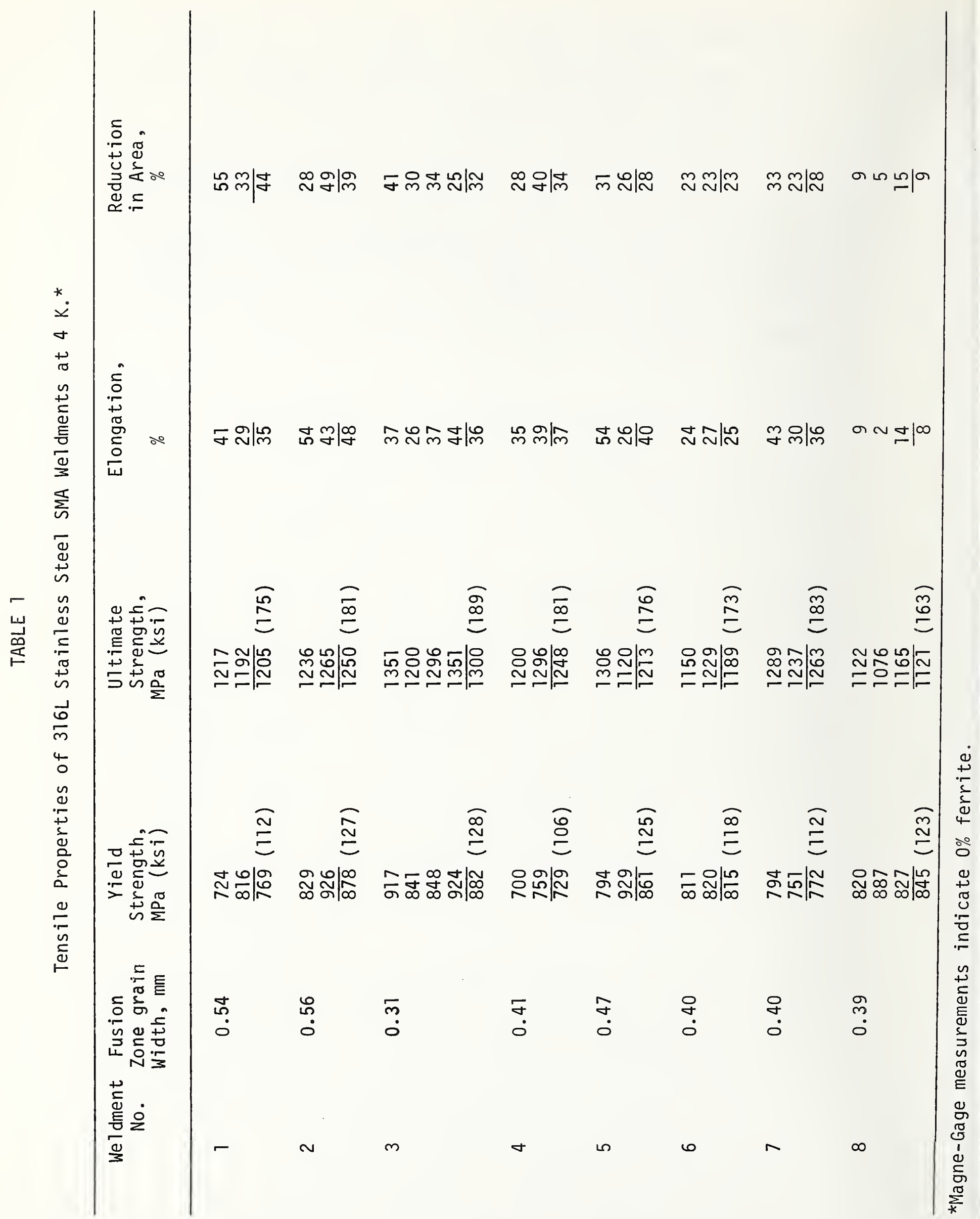




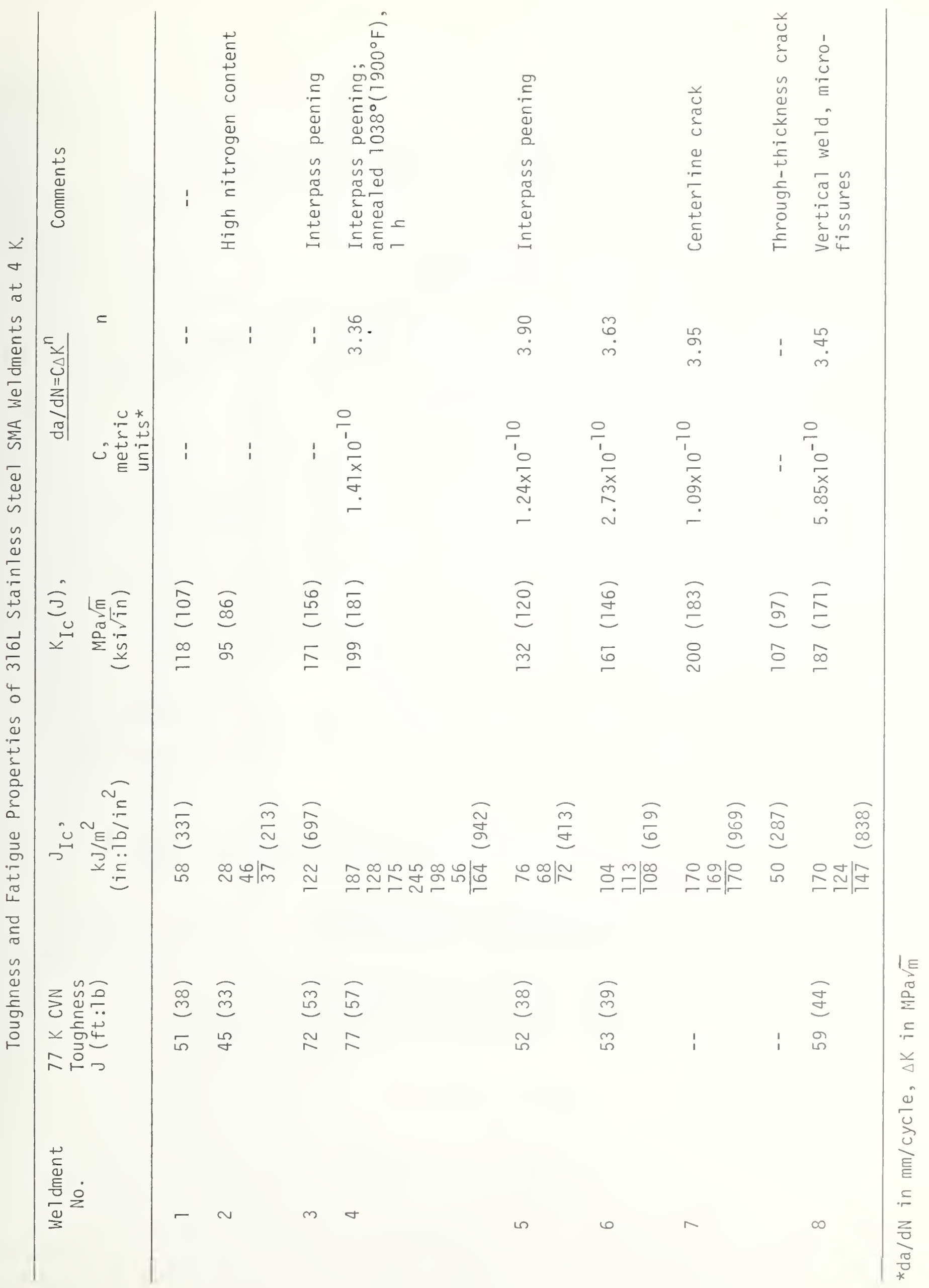


Fig. 1. Critical stress intensity factor, $K_{I C}(J)$ as a function of delta-ferrite content at $4 \mathrm{~K}$, showing the wide variation in fracture toughness that has been found for 316L SMA weldments with $0 \%$ ferrite.

Fig. 2. The relationship between fusion-zone grain width and $4 \mathrm{~K}$ fracture toughness of $316 \mathrm{~L}$ SMA weldments with $0 \%$ ferrite.

Fig. 3. Composite three-dimensional photomicrograph of the fusion zone of a $0 \%$ ferrite $316 \mathrm{~L}$ SMA weldment.

Fig. 4. Macrograph of the deformed region around the crack tip of a compact specimen oriented such that the crack is propagated in the through-thickness direction, showing that plastic strain is transmitted down the length of the columnar grains.

Fig. 5. SEM fractograph of a microfissure on the fracture surface of weldment No. 8, (a) $150 \times$ (b) $1000 \times$.

Fig. 6. SEM fractograph of a grain boundary, which was only partially separated prior to testing, on the fracture surface of weldment No. 8, (a) $50 \times$ (b) $2000 \times$.

Fig. 7. The $4 \mathrm{~K}$ fatigue crack growth rate data for $316 \mathrm{~L}$ SMA weldments (Nos. 4 to 8 ).

Fig. 3. The $4 \mathrm{~K}$ fatigue crack growth rate data for a $11316 \mathrm{~L}$ SMA weldments tested, compared with 304N base-metal data from Read and Reed [17]. 


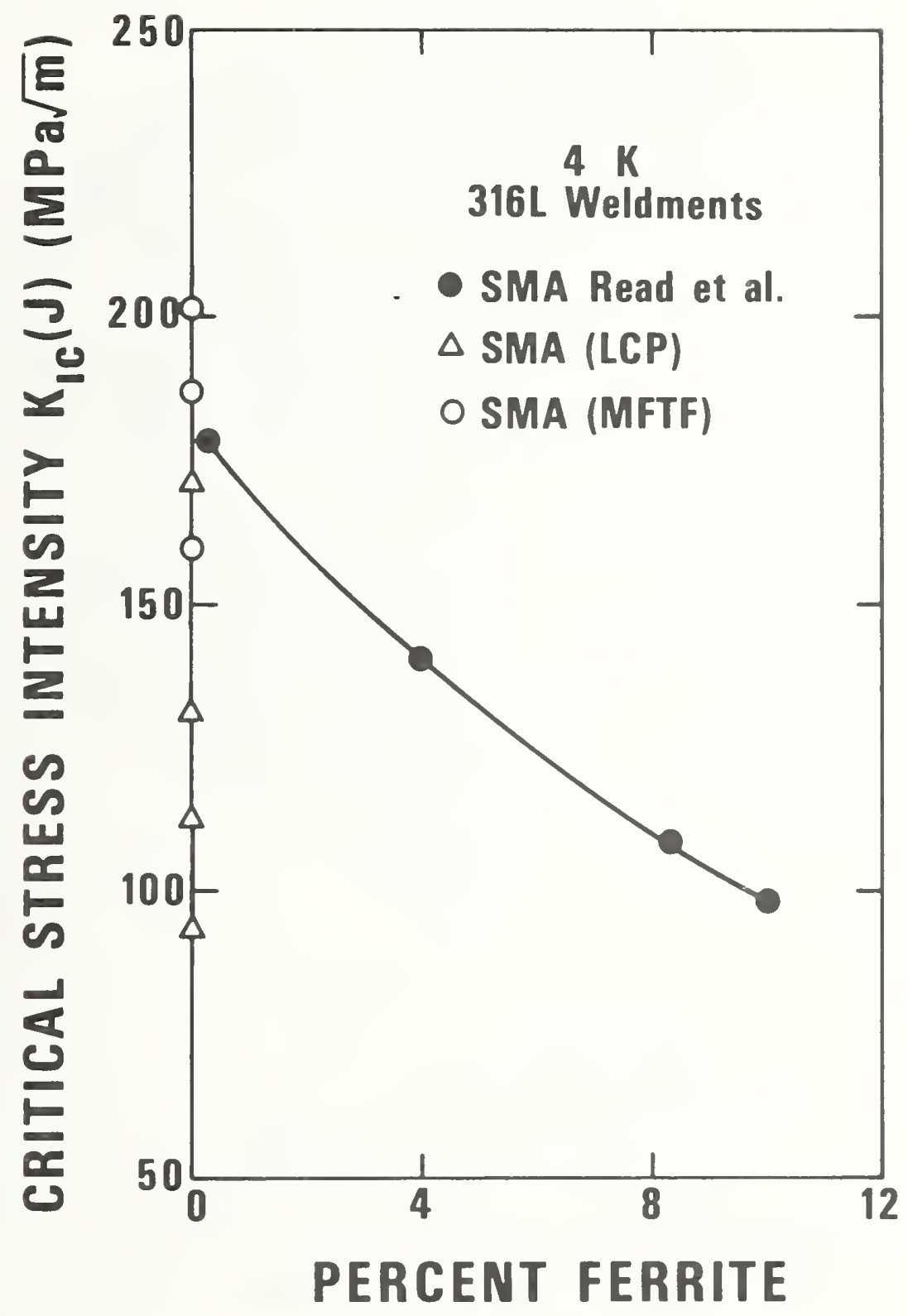

Fig. 1. Critical stress intensity factor, $K_{I C}(J)$, as a function of delta-ferrite content at $4 \mathrm{~K}$, showing the wide variation in fracture toughness that has been found for $316 \mathrm{~L}$ SMA weldments with $0 \%$ ferrite. 


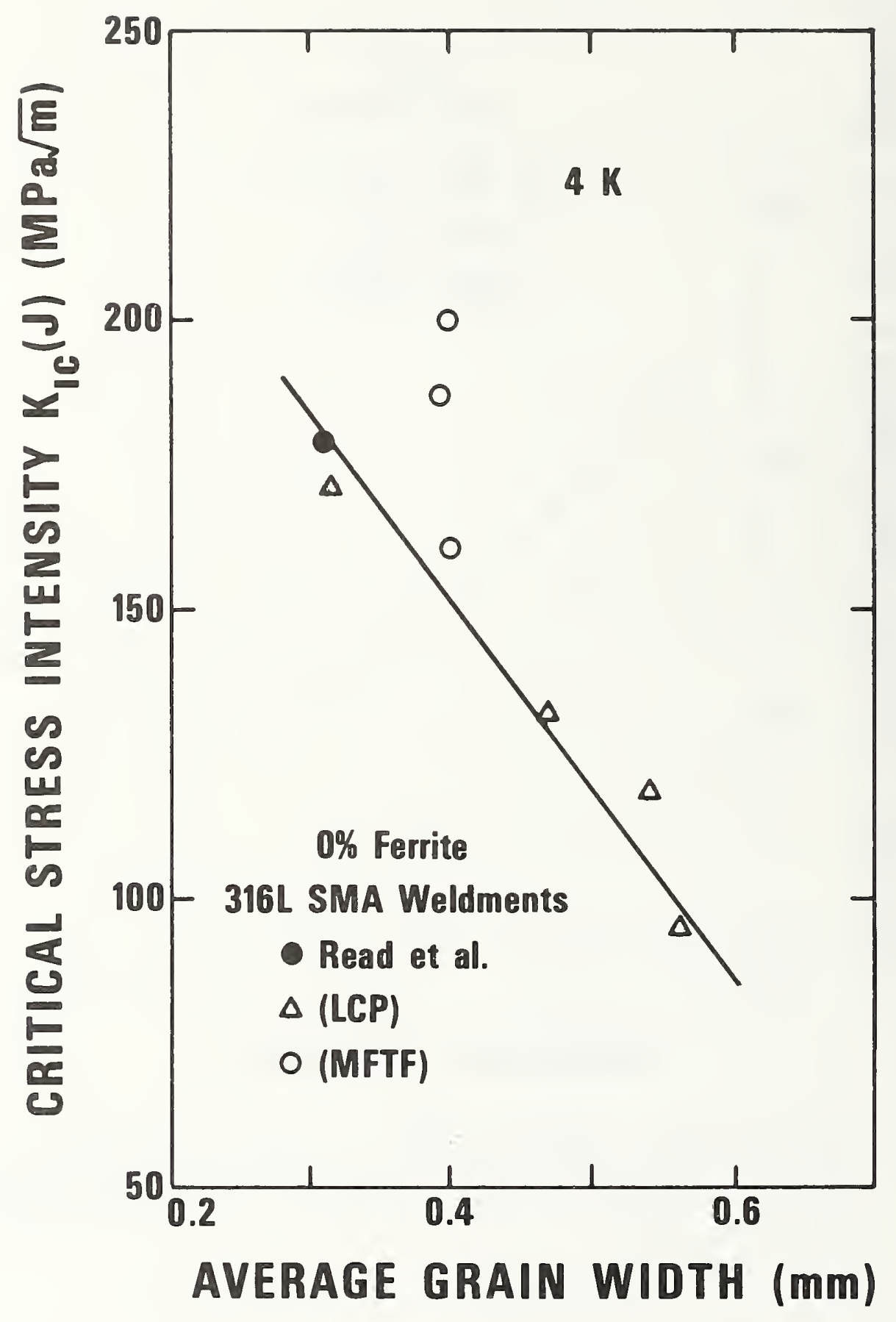

Fig. 2. The relationship between fusion-zone grain width and $4 \mathrm{~K}$ fracture toughness of $316 \mathrm{~L}$ SMA weldments with $0 \%$ ferrite. 


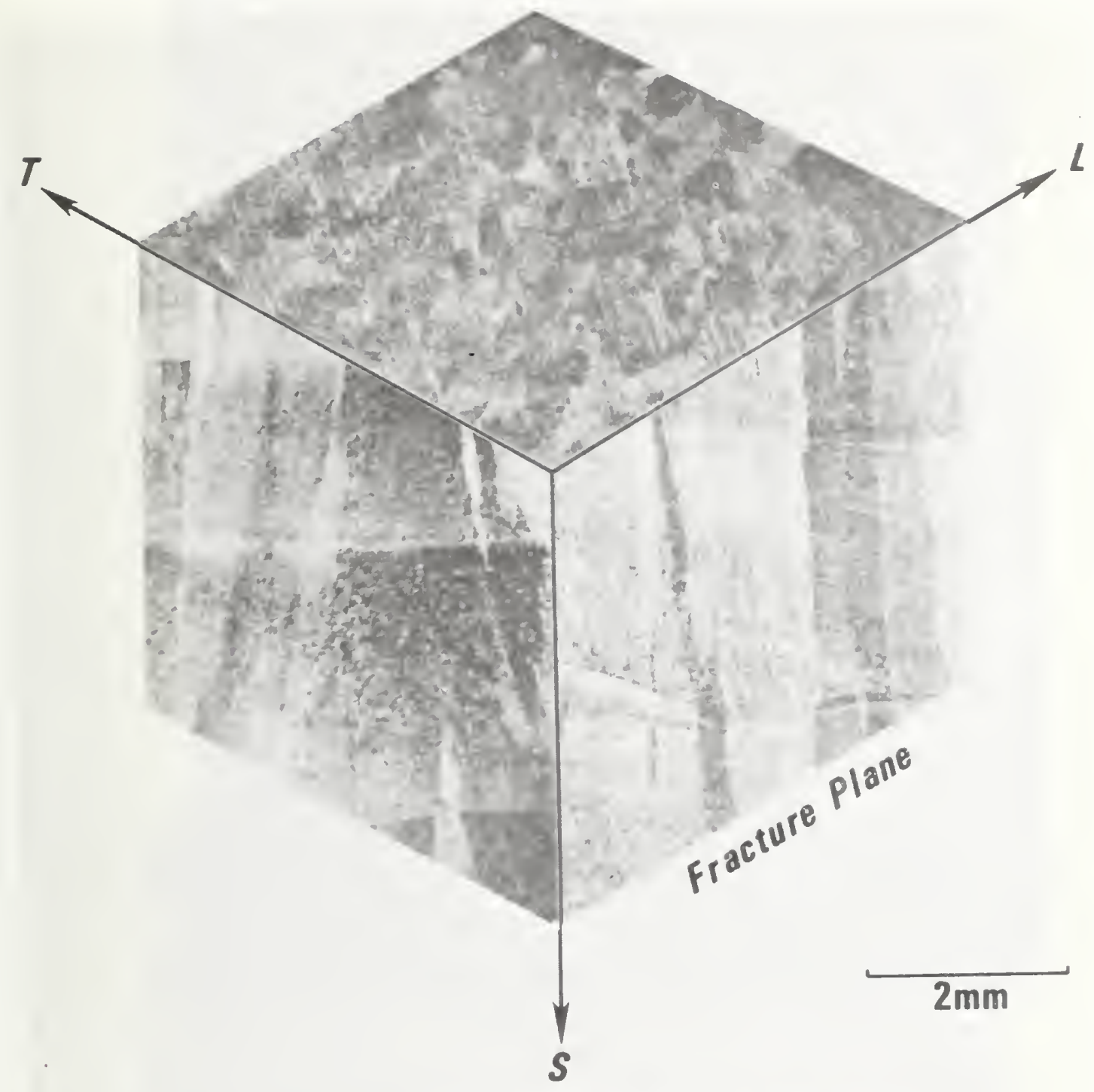

L - Longitudinal or welding direction

$T$ - Long transverse or width direction

S - Short transverse or weld thickness direction

Fig. 3. Composite three-dimensional photomicrograph of the fusion zone of a $0 \%$ ferrite $316 \mathrm{~L}$ SMA weldment. 


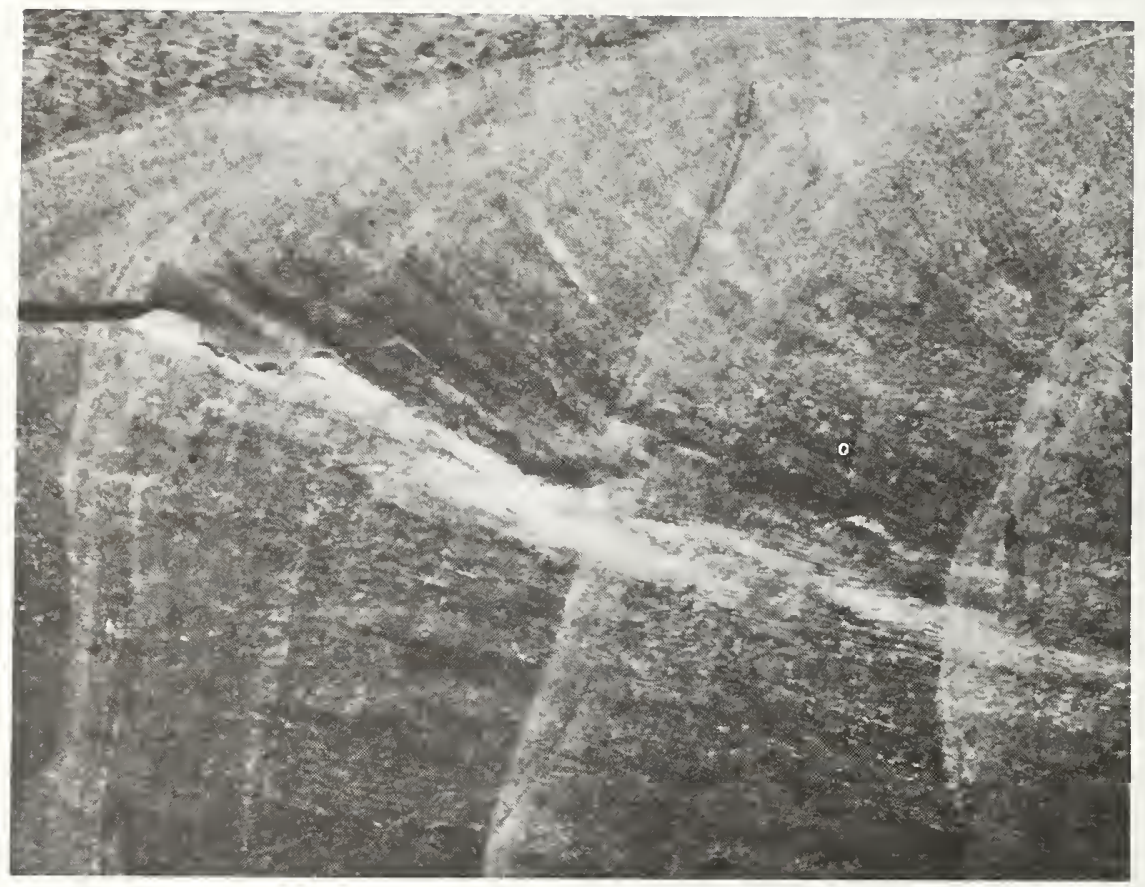

Fig. 4. Macrograph of the deformed region around the crack tip of a compact specimen oriented; such that the crack is propagated in thru thickness direction showing that plastic strain is transmitted down the length of the columnar grains. 

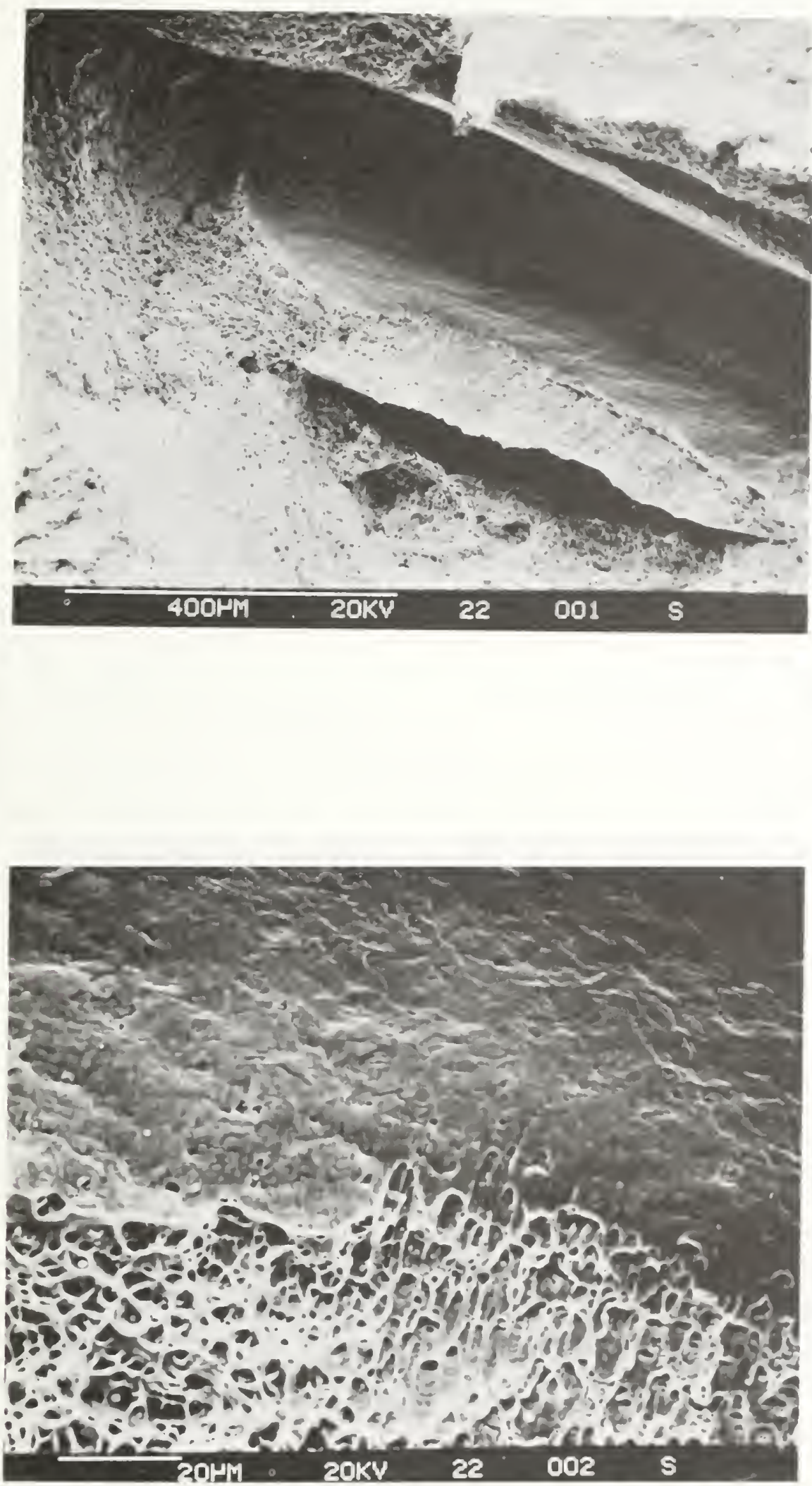

Fig. 5. SEM Fractograph of a microfissure on the fracture surface of weld No. 8 , (a) $150 \times$ (b) $1000 \times$. 

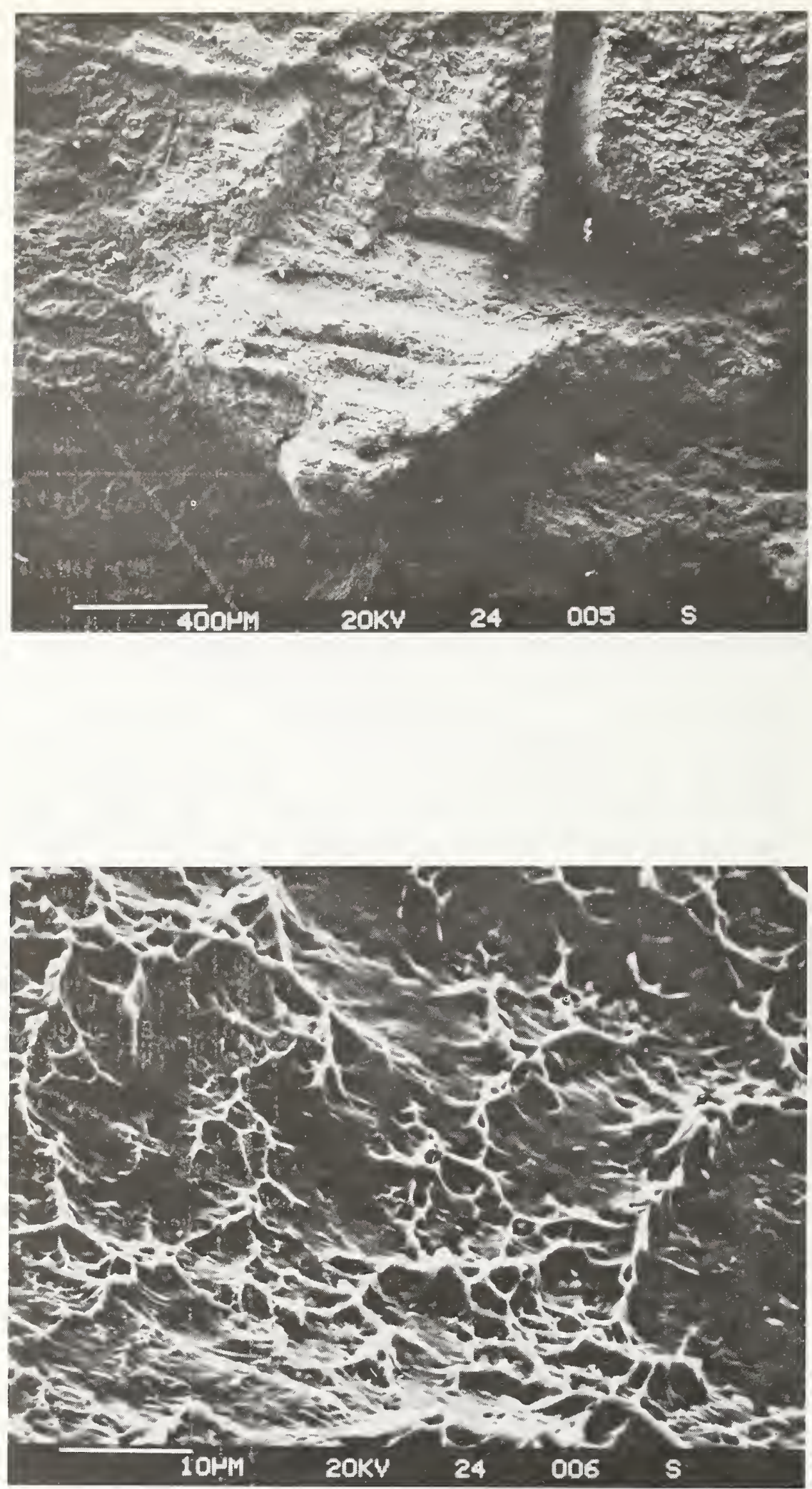

Fig. 6. SEM Fractograph of a grain boundary, which was only partially separated prior to testing, on the fracture surface of weld No. 8 , (a) $50 \times$ (b) $2000 \times$. 


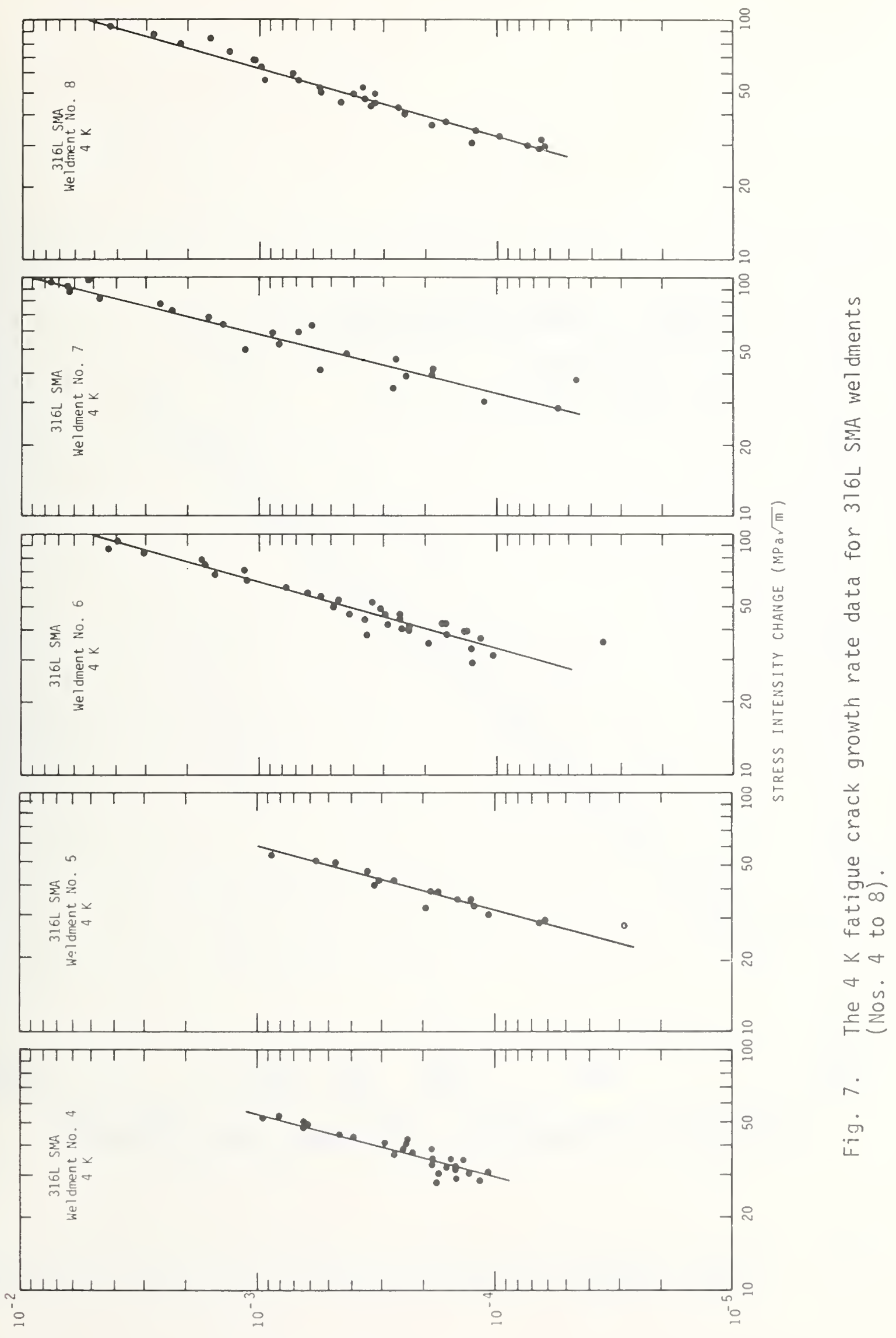

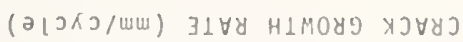




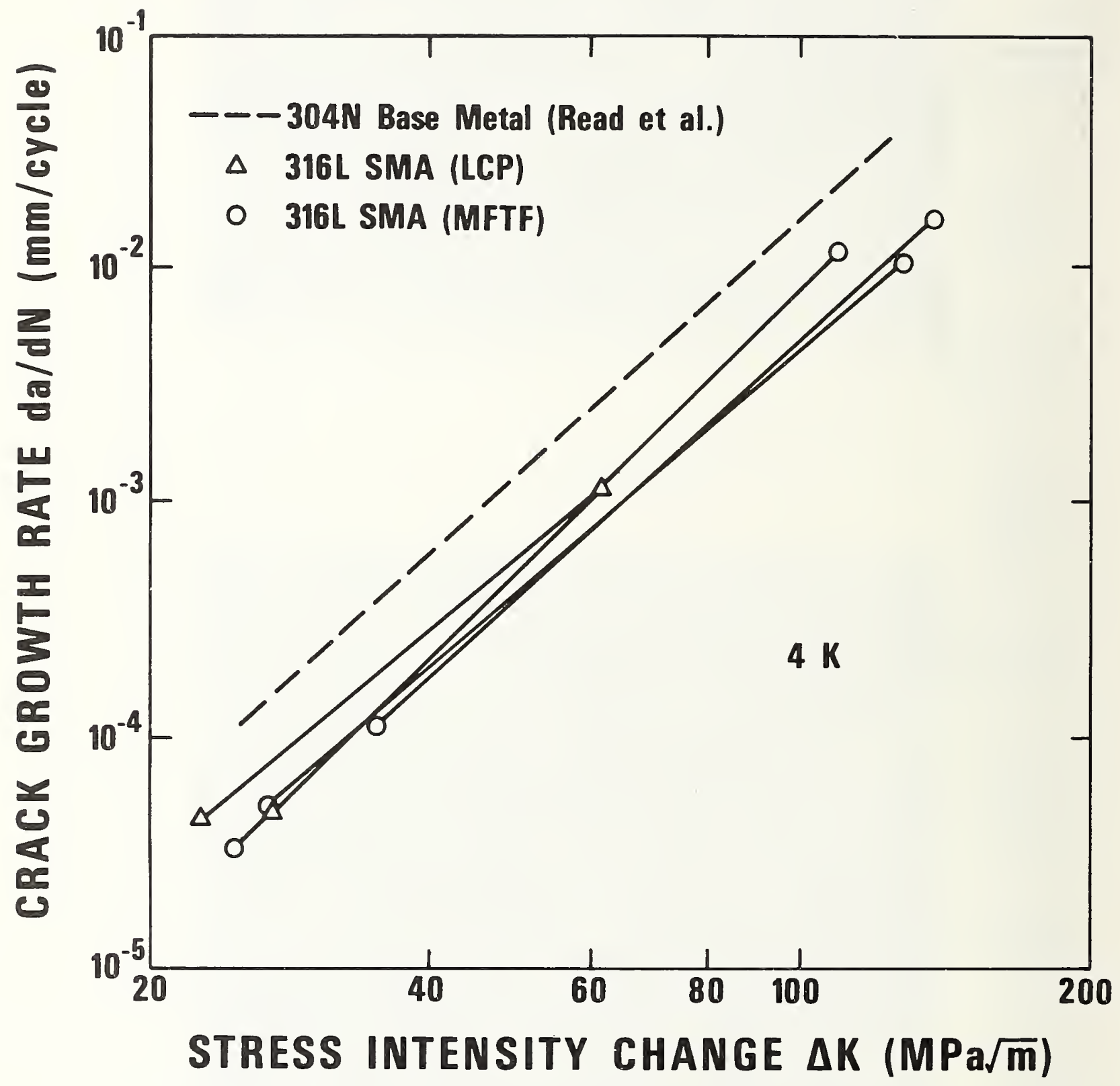

Fig. 8. The $4 \mathrm{~K}$ fatigue crack growth rate data for a11 $316 \mathrm{~L}$ SMA weldments tested, compared with $304 \mathrm{~N}$ base-metal data from Read and Reed [17]. 
WELD PROCESS STUDY FOR 316L STAINLESS STEEL

WELD METAL AT CRYOGENIC TEMPERATURES

Teledyne-lickay 

Weld Process Study for 316L Stainless Steel

Weld Metal at Cryogenic Temperatures

\author{
D.J. Kotecki \\ Taledyne - ilckay
}

Scope

In response to an inquiry from the National Bureau of Standards, Thermophysical Properties Division, Boulder, Colorado, Teledyne McKay proposed to produce a series of type $316 \mathrm{~L}$ stainless steel weldments. Six of these weldments were to be made in 1 -inch thick type $304 \mathrm{~L}$ base plate which would then be returned to NBS for their tests. In addition, under each of the same six welding conditions, all-weld-metal specimens and fissure bend specimens were to be prepared and tested at Teledyne Mckay.

The purpose of this program was to assess the effect of welding process choice and to a lesser extent welding parameters choice on cryogenic toughness of type $316 \mathrm{~L}$ weld metal at two nominal ferrite levels - approximately 5FN and approximately $0 \mathrm{FN}$.

This report describes the welding procedures used to produce the weldments for NBS evaluation and describes the procedures and test results of the all-weld-metal experiments at Teledyne McKay.

\title{
Filler Metals
}

Due to present steel mill melting practices, type $316 \mathrm{~L}$ bare wire is fairly easy to obtain with ferrite calculated by the DeLong diagram as about 5FN. But unless high nitrogen is acceptable, type $316 \mathrm{~L}$ bare wire calculated to have $0 \mathrm{FN}$ is rare. From work done previously at Teledyne McKay $(1,2)$, it is apparent that high nitrogen has a detrimental effect on cryogenic toughness. In order to begin with a low nitrogen wire of 0 FN calculated, tubular wire of special composition was produced for this work.

From the available inventory of type $316 \mathrm{~L}$ wire heats, a heat produced by Car Tech (ht. \#23847) was selected. The mill analysis of this heat was reported as follows:

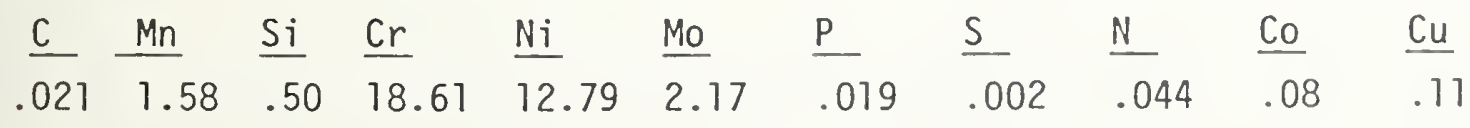

The calculated ferrite by the DeLong Diagram is $5.2 F N$ using the mill analysis. 
A tubular wire was produced aiming deliberately to exceed the 11.0-14.0 percent nickel range for type $316 \mathrm{~L}$ wire in AWS A5.9, so that 0 FN might be obtained. The aim wire composition was as follows:

$\begin{array}{lllllll}\mathrm{C} & \text { Mn } & \text { Si } & \underline{\mathrm{Cr}} & \underline{\mathrm{Ni}} & \text { Mo } & \underline{\mathrm{N}} \\ .02 & 2.3 & 0.4 & 18.5 & 15.5 & 2.3 & .02\end{array}$

The calculated ferrite by the DeLong Diagram for this composition would be 0.2FN. Approximately 220 lbs of this wire were produced. Samples were taken from four locations within this lot (1ot \#9230-497) approximately 60 lbs apart and GTA melts were prepared and checked for nickel, chromium and molybdenum homogeneity. Satisfactory homogeneity was indicated and the wire was accepted for use in the study.

\section{Sample Preparation}

Both the bare wire and the tubular wire were used at 3/32-inch diameter for all test welds.

For the welds in the 1 -inch $304 \mathrm{~L}$ plates to be tested at NBS, the basic joint preparation was a $90^{\circ}$ included angle double vee which was symmetrical about the plate midthickness. No root opening was used and, in the case of GTA welding, no land was used either. For GMA and SA welding, a land of $1 / 8-i n c h+1 / 16$ was used to prevent burn-through. The joints were fit up and restrained by welding each plate to a stainless steel bar at each end to prevent the root from opening ahead of the arc. After the first side of the joint was welded, the root was backgouged with the air-carbon arc process to sound metal, then lightly ground to remove dross from gouging before welding the second side. After completion of welding, the surfaces were ground smoothe, then radiographed. If a defect was found, it was removed by air-carbon arc gouging and repaired before shipping the weldment to NBS.

For the all-weld-metal studies of mechanical properties, all weld joints were in $3 / 4$-inch thick plate with a $45^{\circ}$ included angle single vee joint preparation, a $1 / 2$-inch root opening and a 3/8-inch backup bar. The plate and backup bar used were mild steel. The joint faces and the backup bar were covered by 2 layers of stainless weld metal from the wire under test by the welding process under test before assembling the joint preparation. (This method of producing an all-weldmetal joint is given in AWS A5.22-74. AWS A5.9-77 which applies to the wires under test has no joint preparation. For each wire and welding procedure, an a 11-weld-metal plate was made under the same conditions (except joint preparation) as for the 304L joints shipped to NBS. From each all-weld-metal joint, a longitudinal tensile specimen and 12 full-size Charpy vee notch specimens were machined according to the locations given in AWS A5.5-69. None of the specifications applying to stainless filler metals - A5.4, A5.9 or A5.22 - specifies Charpy vee notch specimens. 
For each wire and each welding procedure, a chemistry/ferrite pad was produced by building up 8 layers (1 pass per layer) of weld metal. The weld was water quenched after each pass except the last two passes. The next-to-last pass was allowed to air cool for 1 minute before quenching. The last pass was air cooled to room temperature. The top surface was then lightly draw-filed as recommended in AWS A5.4-78. Six readings along the weld centerline were taken with a MagneGage calibrated according to AWS A4.2-74 and averaged to obtain the FN of the sample. A light milling cut was then taken from the surface to obtain chips for nitrogen and oxygen analysis. The surface remaining was then lightly ground before running remaining chemical analysis with an emission spectrometer.

For each wire and each welding procedure, a fissure bend specimen was prepared. This consisted of 2 layers of weld beads deposited as stringer beads lengthwise on $3 / 8 \times 3 \times 10$-inch type 304 plate. The second layer consisted of 4 passes. After each pass, the specimen was air cooled to black heat, then water quenched. The specimen was restrained flat by welding it to a l-inch thick plate before beginning the stringer beads. After completion of welding, the top layer of stringer beads was surface ground, removing just enough metal to provide a clean surface at each of the three stringer bead interfaces where fissures are generally found. The ground surface was then examined using fluorescent dye penetrant and any indications in the center 4 inches of the length were counted. The specimen was then bent around a 1-1/2-inch diameter to a $120^{\circ}$ angle and again examined with fluorescent dye penetrant. The indications were counted in the center 4 inches as before. The fissure bend test used herein is basically as described by Lundin et al (3).

\section{Welding Procedures}

Three welding procedures were used with the $316 \mathrm{~L}$ bare wire. The first was a manual GTA procedure using 1/8-inch tungsten (2\% thoria) at 230-240 amps DCSP with argon shielding. Cold wire addition was made by feeding the wire through a hand-held GMA gun which did not supply current. The on-off switch on the gun provided a convenient means of adding filler at will without interrupting the welding to change filler wires as would be necessary with straight cut lengths of filler wire. For the 1-inch $304 \mathrm{~L}$ plate provided to NBS, no filler was used in the root pass only, and a total of 13 passes were used to complete the joint. Each layer of weld was a single pass except the top layers which were two passes each. For the all-weld-metal joint in 3/4-inch plate, filler was used for all passes. Fourteen passes, two per layer, were used to complete the joint. These weldments are labeled 9230-508-1.

The GMA procedure for the $316 \mathrm{~L}$ bare wire consisted of semi-automatic welding at 400 amps, 28-30 volts DCRP in 99\% Argon - 1\% oxygen gas at $40 \mathrm{cfh}$ with $3 / 4-$ inch electrode extension. The 1 -inch $304 \mathrm{~L}$ plate required 4 single-pass layers ( 2 per side) and 2 two-pass layers (1 per side) for a total of 8 passes. The a 11-weldmetal joint used a single-pass root, 4 two-pass layers and a single three pass layer for a total of 12 passes. These weldments are labeled 9230-508-2. 
The SA procedure for the $316 \mathrm{~L}$ bare wire consisted of machine welding at 300 amperes, 29 volts DCRP, 16 inches per minute travel, 1 inch electrical extension with Lincoln ST100 flux. For the 1 -inch $304 \mathrm{~L}$ plate, a single pass root and second layer on each side was followed by two two-pass layers and one three-pass layer for a total of 18 passes. For the 3/4-inch all-weld-metal plate a single pass root was followed by five 2-pass layers and a single 5-pass cover layer to a. total of 16 passes. These weldments are labeled 9230-508-3.

Three welding procedures were used with the modified $316 \mathrm{~L}$ tubular wire also. The first of these consisted of semi-automatic GMA welding at 400 amps, 28-30 volts DCRP in 99\% Argon - 1\% oxygen gas at 40 cfh with 3/4-inch electrode extension. The 1 -inch 304L plate required a single-pass root on each side and two 2-pass layers per side to complete for a total of 10 passes. The all-weld-metal plate required a single pass root, three 2-pass layers and one 3-pass layer for a total of 10 passes. These weldments are labeled 9230-497-5.

The second procedure with the tubular wire was machine SA welding at 300 amps, 29 volts DCRP, 16 inches per minute travel, l-inch electrical extension with Lincoln ST100 flux. The 1 -inch $304 \mathrm{~L}$ plate used a single-pass root on each side, one 2-pass layer on one side and two 2-pass layers on the second side, and one 3-pass layer on each side for a total of 14 passes. These weldments are labeled 9230-497-6.

The third procedure with the tubular wire was machine SA welding at 400 amps, 32 volts DCRP, 10 inches per minute travel, 1-inch electrical extension with Lincoln ST100 flux. The 1 -inch $304 \mathrm{~L}$ plate required a single pass root on each side, one single pass layer on one side and two single-pass layers on the other, and a two-pass layer at the top of each side for a total of nine passes. The all-weld-metal plate used a single pass root, three 2-pass layers and one 3-pass layer for a total of 10 passes. These weldments are labeled 9230-497-7.

For each 1 -inch 304L plate and for each all-weld-metal plate, a maximum interpass temperature of $300 \mathrm{~F}$ was employed.

\section{Results}

The radiographs of all of the 1 -inch $304 \mathrm{~L}$ plate weldments were free of defects except the high heat input SA weld with the tubular wire. This showed slag entrapment. The defect was removed by air-carbon arc gouging followed by light grinding to remove dross. A repair was then made by machine SA at the original welding conditions. Radiography confirmed that a sound repair was made. All of the 1 -inch $304 \mathrm{~L}$ plate weldments have been shipped to NBS for evaluation.

All-weld-metal deposit ferrite and chemical composition were obtained and are given in Table 1. In comparing the SA deposits to the GMA and GTA deposits, several composition changes will be noted. These are to be expected with the Lincoln $\mathrm{ST} 100 \mathrm{flux}$. There is about a $0.5 \%$ increase in $\mathrm{Mn}$ and $\mathrm{Si}$ with this flux and nearly a $1.0 \%$ increase in $\mathrm{Cr}$. An increase in phosphorus, oxygen and carbon is also apparent in the SA deposits. 
In comparing the tubular wire deposits with the bare wire deposits, it will be noted that the bare wire deposits are higher in several residual elements nitrogen, cobalt, vanadium and copper. On the other hand, the tubular wire deposits are higher in titanium. This is as expected. The melting of stainless steel heats in the steel mill involves use of scrap which introduces residual elements. On the other hand, the tubular wire contains a small deliberate addition of titanium for improved GMA operation.

It is worthy of comment that both the bare wire and tubular wire deposits contain appreciable variations in nickel from test to test - nearly a $1 \%$ difference between high and low values in both cases. These differences are not due to interactions with the SA flux. Their origin is unexplained.

The measured FN values for the bare wire deposits are higher than for the corresponding tubular deposits (GMA and SA). The FN values calculated using the DeLong diagram do not in all cases agree well with the measured FN values. The gain in $\mathrm{Si}$ and $\mathrm{Cr}$ with $\mathrm{SA}$ welding is not offset by gains in $\mathrm{C}$ and $\mathrm{Mn}$, so that FN's in SA welds tend to run higher than in GTA or GMA welds.

The fissure bend test results are given in Table 2. Despite the low FN values measured on some of the welds, the fissure counts in all cases are quite low. All of the fissures noted are along and perpendicular to the interface between two weld passes in the weld metal which is reheated by a subsequent weld pass.

The all-weld-metal tensile and impact values obtained are given in Table 3 . The room temperature tensile and yield strengths for the bare wire run appreciably higher than for the tubular wire. This is presumably due to the higher ferrite and nitrogen of the bare wire deposits.

The Charpy vee notch impact results show, for the wires tested, significantly better toughness for the GMA deposits than for GTA or SA deposits. The better results for GMA than for GTA seem to agree with our internal observation in stainless covered electrodes that larger diameter rods (bigger beads) give better toughness at cryogenic temperatures than smaller diameter rods (smaller beads). Note also that high heat input SA does better than normal SA with the tubular wire. It is not clear why SA should do noticeably poorer in cryogenic toughness than the other processes - higher silicon and oxygen as shown in Table 1 may be part of the problem with SA. However, other tests we have run with fully austenitic weld metal of $16 \mathrm{Cr}-16 \mathrm{Ni}-2 \mathrm{Mo}$ have shown equal toughness ( $30 \mathrm{mils}$ lateral expansion at -320F) for SA and GMA deposits. It should be noted that, while the high heat input SA weld did fairly well in toughness, the welder who made these weldments felt this was not a good way to weld - it is too easy to trap slag because the bead is so large it tends to roll over on the edges.

Based on our tests with covered electrodes as reported in References 1 and 2 , better toughness would have been expected with the low FN, low nitrogen tubular 
wire than with the bare wire for the same welding process. This is certainly not true for the GMA and SA welds tested herein. Since the oxygen and silicon are virtually identical for GMA and normal heat input SA welds with the two wires, the only available explanation for this behavior would seem to involve residual titanium in the tubular wire deposits or lack of other residual elements.

The final evaluation of the test weldments must await the fracture toughness data to be developed at NBS on the 1 -inch type 304L plates.

\section{References}

1. E. R. Szumachowski and H. F. Reid, "Cryogenic Toughness of SMA Austenitic Stainless Steel Weld Metals: Part 1 - Role of Ferrite", Welding Journal, V57, N11 (November, 1978), pp 325s-333s.

2. E. R. Szumachowski and H. F. Reid, "Cryogenic Toughness of SMA Austenitic Stainless Steel Weld Metals: Part 2 - Role of Nitrogen, "Welding Journal, V58, N2 (February, 1979), pp. 34s-44s.

3. C. D. Lundin, W. T. DeLong and D. F. Spond, "Ferrite-Fissuring Relationship in Austenitic Stainless Steel Weld Metals", Welding Journal, V54, N8 (August, 1975), pp. $241 \mathrm{~s}-246 \mathrm{~s}$. 
Table 1 All-Weld Metal Composition and Ferrite

316L Bare

\begin{tabular}{|c|c|c|c|c|c|}
\hline & & & & & \\
\hline $\begin{array}{c}\text { GTA } \\
9230-508-1\end{array}$ & $\begin{array}{c}\text { GMA } \\
9230-508-2\end{array}$ & $\begin{array}{c}\text { SA } \\
9230-508-3 \\
\end{array}$ & $\begin{array}{c}\text { GMA } \\
9230-497-5 \\
\end{array}$ & $\begin{array}{c}S A \\
9230-497-6 \\
\end{array}$ & $\begin{array}{l}\text { SA high input } \\
\text { input } \\
9230-497-7\end{array}$ \\
\hline .017 & .017 & .023 & .014 & .016 & .017 \\
\hline 1.39 & 1.40 & 1.97 & 2.17 & 2.50 & 2.43 \\
\hline .45 & .47 & .84 & .46 & 1.03 & .84 \\
\hline 18.02 & 17.95 & 18.95 & 18.68 & 19.61 & 19.07 \\
\hline 11.89 & 11.76 & 12.75 & 15.15 & 15.32 & 14.59 \\
\hline 2.12 & 2.12 & 2.08 & 2.31 & 2.21 & 2.22 \\
\hline .003 & .003 & .005 & .013 & 11.01 & 1 010 \\
\hline .020 & .020 & .031 & .010 & .021 & .021 \\
\hline .069 & .069 & .065 & .030 & .016 & .018 \\
\hline .053 & .066 & .110 & .072 & .106 & .087 \\
\hline .092 & .090 & .095 & .012 & .025 & .020 \\
\hline .063 & .063 & .06 & .013 & .017 & .016 \\
\hline .02 & .02 & .02 & .02 & .02 & .02 \\
\hline .021 & .022 & .024 & .15 & .092 & .104 \\
\hline .089 & .086 & .10 & .037 & .043 & .042 \\
\hline 1.5 & 3.0 & 7.4 & 0.9 & 2.2 & 1.8 \\
\hline 4.4 & 4.7 & 5.7 & 0.8 & 6.8 & 5.2 \\
\hline
\end{tabular}

Table 2 Fissure Bend Test Results

316L Bare

\section{GTA \\ GMA}

Fissure Size

Before Bending point

up to $1 / 16^{\prime \prime}$

$1 / 16-1 / 8^{\prime \prime}$

over $1 / 8^{\prime \prime}$
9230-508-1 9230-508-2

9230-508-3

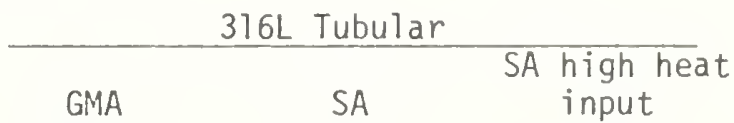

\section{After Bending}

point
up to $1 / 16^{\prime \prime}$
$1 / 16-1 / 8^{\prime \prime}$
over $1 / 8^{\prime \prime}$

$\begin{array}{ll}0 & 0 \\ 0 & 0 \\ 0 & 0 \\ 0 & 0\end{array}$

7
0
0
0

$\underline{9230-497-5}$

9230-497-6 9230-497-7

over $1 / 8^{\prime \prime}$

0
0
0
0

$\begin{array}{ll}0 & 1 \\ 0 & 6 \\ 0 & 0 \\ 0 & 0\end{array}$

$\begin{array}{ll}0 & 0 \\ 0 & 0 \\ 0 & 0 \\ 0 & 0\end{array}$


Table 3 Tensile and Impact Test Results

Tensile

Strength, ksi

316L Bare

316L Tubular

\section{\begin{tabular}{ccc} 
GTA & GMA & SA \\
$9230-508-1$ & $9230-508-2$ & $9230-508-3$ \\
\hline
\end{tabular}}

\begin{tabular}{ccl} 
& $316 L$ Tubular & \\
\hline GMA & SA high \\
$9230-497-5$ & SA heat input \\
\hline
\end{tabular}

Yield

Strength, ks i

87.31

80.34

85.14

72.97

78.57

80.53

$\%$ Elongation

62.40

52.04

63.92

48.06

56.08

46.67

$\%$ Reduction in Area 54.6

45

54.9

36

30

32

34

33.6

41.2

37.8

Charpy vee notch

ft-lbs (mils)

o- 150

$78.8(38)$

$73.8(29)$

$83.9(43)$

$36.9(15)$

$36.2(19)$

$\frac{91.8(54)}{84.4(46)}$

$\frac{34.7}{35.9}\left(\frac{14)}{16)}\right.$

$39.0(40)$

$19.5(10)$

$41.2(24)$

$\frac{73.8(43)}{75.5(36)}$

$\frac{40.5}{42.9(36)}$

$18.1(15)$

$32.5(24)$

avg.

$57.1 \quad(39)$

$73.8(45)$

$89.7(57)$

31.1 (14)

$34.0 \quad(28)$

$\frac{14.5(10)}{17.4(12)}$

$\frac{26.0(15)}{33.2(27)}$

c-200 $\frac{65.1}{65.3}\left(\frac{34)}{39)}\right.$

$70.1(40)$

32.5 (18)

$32.5(22)$

$\frac{81.0(43)}{80.3(47)}$

$\frac{32.5(16)}{32.0(16)}$

$13.7(7)$

28.2 (19)

avg.

54.2 (27)

$70.9(44)$

27.5 (11)

$\frac{37.6}{34.7}(32)$

13.7 ( 7)

$28.2(24)$

$\frac{33.3(21)}{29.2(21)}$

e-250F

$62.9(27)$

$60.7(30)$

25.3 (10)

23.9 (14)

\begin{tabular}{l}
$14.5(8)$ \\
\hline $14.0(7)$
\end{tabular}

avg.

$\frac{49.2(28)}{55.4(27)}$

$\frac{72.3}{68.0}\left(\frac{44)}{39}\right)$

$\frac{28.2(11)}{27.0(11)}$

33.3 (18)

$13.0(6)$

27.5 (16)

$\frac{29.6(20)}{28.9(17)}$

$13.7(7)$

23.1 (11)

$\frac{13.7}{13.5}\left(\frac{7)}{7)}\right.$

$\frac{23.1}{24.6}(14)$

co-320F

41.2 (12)

52.7 (26)

$21.0(2)$

25.3 (18)

$11.6(1)$

31.8 (17)

47.7 (24)

$62.2(31)$

$21.0(2)$

$20.2(15)$

$\frac{39.8(18)}{42.9(18)}$

$\frac{61.5(39)}{58.6(32)}$

$\frac{23.9(17)}{23.1(17)}$

10.7 (3)

31.1 (15)

$\frac{13.7(5)}{11.8(3)}$

$\frac{23.7(12)}{28.7(15)}$ 
THE COMPUTER-AIDED J-INTEGRAL TEST FACILITY AT NBS

National Bureau of Standards 
THE COHPUTER-AIDED J-INTEGRAL TEST FACILITY AT NBS

D. T. Read

ABSTRACT

The computer-aided J-integral testing facility that has been implemented at NBS-Boulder over the past year is described briefly.

INTRODUCTION

Acceptance of the parameter $J_{\text {Ic }}$ as a measure of the fracture resistance of metals has become widèspread in recent years. A large volume of J-integral fracture toughness data on a variety of candidate materials for low temperature applications has been accumulated. J-integral testing has the advantage of being applicable to smaller specimens (up to 100 times smaller) and tougher materials then the plane strain fracture test ( $K_{I c}$ test). A disadvantage of the J-integral technique has been its experimental difficulty. Previous versions of this test have required approximately five specimens and lengthy data reduction procedures [1]. Recently developed single-specimen J-integral test techniques [2] have eliminated the multiple specimen requirement, but the data reduction procedure was still lengthy. In the computer-aided J-integral test, most of the data-reduction procedure is automated; the apparatus produces a plot of J-integral value against crack extension from which $J_{\text {Ic }}$ can be quickly and simply extracted.

\section{THE J IC MEASUREMENT PROBLEM}

The measurement problem in $J_{I c}$ testing is to obtain the required plot of J-integral (J) versus crack extension ( $\Delta a)$ (Fig. 1) from the measured quantities, which are the load ( $P$ ) on the specimen and the relative displacement $(\delta)$ of two measurement points located on the specimen load line on opposite sides of the notch. The $J$ value is proportional to the area under the ( $p, \delta)$ curve (Fig. 2), and can be 
easily determined for any point along the curve. The shaded area in Fig. 2 is proportional to $\mathrm{J}$ at the point labeled "a." The principle used to measure $\Delta \mathrm{a}$ is that the crack length, a, is related to the slope of the specimen's $(P, \&)$ curve for elastic conditions through the known specimen compliance function $[3]$. The $\Delta$ a measurement procedure is to partially (about 10\%) unload the specimen while recording load and displacement changes (Figs. 2 and 3). Subsequent unloadings at increasing crack extension values result in increased compliance. The crack extension at a given unloading is the difference between the crack length measured in that unloading minus the initial crack length, measured by an unloading carried out before crack extension.

\section{EQUIPMENT AND PROCEDURE}

The loading apparatus used for computer-aided J-integral testing was described previously by Fowlkes and Tobler [4]. The loading is controlled in conventional fashion by the operator. The computer is used only in data acquisition and reduction. An analog ramp generator controlled by the operator applies a smoothly varying signal to the test machine control circuitry to allow unloading-reloading cycles as necessary. The additional equipment needed for computer-aided testing includes a multichannel analog-digital conversion system, the computer itself, a CRT terminal, a dual floppy disk data storage unit, and a digital plotter (Fig. 4).

Two signals are used to direct the operation of the data acquisition system. One is derived from the output of the ramp generator by which the operator initiates the unloading-reloading cycle. When the ramp generator is activated, a signal transmitted to the processor commands it to begin to acquire and store load and displacement change data during the unloading-reloading cycle. Data are stored until the load again reaches the value it had before the unloading. The test continues 
through as many unloading cycles as desired until the operator activates the quit signal, which directs the processor to await the operator's command (entered at the CRT terminal) to stop the data acquisition procedure and terminate the test.

The computer-aided J-integral test facility at NBS is similar to that described by Joyce and Gudas [3]. The differences are in the specific types of equipment used and in the real-time outputs. "Real time" is used here to mean "during the course of the test," as opposed to after the test is completed.

The procedure for extracting $\mathrm{J}$ and $\Delta \mathrm{a}$ from the directly measured load and displacement on a deeply notched compact tensile specimen is as follows

The electrical signals from the load cell and displacement gage are amplified by the electronics supplied with the closed-loop servo-hydraulic apparatus used for the test. A plot of load against displacement similar to Fig. 2 is produced by an $x-y$ plotter throughout the course of the test. Either signal may be displayed on a digital readout. The plot and readout are used by the operator to monitor the progress of the test.

The amplified load and displacement signals are also introduced into an analog-to-digital conversion system to permit calculation of $\mathrm{J}$ and $\Delta$ a. At this point, the overall levels of the signals range between 0 and $10 \mathrm{~V}$. These signals are converted to digital form with a resolution of 16 bits; the least significant bit represents about $0.3 \mathrm{mV}$. The overall load and displacement values are used for calculating the instantaneous J value, which is proportional to the area under the load-displacement curve. Stored overall-displacement points are separated by $2.5 \times 10^{-3} \mathrm{~mm}$. Smaller observed overall-displacement increments are not stored. Computations of the instantaneous $J$ value are made when the overall displacement 
has increased sufficiently from the previously stored value.

During the incremental unloading required to measure $\Delta \mathrm{a}$, displacement changes of the order of $0.05 \mathrm{~mm}$ and load changes of the order of $5 \mathrm{kN}$ must be correlated accurately. These changes correspond to a change in the overall displacement signal of about $70 \mathrm{mV}$ and a change in the load signal of about $1 \mathrm{~V}$ : Because the analog-to-digital converter used has only 16-bit resolution, the displacement signal cannot be converted directly to digital form with precision sufficient for accurate measurement of this displacement change. The measurement of the small displacement changes which occur during the unloading-reloading cycles is facilitated by regarding the overall displacement as consisting of small changing displacements superimposed on a large reference displacement value. The measurement is accomplished by cancelling out the reference part, then converting the small displacement changes to digital form with high resolution. To achieve this cancellation, the overall displacement is converted to digital form at the beginning of each unloading-reloading cycle. This initial value is treated as the reference part.

To cancel out this reference part of the displacement signal, a digitalto-analog converter with 14-bit resolution is used to apply a voltage equivalent to the reference part of the displacement signal to one terminal of a differential high-sensitivity analog-to-digital conversion channel. The overall displacement signal is applied to the other input terminal of this channel. This results in the analog-to-digital conversion of a voltage equal to the difference between the instantaneous value of the displacement signal and its value at the beginning of the unloading. This difference signal is the required change-of-displacement signal and is converted to digital form with 16 bit resolution of its $80 \mathrm{mV}$ range. The least significant bit represents about $2.5 \mu \mathrm{V}$, which is quite sufficient. The load change signal is produced in a similar 
sianner using another digital-to-analog converted signal and converted to digital form with 16-bit resolution at the $1.25-\mathrm{V}$ level. Here the least-significant bit represents about $40 \mu \mathrm{V}$, which is again quite sufficient.

Approximately 80 load-change and displacement-change data points are obtained for each unloading-reloading cycle over a 30 s period. These data are plotted during the unloading-reloading cycle using a digital plotter, forming a plot like Fig. 3. From this plot, the presence of excessive noise or other improper behavior in the signals can be easily observed. The load-change and displacement-change data are correlated using a least-squares fit. From the resulting slope, the instantaneous crack length is calculated using the known expression for the compliance of the specimen.

Each $(\mathrm{J}, \Delta \mathrm{a})$ datum is plotted by the digital plotter as soon as it is available, forming a plot similar to Fig. 1. This plot allows convenient monitoring of the progress and quality of the test in real time. The values are also displayed on a CRT terminal for transcription. This step will be replaced by an automatic print-out when facilities become available. The least-squares-fit and data output procedure takes about twelve seconds.

The record of the completed test consists of the $(J, \Delta \mathrm{a}),(P, \delta)$, and $(\Delta P, \Delta \delta)$ plots, the transcribed $(J, \Delta a)$ data, and three files stored on a floppy disk during the test, one containing the $(\mathrm{J}, \Delta \mathrm{a})$ values and a few other key data, one containing all the $(P, \delta)$ data, and one containing a 11 the $(\Delta P, \Delta \delta)$ data.

\section{CONCLUDING COMMENTS}

This system has been in use for six months and has proved quite satisfactory. In comparison with the multiple-specimen and noncomputeraided single-specimen techniques previously used, it has eliminated 
about $4 \mathrm{~h}$ of data reduction per test, and has provided a real-time readout of the test progress and quality. The cost of the complete data-acquisition system, including analog-to-digital converters, processor, digital plotter, and CRT terminal, was about $\$ 25,000$.

\section{REFERENCES}

1. J. D. Landes and J. A. Begley, "Test Results form J-Integral Studies: An Attempt to Establish a J Ic Testing Procedure," in Fracture Analysis, ASTM STP 560, American Society for Testing and Materials, Philadelphia, PA (1974), pp. 170-186.

2. G. A. Clarke, W. R. Andrews, P. C. Paris, and D. W. Schmidt, "Single Specimen Tests for J Ic Determination," in Mechanics of Crack Growth, ASTM STP 590, American Society for Testing and Materia1s, Philadelphia, PA (1976), pp. 27-42.

3. J. A. Joyce and J. P. Gudas, "Computer Interactive J Ic Testing of Navy Alloys," in Elastic-Plastic Fracture, ASTM STP 590, American Society for Testing and Materials, Philadelphia, PA (1979), pp. 451-468.

4. C.W. Fowlkes and R. L. Tobler, "Fracture Testing and Results for a Ti-6Al-4V Alloy at Liquid Helium Temperature," Eng. Fract. Mech. 8 (1976), pp. 487-500. 


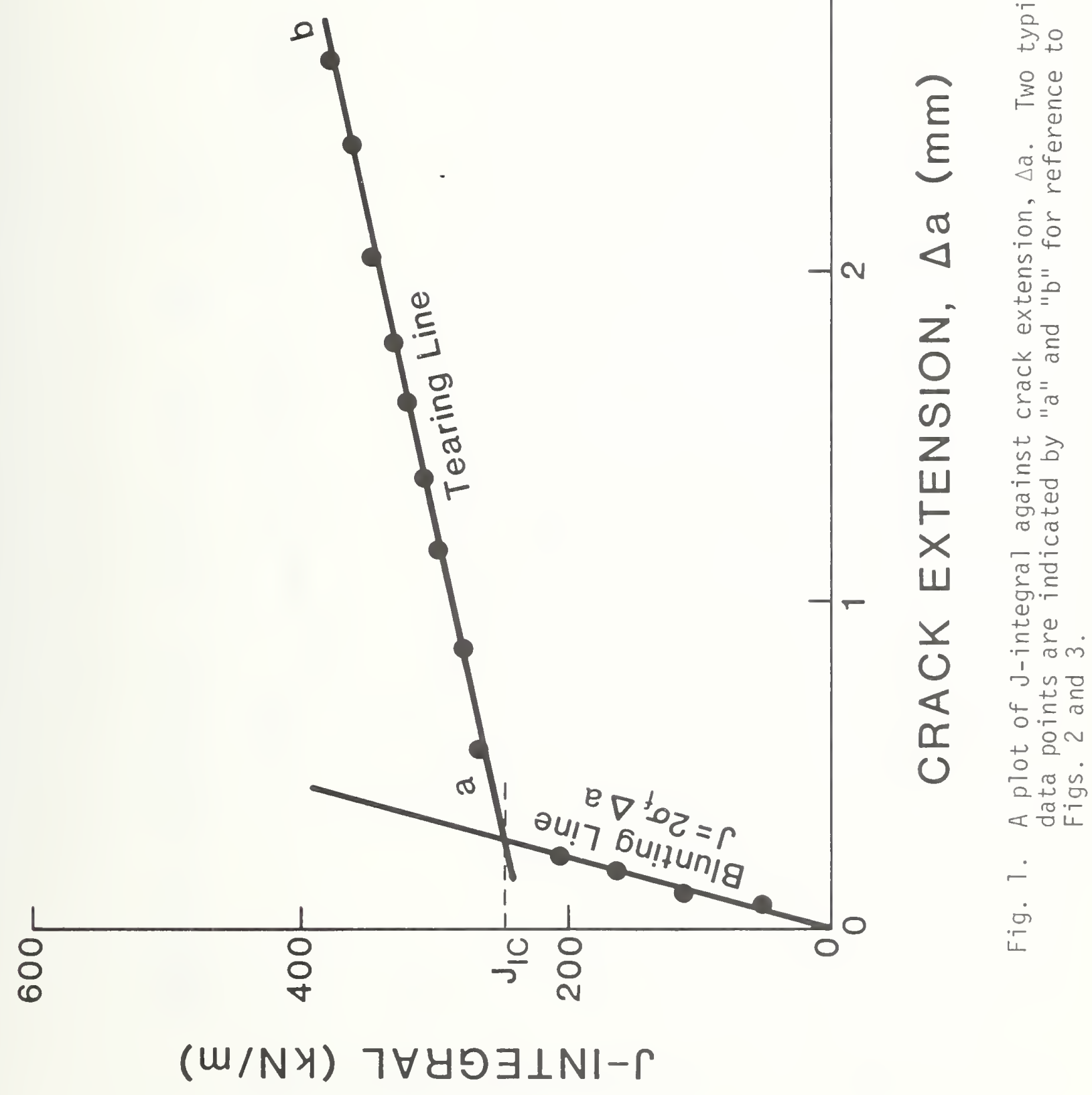




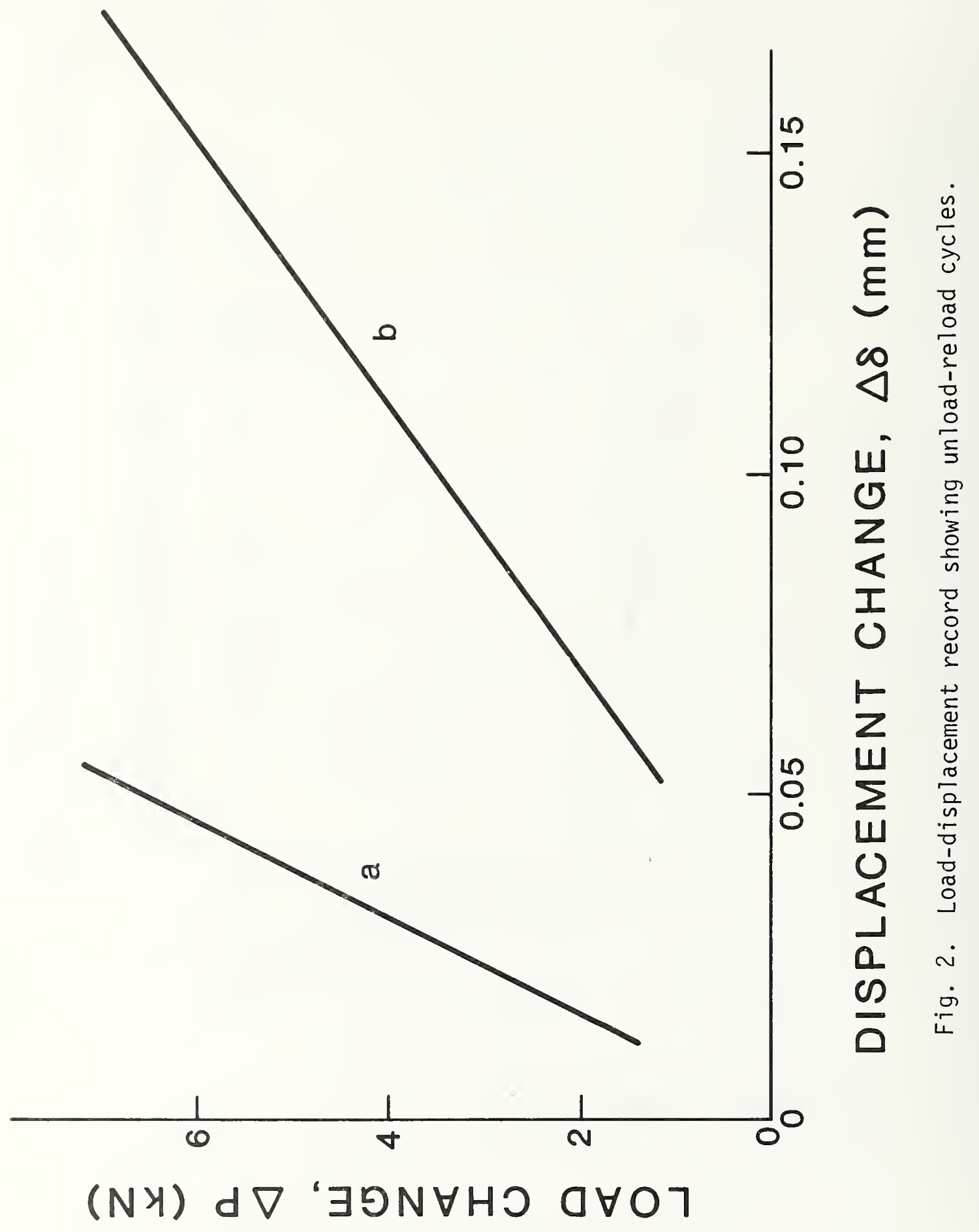




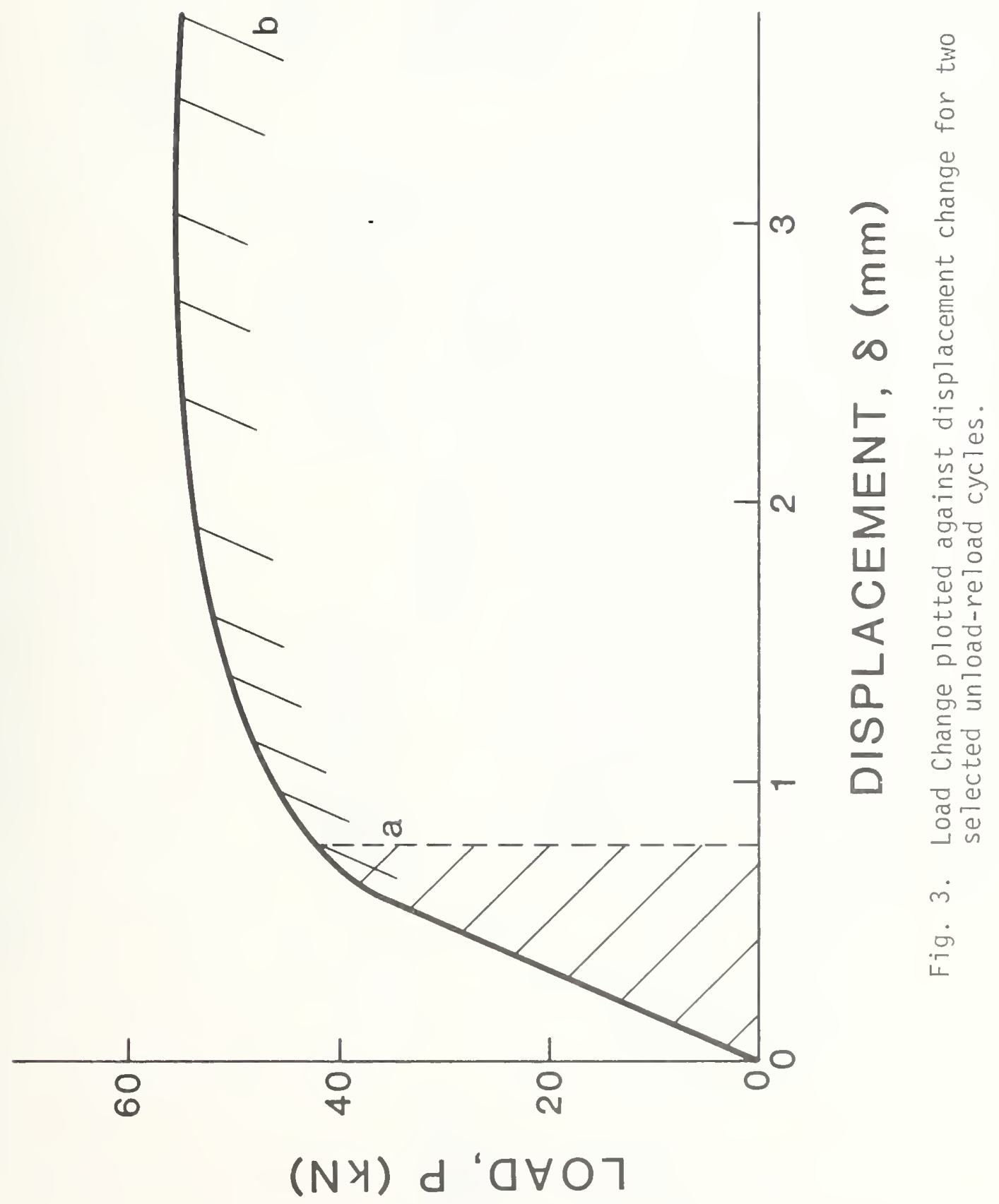




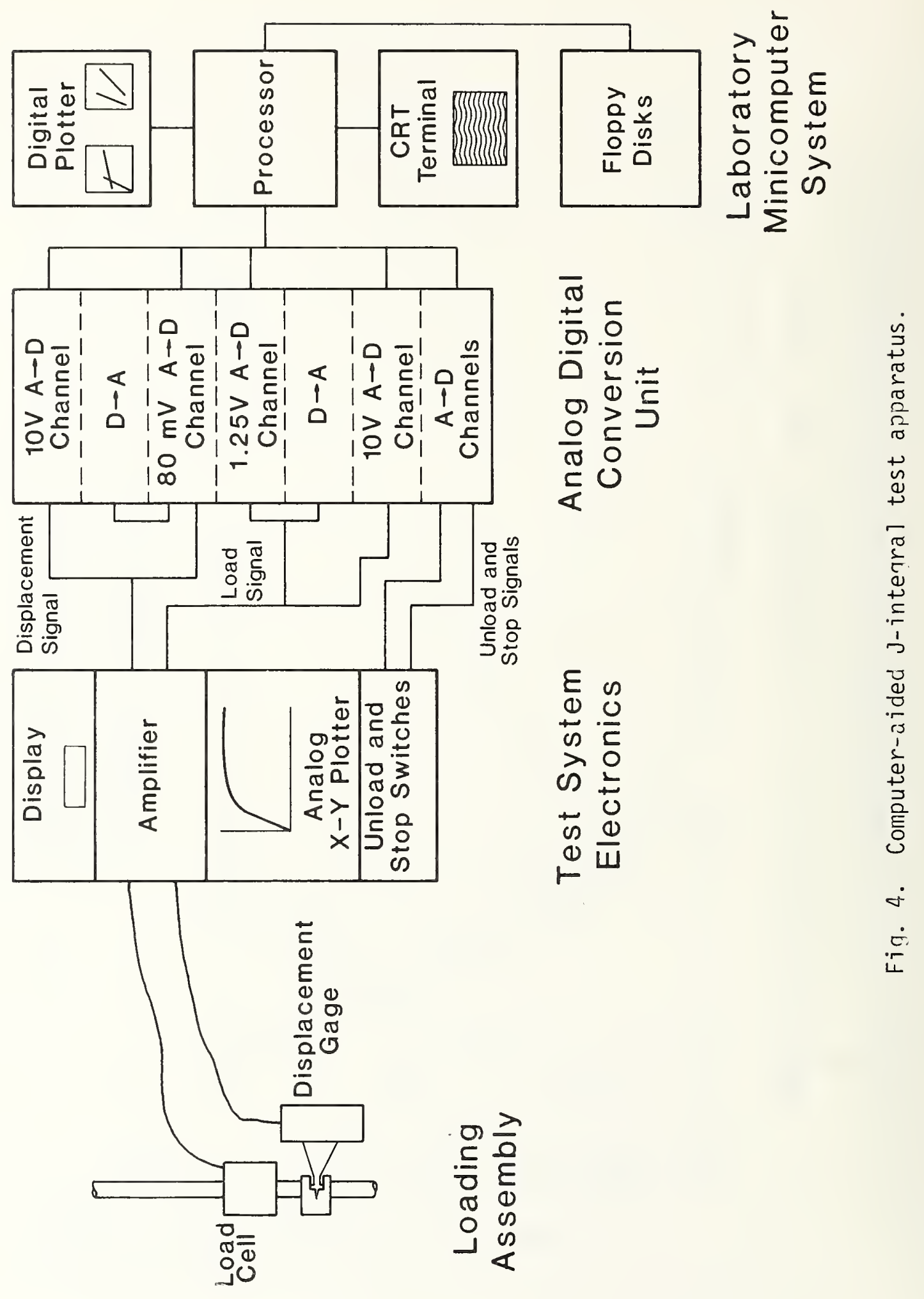




\section{TENSILE AND NOTCH-TENSILE PROPERTIES \\ AT ROOM TEMPERATURE AND $4 \mathrm{~K}$ \\ OF WELDS IN ALUMINUM ALLOY 5083-0 PLATE}

ALCOA 

TENSILE AND NOTCH-TENSILE PROPERTIES

AT ROOM TEMPERATURE AND 4K

OF WELDS IN ALUMINUM ALLOY 5083-0 PLATE

\author{
R. A. Kelsey \\ L. N. Mueller \\ ENGINEERING PROPERTIES AND DESIGN DIVISION \\ ALCOA LABORATORIES \\ ALCOA. CENTER, PA 15069
}




\section{ABSTRACT}

Tensile and notch-tensile data at room temperature and $4 \mathrm{~K}$ were obtained for butt welds in $51 \mathrm{~mm}$ thick 5083-0 plates donated by five companies. The welds were made by the conventional gas-metal arc welding (GMAW) process and by a high desposition rate GMAW process.

The investigation shows that the data are fairly consistent for welds made by the various companies, despite the fact that there were considerable variations in welding procedures.

The strengths of the the welds are appreciably higher at $4 \mathrm{~K}$ than at room temperature. Notch yield ratios, which are an indication of fracture toughness, are quite high, indicating that the welds are very tough. 
A ruminum alloy base metals and weldments have excellent properties at low temperature and therefore have been widely used in cryogenic structures [1]: . The principal application in recent years has been in the use of alloy 5083-0 in the construction of welded $35 \mathrm{~m}$ diameter spheres for the shipboard transportation of liquefied natural gas [2-5]. These spheres are made by joining together segments in plate thicknesses ranging from 51 to $203 \mathrm{~mm}$. As a result of these applications considerable tensile, fracture toughness, and fatigue data have been obtained on base metal and welds in 5083-0 plate at temperatures down to $77 \mathrm{~K}$ [6-25]. However, relatively little data has been obtained on 5083 base metal at $4 K[7,11,23]$ and the only data available on the properties of welds in 5083 at $4 \mathrm{~K}$ is some work done at Alcoa Laboratories about ten years ago [12].

The program reported herein was sponsored by National Bureau of Standards and carried out at Alcoa Laborätories to obtain additional data on tensile ind toughness properties of welds in 5083-0 plate at $4 \mathrm{~K}$.

The program had the following objectives:

1. Develop tensile and notch-tensile data on welds in 5083-0 at $4 \mathrm{~K}$ and compore with room temperature data;

2. Compare the tensile and notch-tensile properties of welds made by different companies;

3. Compare the tensile and notch-tensile properties of welds made by the conventional gas-metal arc welding (GMAW) process with those made by the high deposition rate (HDR) GMAW process.

This report also ₹ummarizes some previously published data on tensile properties of base metal and welds in aluminum alloys 2219 and 7039 at $4 \mathrm{~K}[11,12,26]$. These alloys, in addition to having adequate toughness, have significantly higher yield and tensile strength than 5083.

\section{I1. MAEERIARS}

Welded panels of aluminum alloy 5083-0 plate for this program were donated by the following companies:

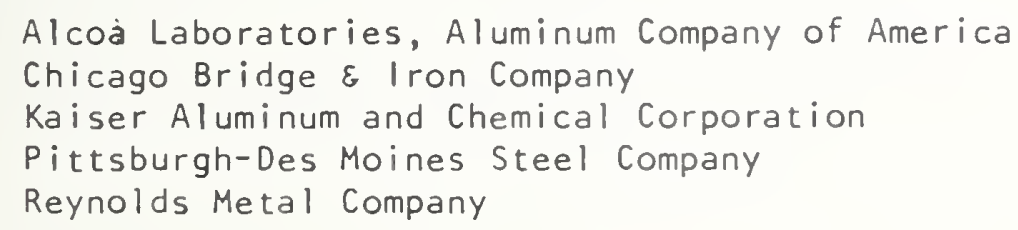

Each company was asked to donate two panels in $51 \mathrm{~mm}$ thick 5083-0 plate welded by the GMAW process using either 5556 or 5183 electrode, with each panel welded by a different welder. Alcoa and Kaiser also each donated two panels welded by a high deposition rate GMAW process using 5183 electrode, again using a different welder for each panel.

* Numbers in brackets refer to references 1 isted at end of text. 
Figure 1 shows that the room temperature tensile properties of the alloy 5083-0 plates furnished by the five suppliers exceeded the guaranteed minimum values.

\section{WELDING PROCEDURES}

The selection of welding procedures was left up to the various companies. They were merely requested to weld $51 \mathrm{~mm}$ thick $5083-0$ plate in the flat position by the GMAW process using a double-vee butt joint and either 5183 or 5556 electrode. It was specified that all panels should meet ASME radiographic quality standards.

Table I summarizes the welding procedures used by the various companies. These data show that there was considerable variation among the six suppliers. The number of passes used to complete the weids made by the conventional GMAW process ranged from 16 to 55, two companies used 3/32-in. diameter electrode; the others used 1/16-in. diameter. Voltages ranged from 24 to 34 volts and current ranged from 230 to 390 amps. One company used pure argon shielding gas, the others used a mixture of argon and helium, in various proportions. Interpass temperatures ranged from $150^{\circ} \mathrm{F}$ to $500^{\circ} \mathrm{F}$. Welds were made automatically or semi-automatically; none were made manually. In the case of the high deposition rate welds, one company made the weld in four passes, using 1/8-in. diameter electrode, 580 amps current and 34 volts; the other company used two passes, 3/16-in, diameter electrode, 740 amps current, and 33 volts.

IV. TEST PROCEDURES

The tests at $4 \mathrm{~K}$ were made in liquid helium in a cryostat described previously [11].

Two types of tensile specimens were used to measure the cross-weld tensile properties: room temperature and $4 \mathrm{~K}$ tests were made using $12 \mathrm{~mm}$ diameter specimens while room temperature tests were also made using full-section retangular specimens (Fig. 2). The $12 \mathrm{~mm}$ diameter specimens were located at the mid-depth of the weld and had a $102 \mathrm{~mm}$ long uniform diameter test section, which encompassed the root of the weld and the adjacent heataffected zone in the base metal on either side of the weld. Thus, fracture occurred in the weakest region. The full-section tensile specimens were 25 $\mathrm{mm}$ wide and were tested with the weld reinforcement intact. The weld joint was located at the mid-length of the $279 \mathrm{~mm}$ long test section. Yield strength and elongation values at room temperature were based on deformation measurements made over a $51 \mathrm{~mm}$ gage length for the $12 \mathrm{~mm}$ diameter specimen and over à $254 \mathrm{~mm}$ gage length for the full-section specimen. In the tests at $4 \mathrm{~K}$ yield strength was determined from load-head motion curves.

Cross-weld notch-tension specimens (Fig:3) were tested at room temperature and 4K. The notch-tension test has been used for a number of years to evaluate the relative notch toughness of various metals [27,28], including aluminum alloys $[29,30]$, but there are size limitations and conplications with such things as fatigue precracking that make it less attractive than other available procedures for measuring fracture toughness $\left(K_{1}\right)[31]$. However, it has been demonstrated that there is reasonably good correlation between the notch-yield ratio (NYR)* and $K$ to warrant the acceptance of the notch-tension test as a quality control screening of fracture toughness [32].

NYR $=\frac{\text { Notch-tensile strength }}{\text { Tensile yield strength }}$ 
The ASTM Tentative Method for Sharp-Notch Tension Testing of Cylindrical Specimens (E602-76T) specifies two specimen diameters, namely 12 and $27 \mathrm{~mm}$. In extremely tough materials, such as base metal and welds in alloy 5083-0, the NYR relationship may suffer loss of sensitivity to $K_{I}$ because of general yielding (on the cross-section containing the notch) prior to fracture. For this reason, the larger diameter specimen $(27 \mathrm{~mm})$ was used in this investigation to reduce net section yielding and thus make the test results more discriminating, in terms of toughness indices.

\section{RESULTS AND DISCUSSION}

The main purpose of this investigation was to evaluate the effect of supplier (welder), welding process, and test temperature on tensile and notch-tensile properties obtained from specimens taken across the root of the weld. Obviously, data obtained in this mannei can only be considered to provide a relative measure of weld joint performance since the results may be affected by metallurgical structure and physisal or metallurgical discontinuities unique to the root region. Therefore, to obtain a more representative evaluation of overall (or average) joint performance, room temperature tensile tests were made of full-section specimens (Fig. 2). Analysis of tensile properties obtained from the full-section specimens (Table 2 and Fig. 4) shows that at the 95 percent confidence level there is no significant difference in the room temperature tensile properties between welds made by the five suppliers or between conventional GMA welds and high deposition rate GMA welds made by Suppliers 4 and 5. The yield strengths range from 152 to $176 \mathrm{MPa}$, with a mean value of $161 \mathrm{MPa}$. Tensile strengths range from 273 to $355 \mathrm{MPa}$, with a mean value of $314 \mathrm{MPa}$. The minimum tensile strength specified by the ASME Boiler and Pressure Vessel Code for butt welds in $51 \mathrm{~mm} 5083-0$ plate is $269 \mathrm{MPa}$. Elongations based on a $10^{\prime \prime}$ in. gage length range from 7.7 to 18.6 percent, with a mean value of 12.9 percent

\section{CONVENTIONAL GMA WELDS}

The results of tests of the tensile and notch-tensile specimens taken form the mid-depth of the weld were evaluated by analysis of variance at the 95 percent confidence level.

Important statistically significant trends of data for the conventional GMA welds, Table 3, Figs. 5-8, may be summarized as follows:

1. Supplier has a slight effect and temperature a relatively greater effect on yield strength. The mean yield strength at $4 \mathrm{~K}(201 \mathrm{MPa})$ is 23 percent higher than that at room temperature.

2. Supplier has a slight effect and temperature a relatively greater effect tensile strength. The mean tensile strength at $4 \mathrm{~K}(412 \mathrm{MPa})$ is 44 percent higher than that at room temperature. The variability of the data is greater at $4 \mathrm{~K}$ than at room temperature.

3. Supplier and temperaturehave a slight effect on NYR. The mean value at $4 \mathrm{~K}$ (1.80) is 8 percent lower than that at room temperature. Note that although both yield strength and notch-tensile strength increase with decreasing temperature, the percent increase in yield strength is greater and therefore the net effect is that NYR decreases with decreasing temperature. The NYR values obtained for these welds are indicative of a very tough material. By way of comparason, high toughness aluminum alloys used in aircraft structures have NYR's of 1.5 or less. 
Important statistically significant trends based on a comparison of conventional GMA welds and high deposition rate GMA welds from Suppliers 4 and 5, Table 4 and Figs. 9-12, may be summarized as follows:

1. Supplier has a slight effect and temperature a relatively greater effect on yield strength of HDR welds. At room temperature, the HDR welds have lower yield strength but at $4 \mathrm{~K}$ the yiefdrencths similaforelds made by both processes. It is important to remember that the tests of full-section specimens show no significant difference in room temperature yield strength of welds made by the two processes.

2. Supplier has a slight effect and temperature a relatively greater effect on tens:le strength of HDR welds. Tensile strengths of conventional and HDR welds are similar at a given temperature. The variability in tensile strength of HDR welds is greater at $4 \mathrm{~K}$.

3. NYR's are slightly higher at room temperature and slightly lower at $4 \mathrm{~K}$ for the HDR welds, as compared to conventional welds, but all values are still indicative of a very tough material.

High deposition rate welding processes have several obvious advantages. Time for welding thick plate can be reduced 50 to 80 percent compared to conventional GMA welding time. Gas consumption is significantly reduced as compared to conventional welds. Greater joint gaps can be tolerated without necessity of a backup. High deposition rate welds can be made in the horizontal and vertical positions, as well as in the flat position.

\section{COMPARISON OF BASE METAL AND WELDS IN ALLOYS 7039,2219 AND 5083}

Tensile properties at room temperature and $4 \mathrm{~K}$ for base metal and conventional GMA welds in nominal $51 \mathrm{~mm}$ thick plate in alloys 7039-T63, 2219-T851 and 5083-0 are shown in Table 5. These data show that both 2219 and 7039 base metals have significantly higher yield and tensile strengths than does 5083 at 4K. Welds in 2219 also have significantly higher yield strength than 5083 . No $4 \mathrm{~K}$ data are available for welds in 7039 or any of the other Al- $\mathrm{n}-\mathrm{Mg}$ alloys. NYR data available for base metal and welds in 2219 and 7039 indicate that these materials have adequate toughness at $4 \mathrm{~K}$.

Al- $\mathrm{Zn}-\mathrm{Mg}$ alloys are of particular interest because their relative insensivity to cooling rate following quenching from solution heat treacing temperature results in high tensile properties in thick sections. This, and their ability to naturally age harden, also results in good weld strengths. Some work has been done in developing filler alloys for welding Al-Zn-Mg alloys which shows that it is possible to obtain weld strengths higher than those obtained using commercially available filler alloys such as 5356. Work is needed to develop these filler metals to provide optimum strength at $4 \mathrm{~K}$, as well as to develop optimum procedures for welding thick sections in these materials. Furthermore, it may also be possible to develop Al-Zn-Mg base metals strengths at $4 \mathrm{~K}$. 


\section{VI.. SUMMARY AND CONCLUSIONS}

This report contains tensile and notch-tensile data at room temperature and $4 \mathrm{~K}$ for butt welds in $51 \mathrm{~mm}$ thick aluminum alloy 5083-0 plates donated by five companies. Welds were made the conventional gas-metal arc welding (GMAW) process and by a high desposition rate GMAW process.

The results of this investigation, which were evaluated statistically by the method of variance, show that:

1. Properties of welds made by the five companies were quite consistent, despite the fact that there.were considerable variations in welding procedures.

2. At $4 \mathrm{~K}$ the mean yield strength (201MPa) and the mean tensile strength ( $421 \mathrm{MPa}$ ) are 23 and 44 percent higher, respectively, than those at room temperature.

3. Notch yield ratios, which are an indication of fracturetoughness, are quite high, indicating that the welds are very: tough.

4. Properties of welds made by the high deposition rate process, which can reduce welding time for thick plates by 50 to 80 percent, are comparable to properties of welds made by the conventional GMAW process. 


\section{REFERENCES}

1. Rosenthal, Alan, "Aluminum Welding Advances Launch New Wave of Commercial, Naval Craft," Modern Metals, September, 1967.

2. "Giant Aluminum LNG Sphere 12 Stories High Arrives at General Dynamics Quincy Yard," Maritime Reporter and Engineering News, January 15, 1977, pp. 8-9.

3. "Aluminum in Hot Pursuit of Cryogenics," Welding Design and Fabrication, 1974.

4. "LNG Keeps Growing Around the World," Pipeline and Gas Journal, June, 1976, pp. 18-22.

5. Meyer, H. and Paetow, K.H., "125,000 $\mathrm{m}^{3}$ LNG/LPG Tanker at HDW," Schiff and Hafen, 11, 1975, pp. 989-997.

6. Kaufman, J. G., and Nelson, F. G., "Cryogenic Temperatures of Fatigue Strength of Al-Mg Alloys," Space/Aeronautics, July 1962.

7. Rice, L. P., Campbell, J. E., and Simmons, W. F., "The Tensile Property Evaluation of One 5000-Series Aluminum Alloy at the Temperature of Liquid Helium," Advances in Cryogenic Engineering, Vol. 8, 1963, pp. 671-677.

8. Kaufman, J. G., and Holt, M., "Fracture Characteristics of Aluminum Alloys," Aluminum Company of America, Alcoa Laboratories, Technical Paper No. 18, 1965.

9. Kaufman, J. G., and Wanderer, E. T., "Aluminum for Cryogenic Applications," Machine Design, November 11, 1965.

10. Nelson, F. G., Kaufman, J. G., and Holt, M., "Fracture Characteristics of Welds in Aluminum Alloys," Welding Journal, July 1966.

11. "Kaufman, J. G., Bogardus, K. O., and Wanderer, E. T., "Tensile Properties and Notch Toughness of Aluminum Alloys at $-452^{\circ} \mathrm{F}$ in Liquid Helium," Advances in Cryogenic Engineering, Vol. 13, 1968, pp. 294-308.

12. Nelson, F. G., Kaufman, J. G., and Wanderer, E. T., "Tensile Properties and Notch Toughness of Groove Welds in Wrought and Cast Aluminum Alloys at Cryogenic Temperatures," Advances in Cryogenic Engineering, Vol. 14, 1969, pp. 71-82.

13. Nelson, F. G., Kaufman, J. G., and Wanderer, E. T., "Tear Tests of 5083 Plate and of 5183 Welds in 5083 Plate and Extrusions," Vol. 15, Advance in Cryogenic Engineering, 1970.

14. Kaufman, J. G., Nelson, F. G., and Wanderer, E. T., "Mechanical Properties and Fracture Characteristics of 5083-0 Products and 5183 Welds in 5083 Products," Vol. I, Proceedings of the XIII International Congress of Refrigeration, Washington, DC, 1971 .

15. Holt, M., and Kaufman, J. G., "Indices of Fracture Characteristics of Aluminum Alloys Under Different Types of Loading," Current Engineering Practice, Vol. 16, No. 3, 1973. 
16. Nelson, F. G., and Kaufman, J. G., "Fracture Toughness of Plain and Welded 3-in. Thick Alum inum Alloy Plate," ASTM STP 536, Progress in Flaw Grow th and Fracture Toughness Testing, 1973, pp. 350-376.

17. Saunders, W. W., Jr., and Gannon, S. M., "Fatigue Behavior of Aluminum Alloy 5083 Butt Welds," Welding Research Council Bulletin 199, October 1974.

18. Kelsey, R. A., Nordmark, G. E., and Clark, J. W., "Fatigue Crack Growth in Aluminum Alloy 5083-0 Thick Plate and Welds for Liquefied Natural Gas Tanks," ASTM STP 556, Fatigue and Fracture Toughness - Cryogenic Behavior, 1974, Pp. 159-185.

19. Kaufman, J. G., Nelson, F. G., and Wygonik, R. H., "Large-Scale Fracture Toughness Tests of Thick 5083-0 Plate and 5183 Welded Panels at Room Temperature, -260 and $-320^{\circ} \mathrm{F}$, ASTM STP 556, Fracture and Fracture Toughness - Cryogenic Behavior, 1974 , pp. 125-158.

20. Kelsey, R. A., Wygonik, R. H., and Tenge, P., "Crack Growth and Fracture of Thick 5083-0 Plate Under Liquefied Natural Gas Ship Spectrum Loading," ASTM STP 579, Properties of Materials for Liquefied Natural Gas Tankage, 1975, pp. 44-79.

21. Kaufman, J. G., and Kelsey, R. A., "Fracture Toughness and Fatigue Properties of 5083-0 Plate and 5183 Welds for Liquefied Natural Gas Applications," ASTM STP 579, Properties of Materials for Liquefied Natural Gas Tankage, 1975, Pp. $138-158$.

22. Bogardus, K. O., and Malcolm, R. C., "Design Stresses for Aluminum Alloy 5083-0 and 5183 Welds at Cryogenic Temperatures," Ibid, pp. 190-204.

23. Tobler, R. L., and Reed, R. P., "Fracture Mechanics Parameters for a 5083-0 Aluminum Alloy at Low Temperatures," J. of Engr. Materials and Technology, Vol. 99, Oct. 1977, pp. 306-312.

24. Kelsey, R. A., "Fatigue and Fracture Characteristics of Al-Mg Butt Welds," Aluminium, October 1977, pp. 600-606.

25. Kelsey, R. A., "Mechanical Properties of USA/USSR Al-Mg Plate and Welds for LNG Applications," Vol. 24, Advances in Cryogenic Engineering, 1978.

26. Kaufman, J. G. and Wanderer, E. T., "Tensile Properties and Notch Toughness of Some 7 XXX Alloys at $-452^{\circ} \mathrm{F}, "$ Advances in Cryogenic Engineering, Vol. 16, 1971, pp. 27-36.

27. Sachs, G., Ebert, L. J., and Brown, W. F., Jr., Transactions, American Institute of Mining, Metallurgical, and Petroleum Engineers, Iron and Steel Divisions, 1948, p. 424 .

28. Baker, J. F. and Tipper, C. F., Welding Research Council Bulletin, No. 37, June 1957.

29. Kaufman, J. G. and Johnson, E. W., Advances in Cryogenic Engineering, Vol. 6, 1960, pp. 637-649.

30. Kaufman, J. G. and Holt, Marshall, "Fracture Characteristics of Aluminum Alloys," Technical Paper No. 18, Alcoa Laboratories, 1965. 
31. Brown, W. F., Jr., "The Circumferentially Notched Cylindrical Bar as a Fracture Toughness Test Specimen," presented at the G. R. Irwin Symposium on Linear Fracture Mechanics, Lehigh University, 29-30 July 1974.

32. Kaufman, J. G., Sha, G. T., Kohm, R. F., and Bucci, R. J., "Notch-Yield Ratio as a Quality Control Index for Plane Strain Fracture Toughness," ASTM STP 601, 1976, pp. 169-190. 


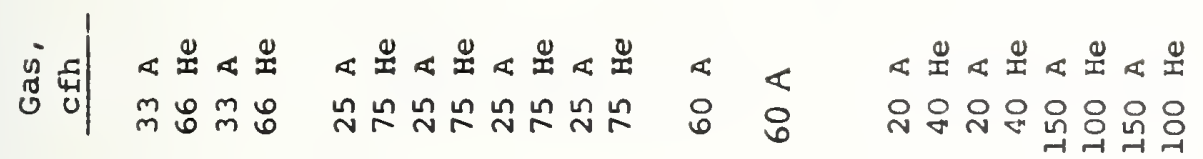

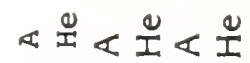
แกำกำล

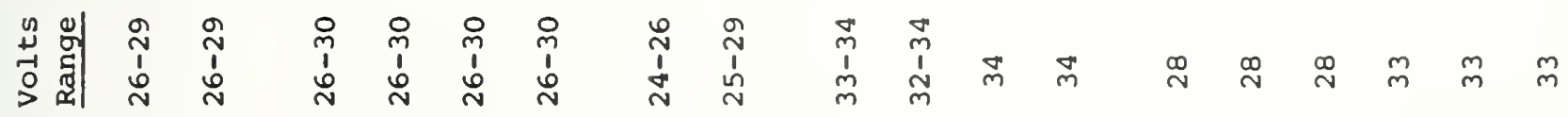

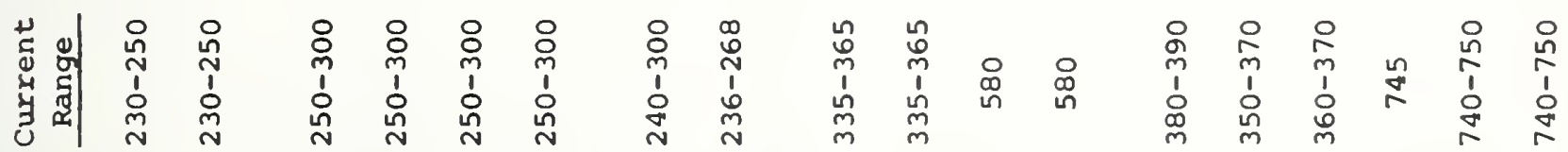

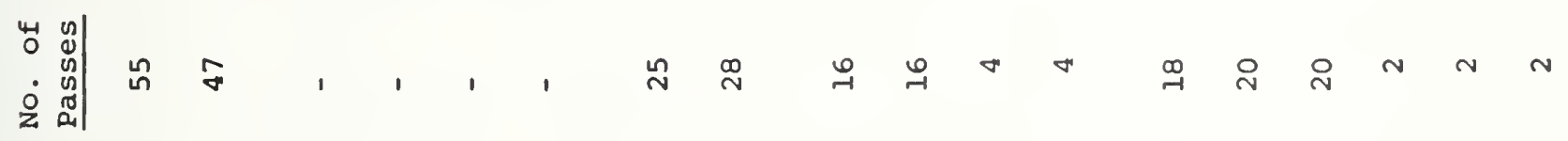

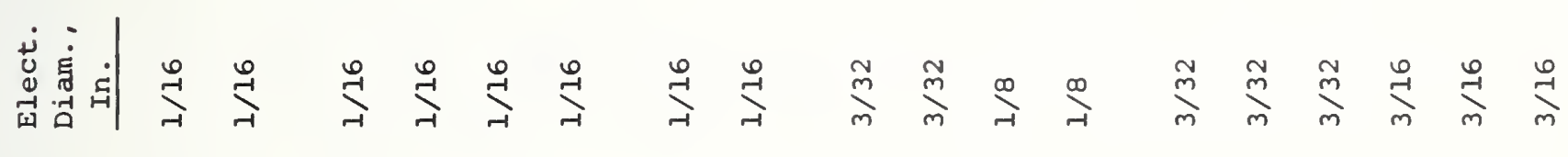

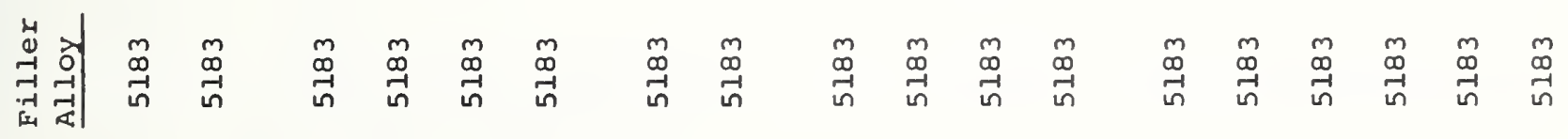

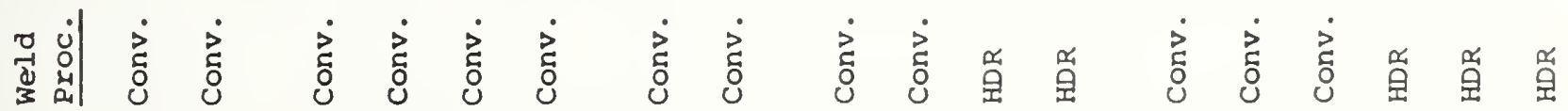

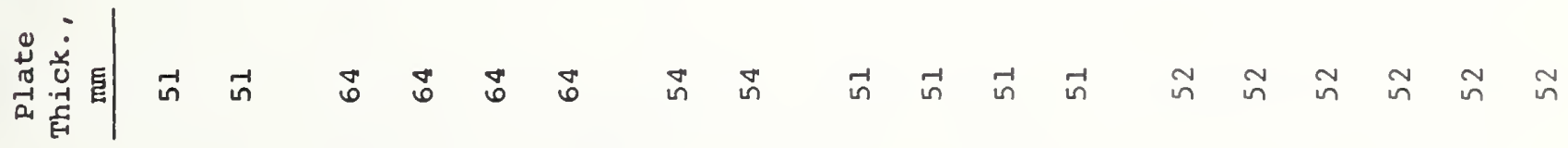

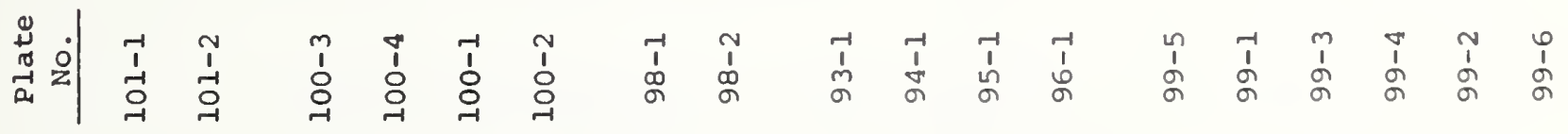
意 $\cdots$ 


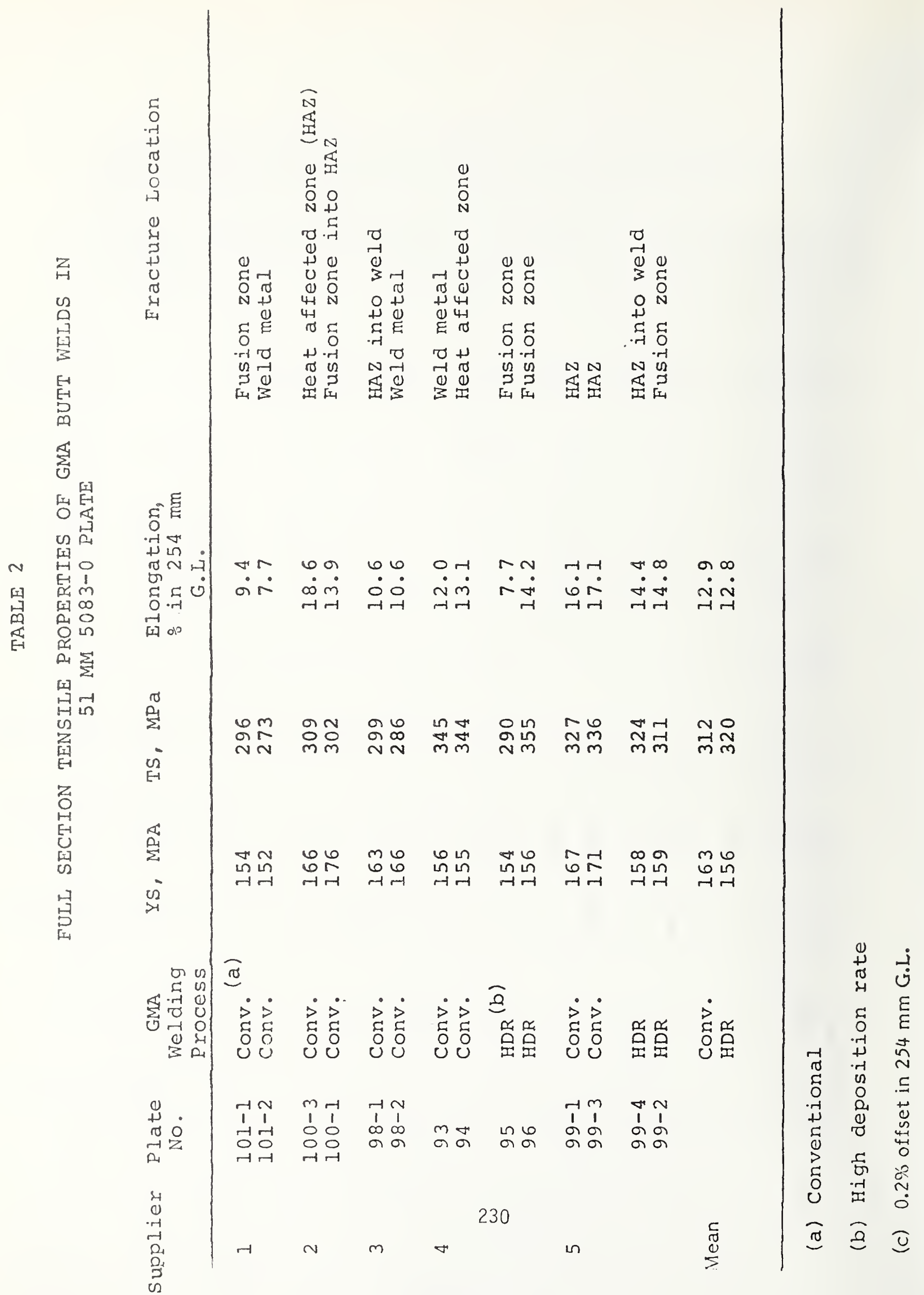




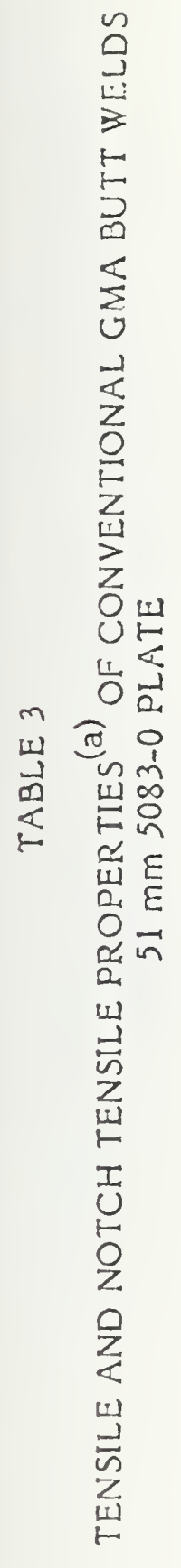

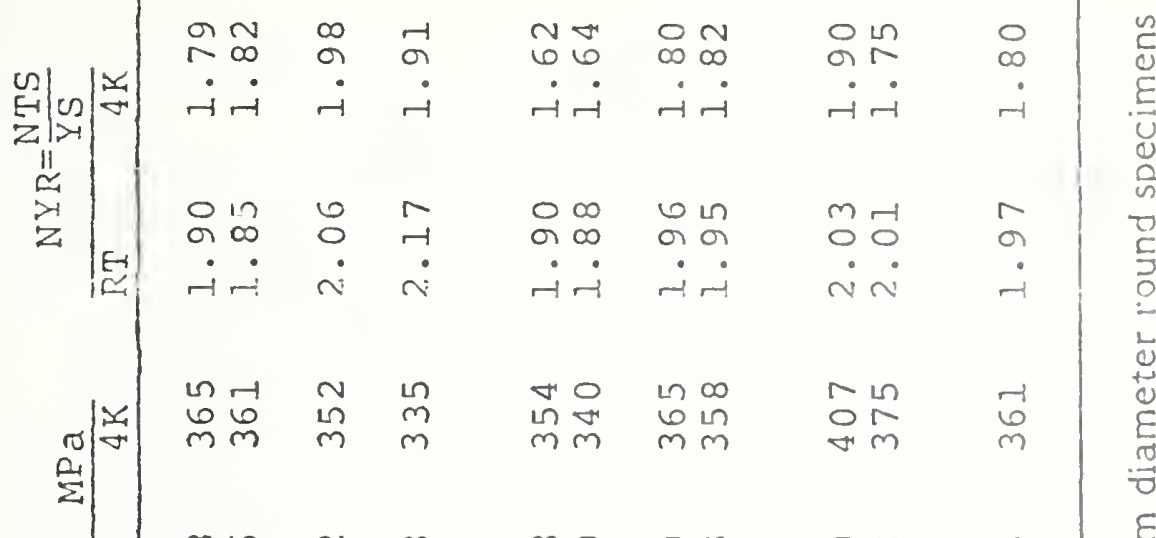

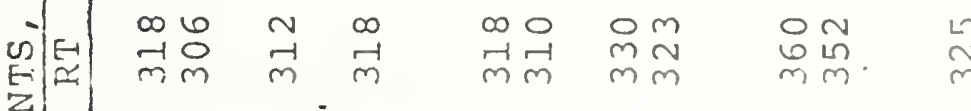

of

S.

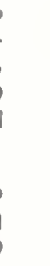

E N

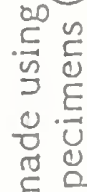

$\stackrel{0}{\geqslant}$

$\approx$

$\stackrel{2}{\leftrightarrow} 0$

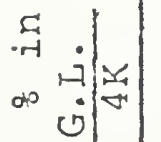

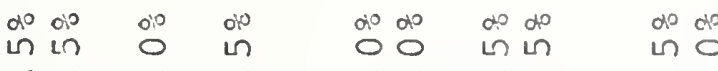

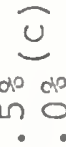

$\dot{m} \dot{\sim} \dot{0} \dot{0} \dot{0} \dot{0} \dot{\sim} \quad 0$

药苜

$\begin{array}{lll}\infty & 0 \\ -1 & -1\end{array}$

$\infty \circ \infty \infty$

N N

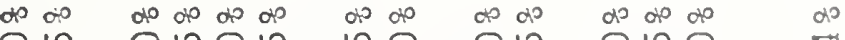

on 0 in 0 in in 0 in 0 in 0

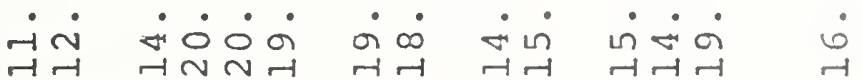

$\vec{n} \subset$

证

D茎

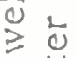

$\stackrel{\frac{0}{\xi}}{\stackrel{0}{E}}$

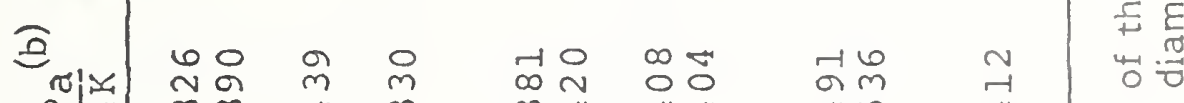

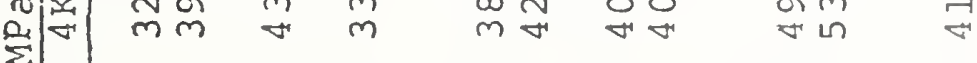

둥

a I $\infty 0 m \pi$ In

EีE

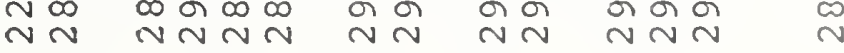

บิ

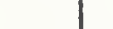

(1)

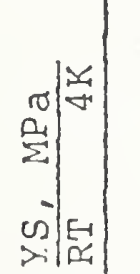

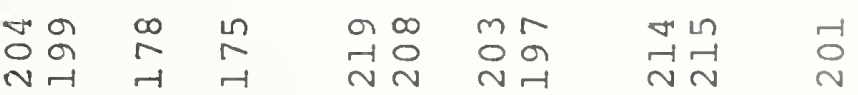

U丂

¿ $\stackrel{\widetilde{T}}{E}$

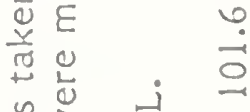

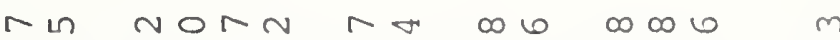

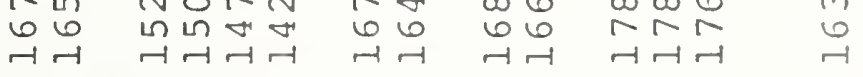
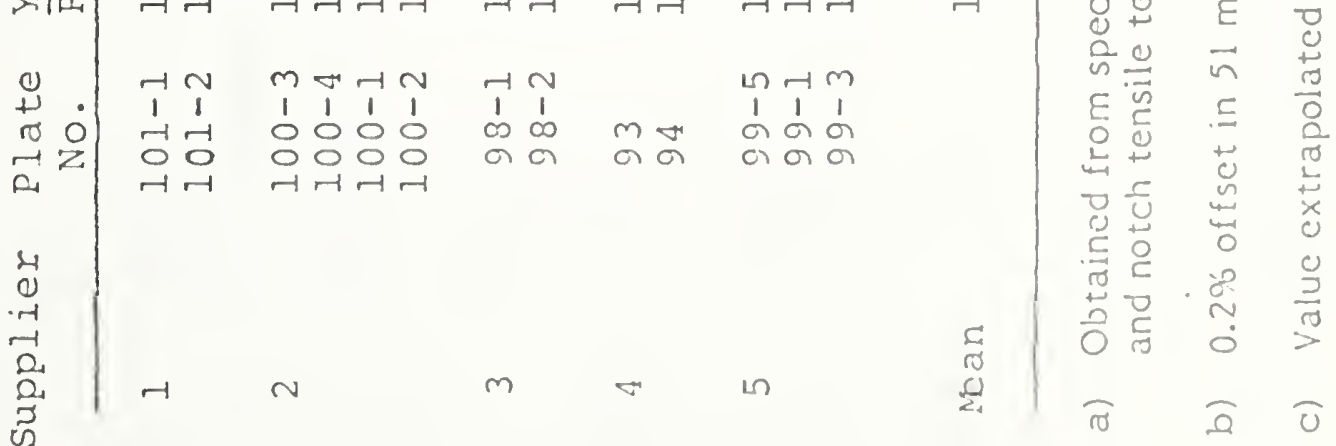


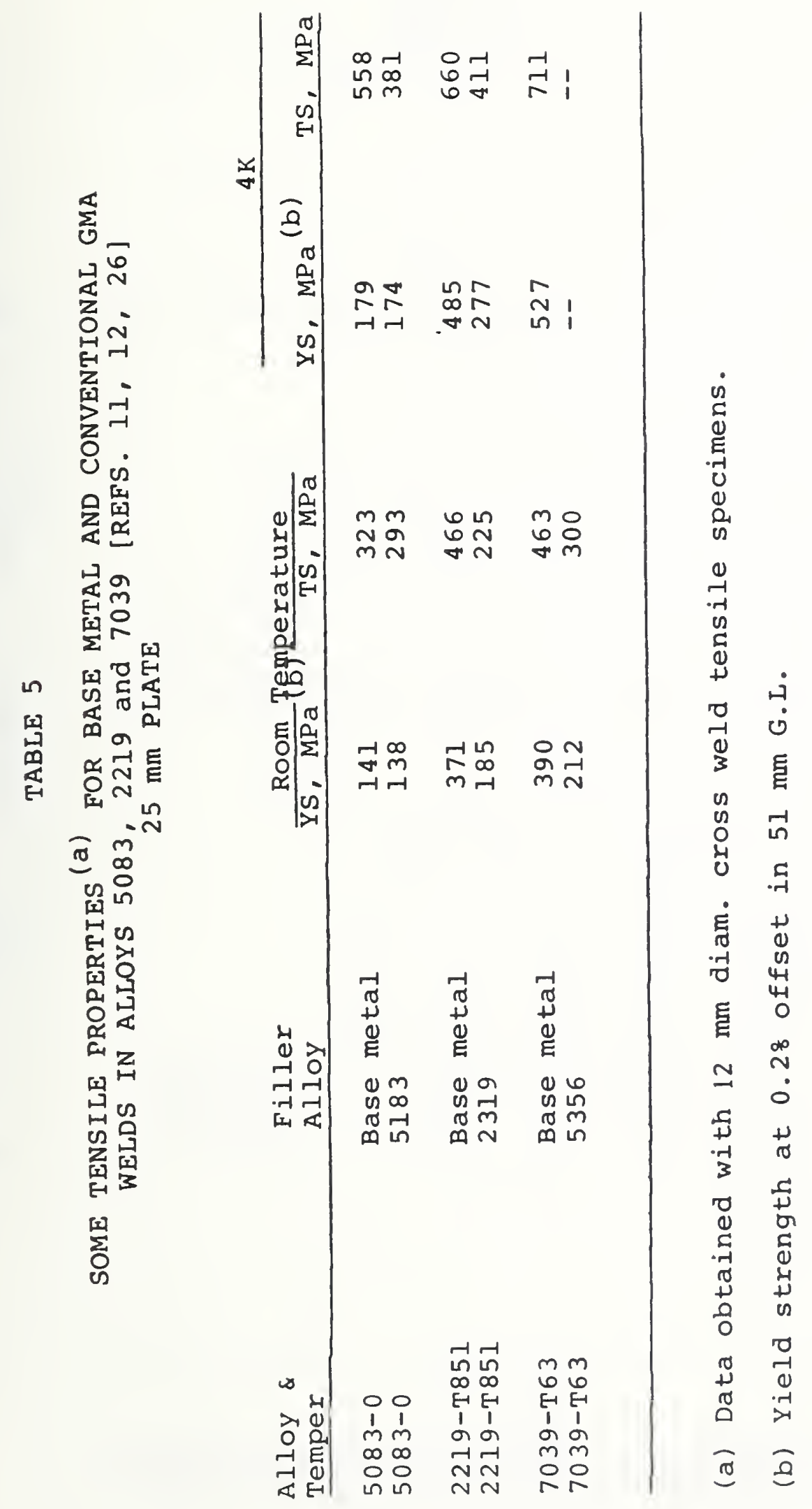


SMALL SYMBOL = INDIVIDUAL VALUES

LARGE SYMBOL = MEAN VALUES

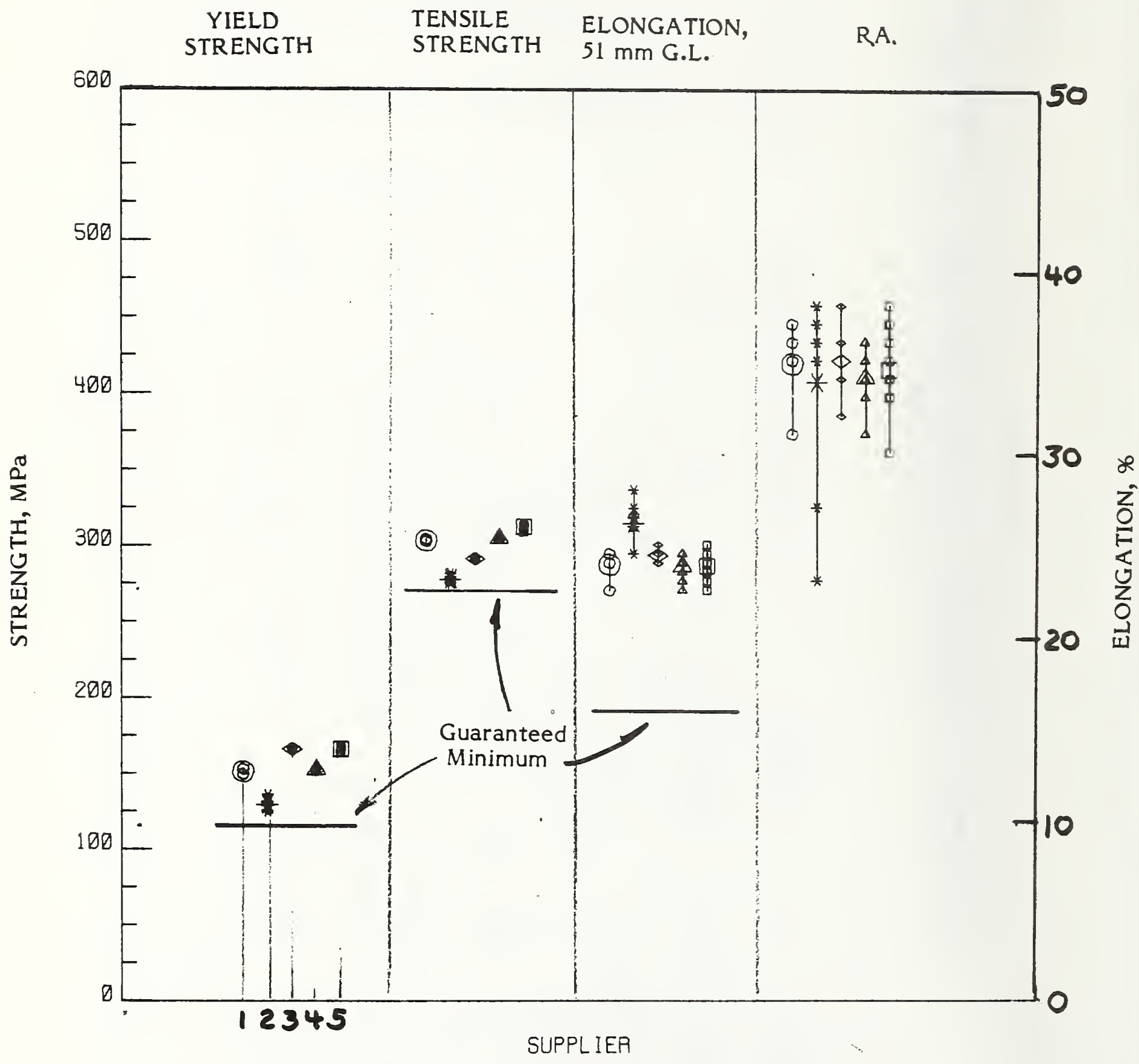

ROOM TEMPERATURE 5083-0 BASE METAL TENSILE PROPERTIES $1 / 2$ INCH DIAMETER SPECIMENS 


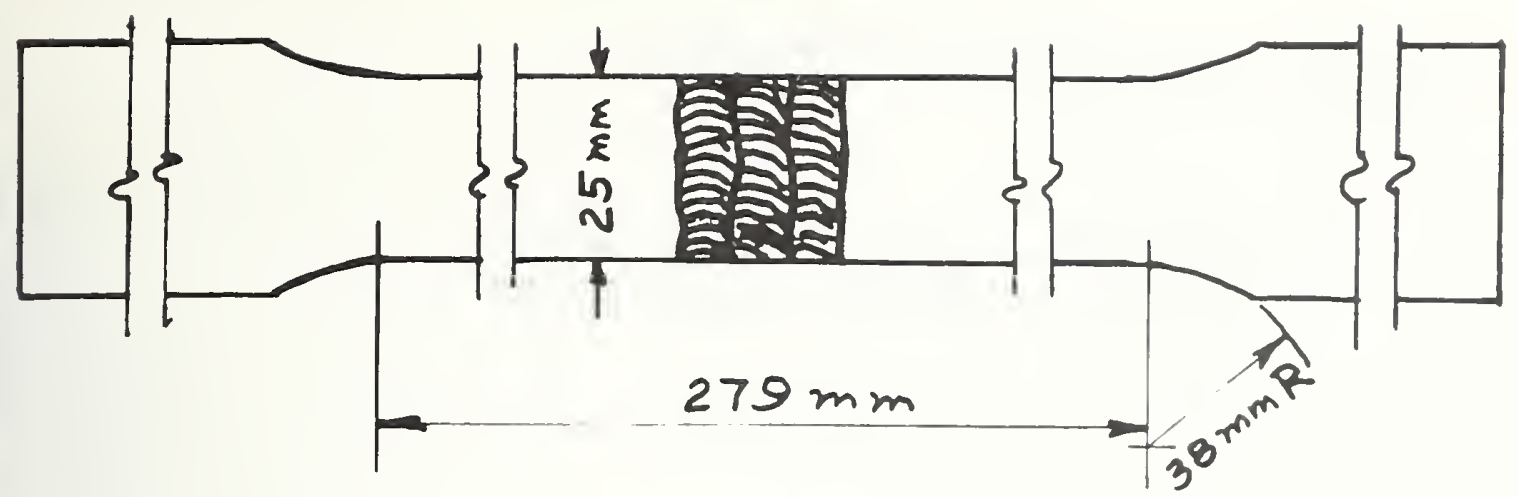

- Weld METAL

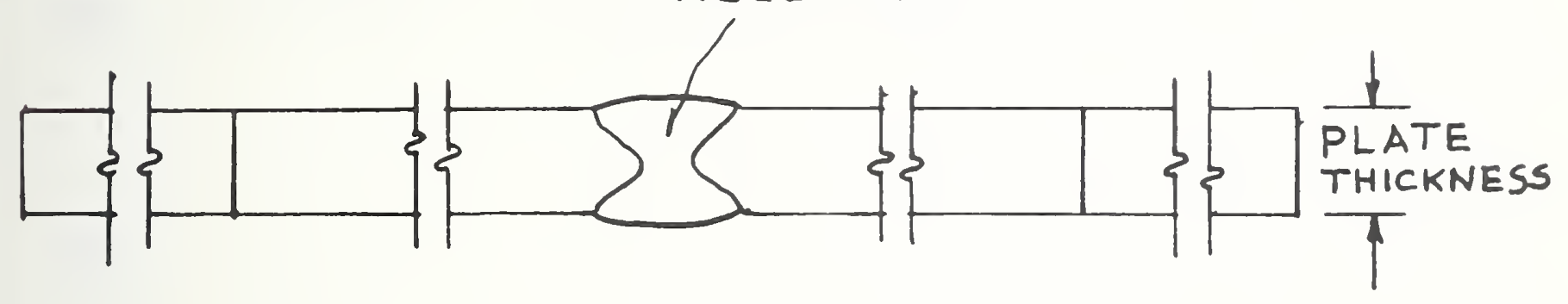

FIG. 2 FULL-SECTION TENSION SPECIMEN

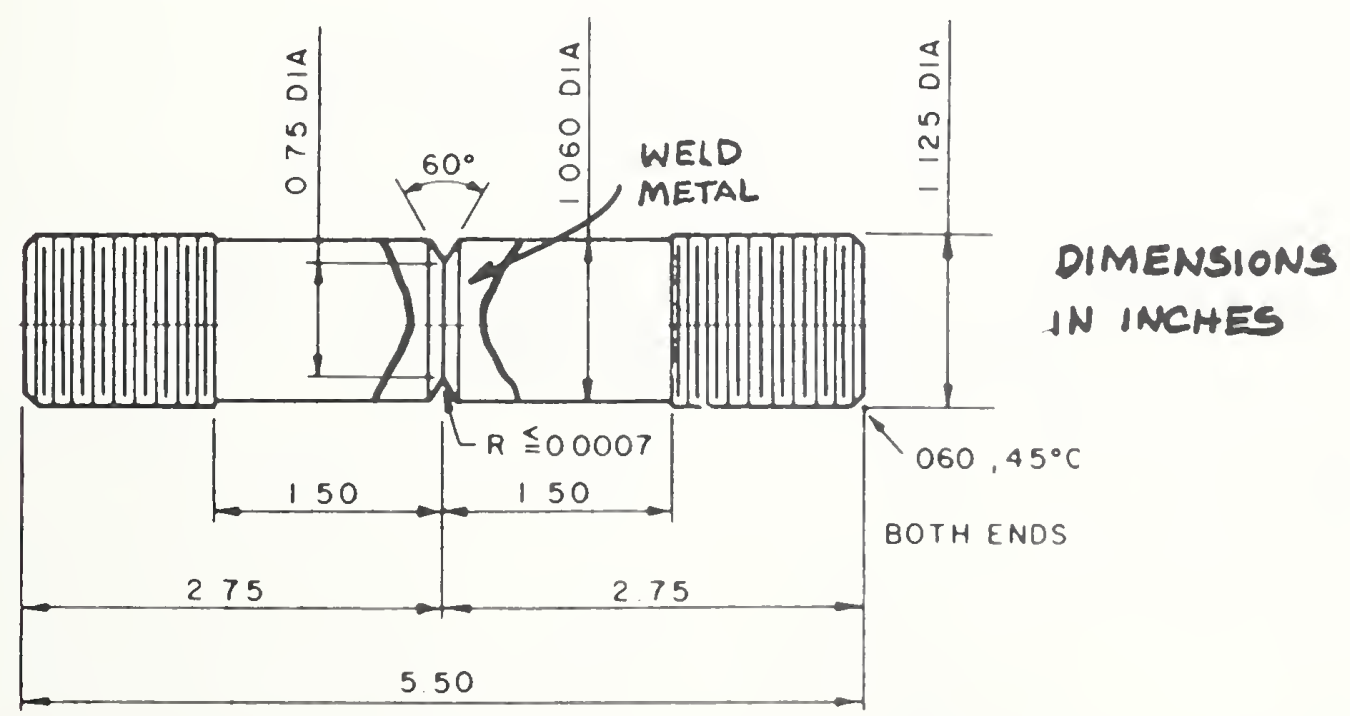

FIG. 3 NOTCHED-TENSION SPECIMEN 
SMALL SYMBOL = INDIVIDUAL VALUES

LARGE SYMBOL $=$ MEAN VALUES

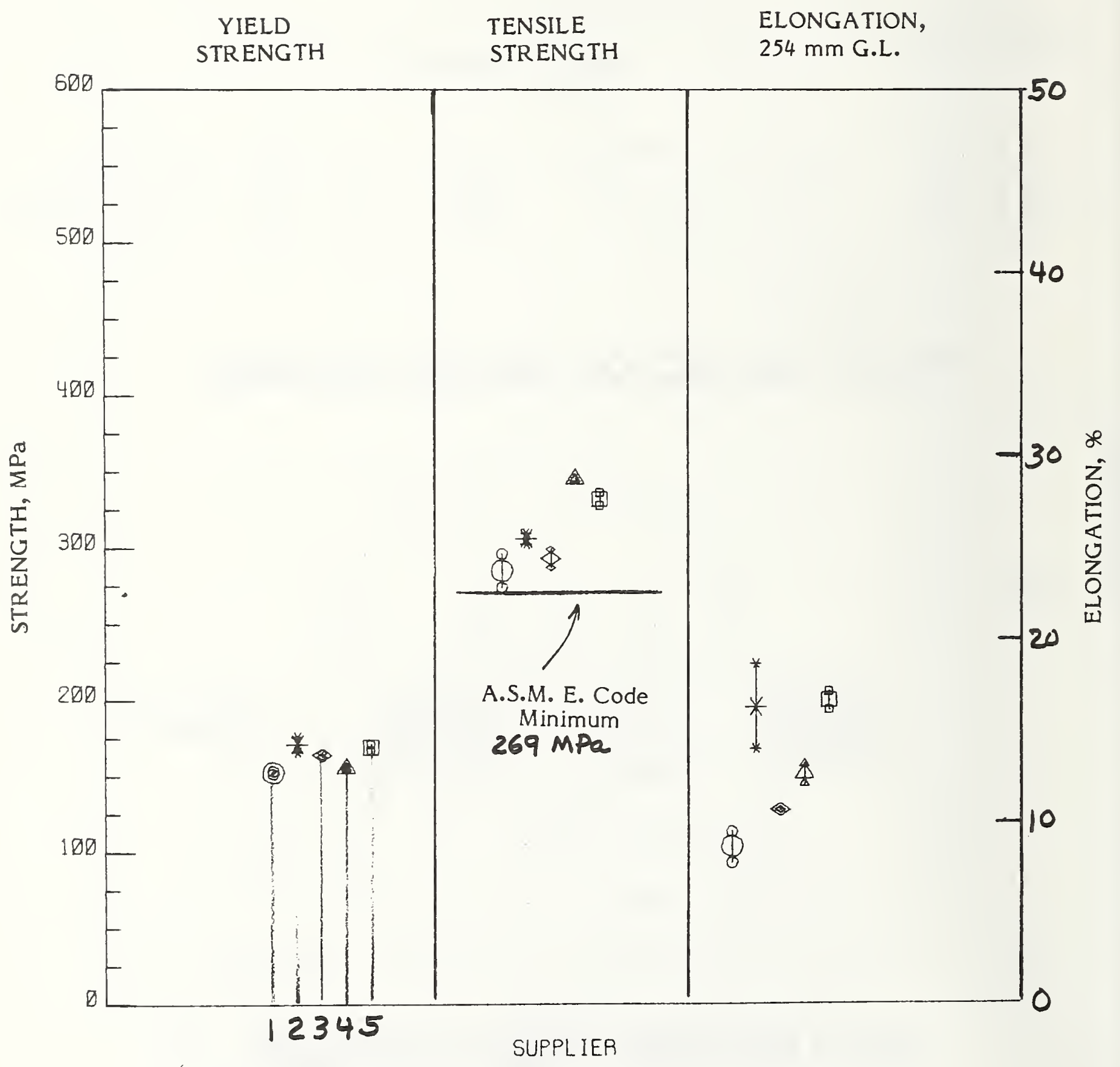

ROOM TEMPERATURE CROSS WELD TENSILE PROPERTIES

FULL SECTION SPECIMENS 
SMALL SYMBOL = INDIVIDUAL VALUES

LARGE SYMBOL = MEAN VALUES

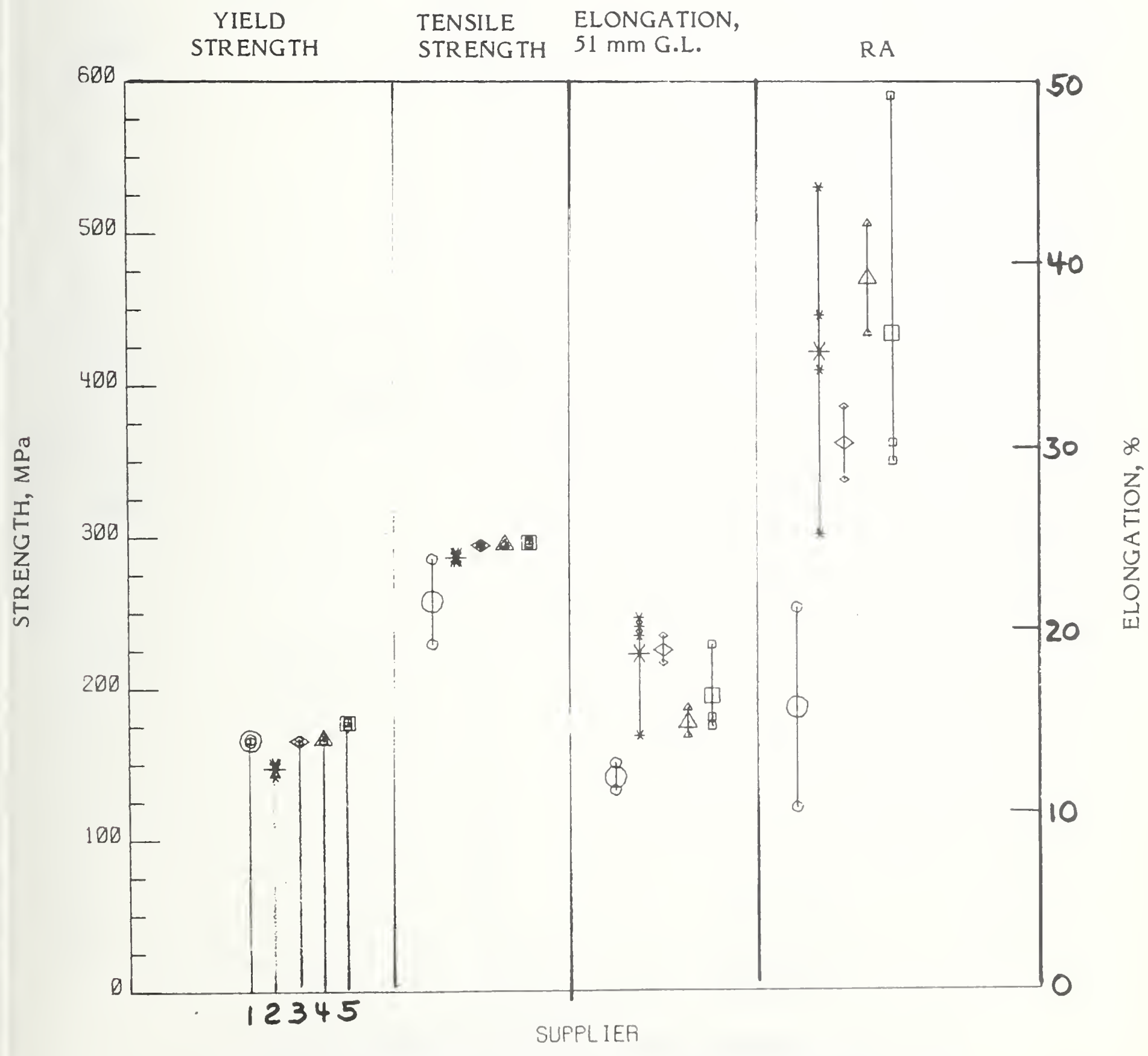

ROOM TEMPERATURE CROSS WELD TENSILE PROPERTIES 
CONVENTIONAL GMA WELDS

SMALL SYMBOL = INDIVIDUAL VALUES

LARGE SYMBOL = MEAN VALUES

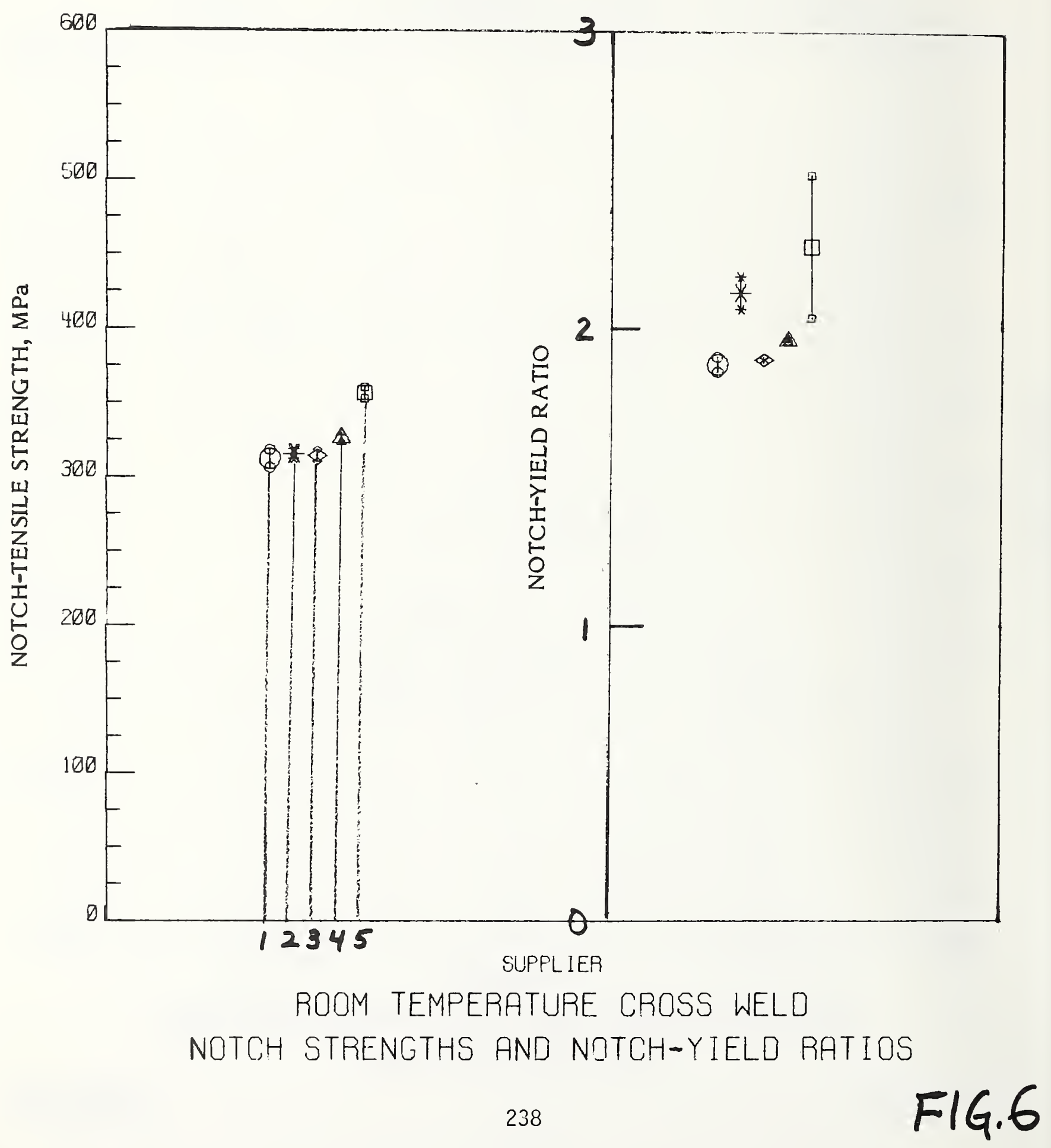


SMALL SYMBOL = INDIVIDUAL VALUES

LARGE SYMBOL = MEAN VALUES

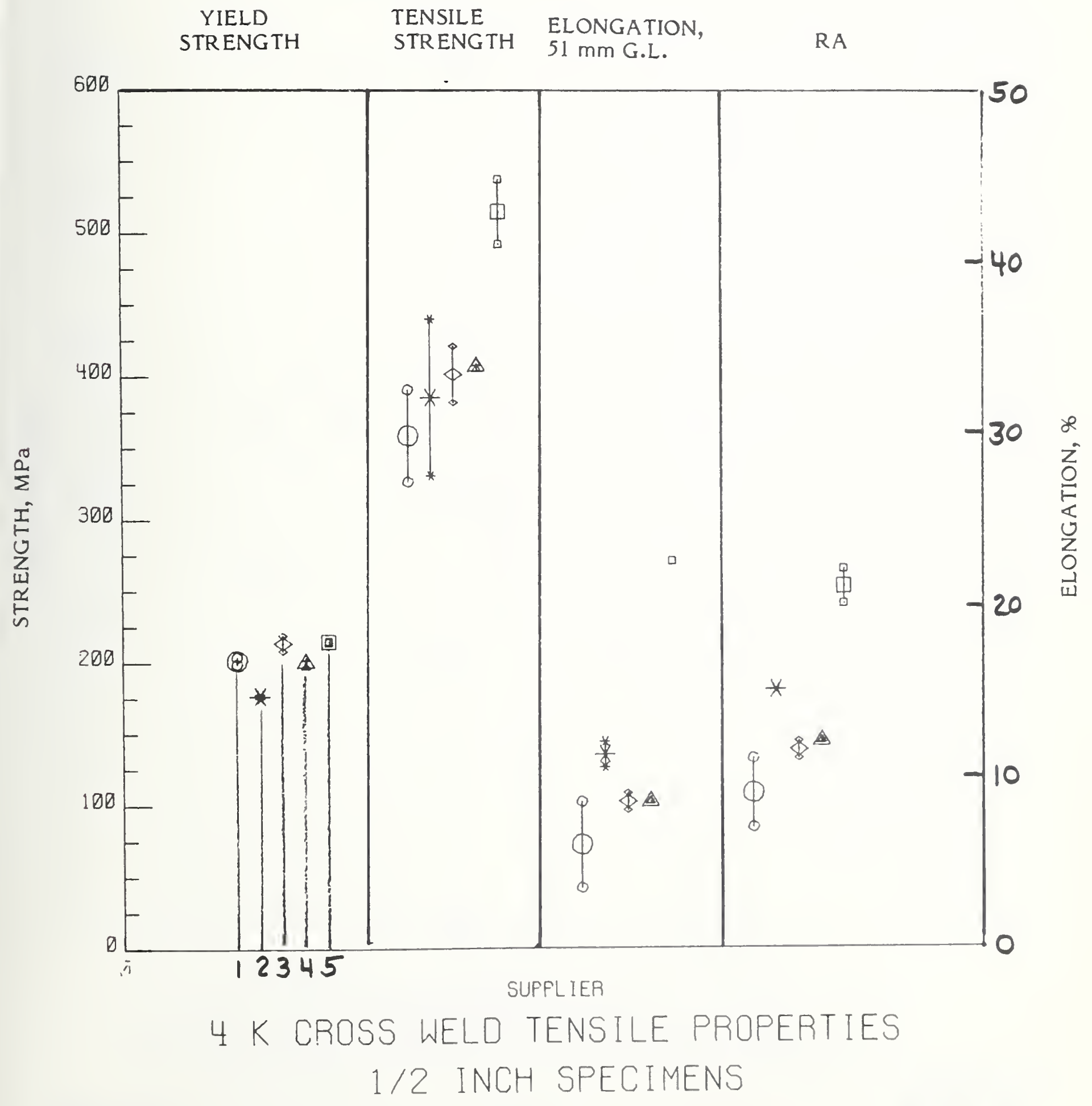

$\begin{array}{lll}\text { TENSILE } & \text { ELONGATION, } & \text { RA } \\ \text { STRENGTH } & 51 \mathrm{~mm} \mathrm{G.L.}\end{array}$ 
SMALL SYMBOL = INDIVIDUAL VALUES

LARGE SYMBOL = MEAN VALUES

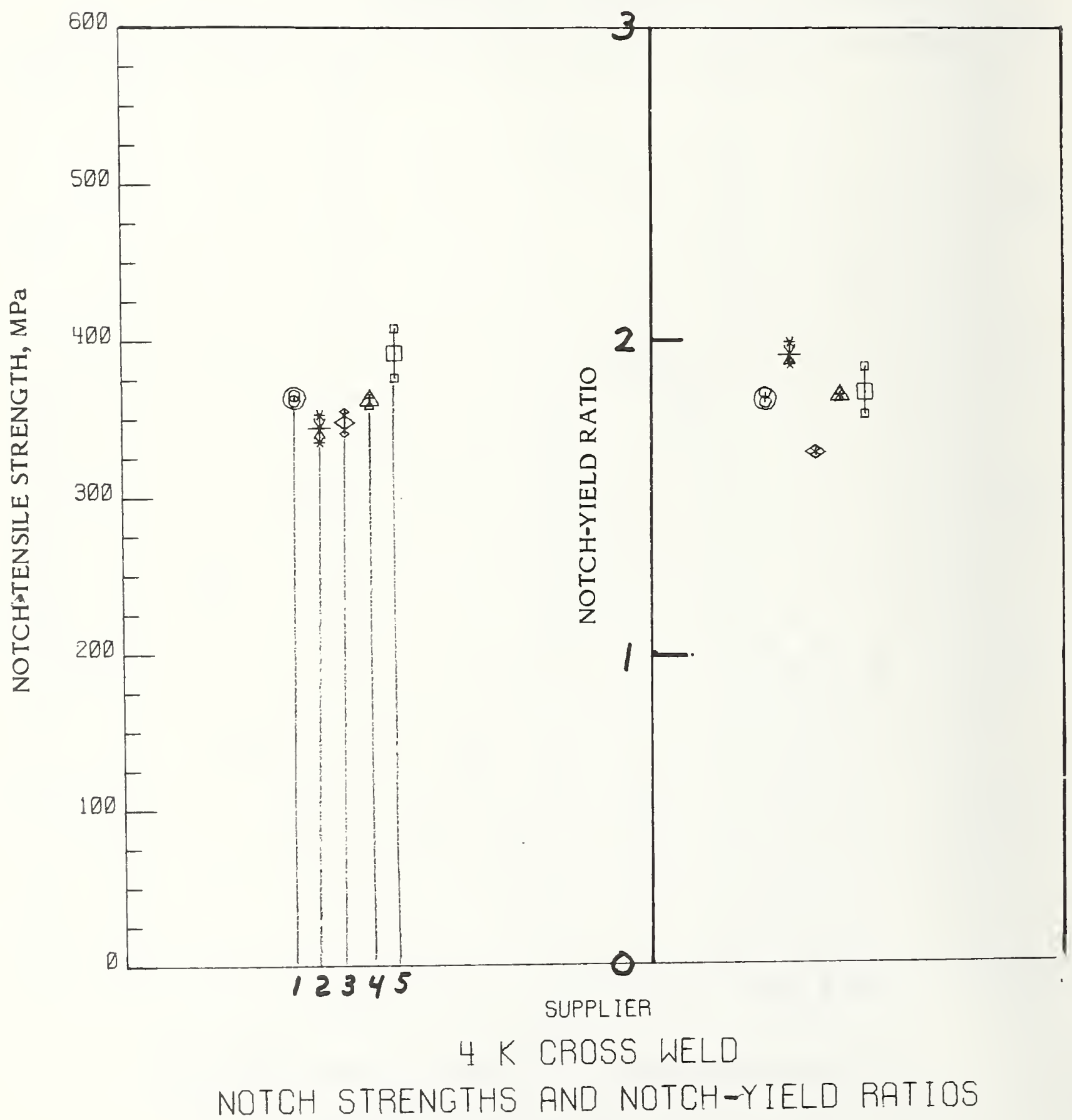


SMALL SYMBOL = INDIVIDUAL VALUES

LARGE SYMBOL = MEAN VALUES

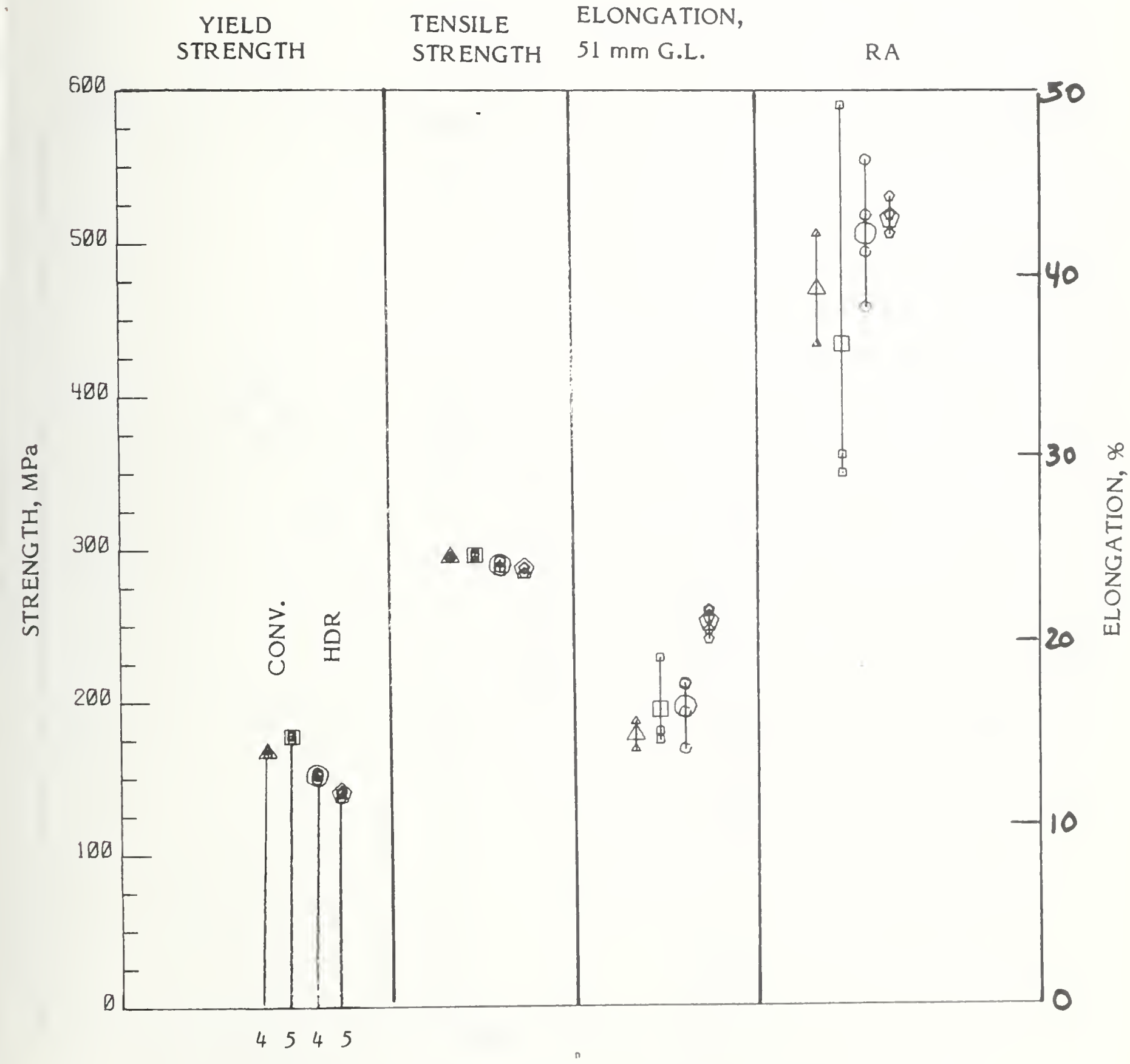

ROOM TEMPERATURE CROSS WELD TENSILE PROPERTIES OF ALCOA AND KAISER CONVENTIONAL AND HDR WELDS 
SMALL SYMBOL = INDIVIDUAL VALUES

LARGE SYMBOL = MEAN VALUES

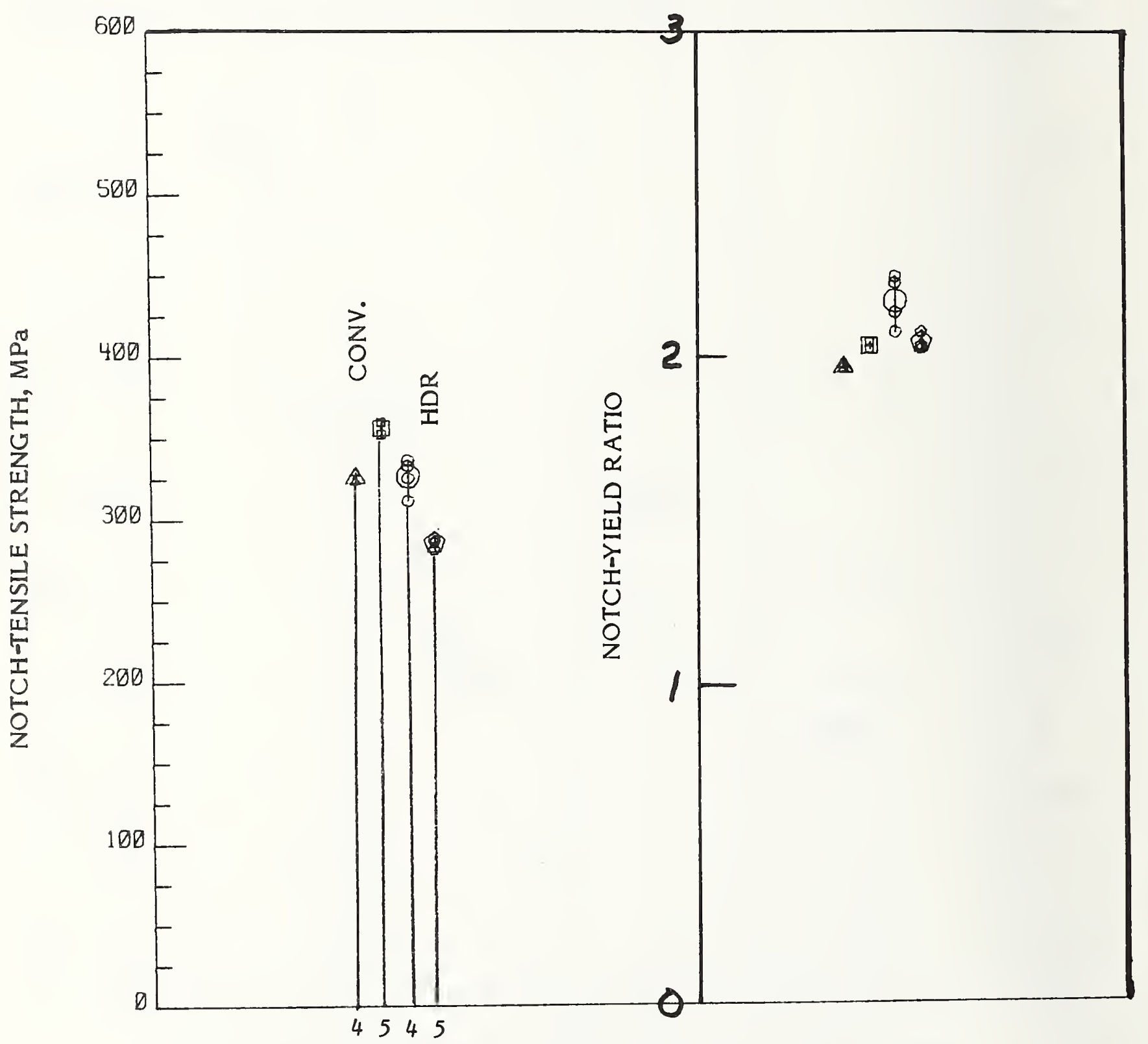

ROOM TEMPERATURE CROSS WELD NTS AND NYR OF ALCOA AND KRISER CONVENTIONAL AND HDR WELDS 
CONVENTIONAL GMA WELDS

SMALL SYMBOL = INDIVIDUAL VALUES

LARGE SYMBOL = MEAN VALUES

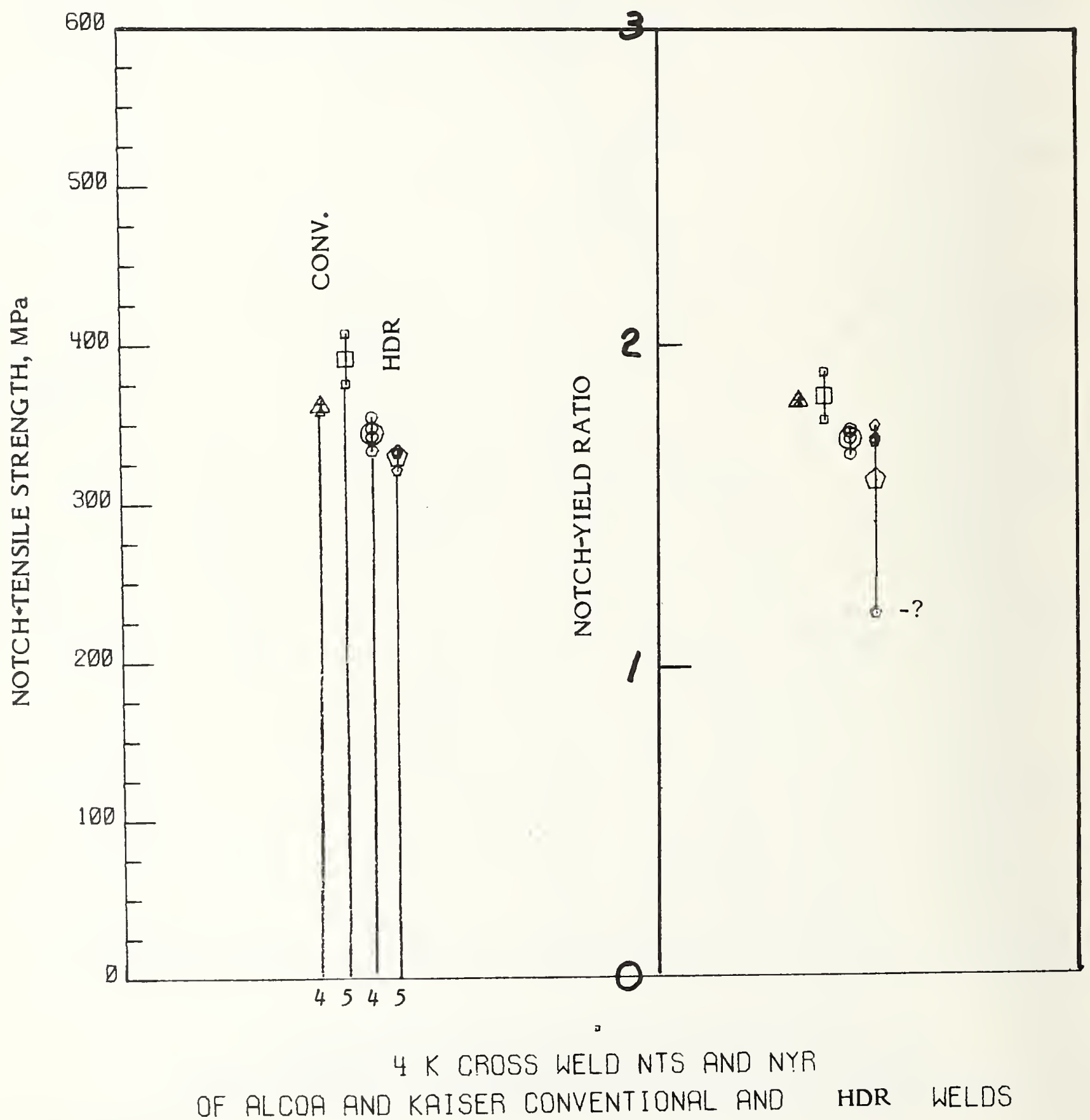


NOTE ON A SIMPLE TEST METHOD FOR ESTIMATING J IC

National Bureau of Standards 

Note on A Simple Test Method for Estimating $\mathrm{J}_{\mathrm{IC}}$

T. A. Whipple and H. I. McHenry National Bureau of Standards

Boulder, Colorado

\begin{abstract}
Fracture toughness testing is generally a time-consuming and expensive procedure; therefore, there has been a significant amount of effort directed toward developing an-inexpensive and rapid method of estimating the fracture toughness of materials. In this paper, a simple method for estimating $J_{\text {IC }}$ through the use of small, notched, bend bars is evaluated. The test only involves the measurement of the energy necessary to fracture the sample. Initial tests on Fe-18Cr-3-Ni-13Mn and 304LN stainless steel at 76 and $4 \mathrm{~K}$ have yielded results consistent with other fracture toughness tests, for materials in the low- to mediumtoughness range.
\end{abstract}




\section{INTRODUCTION}

The fracture toughness of stainless steel welds at $4 \mathrm{~K}$ varies significantly depending on the weld metal chemistry and the welding process and procedures, as shown by Whipple, McHenry, and Read in this report $(p .167)$. Consequent1y, it is necessary to qualify welding procedures and consumables for liquid helium service. Weld qualification testing is currently done for the various magnet programs by NBS using the $J_{\text {IC }}$ procedures described by Read in this report (p. 205). Read's method is suitable for research purposes, but it is too expensive and complex for routine qualification testing. A simple and inexpensive method of measuring or estimating $\mathrm{J}_{\mathrm{IC}}$ at $4 \mathrm{~K}$ is needed to permit fabricators and independent laboratories to conduct qualification tests.

The idea of simply conducting a Charpy test at $4 \mathrm{~K}--$ or better yet at $77 \mathrm{~K}$-- is not regarded as suitable. In a Charpy impact test at $4 \mathrm{k}$, the rapid deformation prior to fracture causes adiabatic heating of the specimen and invalidates the results. This problem is inherent to all structural alloys because of their low specific heat at $4 \mathrm{~K}$. Previous work at NBS [1] indicates that testing at higher temperatures, e.g., in Tiquid nitrogen at $77 \mathrm{~K}$, does not provide a reliable indicator of toughness at $4 \mathrm{~K}$.

Begley [2] developed a method of estimating $J_{\text {Ic }}$ toughness from the fracture energy of notched bend bars based on the following relationship:

$$
\frac{E_{T}}{B(W-a)}=J_{I c}+a(W-a) \text {, for } \frac{\rho}{W-a}=\text { constant }
$$

where $\mathrm{E}_{\mathrm{T}}$ = fracture energy

$$
J_{I C}=\text { fracture toughness }
$$


$\rho=$ notch root radius

$B=$ thickness

$W=$ width

$a=$ crack length

$\alpha=$ empirical constant

This relationship was derived on the assumption that fracture occurs by a ductile tearing mode after general yielding. These assumptions are reasonable for austenitic stainless steel weldments tested using deeply notched bend bars. In this note a limited experimental program to evaluate Begley's method is discussed.

\section{Materials}

The test materials were 304LN stainless steel and Fe-18Cr-3Ni-13Mn for which the $K_{I C}(J)$ was known from previous tests [3]. These materials were selected because of the wide range of fracture toughness values, measured by either the single- or multiple-specimen $J_{\text {Ic }}$ test methods, as shown in Table I.

\section{Experimental Procedure}

The samples used were 10-mm x 10-mm (Charpy-impact-size) bend bars with two different notches. One notch was 5-mm (0.197-in) deep with a root radius of $0.5-\mathrm{mm}(0.02-\mathrm{in})$ the other was $7.5-\mathrm{mm}(0.296-\mathrm{in})$ deep with a root radius of $0.25-\mathrm{mm}(0.01-$ in). This gave both samples a (Wa) $/ \rho$ of 10. Impact tests were conducted at $76 \mathrm{~K}$ and slow-bend tests at 76 and $4 \mathrm{~K}$. The specimens were oriented such that the notch was in the rolling direction perpendicular to the plate surface.

Impact Tests: Impact tests were conducted according to the procedures described in ASTM E23, with the exception of the notch geometry as described above. 
Slow-Bend Tests: The fixture for slow-bend testing was designed such that it fit into the cryostat used for tensile testing, which has been described by Reed [4]. The loads are applied to the sample through three $6.35-\mathrm{mm}(0.25-\mathrm{in})$ diameter pins.

The load versus time curve is recorded on a strip chart recorder. The time scale on the test record is converted to deflection by using the known machine speed. The total energy for the test is equal to the area under the load deflection curve. To obtain the energy used to fracture the sample, the energy stored in the machine at the fracture load is subtracted from the total energy. The value for the machine energy as a function of load was found by bending an unnotched sample in the test fixture at the test temperature. The deflection of the unnotched sample (calculated from beam equations) was subtracted from the total deflection to obtain the machine deflection as a function of load; which is then converted to energy.

\section{Results and Discussion}

Table I gives the results obtained from the impact and slow bend tests, along with the J Ic results from the standard tests. The J Ic results for Fe-18Cr-3Ni-13Mn were obtained by Read and Reed [3] on the same heat of material by the multiple-specimen J-integral test. The J Ic results for $304 \mathrm{LN}$ were obtained on the same heat of material by the single-specimen $\mathrm{J}$-integral test.

Figure 1 is the plot of the normalized fracture energy versus the remaining ligament showing the extrapolation to zero remaining ligament which yields the estimate of $\mathrm{J}_{\mathrm{IC}}$. These values are given in Table I. 
It is interesting to note that the normalized fracture energies for impact tests are significantly higher than those for the corresponding slow-bend tests. However, the extrapolation yields J Ic values that are very similar. This is probably due to vibrational and other losses in the impacting process, which are a function of the energy required to break the sample and are negated by extrapolation to zero ligament.

Figure 2 is a comparison of the $J_{\text {Ic }}$ values measured by the singleor multiple-specimen tests and.the estimated $J_{I c}$ values obtained in this study. It shows that the estimation is excellent at low toughness values and becomes conservative as the toughness increases. This is not surprising, considering the size of sample used for these tests. According to the proposed validity criteria for $J_{\text {Ic }}$ testing of:

$$
B,(W-a)>25 \frac{J_{I C}}{\sigma_{y}}
$$

The maximum $\mathrm{J}_{\mathrm{Ic}} / \sigma_{\mathrm{y}}$ for these tests should be $0.0002 \mathrm{~mm}(0.0079 \mathrm{in})$. This means that at $4 \mathrm{~K}$ for $304 \mathrm{LN}$ the maximum $\mathrm{J}_{\mathrm{IC}}$ is $154 \mathrm{~kJ} / \mathrm{m}^{2}$. (900 $\left.\mathrm{in} \cdot 1 \mathrm{~b} / \mathrm{in}^{2}\right)$ and for Fe-18Cr-3Ni-13Mn it is $229 \mathrm{~kJ} / \mathrm{m}^{2}\left(1310 \mathrm{in} \cdot 1 \mathrm{~b} / \mathrm{in}^{2}\right)$ at $76 \mathrm{~K}$. By this criterion, all the $304 \mathrm{LN}$ tests are invalid and all the Fe-18Cr-3Ni-13Mn tests are valid.

From the Timited data obtained to date, Begley's test method appears to be a promising $J_{I c}$ estimation method. When Charpy-sized specimens are used, it is particularly suitable for materials in the low- to medium-toughness range. Thus, it may prove very useful for testing stainless steel weldments, which generally have a $J_{\text {Ic }}$ below $175 \mathrm{~kJ} / \mathrm{m}^{2}$ $\left(1000 \mathrm{in} \cdot 1 \mathrm{~b} / \mathrm{in}^{2}\right)$ at $4 \mathrm{~K}$. The application of this test to stainless steel weldments is currently under study. 
1. D. T. Read, H. I. McHenry, P. A. Steinmeyer, and R. D. Thomas, Jr., "Metallurgical Factors Affecting the Toughness of 316L SMA Weldments at Cryogenic Temperatures," in Material Studies for Magnetic Fusion Energy Applications at Low Temperatures-II, NBSIR 79-1609, 313 to 352, (1979).

2. J. A. Begley, "An Estimate of Ductile Tearing J Jc Toughness from the Fracture Energy of Notched Bend Bars," unpublished.

3. D. T. Read and R. P. Reed, "Toughness, Fatigue Crack Growth, and Tensile Properties of Three Nitrogen-Strengthened Stainless Steels at Cryogenic Temperatures," in Material Studies for Magnetic Fusion Energy Applications at Low Temperatures-I, NBSIR 78-884, 93 to 153, (1978)

4. R. P. Reed, "A Cryostat jor Tensile Tests in the Temperature Range 300 to $4 \mathrm{~K}, "$ in Advances in Cryogenic Engineering, Vol. 7, Plenum Press, New York, 1962, pp. 448-454. 


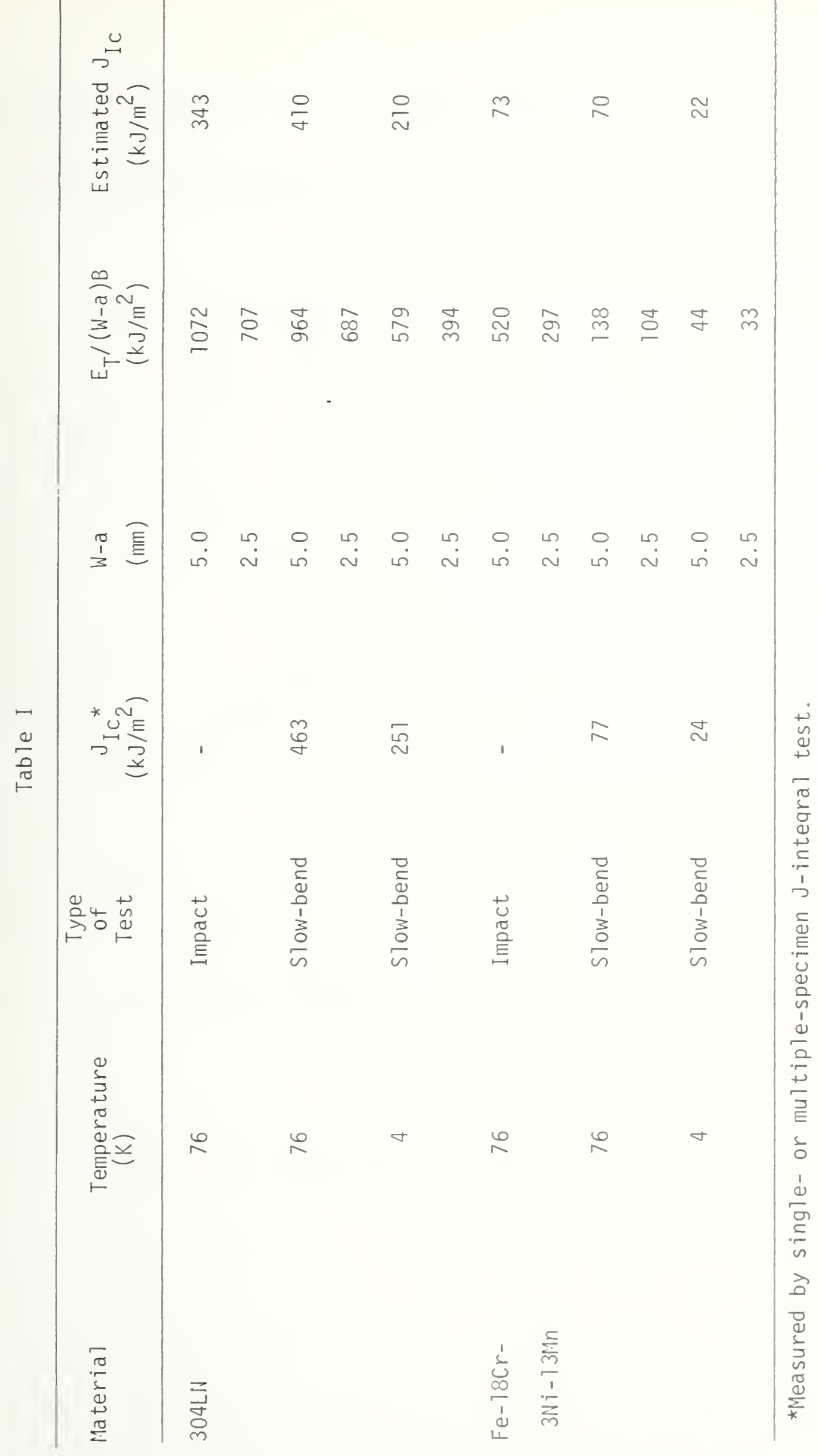


Figure 1. Normalized fracture energy as a function of the ligament width with the extrapolation to zero remaining ligament.

Figure 2. Comparison of the J values obtained by the estimation procedure and by the ${ }^{c}$ single or multiple specimen tests. 


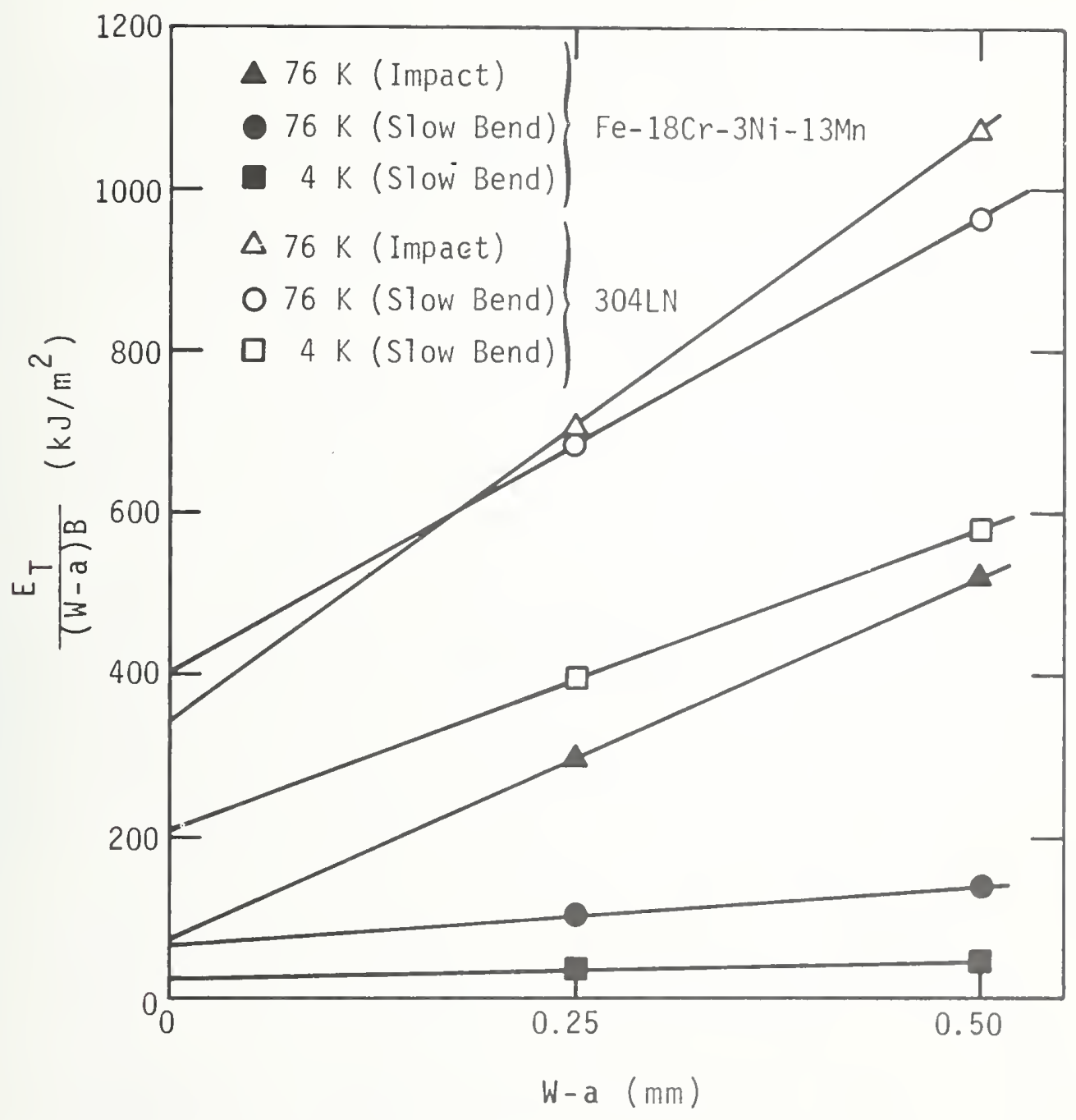

Figure 1. Normalized fracture energy as a function of the liqament width with the extrapolation to zero remaining ligament. 


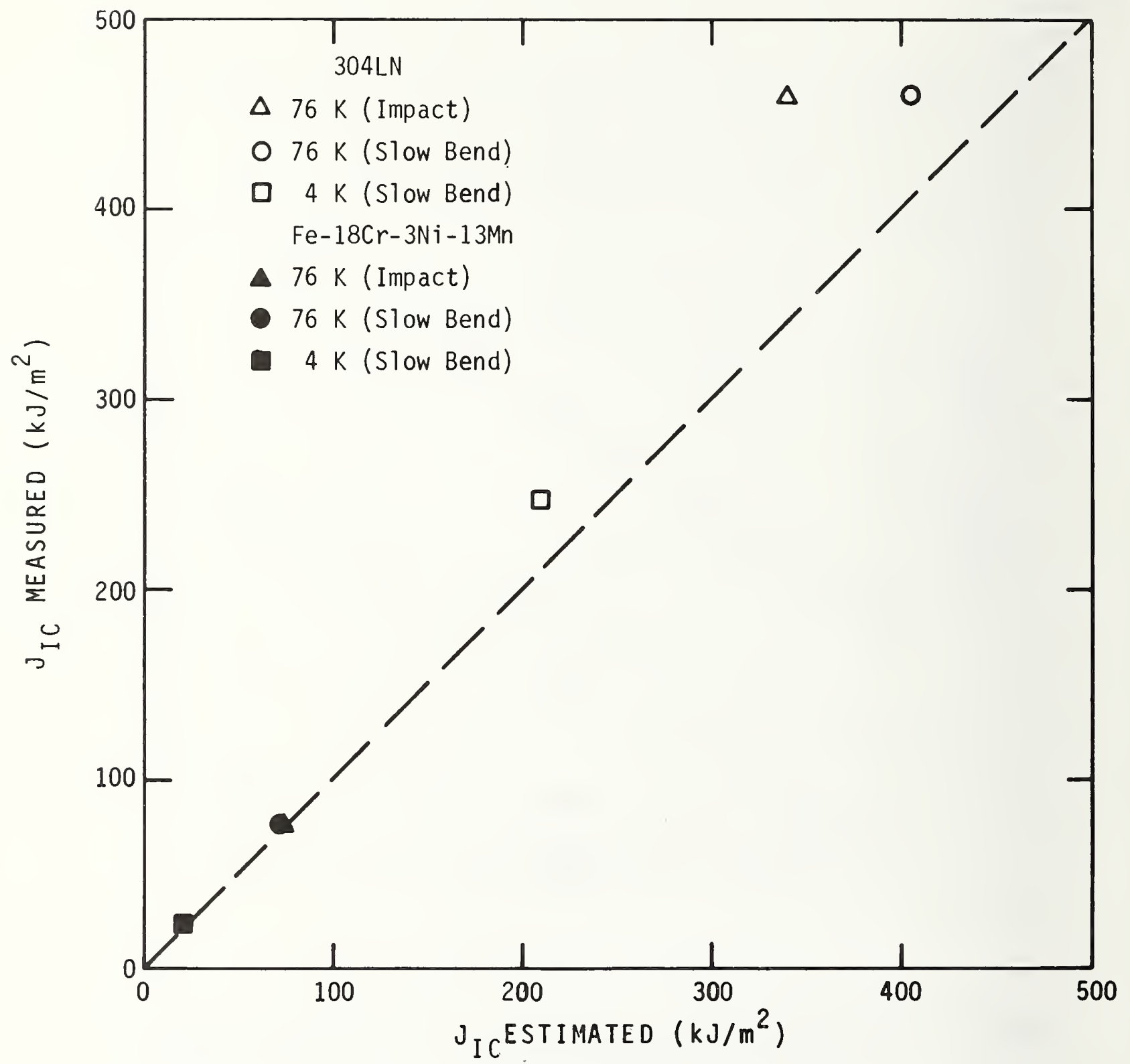

Figure 2. Comparison of the $\mathrm{J}_{\mathrm{IC}}$ values obtained by the estimation procedure and by the single or multiple specimen tests. 


\section{Nonmetallics}



NONMETALLICS FOR MAGNET SYSTEMS

Nationa T Bureau of Standards 

R. E. Schramm, M. B. Kasen, H. M. Ledbetter, J. G. Hust, and A. F. Clark Fracture and Deformation Division and

Thermophysical Properties Division National Bureau of Standards

Boulder, CO 80303

\section{INTRODUCTION}

NBS has undertaken the task of characterizing the mechanical and physical parameters of G-10CR and G-11CR glass cloth/epoxy composites between room temperature and $4 \mathrm{~K}$. These materials meet current NEMA G-10 and G-11, MIL-P-18177C, and Federa1 LP-509 specifications. In contrast to proprietary NEMA grades, the CR laminates are produced to common specifications covering all aspects of components and procedures. These products have minimum cryogenic property variability and are commercially available from several manufacturers.

Determination of mechanical properties involved: 1) tensile tests to measure Young's modulus, Poisson's ratio, ultimate strength, and failure strain, 2) compression strength tests, and 3) interlaminar shear strength tests. These were done for both major directions in the glass cloth plane (warp and fill). Compression strength was also measured in the direction normal to this plane. Ultrasonic resonance offers unique possibilities to examine elastic properties and was used to measure modulus and internal friction.

Thermal properties measured were conductivity and contraction. Values of electrical resistivity and dielectric strength provided by a subcontractor were included in the last report. C. J. Long of ORNL conducted radiation resistance tests. 

CRYOGENIC PROPERTIES OF FILAMENTARY-REINFORCED

COMPOSITES: AN UPDATE

Nationa? Bureau of Standards 

CRYOGENIC PROPERTIES OF FILAMENTARY-REINFORCED COMPOSITES: AN UPDATE

M. B. Kasen

Fracture and Deformation Division

National Bureau of Standards

Boulder, Colorado 80303

\section{ABSTRACT}

Current knowledge of the effect of cryogenic temperatures on the mechanical, elastic, thermal and electrical properties of reinforced plastic laminates is reviewed. Directions of fundamental research and of test method development are defined and discussed. Recommendations are made for effective future research.

It is confirmed that conventional laminates developed for room temperature service are viable engineering materials at cryogenic temperatures. Averages of mechanical and eiastic properties increase on cooling. But increased variability in strength properties on cooling remains a problem. This variability reflects the increasing notch sensitivity of the matrix resins on cooling.

It is concluded that the greatest benefit would accrue from development of matrix resin systems combining room temperature strength with improved cryogenic toughness. 


\section{INTRODUCTION}

The cryogenic properties of fiber-reinforced composites were last reviewed by Kasen in 1975 (1-3). These reviews identified a number of thermal and mechanical property trends for the room temperature to cryogenic temperature range for a variety of composite materials. A global view of available data showed that cooling generally had a beneficial effect on mechanical properties. No instance of serious property degradation was reported. Cotton, glass, graphite, aramid and boron-reinforced polymers and boron-reinforced aluminum therefore appeared to have potential for cryogenic service.

But, it was equally evident that a primary obstacle to expanded use of composites was the lack of a systematic data base relating cryogenic properties to well characterized composite materials. Available data often reported significantly differing temperature dependencies for mechanical properties of a given type of composite material. This reflected a diversity of data sources each having different program objectives and using different experimental techniques. Property data below liquid nitrogen temperature $(76 \mathrm{~K})$ were 1 imited to $20 \mathrm{~K}$. Almost no data were available at liquid helium temperature $(4 \mathrm{~K})$. Some efforts to improve cryogenic composite performance by flexibilizing the resin system were reported. But results were inconclusive. 
Recent years have seen substantial progress in experimental methodology. Furthermore, developments in composite mechanical theory have defined ways to produce a more systematic characterization of cryogenic composite laminate properties. To a large extent, such refinements paralleled the rapid development of overall composite technology.

Recent efforts to understand composite behavior better at cryogenic temperatures have largely been stimulated by the need to develop power generation systems as alternatives or improvements to conventional systems $(4,5)$. Current worldwide interest in energy generation by magnetic fusion energy (MFE) and magnetohydrodynamic (MHD) technology and in improving the efficiency of rotating machinery has required construction of large superconducting magnets which must function for many years under demanding service conditions. This has placed increasing demands on the performance of composite materials that serve as electrical insulators and primary supports for the magnet windings. It has also stimulated interest in the potential of advanced, high-modulus composites as contributors to lighter weight and increased efficiency of cryogenic power systems.

This paper provides an interim report on the progress since 1975 in understanding the performance of composite materials at cryogenic temperatures. The current data base is discussed within two composite materials categories: 1) woven-fabric and random-mat reinforced composites and 2) uniaxial fiber reinforced composites. The first category encompasses relatively inexpensive laminates, often produced in bulk form by industrial laminating firms. The second category addresses the most advanced, 
high-performance types of laminates. Succeeding sections review the status of fundamental research and of test method development. Finally, the directions of effective future research efforts are considered. WOVEN-FABRIC AND RANDOM-MAT REINFORCED COMPOSITES

\section{OVERV IEW}

Polymer-matrix composites reinforced with woven-fabric or randommat fibers are the least expensive of the laminate systems when they are produced by industrial high pressure laminating methods. The low cost, reasonable strength properties and low thermal and electrical conductivities have made such materials very popular for cryogenic structures.

Glass-fabric reinforced epoxy composites continue to dominate cryogenic interest. Best overall performance is obtained from laminates using conventional, fully-reacted epoxy resin systems. Laboratory work and practical experience have provided evidence that highly flexibilized epoxy systems do not improve the cryogenic performance of glass-fabric reinforced laminates. Furthermore it is becoming clear that such resin systems are a distinct detriment to room temperature performance. The failure of highly flexibilized systems is largely due to their high thermal contraction which creates a high level of residual stress in the cooled laminate, negating the inherent residual strain capability of the matrix at cryogenic temperatures.

A substantial effort has been directed toward reducing the cryogenic property variability of NEMA G-10 and G-11 types of glass-fabric reinforced high-pressure industrial laminates that are produced in large quantities by several U.S. laminating firms. Such products are fabricated to meet normal temperature electrical insulation performance criteria established by the National Electrical Manufacturer's Association (NEMA). Manufacturers 
are given considerable leeway in selection of specific laminate components and in manufacturing techniques. Proprietary NEMA-grade 1 aminates produced by the various firms therefore display substantial variability in those mechanical and thermal properties of greatest interest to the designers of large superconducting magnets and other sophisticated cryogenic apparatus.

Recognizing this problem, a cooperative program was undertaken between the National Bureau of Standards (NBS), the NEMA organization and the U.S. laminating industry to establish cryogenic grades of NEMA G-10 and G-11 glass-fabric reinforced epoxy products. The resulting laminates are designated G-10CR and G-11CR. These CR-grade products are high-quality, state-of-the-art products, differing from proprietary products in that they are produced to closely controlled, uniform specifications covering both component materials and manufacturing techniques. The CR products meet existing NEMA, MIL and Federal specifications for conventional G-10 and G-11 products. G-10CR is a heat-activated, amine-catalyzed, bisphenol A solid-type epoxy resin laminate reinforced with continuousfilament E-glass having a silane finish. G-llCR is an aromatic-amine hardened bisphenol A liquid-type epoxy resin laminate reinforced in the same manner. Such laminates are currently in commercial production and have been incorporated into several prototype superconducting magnets.

The mechanical, thermal and electrical properties of G-10CR and G-11CR have been characterized by NBS and other U.S. laboratories (6). The effect of neutron and gamma irradiation at $4 \mathrm{~K}$ on the mechanical and electrical performance of the materials have been studied by the Oak Ridge National Laboratory (7-8). 
Similar concern for the proper selection of laminate materials for use in superconducting magnet technology has led to a substantial body of cryogenic composite characterization work on a series of European industrial laminates by the European Organization for Nuclear Research (CERN) in Geneva, Switzerland (9). Mechanical and thermal property data were obtained from 275 to $4 \mathrm{~K}$ on E-glass fabric-reinforced bisphenol $A$ epoxy, epoxy-novolac, polyimide, phenolic and silicone laminates plus a pitch-base graphite/bisphenol $A$ and an aramid/bisphenol A laminate. The careful documentation of the studied materials and the sophistication of data acquisition and reduction methods were outstanding in this program. A substantial contribution to understanding the effect of cryogenic temperatures on the performance of glass-mat reinforced epoxy laminates has been made by a leading industrial glass research laboratory (10). Development of a practical nonmetallic containment system for liquefied natural gas required a careful study of the effect of cryogenic temperatures on the integrity of the laminate serving as the primary LNG barrier. This program generated an extensive mechanical and thermal property data base to $76 \mathrm{~K}$ for both discontinuous and continuous strand glass-mat/ epoxy laminates. Performance of the laminate systems under severely constrained thermal shock was also thoroughly investigated. Mechanical and thermal properties of these laminates have been summarized in handbook form (11) along with the properties of other nonmetallic laminates of interest to LNG technology.

Studies on the cryogenic temperature performance of glass-reinforced polyester laminates have been reported by the University of Wisconsin $(12-13)$. The work was motivated by the need to develop an inexpensive 
laminate for the major structural supports and thermal standoffs in very large superconducting energy storage systems.

\section{DATA ANALYSIS}

The most recent data on the temperature dependence of the significant mechanical, thermal, and electrical properties of fabric and matreinforced polymer composites are summarized on Figures 1-10 and on Table I. Data obtained at temperatures defined by the boiling points of cryogens (76 K and $4 \mathrm{~K}$ ) are presented in bar graph form to indicate lack of knowledge of the intervening temperature dependence. The cryogenic temperature values are taken as the average of the data at 76 and $4 \mathrm{~K}$ except where there is evidence of a statistically significant property change from $76 \mathrm{~K}$ to $4 \mathrm{~K}$. Data obtained over closely spaced temperature intervals are presented as continuous curves.

\section{Strength Properties}

The maximum tensile strengths in fabric-reinforced laminates correspond to the warp direction of the fabric where glass content is the highest. The generally lower glass content in the fill direction results in lower strength. The G-10CR and G-11CR laminates have a $42: 32$ warp-to-fill ratio typical of the style of glass fabric used in high-pressure industrial laminates manufactured in the United States. Lowest strength is developed in a $45^{\circ}$ orientation with respect to the warp and fill.

Conversely, a laminate reinforced with continuous or discontinuous randomly oriented glass mat has essentially isotropic properties in the edgewise direction, i.e., in the plane normal to the direction of pressing during laminate cure. But this isotropy is obtained at the 
expense of reduced laminate strength and stiffness compared with the maximum values obtainable from fabric-reinforced laminates.

The most recent data on the effect of cryogenic temperatures on the tensile, compressive and interlaminar shear strengths of fabric and matreinforced polymer composites are summarized on Figures 1-3.

Figure 1 summarizes ultimate tensile strength data. Except as noted, all data are for the warp direction of fabric reinforcement and for the edgewise direction of mat reinforcement. In part, the data compare reported strengths of a series of E-glass fabric-reinforced bisphenol A epoxy laminates having varying glass contents. Conventional bisphenol A epoxy resins (diglycidyl ether of bisphenol A) and epoxy novolacs (glycidyl ethers of novolacs) are most widely used in laminate fabrication (14). The composition of $E$ glass is given on Table II.

These data compared to strengths reported for continuous and chopped-mat E-glass reinforced bisphenol A epoxy products, for E-glass fabric reinforced polyimide, and for polyester and melamine laminates. Available data on the cryogenic performance of epoxy laminates reinforced with aramid fiber fabric (Kevlar 49) and with a pitch-base graphite fabric (HM-S) are also documented along with the small amount of data available for cotton fabric reinforced phenolic (phenolformaldehyde) 1 aminates .

Highest cryogenic tensile strengths were reported for the NEMA G-11CR laminate containing 67-72 weight percent glass. G-10CR, having 64-68 weight percent glass, developed slightly lower strength. CERN (9) reports that a commercial laminate of European manufacture containing 74.8 weight percent glass (Permaglas TE630) developed properties similar 
to the CR grades, while other commercial laminates having glass contents

of 62.5-66.1 weight percent (Vetronite 432.81, Vetronite 432.86, Durostone EPF2) developed slightly lower cryogenic strengths (bar 4, Fig. 1).

These data illustrate the importance of specifying glass content or of buying laminates to a specified range of glass content whenever maximum laminate performance is desired.

NBS data (6) on Figure 2 indicate that the tensile strength in the fill direction of G-10CR and G-11CR are 35-70\% of that in the warp direction. A similar strength anisotropy can be expected for the other fabric-reinforced laminates depending on the warp/fill ratio of the fabric used in their construction.

The tensile strengths developed by the mat-reinforced E-glass/ epoxy products (bars 5 and 6, Fig. 1) are substantially lower than those developed for the warp direction of fabric-reinforced E-glass/epoxy products. But the strength ifference is less when compared to the fill direction of the fabric products. It is expected that the strength of the mat products would exceed that of the fabric products in a $45^{\circ}$ direction from warp and fill.

CERN (9) reports that a commercial polyimide-matrix laminate (Silirite 64 400) developed 7-10\% lower average tersile strength than did bisphenol A epoxy laminates having similar type and content of glass reinforcement (bar 7 , Fig. 1).

The data presented for glass fabric-reinforced melamine (bar 8, Fig. 1) are typical values reported by the manufacturer (11). This type of laminate is commercially produced as NEMA G-5. Data presented 
for glass fabric-reinforced polyester (bar 9, Fig. 1) reflect average data summarized in the literature for a variety of such laminates (11). Glass reinforced laminates all strengthen substantially on cooling. These data suggest that the average tensile strength of epoxy-matrix 1 aminates will increase $45-55 \%$ over the room temperature values, whereas the polyimide, melamine and polyester laminates increase about $35-40 \%$. Despite its fairly wide use, little is known of the effect of cryogenic temperatures on the strength of cotton-reinforced phenolic laminates.* The data appearing in Figure 1 reflect one manufacturer's published data on its proprietary NEMA type CE product (11). Strengths obtained from other manufacturers' products or from the NEMA type LE cotton/phenolic product may differ substantially. But there is no doubt that the strength of the cotton/phenolic product is inferior to that of the glass-reinforced products.

The CERN data (9) on the pitch-base HM-S graphite fabric (Thornel PVCB 45) and on aramid fabric (Kevlar 49) reinforced epoxy laminates summarized on Figure 1 represent the first cryogenic data obtained on these materials. The aramid laminate displays a significant average strength reduction on cooling--possibly a manifestation of internal stresses created by the very large negative coefficient of thermal expansion of this fiber type. The comparatively low strength of the graphite fabric reinforced product reflects the low strength of the inexpensive pitch-based fiber used in its construction. A comparable

*The term Micarta is often used when referring to cotton-reinforced phenolic industrial laminates. However, Micarta is the trade name designating all industrial laminates produced by the Micarta Div., Westinghouse Electric Corp. 
laminate reinforced with graphite fabric using fiber derived from the more expensive polyacrylonitrile (PAN) precursors should develop about twice the tensile strength of the pitch-based product.

The compressive strength data presented on Figure 2 reflect both the warp direction and normal direction where such data are available. The direction designated "normal" is normal to the plane of reinforcement for fabric-reinforced laminates and is parallel to the pressing direction during laminate cure for mat-reinforced laminates.

These data suggest that cryogenic applications requiring compressive strength in the normal direction may be well served by some of the less expensive fabric-reinforced 1 aminates such as the melamine-matrix NEMA G-5 (Bar 4, Fig. 2) or by mat-reinforced laminates (Bar 3, Fig. 2). These laminates, the G-11CR grade of glass/epoxy and the NEMA CE cotton/ phenolic products develop higher average compression strength in the normal direction than in the direction of reinforcement. The NEMA G-10CR product is the only laminate for which the average warp direction compressive strength is reported to exceed that of the normal direction.

The data for G-11CR, G-10CR and for chopped-mat glass/epoxy (Bars 1, 2 , and 3 Fig. 2) represent systematic studies of well characterized materials. Data for NEMA G-5 and CE (Bars 4 and 6, Fig. 2) are manufacturers' typical data. Glass/polyester data reflect the average of literature values.

NBS data (6) indicate that testing in the fill direction of the fabric reinforcement reduces the average ultimate compressive strength by about $30 \%$ for the G-10CR product and by about $24 \%$ for the G-11CR product. 
Interlaminar shear strength, the resistance to shear between the layers of a layered laminate, has become an important design property in large superconducting magnets where glass-fabric reinforced composites are used for electrical insulation and for structural support of superconducting windings. The interlaminar shear strength of the selected materials must be adequate to resist electromagnetic forces within the magnet. The guillotine test method described by ASTM method D2733-70 is the most appropriate. However, the application of this method as described in ASTM standards has been found to yield extremely variable results. In response to the needs of the MFE research efforts, NBS and the MIT Francis Bitter National Magnet Laboratory have refined the test method as described in a subsequent section of this paper.

The temperature/orientation dependence of interlaminar shear in a G-10CR glass-fabric reinforced epoxy industrial laminate appearing on Figure 3 has been reported by MIT (15). NBS data for the warp $\left(0^{\circ}\right)$ direction are in agreement with these data. NBS data for the warp direction of G-11CR noted by circles on Fig. 3 indicate a somewhat lower average interlaminar shear strength for this material.

Data on the average change in laminate strength properties on cooling are useful in comparing cryogenic and room temperature performance. But such data can be misleading from a design standpoint. Here the relevant data are the lower bound of performance--not the average. It is frequently observed that the variatility in strength properties increases with increases in average strength on cooling. The variability appears to be less for the lower strength fabric and mat-reinforced laminates than for the higher performance uniaxial laminates discussed in a later 
section; nevertheless, it is a factor to consider in all laminate types. Variability arises intrinsically due to embrittling and increased notch sensitivity of the polymer matrix in a cooled laminate. It is therefore a larger factor in properties such as shear and compression which are most dependent on matrix properties. Variability is a strong function of the quality of laminate manufacture. In particular, high void contents and resin rich areas must be avoided. Least variability will be experienced with laminates fabricated under the close control exercised by large industrial laminating firms, particularly when a controlled-specification products such as the CR grades are produced. Low pressure laminating techniques such as vacuum bagging and autoclaving used to fabricate components directly to complex shapes can be expected to produce laminates having an inherently larger variability.

\section{Elastic Properties}

Some recent data on the effect of cryogenic temperatures on Young's modulus are presented on Figure 4 for the warp direction of fabric laminates and for the edgewise direction of mat-reinforced laminates. Where data are available, a distinction is made between the change observed between 295 and $76 \mathrm{~K}$ and that observed between 76 and $4 \mathrm{~K}$. In contrast to strength data, the moduli data show a monotonically increasing stiffness with decreasing temperature. Specific identification of the materials is the same as for Figure 3.

The CERN data (9) provide the first cryogenic information on pitchbase fabric graphite/ epoxy laminates and illustrate the stiffness superiority of this type laminate over conventional woven-fabric materials. 
The high modulus is a direct reflection of the high modulus of the graphite fiber. On the other hand, the CERN data indicate that the much higher modulus of aramid fiber (124 GPa, $\left.18 \times 10^{6} \mathrm{psi}\right)$ compared with that of E glass ( $72 \mathrm{GPa}, 10.5 \times 10^{6} \mathrm{psi}$ ) is not reflected in the moduli of woven-fabric laminates. The aramid-fabric laminates produced an average Young's modulus very similar to that of the E-glass laminates for equivalent fiber mass fraction.

Bars 1-4 of Figure 4 show that Young's modulus is directly related to glass content. This again illustrates the significant effect of glass content on laminate performance. The type of matrix has much less effect because its modulus is typically an order of magnitude lower than that of the glass reinforcement. These data indicate that the average modulus of glass fabric-reinforced polymer laminates will increase about $20 \%$ upon cooling to $4 \mathrm{~K}$.

The data presented on Figure 4 were obtained either from strain gaged specimens or from extensometer data. NBS has also studied the elastic properties of $\mathrm{G}-10 C R$ and $G-11 C R$ materials by dynamic resonance methods (16-18). As illustrated on Figures 5 and 6 , this method can generate a continuous temperature-modulus curve for either the laminate or the resin used in the laminate construction. Results, thus far obtained, by the dynamic method agree reasonably well with those obtained by conventional techniques. But the dynamic method has much improved sensitivity. For example, the large difference in the temperature dependence of Young's moduli of the G-1OCR and G-11CR resin systems illustrated on Figure 6 is apparent in the differing temperature dependences noted for the G-TOCR and G-1TCR warp direction laminate moduli 
on Figure 5, but it is not apparent in data obtained from strain gaged specimens. Figure 5 illustrates that the temperature dependence of Young's modulus for the G-10CR resin is substantially greater in the direction normal to the reinforcement than in the warp direction.

Data presented on Figure 4 indicate that a polyimide-matrix laminate (Bar 8) will have a Young's modulus very similar to that of an epoxy matrix laminate of similar glass content (Bar 4).

The epoxy matrix laminate data on Figure 4 indicate a higher Young's modulus than was reported for such laminates in the 1975 review (1). This occurs because the earlier data reflected literature averages and did not distinguish between moduli in the warp and fill directions. The anisotropy of reinforcement results in anisotropy of Young's modulus as illustrated for G-10CR on Figure 7. These data suggest that average moduli values reported for the E-glass fabric bisphenol A epoxy laminates on Figure 4 would decrease about $40 \%$ if the moduli were evaluated in the $45^{\circ}$ direction relative to the warp and fill of the fabric.

The Young's moduli of mat-reinforced laminates (bars 5 and 6 Figure 4) are substantially lower than those of fabric-reinforced laminates when the latter are tested in the warp direction. However, the difference decreases if the aforementioned orientation effect is considered. The Young's modulus of a mat-reinforced product is essentially isotropic in the plane normal to the pressing direction during laminate cure (edgewise direction).

Elastic properties are intrinsically less variable than strength properties. 


\section{Thermal Properties}

Recent data on the temperature dependence of thermal expansion and thermal conductivity of woven fabric and of random mat laminates are summarized on Figures 8-10.

CERN (9) reports the first cryogenic thermal property data for graphite and aramid-fabric reinforced epoxy laminates. Figure 8 shows that the negative coefficients of thermal expansion of graphite and aramid fibers combine with the positive coefficient of the epoxy resin to yield laminates with a high degree of dimensional stability in the warp direction (bars 10 and 11 ). The aramid laminate is more stable than the graphite laminate of similar fiber content owing to the higher negative coefficient of thermal expansion of the aramid fiber. The stability of these products would be lower in the fill direction for an unbalanced-weave fabric and would be still lower in the direction normal to the reinforcement.

The thermal contraction of epoxy resins on cooling is about an order of magnitude greater than for glass (19). Bar 12 on Figure 8 summarizes the contraction for a CY $205+$ HY $905+$ DY $040+$ DY 061 resin system evaluated by CERN. The data on Figure 8 indicate that the contraction of a glass fabric-reinforced laminate is about $60 \%$ of the contraction of the unreinforced resin in the normal direction and about $20 \%$ of the resin contraction in the warp direction. Contractions of the aramid and graphite-reinforced laminates in the warp direction are only about $5 \%$ of that of the unreinforced resin. This difference is reflected in residual laminate stress. The comparatively small dimensional changes observed on cooling from $76 \mathrm{~K}$ to $4 \mathrm{~K}$ indicate that most of the residual stress created by cooling occurs in the $295 \mathrm{~K}$ to $76 \mathrm{~K}$ temperature range. 
This stress is added to that created during cooling the laminates to $295 \mathrm{~K}$ from the elevated cure temperature. The low modulus of epoxy (about 0.1 that of glass) results in most of the stress being resolved onto the matrix.

The glass content would therefore be expected to play a significant role in establishing contraction in the fiber direction. But such a correlation is not evident in the data on Figure 8 .

The thermal contraction of mat-reinforced laminates in the edgewise direction is substantially higher than that for fabric-reinforced laminates in the warp direction. This is due to the random fiber orientation and lower glass content of the mat product. But contraction of the mat products is isotopic in the edgewise direction while that of the fabric product is anisotropic. Thermal contraction of fabric-reinforced laminates in a $45^{\circ}$ direction relative to warp and fill would probably be greater than that of the mat-reinforced laminates in the normal direction.

Figures 9 and 10 summarize data reported on the temperature dependence of thermal conductivity for a variety of well-characterized industrial laminates $(6,9,10,11)$.

Figure 9 compares the conductivity of a series of E-glass reinforced bisphenol A laminates and for two unreinforced bisphenol A epoxy resins. The NBS data were obtained in the warp and normal directions on NEMA G-10 and G-11 laminates produced to the CR grade specification (bars 1 and 2) and on the epoxy systems used for these grades (bar 3). Although different resin systems are used for the two CR grades, their conductivities were sufficiently similar (within 5\%) to justify their combination into a single bar on Figure 9 (20). CERN (9) characterized one 
European commercial industrial laminate (Vetronite 432.86 ) in both the warp and normal direction (bar 4) and a series of other commercial industrial laminates in the normal direction. Five laminates had very similar conductivites despite variations in glass content from 62-74 percent by weight (bar 5). One CERN laminate (Vetronite 541.02) displayed a significantly lower conductivity than the others (bar 6). CERN also measured the thermal conductivity of a bisphenol A epoxy resin system (CY $205+$ HY $905+$ DY $040+$ DY 061) typical of that used in the laminates (bar 7). Bar 8 reflects data obtained by a leading industrial glass research company on a glass mat-reinforced epoxy product developed for LNG use. Data on this product are available only to $76 \mathrm{~K}$.

As a group, the NBS data reflect a much higher thermal conductivity at 295 and $76 \mathrm{~K}$ than do the CERN data. Since the type and content of reinforcement is about the same in all the laminates, it would appear that the difference lies in the higher conductivity of the resin used in the NBS laminates (bar 3) compared that used by CERN (bar 7). A comparison of the data on Figure 9 with previously published literature averages for thermal conductivity of glass fabric-reinforced laminates (1) shows that such averages correlate well with the CERN data. Work to clarify this apparent discrepancy is presently underway at NBS.

Figure 10 compares the CERN data (9) on the temperature dependence of thermal conductivity for E-glass fabric-reinforced silicone (Vetronite 432.91) and polyimide laminates (Silirite 64 400, Imelite 6101 ) and for aramid (Kevlar 49) and graphite-fabric (Thornel PVCB 45) reinforced bisphenol A epoxy laminates. All data are for the direction normal to the reinforcement. 
The comparatively high thermal conductivity of the graphite-fabricreinforced laminate (bar 5 ) is due to the relatively high conductivity of graphite compared to glass. The E-glass reinforced polyimide laminates (bars 2 and 3 ) have conductivities very similar to those reported by CERN (9) for epoxy matrix laminates (cf Bar 5, Fig. 9). This suggests that the thermal conductivity and the temperature dependence of conductivity are very similar for polyimide and epoxy resins.

The normal direction thermal conductivity for the glass/silicone and aramid/epoxy laminates are substantialiy lower than for glass/epoxy laminates of equal fiber mass fraction. Normal direction conductivity for cotton phenolic laminates (phenolformaldehyde resin) is similar to that for glass/epoxy laminates.

The author is unaware of any substantial contribution to the characterization of specific heat properties of fabric or mat-reinforced laminates within the cryogenic range since the earlier reviews $(1,2)$. Heberlein (21) has published data indicating that the specific heat of E-glass laminates might be substantially lower than that for laminates fabricated with $S$ glass. But these data did not extend below $230 \mathrm{~K}$.

\section{Electrical Properties}

The effect of cryogenic temperatures on the volume resistivity and electrical strength of G-TOCR and G-1TCR glass fabric-reinforced epoxy Taminates is summarized on Table I (6). These are the first data obtained on these parameters at $4 \mathrm{~K}$. Although the data are not extensive, they indicate that the electrical strength will be independent of both temperature and material. The effect of temperature on the volume resistivity is similar for the two materials, increasing 1.5-2 orders of magnitude on cooling from $295 \mathrm{~K}$ to $4 \mathrm{~K}$. 


\section{OVERVIEW}

Composites reinforced with uniaxial glass, graphite, boron or aramid fibers continue to have limited and specialized applications in cryogenic technology. The aerospace industry is using graphitereinforced laminates for dimensionally stable mirrors and reflectors (4). The relatively small structures already flown have functioned well in the temperature range down to $100 \mathrm{~K}$. Primary concern is predictability of dimensional stability in the very large reflectors presently being designed for use in outer space.

The desire to reduce the weight of superconducting machinery and of superconducting magnetohydrodynamic power generators has provided the primary impetus for continued study of the performance of advanced composites at cryogenic temperatures. Most of the related research has been carried out by NBS with the assistance of U.S. industry (22-25) and by CERN (9).

The 1975 review (2) indicated that uniaxial glass, graphite, boron and aramid fibers were all viable reinforcements for cryogenic laminates. It was shown that a wide variety of polymer matrices could be used, although epoxy systems emerged as the favorite choice. A primary problem was the large variability in the mechanical property data reported in the literature. Unfortunately, it was not possible to distinguish inherent material variability from experimental variability. The experimental problems are now under better control, al though much remains to be done in that area. Improved test methods have established that the earlier indications of strength degradation in graphite-reinforced epoxy 
laminates on cooling were incorrect. Further work has also shown that the use of highly flexibilized resin systems is counter productive in the advanced composites as well as in the glass-reinforced products. Conventional, fully reacted resin systems are the best current choice for high-modulus fiber laminates intended for cryogenic use.

Recent characterization studies on advanced composites have produced mechanical property data of the type required for prediction of the properties of complex angleply laminates using macromechanical laminate theory $(26,27)$. These data, obtained from uniaxial laminates, consist of longitudinal and transverse uniaxial strength, modulus and Poisson's ratio plus in-plane shear strength and modulus. Laminates reinforced with S glass; high, medium and low modulus graphite; boron and aramid fibers have now been characterized in this manner. Results of these studies have been published in NBS reports (24) and in the open literature $(22,23,25)$.

\section{DATA ANALYSIS}

The most recent data on the temperature dependence of the significant mechanical and thermal propertie; of uniaxial fiber reinforced composites are summarized on Figures 11-17. Bar graphs are again used to illustrate trends of strength changes from room temperature to the cryogenic temperature range for data obtained at fixed cryogenic boiling points. The average of data reported at $76 \mathrm{~K}$ and $4 \mathrm{~K}$ are plotted except where the data show a statistically significant change in a property between these temperatures. Data obtained at closely-spaced temperature intervals are presented as continuous curves. 
The uniaxial longitudinal and transverse tensile strengths of glass-, boron-, graphite- and aramid-reinforced epoxy laminates reported by NBS (22-25) and by CERN (8) are summarized on Figure 11 .

Data for epoxy matrix laminates uniaxially reinforced with three types of glass appear on Fig. 11. Typical compositions of each glass are given on Table II.

Type S glass was developed during the early 1960's as a highstrength glass for specialized aerospace purposes. The 901 designation refers to a special solvent-sizing system used with this high-cost, military-specification product. The use of $S$ glass is confined to filament-wound or uniaxial prepreg tape products. Most of the cryogenic data on uniaxial glass-reinforced epoxy laminates have been generated with Type $S$ glass. But potential users should also consider the recently introduced commercial grade of $S$ glass produced under the trade designation S-2. For reportedly comparable room temperature properties, type S-2 is a much lower cost product (28). There are presently no cryogenic data for laminates fabricated from S-2 glass. Type S-2 glass is available in woven fabrics as well as uniaxial fiber.

Type $E$ is the standard electrical insulating grade of glass, most often used in fabric-reinforced industrial laminates but also available in uniaxial form. It is substantially less expensive than types $S$ or $S$ 2. Type $R$ is a glass of European manufacture used in laminates evaluated by CERN (9).

These data show that the uniaxial tensile strength of the S-901 glass/Resin 2 laminate averages approximately $30 \%$ higher than that of 
the E-glass/bisphenol A laminate at room temperature and about $50 \%$ higher at cryogenic temperature. This difference is consistent with published data on the comparative strengths of the two glass types (28). The R-glass/bisphenol A laminate developed uniaxial tensile strengths intermediate between that of the S-901 and E-glass laminates.

Uniaxial longitudinal tensile properties are expected to be fiber dominated. But there is evidence in the literature that the average strength reported for the S-901 laminate on Fig. 11 has been substantially lowered by the use of the highly-flexibilized Resin 2 epoxy formulation Handbook data (29) suggest that the room temperature tensile strength of this laminate is about 30\% 1ower than expected from an S-901 glassreinforced laminate of equal glass content in a conventional, fully reacted epoxy matrix. Cooling has increased the strength of the S$901 /$ Resin 2 laminate, but only to a value expected for a conventionalmatrix laminate at room temperature. A similar discrepancy between the strengths of S-901-glass reinforced laminates involving the two types of matrices was documented in a review article published by the author in 1975 (3), but the implication was not recognized at that time.

The useful strength of glass-reinforced laminates at cryogenic temperatures will be much lower than the ultimate strength whenver damage accumulation in the matrix is unacceptable. Uniaxial glass-reinforced laminates have failure strains approaching $3 \%$ at $4 \mathrm{~K}$; however, the embrittled matrix. will typically fail at less than $1 \%$ strain--about $20-30 \%$ of the ultimate fracture stress. The stress level corresponding to the onset of matrix damage may therefore be lower at cryogenic temperatures than at room temperature. This factor makes Type $S$ glass less 
functionally attractive compared to Type E glass for applications where the increased damping and the slightly decreased modulus accompanying matrix damage cannot be tolerated. Similar functional strength limitations do not exist for laminates reinforced with high-modulus fibers such as graphite or boron for which the ultimate strain to failure is 1 ess than $1 \%$ at all temperatures.

Figure 11 indicates that the graphite-reinforced laminates are much better cryogenic materials than was indicated by data available in 1975 (2). The latter data, compiled from literature sources, suggested that cooling would lower the tensile properties of graphite-reinforced epoxies as a group. Correlation between laminate and fiber properties was not observed and a large scatter in temperature dependency of strength properties was reported. Figure 12 shows that this behavior is not confirmed by the more recent studies at NBS and CERN. It now appears that the effect of cryogenic temperatures on the average uniaxial longitudinal tensile properties is minimal for these materials.

The properties of the matrix and of the matrix-fiber bond strongly influence the uniaxial transverse tensile strength. Thus, the very high transverse strength illustrated for boron-reinforced aluminum on Figure 11 reflects the strength of the 6061 aluminum alloy matrix. The low transverse strength observed for the AS/Resin 2 graphite laminate at $295 \mathrm{~K}$ reflects the weakness of this highly-flexibilized resin at higher temperatures, while the significant decrease in strength on cooling is attributable to a high state of internal stress arising from the high thermal contraction of this resin system combined with the negative 
coefficient of thermal expansion of the graphite fiber. Work at NBS (24) has shown that the average transverse strength of an unflexibilized, conventional, high-strength graphite laminate averages $48 \mathrm{MPa}\left(7 \times 10^{3} \mathrm{psi}\right)$ at $4 \mathrm{~K}$; over $300 \%$ higher than that developed by the flexibilized-matrix Taminate.

The tensile data for unreinforced bisphenol A epoxy illustrated on Figure 11 is reported by CERN for a CY $205+$ HY $905+$ DY $040+$ DY 061 system. The data should be typical of that developed by conventional, fully reacted epoxy resin systems. Lower transverse tensile strengths of the laminates compared to the resin strength indicates low interfacial bond strengths in the laminates.

Recent data on the temperature dependence of the uniaxial longitudinal tensile strength of aramid-fiber-reinforced epoxy appearing on Figure 11 is in agreement with prior literature values (2). These data and the newly acquired data on the uniaxial transverse tensile strength appear to be temperature independent.

The aramid laminate data appearing on Figure 11 reflect average properties of a conventional laminate system. The large negative coefficient of thermal expansion of aramid fiber has led to the belief that the cryogenic performance would be improved if a highly flexibilized matrix such as the Resin 2 formulation was used to accomodate the differential contraction. But NBS studies of the performance of an aramid-fiber laminate using the Resin 2 system has shown that its use is counterproductive. The transverse tensile strength of this combination was found to be so low (0.3 MPa, $42 \mathrm{psi}$ at $245 \mathrm{~K}$ and $0.1 \mathrm{MPa}, 17 \mathrm{psi}$ at $76 \mathrm{~K}$ ) as to render the laminate almost useless for structural applications at any temperature. 
Again, it is believed to be the weakness of the resin at $295 \mathrm{~K}$ and the development of a high state of internal stress at cryogenic temperatures that destroys the performance of the laminate.

Reliable compressive strength properties are difficult to obtain in composite materials. A primary difficulty is the strong dependence of measured values on specimen alignment and on proper specimen support. The large surface-to-volume ratio of typical specimens accentuates the significance of surface flaws. Particularly for the uniaxial longitudinal mode, values tend to have a distribution function which is highly skewed toward low values. The magnitude of the scatter increases as the compression strength increases. Average values of compression data obtained from laboratory tests therefore tend to be systematically biased toward lower values than the true intrinisic material strength. The maximum compression strength values obtained in a test series may more accurately reflect the true compression strengths of high-strength composites than does the mean of the distribution. Uniaxial transverse compressive strength data show comparatively little scatter and a relatively normal distribution. Here, the distribution mean is perhaps the most meaningut indication of compression strength.

Figure 13 summarizes the most recent data obtained by NBS (23-24) on the effect of cryogenic temperatures on compressive strengths. A comparison is made between the uniaxial longitudinal and transverse compressive strengths of epoxy laminates reinforced with glass, boron, graphite and aramid fibers and aluminum reinforced with boron. All data were obtained by an unsupported beam test method. 
Results suggest that the intrinsic uniaxial longitudinal compressive strength of typical $(0.14 \mathrm{~mm}, 5.6 \mathrm{mil}$ diameter) boron-reinforced laminates is on the order of $3450 \mathrm{MPa}\left(500 \times 10^{3} \mathrm{psi}\right)$ at cryogenic temperatures. Differences in strength noted for the epoxy and aluminum-matrix products are attributable to the noted differences in fiber content. These data are at variance with prior data (2) which had indicated a negligible temperature dependence of compressive strength for boron-reinforced aluminum. The recent data also indicate a much higher compressive strength than previously reported in the literature for unsupportedbeam tests. The data on Figure 13 approach calculated compressive strengths based on sandwich-beam specimens (30). Comparative room temperature data were not available for these boron-reinforced materials.

The boron-reinforced materials are clearly the strongest laminates in the transverse as well as in the longitudinal compression. The transverse compressive strength of the 5.6-mil boron-aluminum laminate is substantially better than that reported in 1975 (2). Cooling from 76 to $4 \mathrm{~K}$ improves the transverse strength of the aluminum-matrix material while having little effect on the epoxy-matrix laminates. This is due to the substantial (20-40\%) increase in strength of the 6061 aluminum matrix between these two temperatures (31).

S-901-glass laminates develop compressive strengths about half that of boron laminates, followed in strength by the graphites. Aramid laminates have the lowest compressive strength. But the use of the highly flexibilized Resin 2 epoxy matrix appears to have reduced the compressive properties of the S-901 and type AS graphite laminates compared with similar laminates using conventional epoxy resin matrices. The 
room temperatures values reported for the S-901/Resin 2 laminate on Figure 13 are about 20\% 1ower in the longitudinal direction and about $50 \%$ lower in the transverse direction than that reported for a similar laminate using a conventional resin system (3M XP251S) in MIL-HDBK17A (14). As was the case with the tensile properties of this material, cooling substantially improved the compressive strength of the S-901/Resin 2 laminate at cryogenic temperatures. But improvement in the transverse direction is only sufficient to return the laminate to a transverse compression strength expected from a conventional laminate at room temperature. The deleterious effect of using the highly flexibilized epoxy resin was also seen in the low strengths developed in the laminate reinforced with type AS graphite fiber. Despite a high inherent fiber strength, the longitudinal compressive strength of this laminate has been reduced to no higher values than that obtained with the much lower strength GY-70 fiber laminate. Furthermore, a significant reduction in longitudinal compression strength is noted for the AS/Resin 2 laminate on cooling from 76 to $4 \mathrm{~K}$, a phenomenon not observed in the other laminates. A deterioration in compressive strength is also evident in the transverse direction for this laminate.

The comparatively low longitudinal compressive strength of the aramid-fiber laminate reflects low compressive fiber properties. The strength is low both in comparison to the other type of laminates and as a percentage of its uniaxial tensile strength. The difference is not as noticeable in the transverse compression test mode where strength is more influenced by matrix properties. 


\section{Elastic Properties}

Figure 14 summarizes the data obtained by NBS (22-25) and by CERN (9) on the temperature dependence of Young's modulus in tension for uniaxial longitudinal and transverse directions of glass-, boron-, graphiteand aramid-reinforced epoxy laminates.

Only the aramid-reinforced epoxy laminate displayed a significant temperature dependence in the longitudinal direction. Present values the aramid laminate are significantly lower than values reported for this type laminate in the earlier literature review (2). Furthermore, the substantial modulus increase reported to occur in aramid-reinforced epoxy laminates below $76 \mathrm{~K}(32)$ was not observed by NBS.

The longitudinal tensile moduli of glass-reinforced laminates are dominated by the moduli of the glass which is about an order of magnitude higher than that of the conventional bisphenol A epoxy system illustrated on Figure 14. The longitudinal modulus of a glass-reinforced laminate is therefore strongly dependent on the volume fraction of glass in the laminate. It is also influenced by the type of glass reinforcement. The modulus of type E glass is $10-20 \%$ lower than that of the $S$ type (28). The high transverse modulus reported for the S-901-glass laminate suggests that the type of glass, and perhaps the finish on the glass, has a strong influence on modulus in this direction.

The S-901-Jlass laminate displays a large percentage increase in transverse modulus on cooling. This reflects hardening of the highly flexibilized Resin 2 epoxy matrix in this material. However, a comparison of the present S-901 laminate data with handbook values (29) 
shows that the Resin 2 laminate must be cooled to cryogenic temperatures before developing a modulus equal to that produced at room temperature by a conventional S-glass laminate using a nonflexibilized, fully reacted epoxy resin system.

The boron-reinforced laminates provide an excellent combination of longitudinal and transverse tensile moduli. Doubling of the transverse modulus of the boron/epoxy material is the only significant temperature effect.

The Young's modulus in tension of the AS/Resin 2 laminate is $20-25 \%$ lower in both the longitudinal and transverse direction than expected for a laminate reinforced with this type of fiber in a conventional, fully reacted epoxy matrix (30).

The temperature dependence of inplane shear moduli summarized on Figure 15 represents the first cryogenic data obtained on this parameter. These data, obtained by the $\pm 45^{\circ}$ tensile coupon method (33), indicate a substantial increase of average shear modulus for all types of laminates studied. In-plane shear modulus is strongly influenced by the modulus of matrix. Values reported for the S-901-glass and type AS-graphite laminates on Figure 15 are therefore lower than would be expected in conventional laminates due to the low room temperature shear strength of the highly flexibilized Resin 2 epoxy formulation used in their farbication.

\section{Thermal Properties}

Recent data on the effect of cryogenic temperatures on dimensional stability and thermal conductivity of uniaxial laminates are summarized on Figures 16 and 17. 
Figure 16 summarizes data on the effect of temperature on dimensional stability of well characterized epoxy-matrix laminates reinforced with glass, boron, and graphite and of boron-reinforced aluminum. Data are also provided on the stability of a typical, fully reacted bisphenol $\mathrm{A}$ epoxy resin system and on the highly flexibilized Resin 2 epoxy resin system used with several of the laminates.

The thermal contraction of the laminates is much less than that of the matrix materials. Particularly in the fiber (longitudinal) direction, the reinforcement properties dominate the contraction because the reinforcement modulus is much higher than that of the matrix. The longitudinal modulus is therefore dependent on the fiber volume fraction as well as on the type of fiber, with the matrix playing a minor role.

Thermal stability in the transverse direction of uniaxial laminates is influenced by both matrix and reinforcement properties. A further analysis of the data of Figure 16 shows that the transverse contraction of the glass- and graphite-reinforced bisphenol A laminates (fiber types $R, E, H M-S)$ was about $52 \%$ of that expected for the unreinforced bisphenol $A$ resin, whereas the glass- and graphite-reinforced Resin 2 laminates (S901, AS) contracted about 35\% of that expected from unreinforced Resin 2. The lesser contribution of the Resin 2 matrix to the laminate contraction is due to the low modulus of this highly flexibilized resin at temperatures above the cryogenic range. Comparable values for the boron/epoxy and boron/aluminum laminates are $32 \%$ and $63 \%$, respectively. Here, the comparatively low transverse contraction of the epoxy laminate is due to the very high modulus of the boron compared with the epoxy. The aluminum contributes more to determining the contraction of the laminate because its modulus is much higher than that of epoxy. 
The temperature dependence of thermal conductivity for uniaxial laminates in the longitudinal and transverse direction are summarized on Figure 17. Data for an unreinforced conventional bisphenol A epoxy is included for comparison. All of the epoxy-matrix laminates used a conventional epoxy system. The boron/aluminum laminate had a 6061 aluminum alloy matrix.

Uniaxial laminates are most frequently used as thermal standoffs in cryogenic technology because of the low conductivity of the epoxy-matrix products combined with excellent strength properties. Glass-reinforced epoxy composites are favored because, as illustrated on Figure 17, they provide lower conductivity in the fiber direction than boron, graphite, or aramid-reinforced composites. Boron and aramid-reinforced laminates appear to have about the same conductivity in the longitudinal direction-approximately $20 \%$ higher than that of the glass laminate. The graphitereinforced epoxy laminate has a longitudial conductivity about $45 \%$ higher than that for glass reinforcement. The very high conductivity of the aluminum-matrix laminate limits its use to applications having minimum thermal gradients or to specialized applications where a high thermal conductivity is desired.

Transverse conductivities are all lower than in the longitudinal direction regardless of the relative conductivities of the fiber and matrix. This reflects the thermal resistance of the fiber-matrix interface in the transverse direction.

The aramid-reinforced epoxy laminate displays the largest change in thermal conductivity on cooling. The transverse conductivity data 
plotted for this material on Figure 17 were measured in the direction normal to the reinforcement of a fabric-reinforced laminate (9). It is therefore only an approximation to the transverse conductivity of a uniaxial laminate. But the approximation should be quite good for similar fiber contents in the two types of laminates.

\section{FUNDAMENTAL RESEARCH}

When composites first became of interest for cryogenic applications during the space programs of the 1960 's, it was commonly believed that the primary problem would be the embrittling effect of low temperatures on the polymer systems used for laminate matrices. Research (34) led to the development of an epoxy system known as Resin 2*. The unreinforced resin provided improved shock resistance and low temperature strain capability through the addition of flexibilizing agents. This system was intended for filament winding of cryogenic pressure vessels. The maximum filament stress attainable at cryogenic temperatures was reportedly improved with the Resin 2 formulation compared with that attainable using conventional epoxy systems (34). But, as is clear from the data summarized in preceeding sections of this review, extending the use of the Resin 2 formulation to glass-, graphite- and aramid-fiber reinforced laminates fabricated by other means is counter productive. The mechanical performance of laminates using Resin 2 epoxy is distinctly inferior to laminates fabricated with conventional, fully reacted epoxy resin systems at both cryogenic or room temperature. It now appears that room temperature performance is degraded by the extreme weakness of the resin and cryogenic performance is degraded by high levels of residual stress created by the large thermal contraction of the Resin 2

\footnotetext{
*Epon 828/DSA/Empol 1040/BDMA in proportions 100/115.9/20/1 pbw.
} 
systems compared with that of conventional resin systems. Such stresses substantially limit the effective strain capability of the laminates at $4 \mathrm{~K}$.

Conventional, fully reacted epoxy resin systems are therefore the best current choice for the matrices of laminates to be used at cryogenic temperatures. But the need to develop improved matrix performance for cryogenic laminates remains. The range of useful stress obtainable at cryogenic temperatures is limited in conventional glass-reinforced laminates by the onset of damage in the embrittled matrix at stresses on the order of $20-30 \%$ of the ultimate laminate stress. This is lower than the useful stress at room temperature, despite the much higher ultimate fracture stress at low temperature. Extension of this useful range by improving the effective cryogenic strain capability of the laminate matrix is very desirable. An improved matrix resin would also reduce the microcracking observed in some angleply graphite-reinforced laminates subjected to thermal shock.

But the primary benefit expected from such a resin system is reduced variability in cryogenic strength properties. A major contributor to the variability displayed by conventional laminates is the decrease in toughness and increase in notch sensitivity of fully reacted epoxy resin systems when cooled to cryogenic temperatures. This causes the laminates to become very sensitive to the presence of flaws. In fracture mechanics terms, the critical crack size becomes extremely small. An illustration of this effect is provided by Figure 18 , which summarizes the range of uniaxial longitudinal compressive values obtained during NBS testing of a series of graphite-, glass- and boron-reinforced laminates at $295 \mathrm{~K}$, $76 \mathrm{~K}$ and $4 \mathrm{~K}$. The data have been normalized at $295 \mathrm{~K}$ to illustrate differences in the magnitude of the data spread for each material upon 
cooling. A positive correlation is noted between the amount of data scatter and the average increase in compression strength on cooling. Comparison with Figure 13 shows a positive correlation also exists between variability and inherent compressive strength of the materials. This illustrates that a flaw in the embrittled matrix has increasing significance as compression strength increases. Variability attainable to the increasing notch sensitivity of the resin matrix is a particular problem in compression, shear and off-axis tension properties.

Possibilities for improving epoxy systems for use in cryogenic composite laminates have been recently addressed by Kreibich, Lohse, and Schmid (35) and by Hartwig (36). The possibility of achieving cryogenic flexibility by modifying epoxy resins to facilitate rotational modes of long-chain molecules (crankshaft rotation) is being considered. Such a system would theoretically retain good room temperature strength, have a relatively low thermal contraction, and provide improved cryogenic toughness. Frank (37) has also contributed to the fundamental understanding of polymer embrittlement by considering the role that far infrared spectroscopy can play in assessing the degree of crystallinity existing at cryogenic temperatures. Schmid (38) has considered the connection between secondary valence forces, primary valence energies and low temperature flexibility of polymers.

Kneifel (39) has described some of the initial work undertaken at the Institut für Experimentelle Kernphysik, Karlsruhe, Germany, on the fracture properties of epoxy resins at low temperatures. This work has shown that the fracture toughness, $K_{I C}$, of rigid and semiflexible resins is much higher at $76 \mathrm{~K}$ than at $5 \mathrm{~K}$, indicating the presence of relaxation 
processes at $76 \mathrm{~K}$. A substantial difference was noted in the $5 \mathrm{~K}$ fracture toughness among rigid, semiflexible and flexible epoxy resin systems at room temperature. It is perhaps significant that the flexibilized resins did not show the highest $5 \mathrm{~K}$ toughness.

The conference on Nonmetallic Materials and Composites at Low Temperatures held in Munich, West Germany July 10-11, 1979 (4, 16, 35-39) was a valuable forum for technology transfer in these fundamental areas. Additional conferences addressing this subject are planned by the International Cryogenic Materials Conference (ICMC). 
Variability of reported data on the mechanical performance of composite materials at cryogenic temperature has been identified in this paper as a significant concern. The variability arising from the experimental procedure must be minimized to allow inherent material variability to be assessed.

Cryogenic temperatures increase the difficulty of obtaining valid test results. The cost of cryogenic testing tends to put practical limits on the number of specimens used to evaluate a parameter. Furthermore, the high surface-to-volume ratio of typical laboratory specimens enhances the probability of premature failure due to the embrittling effect of cryogenic temperatures on the resin matrix.

Techniques for obtaining valid fractures within the gage length sufficiently remote from grip effects during uniaxial longitudinal laminate testing have been reasonably well solved at NBS (22-23) and at CERN (40). The technique is to design a grip system permitting some Poisson's contraction to take place during the test within the portion of the grip nearest to the gage section, thereby minimizing stress concentrations in that area. Compression test fixtures which work well at $4 \mathrm{~K}$ have been developed at NBS (23) and refined at CERN (40). Problems of minimizing liquid helium consumption, of achieving proper specimen alignment and of achieving proper specimen support are fairly well in hand, al though refinements will continue to be made.

Some applications of composite materials in superconducting technology place unique demands on laminate interlaminar shear strength. Grooved sections of glass-fabric reinforced epoxy laminates are frequently used to support and insulate superconducting windings. The laminates 
must withstand electromagnetic forces resolved in shear across the portion of the laminate separating the windings. Attempts by NBS and MIT to assess the effect of cryogenic temperatures on interlaminar shear strength have shown results with ASTM test method D 2733-70 ("guillotine" method) are highly variable. Results depend, to a large extent, on how the method is applied in practice. This method, which assesses the stress to separate adjacent plies located between opposing offset slots machined in to the specimen surface, was found to be highly dependent on the degree of specimen side support and on the ratio of slot separation distance $(L)$ to specimen thickness (T). Becker and Erez (15) found that interlaminar strength values increased continuously as the L/T ratio of the specimen decreased, approaching that measured by the torsion method at $L / T=0$. Kasen et a1. (6) found systematic increases in interlaminar shear strength by systematically increasing side support pressure for a specimen having an $L / T$ of 2 . A limiting strength level about equal to that obtained in an unsupported specimen at an $L / T$ value of about 0.83 was defined.

Additional refinement of test methods for assessing interlaminar shear is clearly required. But there is some consolation in observing that inadequacies of existing test procedures are probably yielding data which are conservative for design purposes.

The thermal conductivity data presented on Figure 9 indicate the need for refining methods of measuring the conductivity of polymermatrix laminates in the higher temperature ranges. It is presently necessary to introduce large correction factors into the measured values 
to account for radiation losses from semitransparent laminates such as glass-reinforced epoxy. The effect of specimen thickness on validity of the data must also be more precisely evaluated. These factors are currently being assessed at NBS.

A neglected test-related factor is the specimen size effect. This may be more of a problem in evaluating mechanical property values for composite materials at cryogenic temperatures than at room temperatures due to the increased notch sensitivity of polymer matrices at low temperatures.

Dynamic resonance techniques for assessing the temperature effect on elastic constants of composites have been under development at NBS (16-18). Results of this approach presented on Figures 5-7 i11ustrate the flexibility it offers in assessing elastic constants at arbitrarily selected directions through a laminate. A comparison of Young's moduli values obtained by dynamic methods with those obtained by conventional strain-gaged specimen methods shows good correlation for a number of laminate types. But dynamic methods cannot discriminate between differences in tensile and compressive moduli--results are always averages. There is also some concern that the very low levels of strain inherent in conventional dynamic methods permit sensing of only first-order strain terms in some fabric-reinforced laminates. In this case, moduli values will differ significantly from those derived by mechanical means which incorporate additional strain terms significant in defining practical engineering laminate moduli. Phenomenologically, the usual dynamic modulus methods examine only the very initial portions of a stress-strain curve where the slope may or may not be the same as for larger strains. This problem 
can be overcome by applying dynamic methods to specimens having desired levels of prestrain. Studies in this direction are under way at NBS.

Dynamic methods produce data on damping as well as elastic properties, providing a convenient method of following damage accumulation in laminates subjected to cyclic mechanical stress or to thermal fatigue (41). 


\section{SUMMARY AND RECOMMENDATIONS}

Recent studies clarifying the effect of cryogenic temperatures on the mechanical and physical performance of fiber-reinforced composite materials presented in this review confirm that conventional, off-theshelf laminates developed for room temperature service are viable engineering materials to temperatures as low as $4 \mathrm{~K}$. Averages of static mechanical properties and elastic properties improve on cooling. But it is becoming clear that embritting of the polymer matrix and the consequent decrease in strain capability is limiting the extent to which effective use can be made of such improvements. Many glass-reinforced laminates are in practice 1 imited to $20-30 \%$ of their ultimate tensile strength at cryogenic temperatures because of damage accumulation in the matrix at higher stress levels. This occurs because cooling decreases the strain capability of the polymer matrix while increasing that of glass. Matrix embrittlement does not limit the useful stress range of 1 aminates reinforced with high modulus fibers such as graphite or boron because of the inherentiy low elongation to fracture of the fibers. But for graphite laminates it appears that the negative coefficient of thermal expansion of the fibers combines with the positive coefficient of the polymer matrix to cause microcracking in the embrittled polymer. Embrittlement of the matrix reduces toughness, creates notch sensitivity and increases the variability in mechanical properties at cryogenic temperatures, despite substantially increased average property values.

It therefore seems appropriate to define the primary technical problem as embrittlement and decreased toughness of existing polymer systems used for composite matrices. The approach being taken by 
Ciba-Geigy (35) and the Institut für Technische Physik, Karlsruhe, West Germany (36) are therefore most appropriate. This work should be encouraged along with studies designed to more clearly associate the failure modes and life-cycle performance of laminates with their constitutive properties and the geometry of laminate construction.

\section{ACKNOWLEDGMENTS}

This review was sponsored by the USAF Aero Propulsion Laboratory, Wright-Patterson Air Force Base, Dayton, Ohio under contract FY1455-7900603. Additional support was provided by the Office of Magnetic Fusion Energy, Department of Energy under Interagency Agreement EA 77-A-016010 .

The author is particularly indebted to Dr. Knud Dahlrup-Peterson of CERN for making his data available, for consultation and for review of the final manuscript. The contribution of data and consultation of Dr. John 01 inger of the Owen/Corning Research Laboratory is also gratefully acknowledged. 
The following proprietary materials referred to in this report are those used by the cited author. Generic names have been substituted wherever it was possible to do so without sacrificing clarity. The use of trade names in no way implies approval, endorsement or recommendation of specific commercial products by NBS.

Fibers and Reinforcements:

$S, S-901, S-2$

Kevlar 49

AS, HM-S

GY -70

R

Resin System Components

CY 205, HY 905, DY 040

DY 061

Empol 1040

Epon 828

DSA

BDMA

\section{Laminates}

Micarta

Permaglas 1630

Vetronite $54.02,432.81$, 432.86

Durostone EPF 2, EPF 4

Silirite 64400
Owens/Corning G1ass Company

E. I. Du Pont de Nemours \& Company

Courtalds Ltd.

Celanese Corporation

Saint-Gobain Industries

Ciba-Geigy $A G$

Emery Industries, Inc.

Shell Chemical Company

dodecenyl succinic anhydride

benayldimethyl amine

Westinghouse Corporation

European commercial laminates 
1. Kasen, M. B. "Mechanical and thermal properties of filamentaryreinforced structural composites at cryogenic temperatures, 1: glass-reinforced composites," Cryogenics 15 (1975) 327.

2. Kasen, M. B. "Mechanical and thermal properties of filamentaryreinforced structural composites at cryogenic temperatures, 2: advanced composites," Cryogenics 15 (1975) 701.

3. Kasen, M. B. "Properties of filamentary-reinforced composites at cryogenic temperatures" ASTM STP 580, American Society for Testing and Materials (1975) 586.

4. Kasen, M. B. "Cryogenic applications of composite technology in the U.S.A. Nonmetallic Materials and Composites at Low Temperatures (1979) Plenum Press, NY 317.

5. Kasen, M. B. "Composite laminate applications in magnetic fusion energy magnet systems" Proceedings 1978 Interriational Conference on Composite Materials (1978) 1493.

6. Kasen, M. B., MacDonald, G. R., Beekman, D. H. and Schramm, R. E. "Mechanical, electrical and thermal characterization of G-10CR and G-11CR glass cloth/epoxy laminates between room temperature and $4 \mathrm{~K}$ " Advances in Cryogenic Engineering, V 26 Plenum Press, NY $(1980)$.

7. Kernohan, R. H., Coltman, R. R. and Long, C. J. "Radiation effects on organic insulators for superconducting magnets," Oak Ridge National Laboratory Report ORNL/TM-6708 (1979).

8. Coltman, R. R., Klabunde, C. E., Kernohan, R. H. and Long, C. J. "Radiation effects on organic insulators for superconducting magnets," Oak Ridge National Laboratory Report ORNL/TM-7077 (1979).

9. Dahlrup-Peterson, K. and Perrot, A. "Properties of organic composite materials at cryogenic temperatures: CERN ISR-BOM/79-39." (November, 1979).

10. 01 inger, J. Owens/Corning Fiberglass Corporation Technical Center, Granville, Ohio (personal communication).

11. LNG Materials and Fluids-A Users Manual of Property Data in Graphic Format. Supplement 2 to First Ed. (1980). Cryogenic Data Center, National Bureau of Stnadards, Boulder, CO 80302.

12. Stone, E. L., ET-Marazki, L. O. and Young, W. C. "Compressive fatigue tests on a unidirectional glass/polyester composite at cryogenic temperatures" Nonmetallic Materials and Composites at Low Temperatures Plenum Press, NY (1979) 283. 
13. Stone, E. L. and Young, W. C. "Coefficient of friction measurements of fiberglass/epoxy at cryogenic temperatures" Advances in Cryogenic Engineering V 26 Plenum Press, NY (1980).

14. Plastics for Aerospace Vehicles, Part 1. Reinforced Plastics. MIL-HDBK-17A, Department of Defense, Washington, D.C. (Jan. 1971).

15. Becker, H. and Erez, E. "A study of interlaminar shear strength at cryogenic temperatures" Advances in Cryogenic Engineering V 26 Press NY (1980).

16. Ledbetter, H. M. "Dynamic elastic modulus and internal friction in fibrous composites" Nonmetallic Materials and Composites at Low Temperatures Plenum Press NY (1979) 267.

17. Ledbetter, H. M. "Dynamic elastic modulus and internal friction in G-10CR and G-11CR fiberglass-cloth-epoxy laminates" NBS Technical Report NBSIR 79-1609 (1979) 437.

18. Ledbetter, H. M. in "Materials Studies for Magnetic Fusion Energy Applications at Low Temperatures: II," Eds, F. R. Fickett and R. P. Reed, NBSIR 79-1609 (1979) 437.

19. Corruccini, R. J. and Gniewek, J. J. "Thermal expansion of technical solids at low temperatures; A compilation from the literature." NBS monograph No. 29 (1961).

20. Hust, J. NBS, Boulder, Colorado (personal communication).

21. Heberlein, D. C. "Heat capacities of E-glass, cross-ply; S-glass, cross-ply; and S-glass, unidirectional epoxy composites" U.S. Army Mobility Equipment Research and Development Command Report 2199 , Fort Belvoir, Virginia (1976).

22. Schramm, R. E. and Kasen, M. B. "Static tensile properties of boron-aluminum and boron-epoxy composites at cryogenic temperatures" Advances in Cryogenic Engineering V 22 Plenum Press, NY (1977) 205.

23. Schramm, R. E. and Kasen, M. B. "Cryogenic mechanical properties of boron-, graphite- and glass-reinforced composites" Materials Science and Engineering 30 (1977) 197.

24. Schramm, R. E. and Kasen, M. B. "Semi-annual report on materials research in support of superconducting machinery: advanced composites" NBS-ARPA Reports NBSIR 74-359 (1974) 101, NBSIR 74-393 (1974) 123, NBSIR 75-810 (1975) 123, NBSIR 75-828 (1975) 1, NBSIR 76-839 (1976) 1 , NBSIR 76-848 (1976) 1.

25. Kasen, M. B., Schramm, R. E., and Tobler, R. L. "Advanced composites for cryogenic applications" in preparation, NBS Boulder, Colorado. 
26. Lackman, L. M., Arvin, G. H. et a1., Advanced Composites Design Guide, 3rd Ed., Vol. II: Analysis, Air Force Materials Laboratory, Wright-Patterson Air Force Base, $\mathrm{OH}$ (1973).

27. Wadoups, M. E., "Characterization and design of composite materials", in Composite Materials Workshop, Technomic Publishing Co., Inc., Standford, Conn. (1968) 254.

28. Loud, S. N. "Advanced composites applications of S-2 glass fiber", Technical Paper, 34th Annual Technical Conference, Society of the Plastics Industry, Section 20-F (1979) 1.

29. "Plastics for aerospace vehicles, Part 1: Reinforced plastics" MILHDBK-17A, Department of Defense, Washington DC (1971).

30. Lackman, L. M., Arvin, G. H. et a1., "Advanced composite design guide, 3rd edn, Volume IV: Materials", Air Force Materials Laboratory, Wright-Patterson Air Force Base, Ohio (1973).

31. Handbook on materials for superconducting machinery" MCIC-HB-04, Metals and Ceramics Information Center, Battelle, Columbus $\mathrm{OH}$ (1977)

32. Hoggatt, J. T. "Development of cryogenic PRD-49-1 filament wound tanks", NASA CR-120835, National Aeronautics and Space Administration, Lewis Research Center, Cleveland, Ohio (1971).

33. Sims, D. F. and Halpin, J. C. "Methods for determining the elastic and viscoelastic response of composite materials" ASTM STP 546, American Society for Testing and Materials (1974) 46.

34. Soffer, L. M., Molho, R. "Cryogenic resins for glass filament-wound composites", NASA CR-72114 (Final) National Aeronautics and Space Administration. Lewis Research Center, Cleveland, Ohio (1967).

35. Kreibich, U. T., Lohse, F., Schmid, R. "Polymers in low temperature technology" Nonmetallic Materials and Composites at Low Temperatures" Plenum Press, NY (1979) 1.

36. Hartwig, G. "Mechanical and electrical low temperature properties of high polymers" Nonmetallic Materials and Composites at Low Temperatures" Plenum Press, NY (1979) 33.

37. Frank, W. F. X. "Spectroscopic analysis of high polymers for use at low temperatures" Nonmetallic Materials and Composites at Low Temperatures Plenum Press, NY (1979) 51.

38. Schmid, R. "Correlation between valence energies and low temperature flexibility" Nonmetallic Materials and Composites at Low Temperatures Plenum Press, NY (1979) 79.

39. Kneifel, B. "Fracture properties of epoxy resins at low temperatures" Nonmetal1 ic Materials and Composites at Low Temperatures Plenum Press, NY, (1979) 123. 
40. Dahlrup-Peterson, K. "The ISR Cryogenic materials laboratory for testing of composites, installation and results" Advances in

Cryogenic Engineering V 26 Plenum Press, NY (1980).

41. Kasen, M. B., Schramm, R. E., Read, D. T. "Fatigue of composites at cryogenic temperatures," ASTM STP 636, American Society for Testing and Materials, (1977) 141.

42. Hust, J. G., Arvidson, J. M. "Thermal conductivity of glass fiber/ epoxy composite support bands for cryogenic dewars" NBS report 275.03-78-2, National Bureau of Standards (1978).

43. Hust, J. G., "Thermal conductivity" Semi-annual report on materials research in support of superconducting machinery, NBS-ARPA report NBSIR 76-848 (1976) 305.

44. Hust, J. G., "Low-temperature thermal conductivity of two fiberepoxy composites" Cryogenics 15 (1975) 126. 
TABLE I

ELECTRICAL PROPERTIES OF G-10CR AND G-11CR

\begin{tabular}{|c|c|c|c|}
\hline $\begin{array}{c}\text { Temperature } \\
(K)\end{array}$ & $\begin{array}{l}\text { Thickness } \\
(\mathrm{cm})\end{array}$ & $\begin{array}{l}\text { Volume } \\
\text { Resistivity } \\
(\Omega \cdot \mathrm{cm})\end{array}$ & $\begin{array}{l}\text { Voltage Stress } \\
\text { at Breakdown } \\
(\mathrm{kV} / \mathrm{mm})\end{array}$ \\
\hline & & $C R$ & \\
\hline \multirow[t]{3}{*}{295} & 0.030 & & 48.4 \\
\hline & 0.036 & $8.9 \times 10^{15}$ & 45.7 \\
\hline & 0.051 & $9.3 \times 10^{14}$ & \\
\hline 77 & 0.051 & $1.5 \times 10^{17}$ & \\
\hline \multirow[t]{2}{*}{4} & 0.036 & $4.0 \times 10^{17}$ & 48.4 \\
\hline & 0.051 & $4.1 \times 10^{17}$ & \\
\hline \multicolumn{4}{|c|}{$\mathrm{G}-10 \mathrm{CR}$} \\
\hline \multirow[t]{2}{*}{295} & 0.030 & $7.3 \times 10^{15}$ & \\
\hline & 0.051 & $1.3 \times 10^{15}$ & \\
\hline 77 & 0.051 & $6.1 \times 10^{16}$ & \\
\hline \multirow[t]{2}{*}{4} & 0.030 & $2.0 \times 10^{17}$ & 48.0 \\
\hline & 0.051 & $2.0 \times 10^{17}$ & \\
\hline
\end{tabular}


Typical Compositions of Glass Used as Reinforcement for Cryogenic Laminates

(Weight Percent)

\begin{tabular}{lccc}
\hline Element & $E$ & $\begin{array}{c}\text { Giass Designation } \\
\text { S-910/S-2* }\end{array}$ & $R^{\star \star}$ \\
\hline $\mathrm{SiO}_{2}$ & 54.4 & 65.0 & 60.0 \\
$\mathrm{Al}_{2} \mathrm{O}_{3}$ & 14.4 & 25.0 & 25.0 \\
$\mathrm{CaO}$ & 4.5 & 10.0 & 6.0 \\
$\mathrm{~B}_{2} \mathrm{O}_{3}$ & 8.0 & & \\
$\mathrm{Na}_{2} \mathrm{O}+\mathrm{K}_{2} \mathrm{O}$ & 0.5 & & \\
$\mathrm{Fe}_{2} \mathrm{O}_{3}$ & 0.4 & & \\
$\mathrm{~F}_{2}$ & 0.3 & & \\
\hline
\end{tabular}

*Owens/Corning Corp., Toledo, Ohio

**Veltroflex Div., Saint-Gobain Industries, Neuilly-sur-Seine, France 


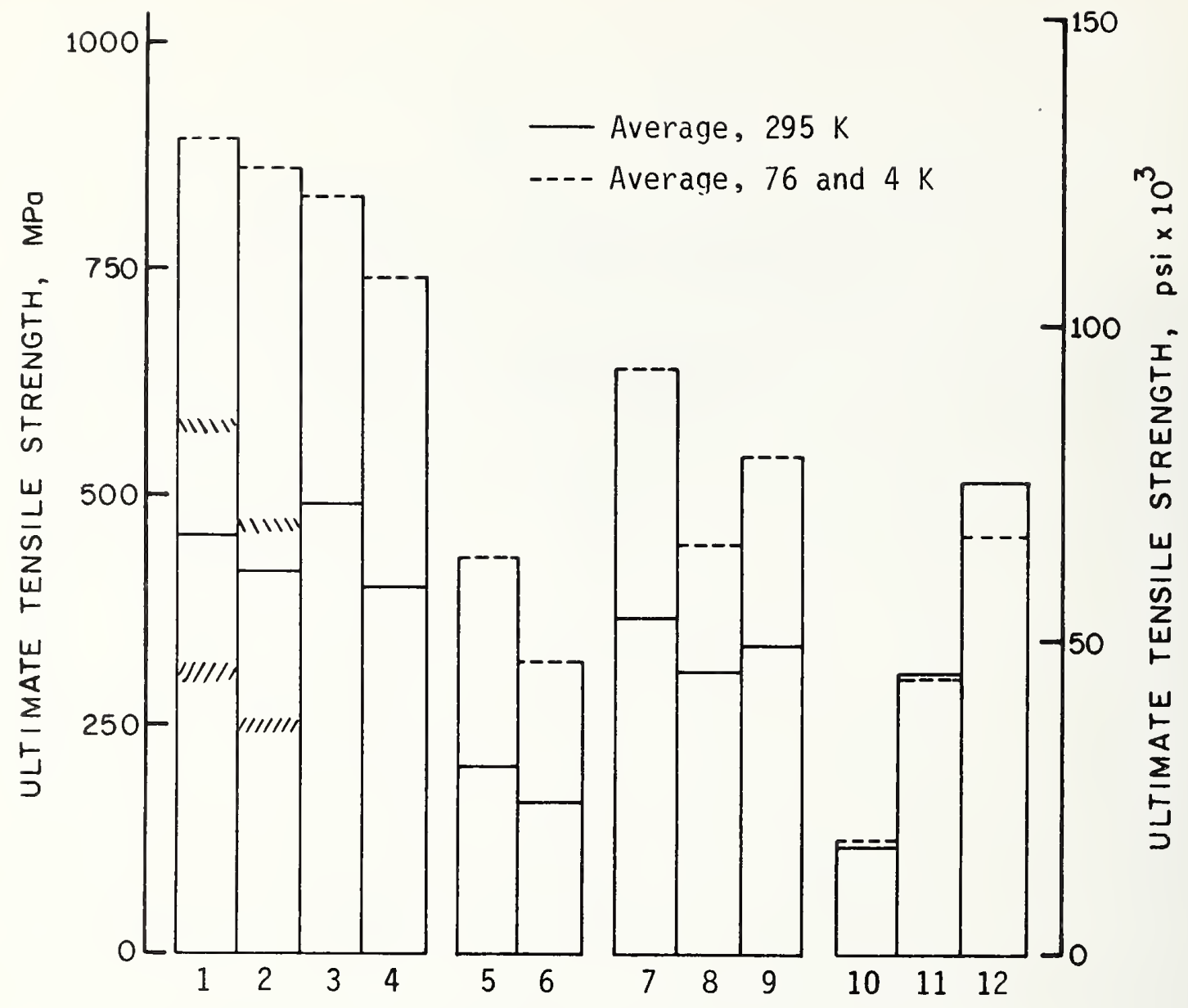

Fig. 1 Temperature dependence of ultimate tensile strength of fabricreinforced polymer-matrix laminates. All data in warp direction except for G-10CR and G-11CR where fill direction strengths are indicated by $/ / / /$ for $295 \mathrm{~K}$ and $111176 / 4 \mathrm{~K}$.

E-glass Fabric Bisphenol A epoxy

$\begin{array}{lll}1-(G-11 C R), 67-72 \text { W/o glass Ref. } \frac{6}{6} \\ 2-(G-10 C R), 64-68 \text { w/o glass Ref. } \frac{6}{9} \\ 3-74.8 \text { W/o glass } & \text { Ref. } \frac{9}{9} \\ 4-62.5-66.1 \text { W/o glass } & \text { Ref. }\end{array}$

E-glass Mat Bisphenol A epoxy

5 - Chopped-mat, $45-55$ w/o glass Ref. 11

6 - Continuous llat, 50-60 w/o glass Ref. 11

liscellaneous E glass Fabric laminates

$$
\begin{array}{ll}
7 \text { - polyimide, } 66.9 \text { w/o glass } & \text { Ref. } \frac{9}{11} \\
0 \text { - Melamine (G-5) } & \text { Ref. } \frac{71}{11} \\
9 \text { - Polyester } & \text { Ref. }
\end{array}
$$

Other Laminates

$$
\begin{aligned}
& 10 \text { - Cotton Fabric/Phenolic, (GE) Ref. } 11 \\
& 11 \text { - Pitch-Base Graphite Fabric/Bis } \\
& \text { A epoxy, 61.8 w/o Graphite Ref. } \underline{9} \\
& 12 \text { - Aramid-Fabric/Bis A epoxy, 61.5 } \\
& \text { w/o Aramid } \\
& \multicolumn{2}{c}{31 \%}
\end{aligned}
$$




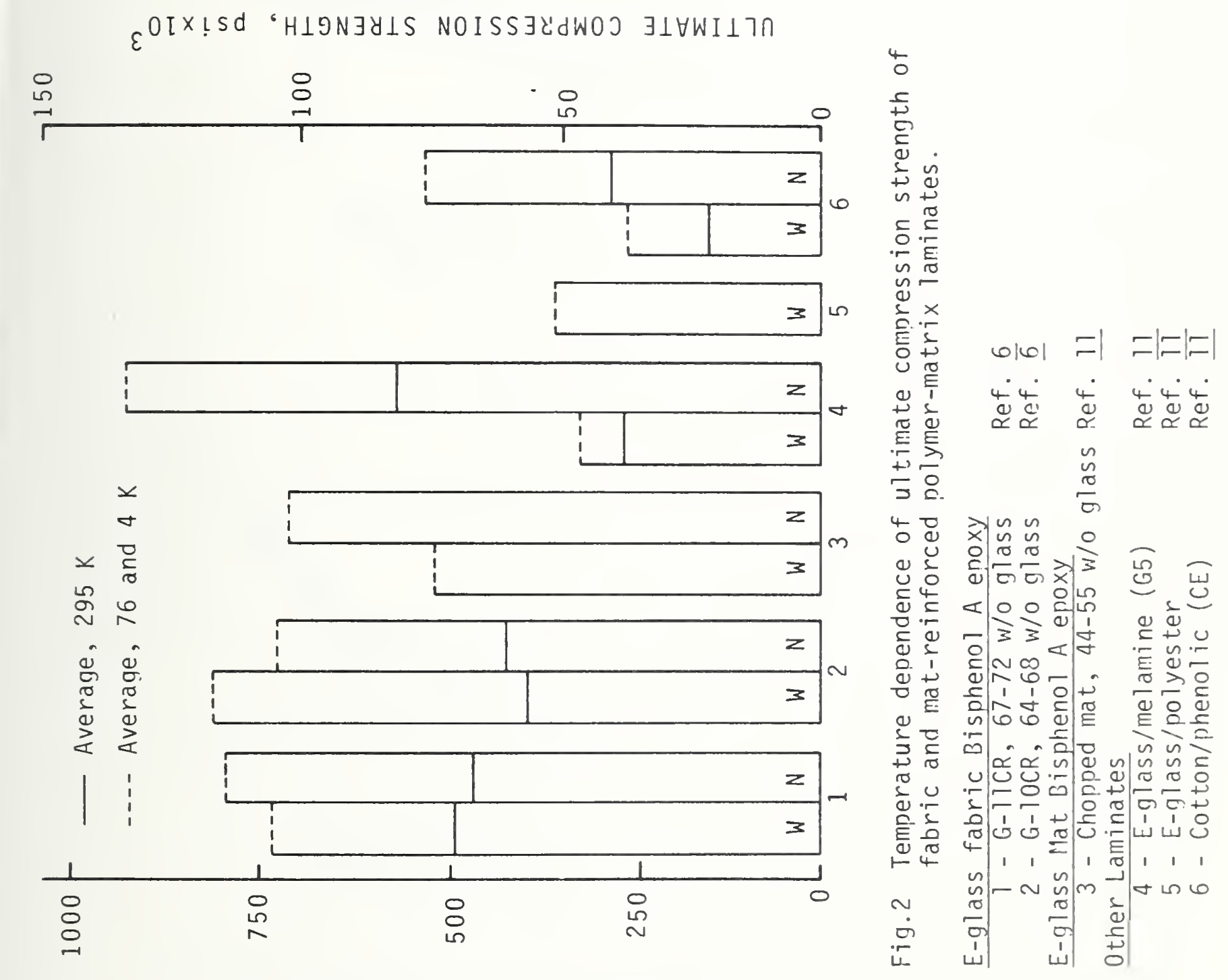

BdW ' $H \perp 9 N \exists y \perp S$ NOISS JydWOJ $\exists \perp \forall W I \perp 7 n$ 


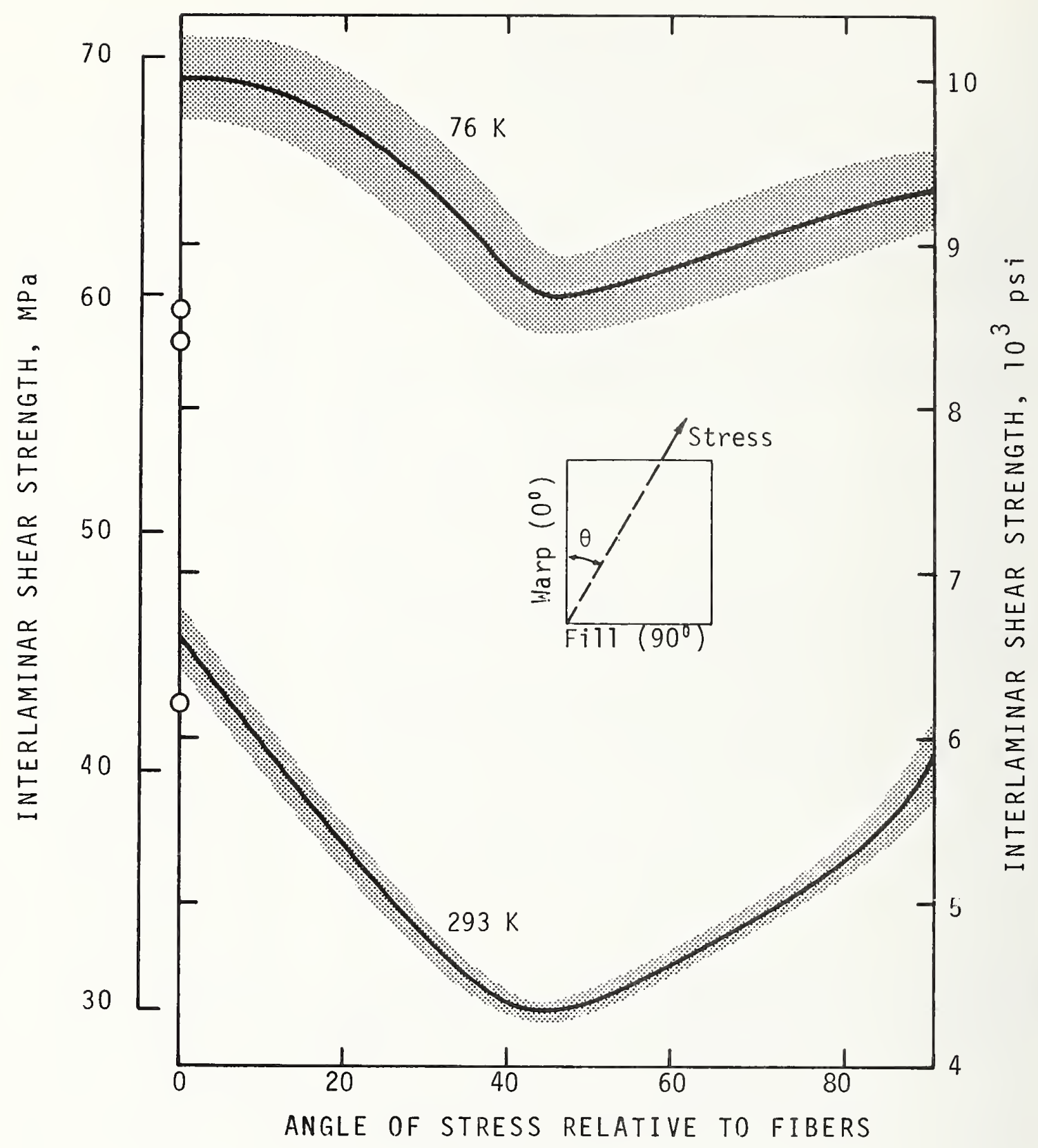

Fig. 3 Anqular dependence of interlaminar shear strength of G-10CR glass-fabric epoxy laminate at $295 \mathrm{~K}$ and $76 \mathrm{~K}$. Shaded areas reflect 2-sided, 95\% confidence intervals. Ref. 15 using modified ASTIA D 2733-70 method. IIBS data for G-1ICR indicated by circles (6). 


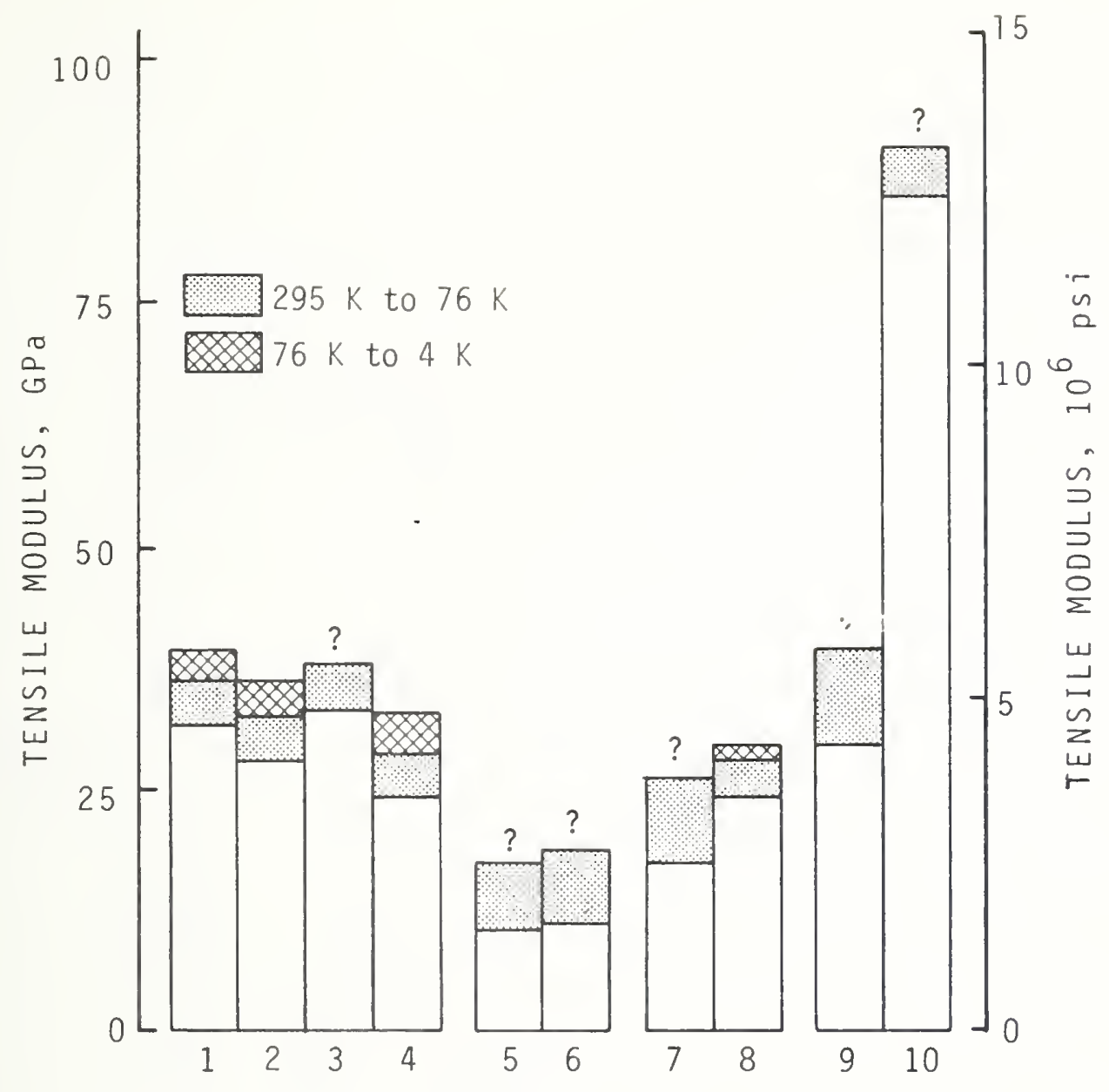

Fig. 4 Temperature dependence of tensile moduli of fabric-and matreinforced polymer-matrix laminates. Warn direction of fabric or edgewise direction of mat.

E-Glass Fabric Bisphenol A Epoxy

1 - G-1TCR: 67-72 w/o glass

2 - G-10CR, 64-68 w/o glass

$3-74.8 w / 0$ glass

$4-62.5-66.1 \mathrm{w} / \mathrm{O}$ glass

Ref. 6

Ref. $\overline{6}$

Ref. $\overline{9}$

Ref. $\overline{9}$

E-Glass llat Bisphenol A epoxy

5 - Chopped Mat, $45-55 \mathrm{w} / 0$ glass Ref. 11

6 - Continuous Mat, 50-60 w/o glass Ref. 11

Miscellaneous E-glass Fabric Laminates

$\begin{array}{ll}7 \text { - Polyester } & \text { Ref. } 11 \\ 8 \text { - Polyimide, } 66.9 \text { w/o glass } & \text { Ref. } \frac{9}{2}\end{array}$

Other Laminates

9 - Aramid/fpoxy 61.5 w/o fiber Ref. 9

10 - Pitch Base Graphite/Enoxy, 61.3 w/o fiber Ref. $\underline{\text { O }}$ 


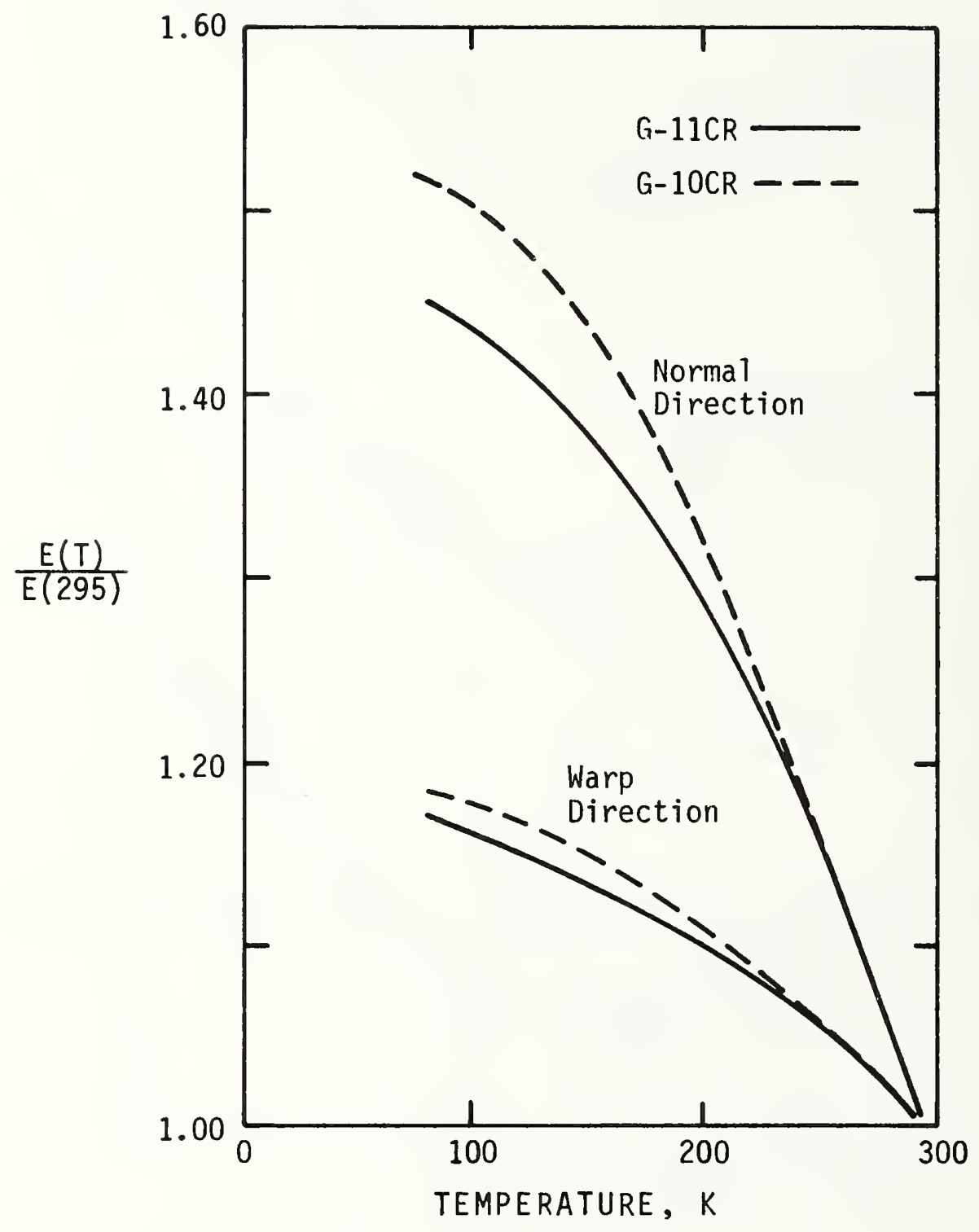

Fig. 5 Temperature dependence of two principal Young's moduli for G-11CR and G-10CR glass fabric-reinforced epoxy laminates. Resonance method (18). 


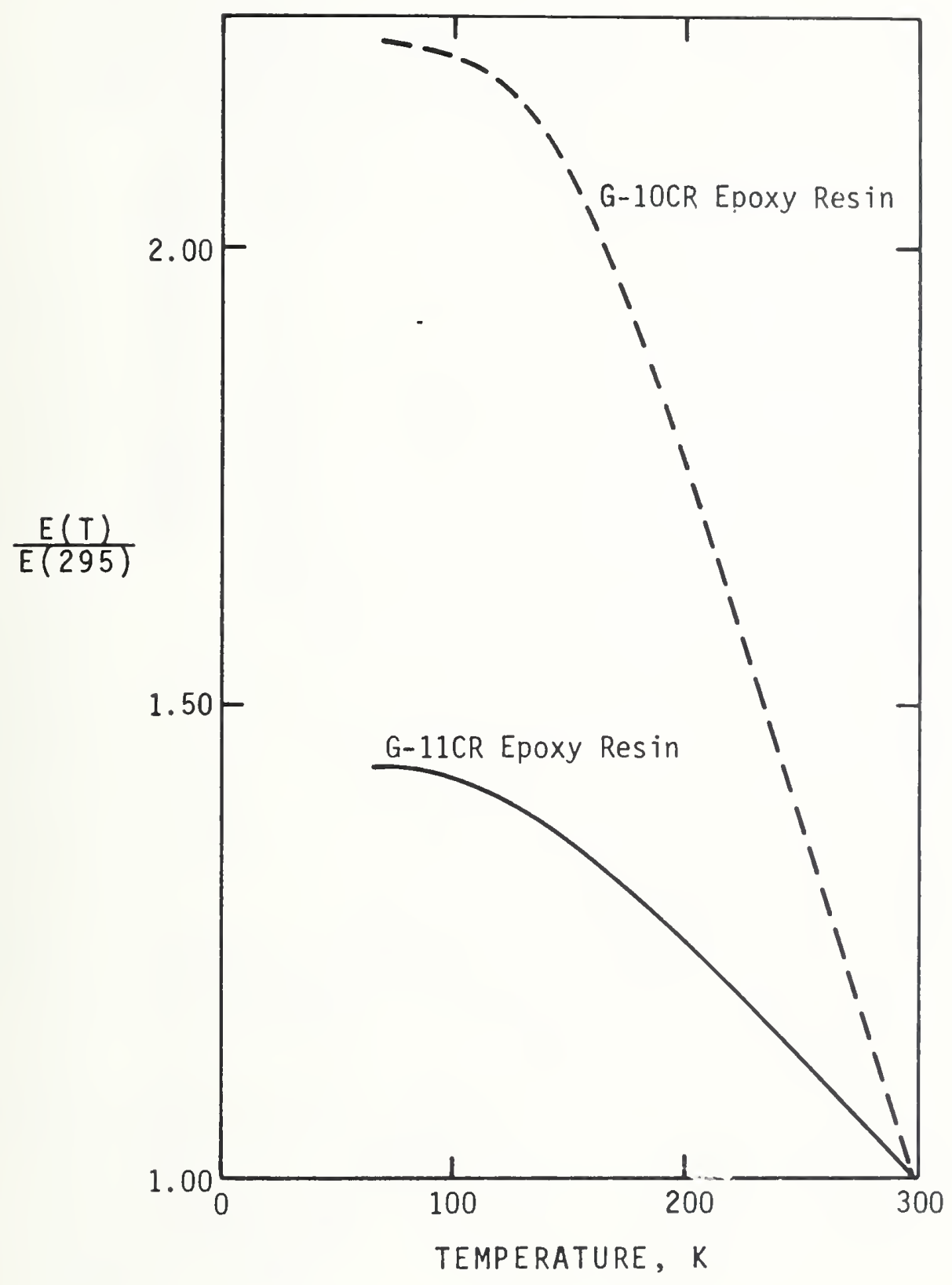

Fig. 6 Temperature dependence of modulus of the bisphenol A epoxy resin systems used in G-10CR and G-11CR qlass-fabric reinforced epoxy laminates. Resonance method (18). 


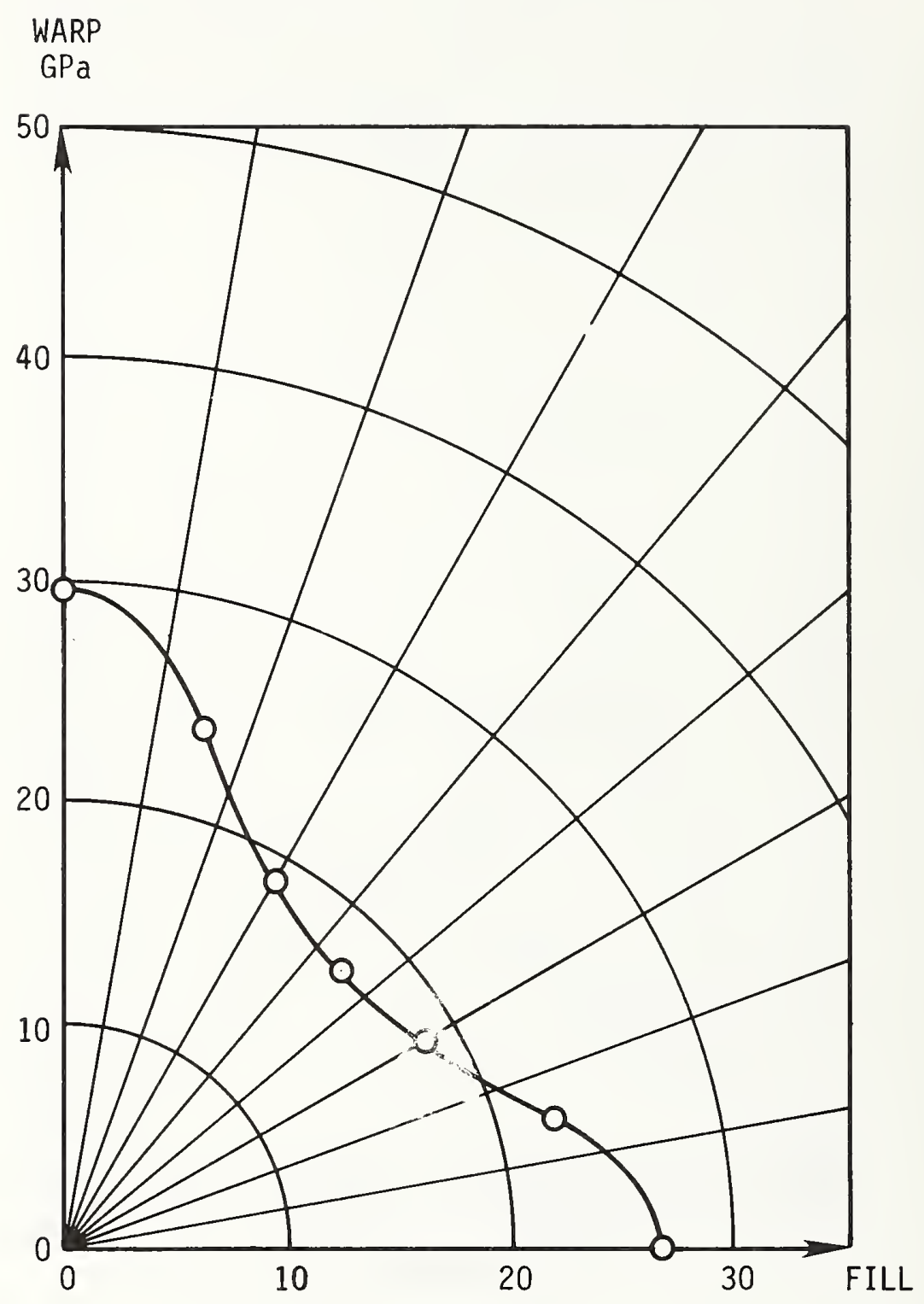

Fig. 7 Orientation dependence of room temperature Young's modulus of G-10CR glass-fabric/epoxy laminate. Resonance method (18). 

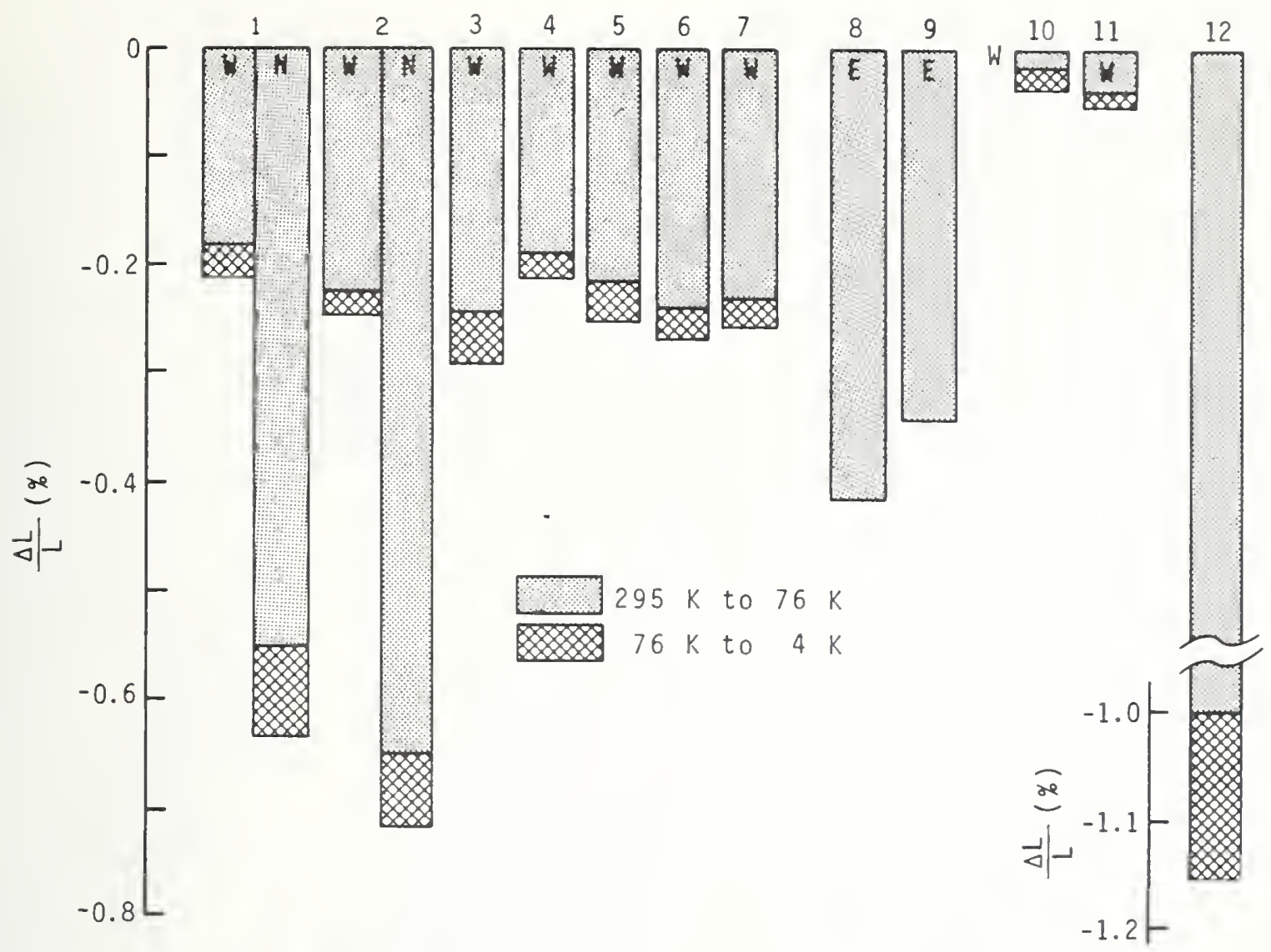

Fig. 3 Temperature dependence of thermal contraction for fabric-- and mat-reinforced laminates. For fabric laminates, $\omega=$ warp direction, $\mathbb{N}=$ normal direction. For mat laminates, $E=$ edgewise direction.

$\frac{\text { E-Glass Fabric Bisphenol A Epoxy }}{1-\text { G-11CR } 67-72 \text { w/o glass }}$

2 - G-10CR 64-68 W/o glass

Ref. $\frac{6}{6}$

$3-64.4$ w/o glass

Ref. $\overline{6}$

$4-66.1$ w/o glass

Ref. $\overline{9}$

$5-67$ w/o glass

Ref. $\overline{9}$

$6-62.5$ w/o glass

Ref. 9

$7-74.8$ w/o glass

Ref. $\overline{9}$

Ref. $\overline{9}$

E-Glass llat Bisphenol A Epoxy

8 - Chopped llat, 45-55 w/o glass Ref. $\frac{11}{\operatorname{Ref} .}$

Miscellaneous Laminates

10 - Aramid/Epoxy, $61.5 \mathrm{w} / 0$ fiber Ref. 9

11 - Pitch-base Graphite/Epoxy, 61.8 w/o fiber Ref. 9

12 - Unreinforced Epoxy

Ref. 9 


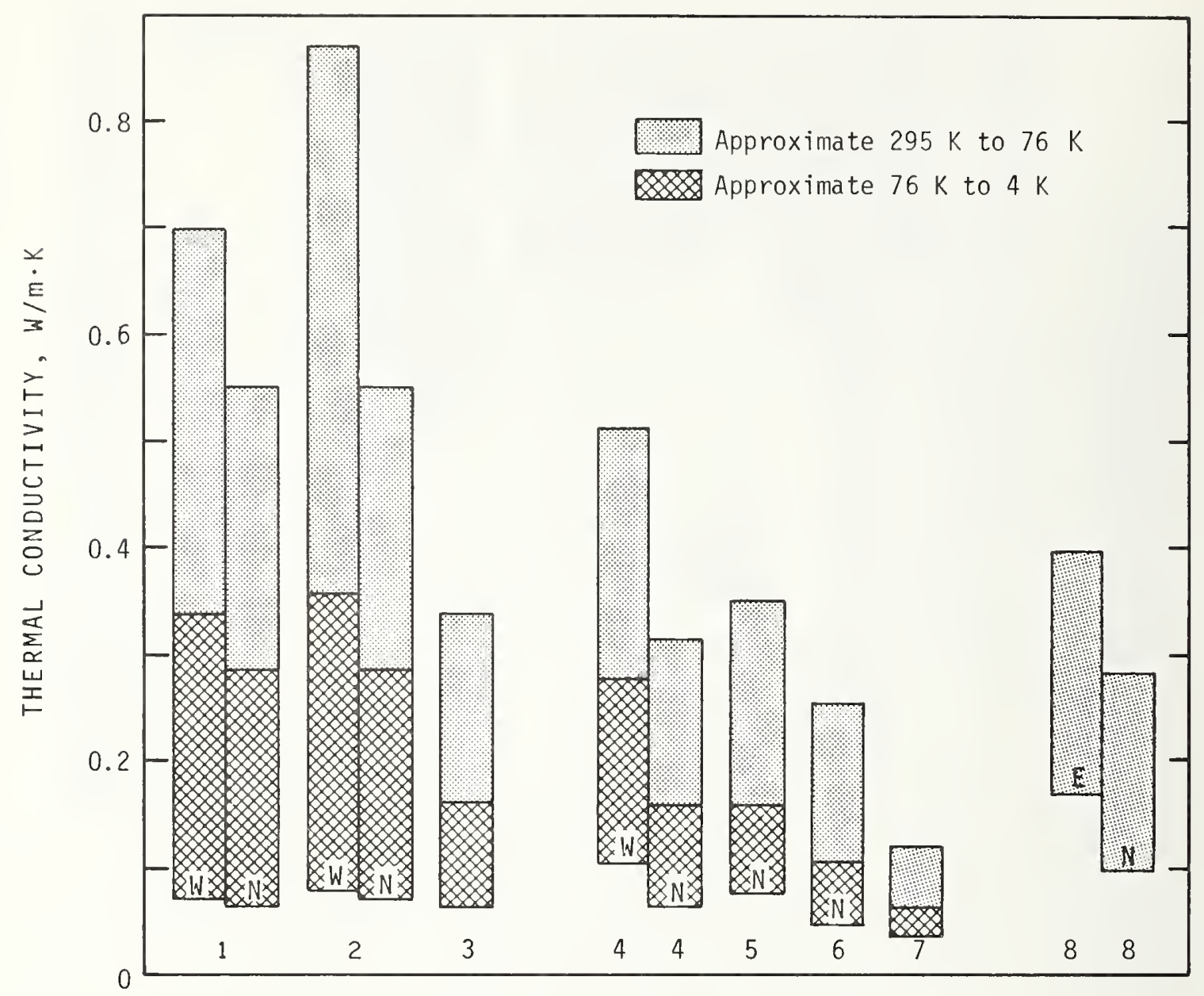

Fig. 9 Temperature dependence of thermal conductivity for a series of E-glass reinforced bisphenol A epoxy laminates and for unreinforced bisphenol A epoxy. Data are illustrated for fabric reinforcement ( $W=$ warp, $N=$ normal) and for mat reinforcement ( $E=$ edgewise, $N=$ normal).

E-G1ass Fabric Bisfhenol A Epoxies

NBS Data

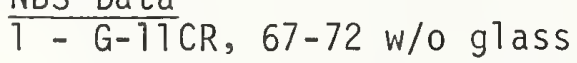

2 - G-10CR, 64-68 W/o glass

3 - Bisphenol A epoxies

Ref. $\frac{6}{5}$

Ref. $\overline{5}$

CERN Data (Ref. 9 )

Ref. $\overline{2} 0$

$4-64.5 \mathrm{w} / \mathrm{0}$ glass

5 - 62-74 w/o glass (5 1aminates)

6 - $67.5 \mathrm{w} / 0$ glass

7 - Bisphenol A Epoxy

E Glass Mat Bisphenol A Epoxies

8 - Continuous-Mat, 50-60 w/o glass Ref. 11 


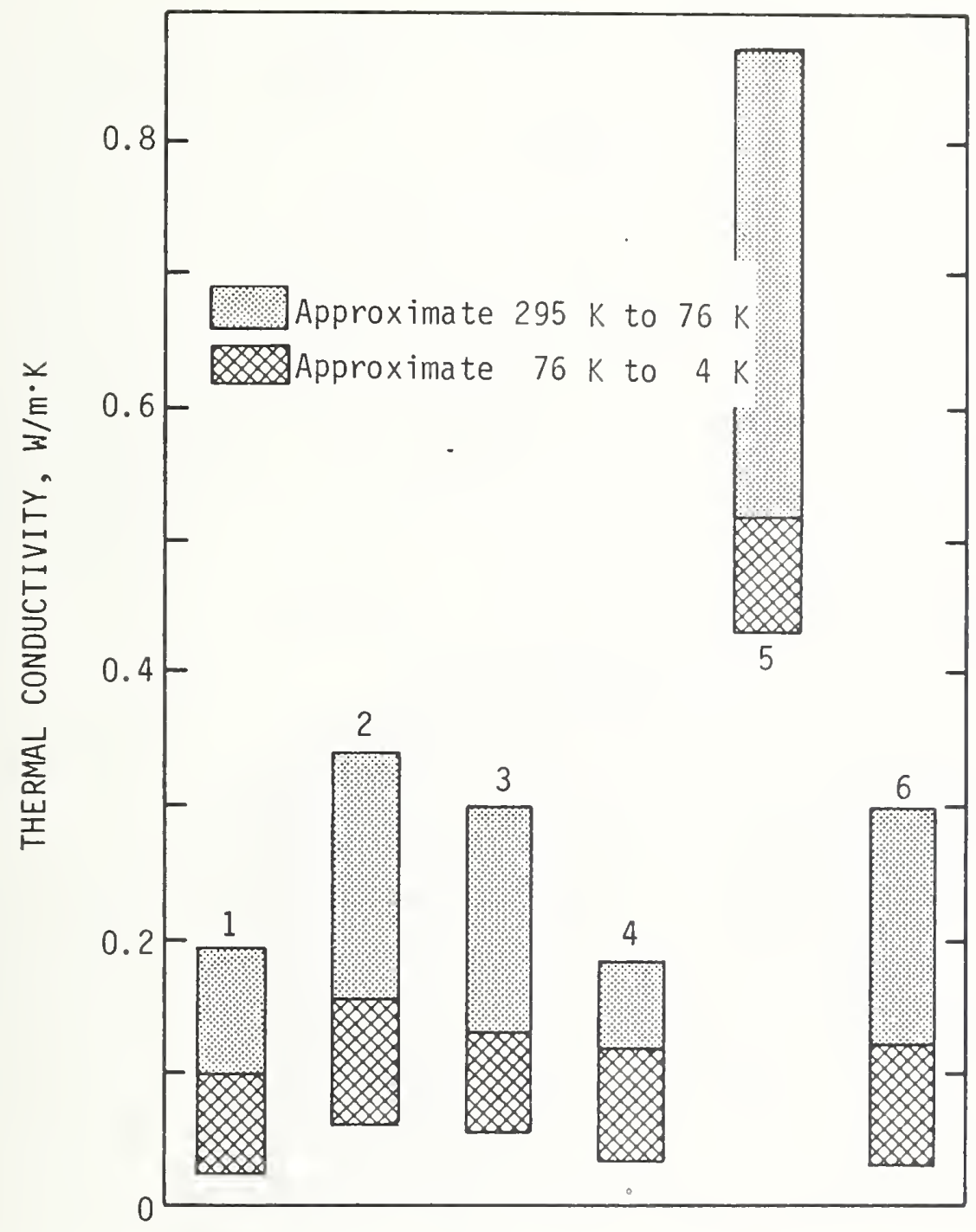

Fig. 10 Temperature dependence of thermal conductivity in the direction normal to the reinforcement (flatwise direction) for a series of silicon-, polyimide-, enoxy-, and phenolic-matrix laminates. Ref. 9 .

E-Glass Fabric Laminates

7 - Silicone Matrix, $70 \mathrm{w} / 0$ glass

2 - Polyimide Matrix, 66.9 w/o glass

3 - Polyimide Matrix, 58.9 w/o glass

Miscellaneous Bisohenol A Laminates

4 - Aramid-Fabric, 67.5 w/o fiber

5 - Pitch-Base Graphite 61.8 w/o fiber

Phenolic Laminates

$6-65$ w/0 cotton 


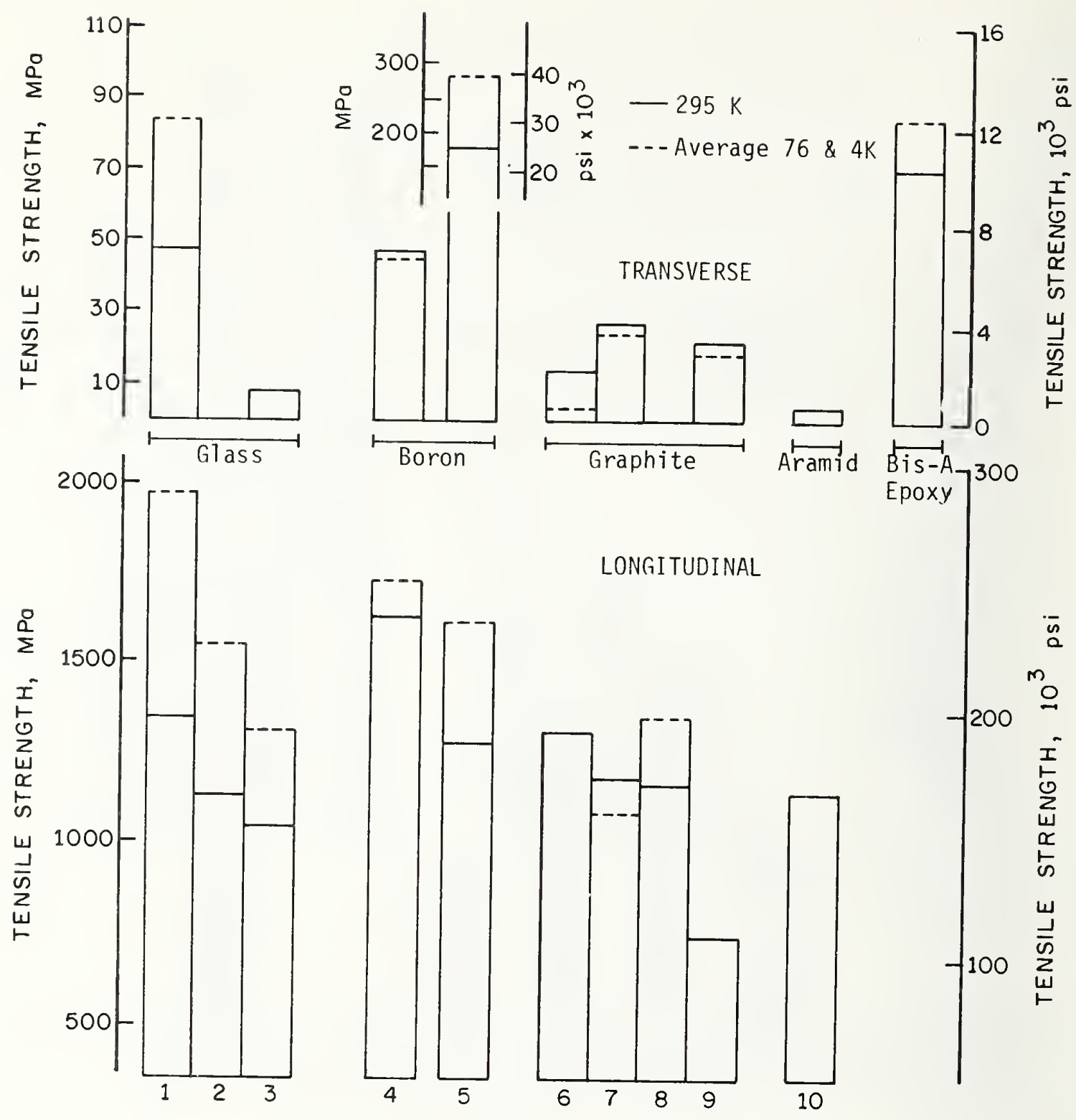

Fig. 11 Temperature dependence of the uniaxial longitudinal and transverse tensile strengths of glass-, boron-, graphiteand aramid-reinforced epoxy laminates.

Glass Reinforcement:

$\begin{array}{lll}1-\text { S-901/Resin 2, } 66 \text { v/o fiber } & \text { Ref. } \\ 2-\text { R/Bisphenol A, } 63 \text { v/o fiber } & \text { Ref. } \frac{23}{9} \\ 3-\text { E/Bisphenol A, } 50.6 \text { v/o fiber } & \text { Ref. } \underline{9}\end{array}$

Boron Reinforcement:

$4-5.6 \mathrm{mi}$ B/2387 epoxy, 52 v/o fiber Ref. 23

5 - $5.6 \mathrm{mil} \mathrm{B} / 6061$ aluminum, $47 \mathrm{v} / 0$ fiber Ref. 23 Graphite Reinforcement

$6-$ As/Resin 2, 64 v/o fiber, Ref. 23

7 - HM-S/934, 62 v/o fiber Ref. $\frac{23}{25}$

8 - HM-S/Bisphenol A, 55 v/o fiber Ref. $\underline{9}$

9 - GY-70/934, 65 v/o fiber Ref. 25

Aramid Reinforcement

$10-\operatorname{Kev} 7 a r 49 / 934,67$ v/o fiber Ref. 25 


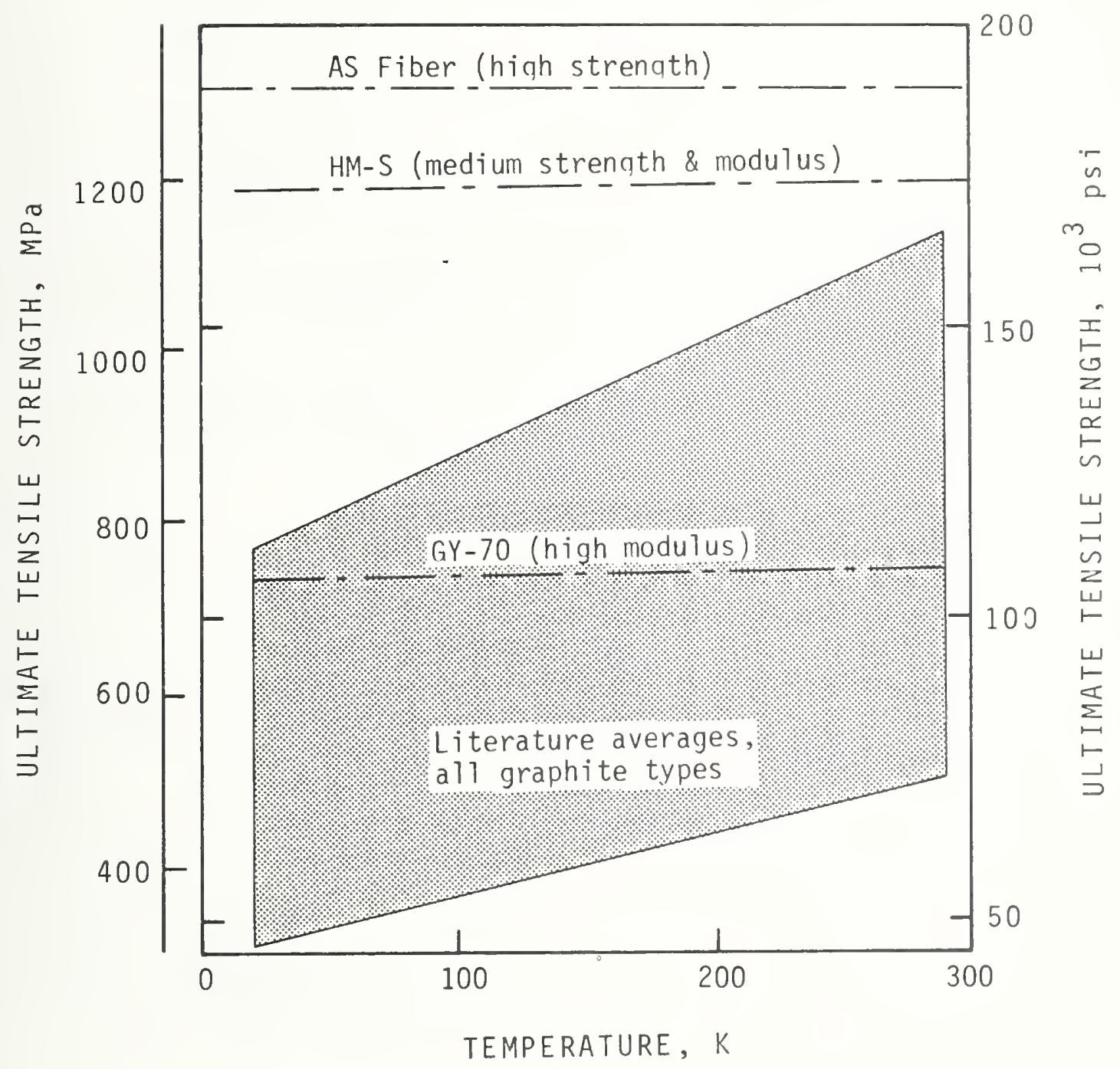

Fig. 12 Comparison between the combined literature data (2) on the temperature dependence of uniaxial ultimate tensile strength of graprite-reinforced laminates (shaded area) and the data obtainec at NBS $(23,25)$ and CERN (9). 

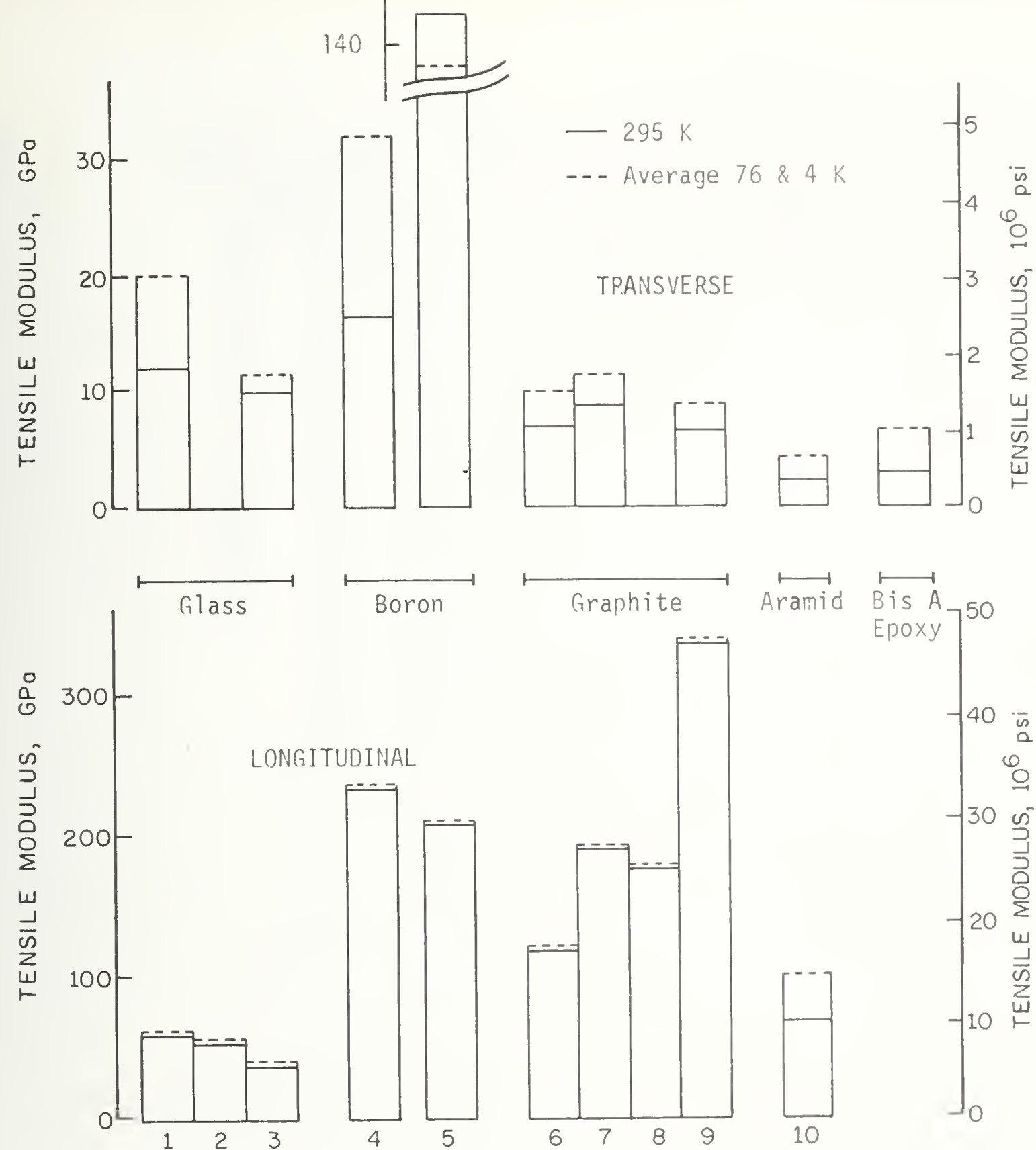

Figure 14 Temperature dependence of uniaxial longitudinal and transverse tensile moduli of glass; boron-graphite-and aramid-reinforced laminates.

Glass Reinforcement

1 - S-901/Resin 2, $66 \mathrm{v} / 0$ fi Ref. 23

2 - R/Bisphenol A, $63 \mathrm{v} / 0$ fiber Ref. 9

3 - E/Bisphenol A, $50.6 \mathrm{v} / 0$ fiber Ref. 9

Boron Reinforcement

$4-5.6 \mathrm{mil}$ B/2387 epoxy, 52 v/o fiber Ref. $\frac{23}{\operatorname{Ref} .23}$
$5-5.6 \mathrm{mil}$ B/6067 aluminum, 47 v/o fiber

Graphite Reinforcement

6 - AS/Resin 2, 64 v/o fiber, Ref. 23

7 - HII-S/934, 62 v/o fiber Ref. 25

8 - HH-S/Bisphenol A, 55 v/o fiber Ref. $\overline{9}$

9 - GY-70/934, 65 v/0 fiber Ref. $\overline{25}$

Aramid Reinforcement

10 - Kevlar 49.934, 67 v/o fiber Ref. 25 


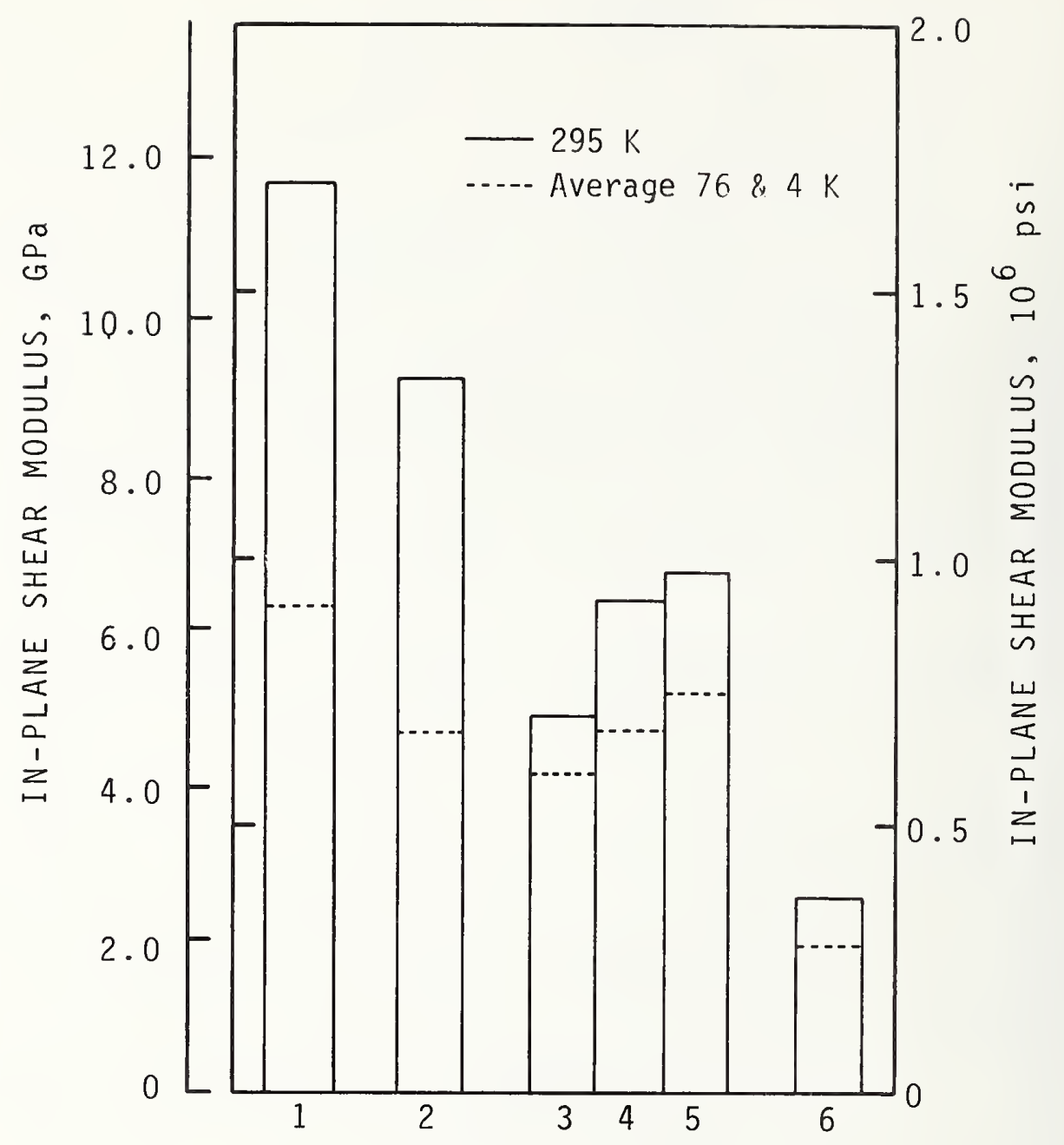

Fig. 15 Temperature dependence of in-plane shear modulus, $F_{12}$, of uniaxial glass-, boron-, graphite- and aramid-reinforced epoxy laminates (23).

1 - S-901-glass/Resin 2, 66 v/o fiber Ref. 23

2 - $5.6 \mathrm{mil}$ Boron/2387 epoxy, 52 v/o fiber Ref. 23

3 - AS Graphite/Resin 2, 64 v/o fiber Ref. 23

4 - HM-S graphite/934 epoxy, 62 v/o Ref. 25

5 - GY-70 graphite/934 epoxy, 65 v/o Ref. 25

6 - Kevlar 49 aramid/934 epoxy 67 v/o Ref. $\underline{25}$ 

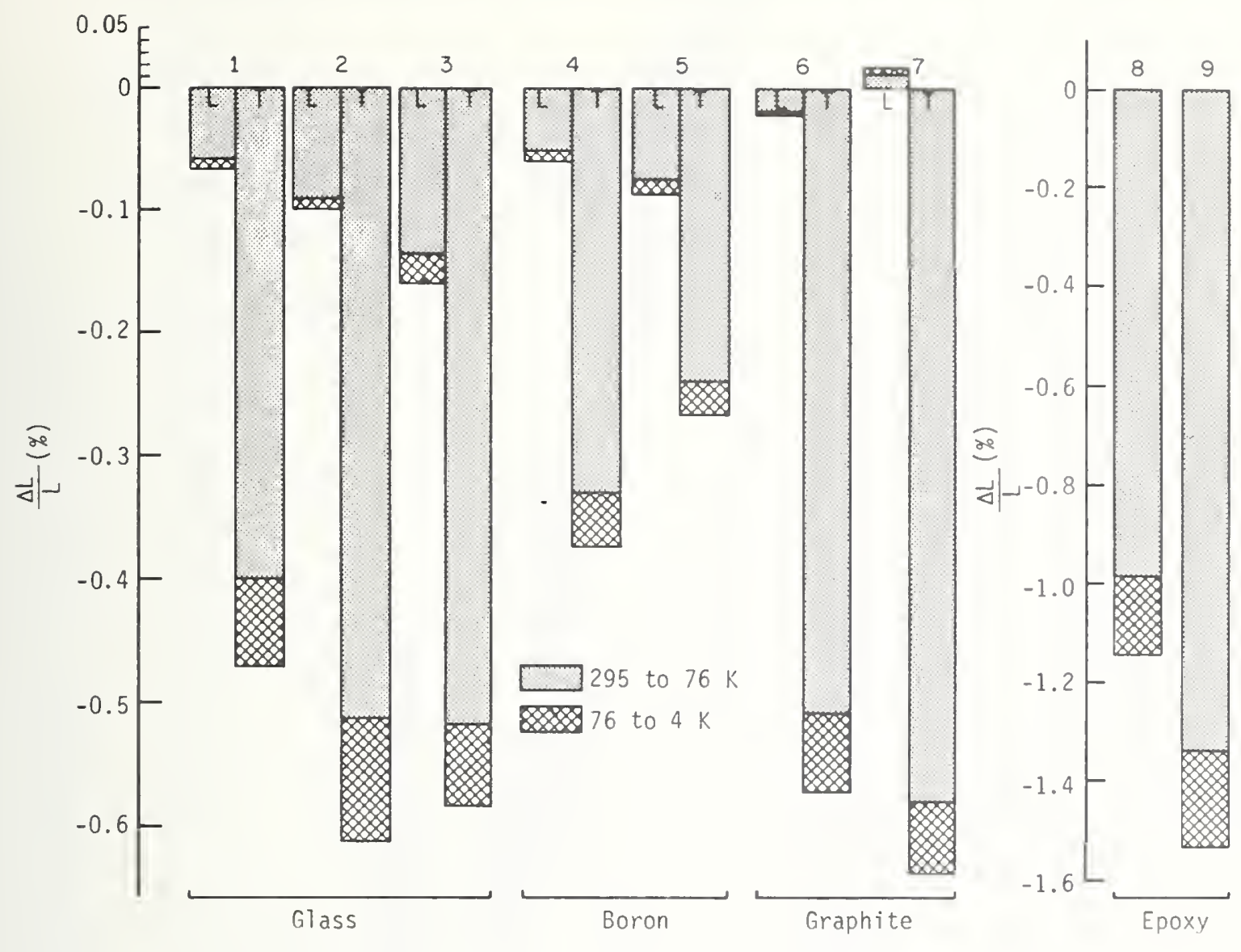

Fig. 16 Temperature dependence of thermal expansion of uniaxial glass-, boron-, and graphite-reinforced laminates in the longitudinal $(L)$ and transverse $(T)$ directions. Epoxy matrices are a conventional bisphenol $A$ (Bis $A$ ) or a flexibilized formulation (Resin 2, Ref. 4).

Glass Reinforcement

1 - S-901/Resin 2, 66 v/o fiber Ref. 23

2 - R/Bisphenol A, $63 \mathrm{v} / 0$ fiber Ref. $\overline{9}$

3 - E/Bisphenol A, 50.6 v/o fiber Ref. $\overline{9}$

Boron Reinforcement

4 - $5.6 \mathrm{mil}$ B/2387 epoxy, 52 v/o fiber Ref. 23

5 - 5.6 mil B/6061 aluminum 47 v/o fiber Ref. 23

Graphite Reinforcement

6 - AS/Resin 2, 64 v/0 fiber, Ref. $\frac{23}{9}$

Epoxy Resins

$\begin{array}{ll}8-\text { Bisphenol A } & \text { Ref. } \frac{9}{20} \\ 9-\text { Resin 2 } & \text { Ref. }\end{array}$




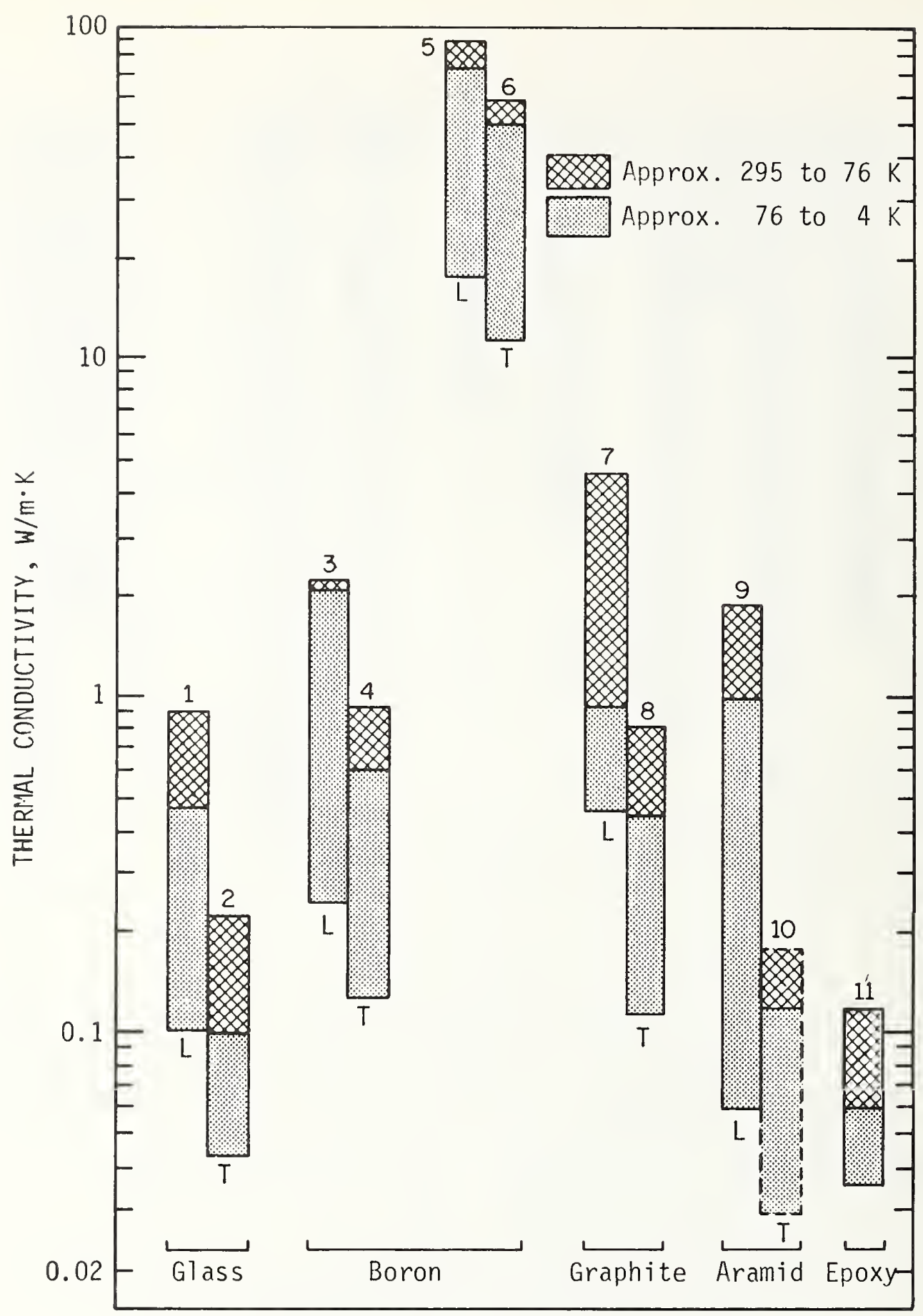

Fig. 17 Temperature dependence of thermal conductivity of uniaxial 1aminates. $\mathrm{L}=$ Longitudina $1, \mathrm{~T}=$ Transverse. Transverse conductivity of the aramid laminate assumed from fabricreinforced data.

1 - S-glass/epoxy, 65 v/o fiber Ref. 42

2 - S-glass/epoxy, $63 \mathrm{v} / 0$ fiber Ref. $\overline{9}$

$3-4-5.6 \mathrm{mil}$ Boron/epoxy, $52 \mathrm{v} / \mathrm{o}$ fiber Ref. 43

5-6- $5.6 \mathrm{mil}$ Boron/aluminum, $47 \mathrm{v} / 0$ fiber Ref. 43

7 - Graphite/epoxy

8 - Graphite/epoxy

9 - Aramid/epoxy

10 - Aramid/epoxy

11 - Bispheno1 A epoxv

Ref. $\frac{43}{9}$

Ref. $\overline{9}$

Ref. $\overline{44}$

Ref. $\overline{9}$

Ref. $\overline{9}$ 


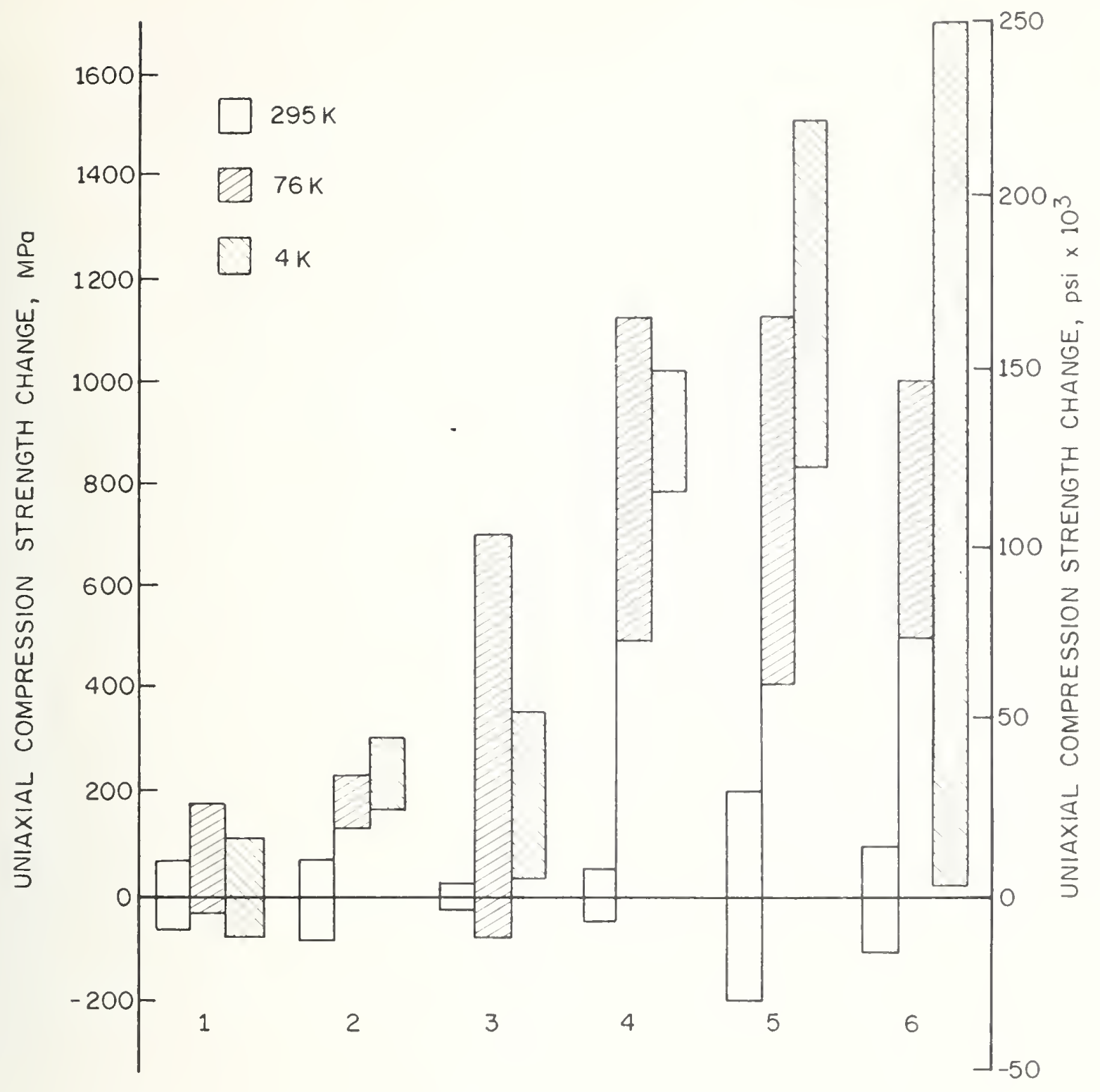

Fig. 18 Range observed in uniaxial longitudinal compression strength at $295 \mathrm{~K}, 76 \mathrm{~K}$ and $4 \mathrm{~K}$ for a series of laminates. All data are normalized at $295 \mathrm{~K}$.

1 - HM-S Graphite/934 epoxy

2 - GY-70 Graphite/934 epoxy

3 - AS Graphite/Res 2 epoxy

4 - S-901 Glass/Res 2 epoxy

5 - 5.6-mil Boron/6061 aluminum

6 - $5.6 \mathrm{mil}$ Boron/2337 epoxy
Ref. 25

Ref. $\overline{25}$

Ref. $\overline{23}$

Ref. $\overline{23}$

Ref. $\overline{23}$

Ref. $\overline{23}$ 

MECHANICAL PROPERTIES OF G-1OCR AND G-11CR

National Bureau of Standards 

Mechanical Properties of G-10CR and G-IICR

R. E. Schramm and M. B. Kasen

The last report contained mechanical characterization data at 295 , 76, and $4 \mathrm{~K}$ in the warp and normal directions for G-10CR and G-11CR from manufacturer A's pilot plant. This characterization has now been completed for the fill direction. The results of all the individual tests are in Table 1. Three additional batches of material have been screened to examine variations between batches and manufacturers:

1) manufacturer A, production plant, 2) manufacturer B, production plant, and 3) manufacturer B, boron-free glass (a special variant which might display less susceptibility to radiation damage). This testing covered only two specimens in each of the configurations at only 295 and 76 K. These results are listed in Table 2.

All of the mechanical data were summarized with most of the electrical and thermal results in a paper presented at the International cryogenic Materials Conference at Madison, Wisconsin in August, 1979. This paper will be published in Advances in Cryogenic Engineering, Vol. 26. This paper discussed our findings and a preprint follows.

As part of a program for the USAE Aero Propulsion Laboratory, we examined the effects of thermal ageing. Short-beam shear specimens of G-10CR and G-11CR from Manufacturer B were heated to $122^{\circ} \mathrm{C}$ for $2 \mathrm{~h}$ and $112 \mathrm{~h}$ and then tested along with untreated specimens at $76 \mathrm{~K}$. The results in Figure 1 indicate no effect on G-10CR. The strength drop noted in G-11CR after $112 \mathrm{~h}$ might indicate some deterioration, but this may not be statistically significant given the normal data scatter. 


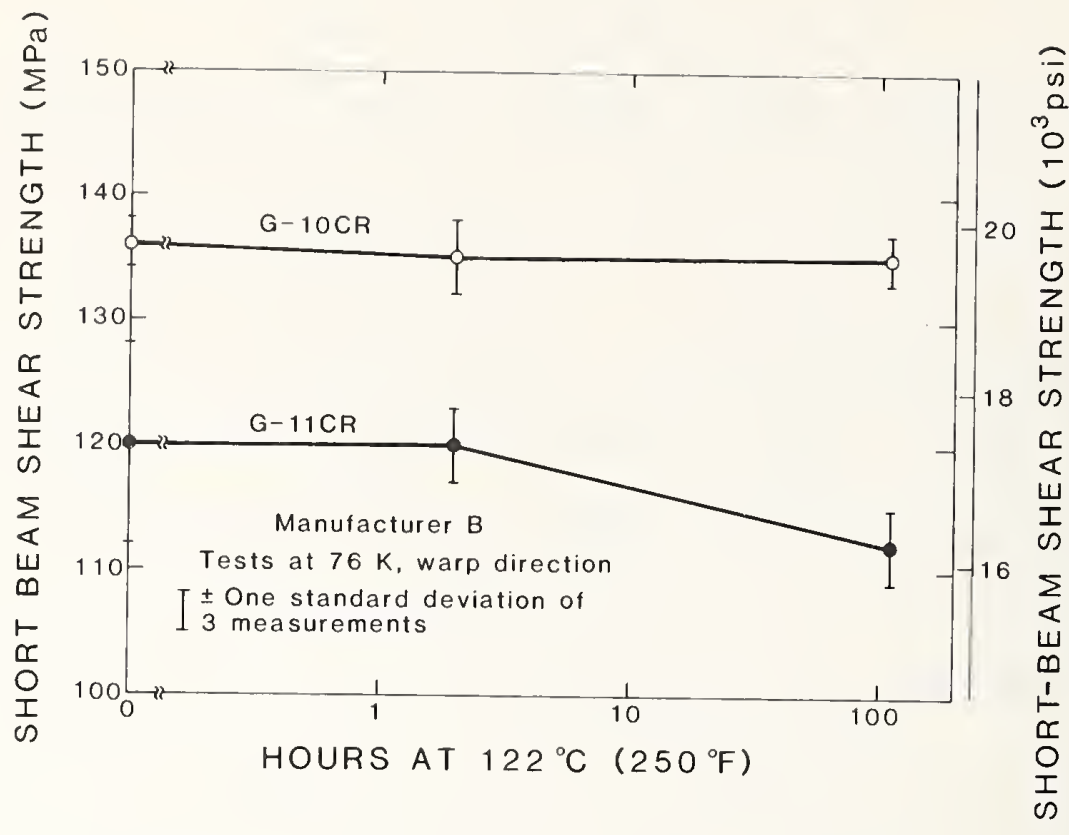

Figure 1. Effect of aging on short-beam shear strength.

In cooperation with MIT, we will conduct interlaminar shear tests on $1.3-\mathrm{cm}(0.5-\mathrm{in})$ thick G-10CR guillotine specimens at $4 \mathrm{~K}$ and then compare these results from $0.38-\mathrm{cm}(0.15-\mathrm{in})$ thick material. Additional work will include fatigue cycling of both shear and compression specimens at $4 \mathrm{~K}$ and measurement of residual strength.

\section{Associated Programs}

The following NBS activities in the nonmetallics area are of potential interest to MFE cryogenic technology:

1. Characterization of the cryogenic properties of high-modulus, advanced composites and the assessment of their applicability to lightweight MHD and rotating machinery superconducting magnets (USAF Aero Propulsion Laboratory). 
2. Interaction with a leading industrial glass research laboratory to disseminate information on the cryogenic mechanical thermal properties of glass mat-reinforced epoxy laminates developed and characterized by this laboratory. These data will appear in the second supplement of the LNG Users Manual.

3. Evaluation of the various mechanical properties and coefficients of friction of polymeric materials vs. metals at cryogenic temperatures (Air Force Materials Laboratory).

\section{FY 80 Nonmetallics Program}

The FY80 nonmetallics program will continue to reflect the needs of the MFE program as defined by ongoing program interaction and suggested by input from the Vail NBS/DoE workshop. Three major areas are presently defined:

1. Increasing the understanding of the fundamental relationship between cryogenic temperature and the performance of nonmetallic composites.

2. Increasing the understanding of the effect of neutron and gamma radiation on the performance of nonmetallic composites at cryogenic temperatures.

3. Continued interfacing between manufacturers of cryogenic composite laminates and the fabricators of MFE superconducting magnet systems. 


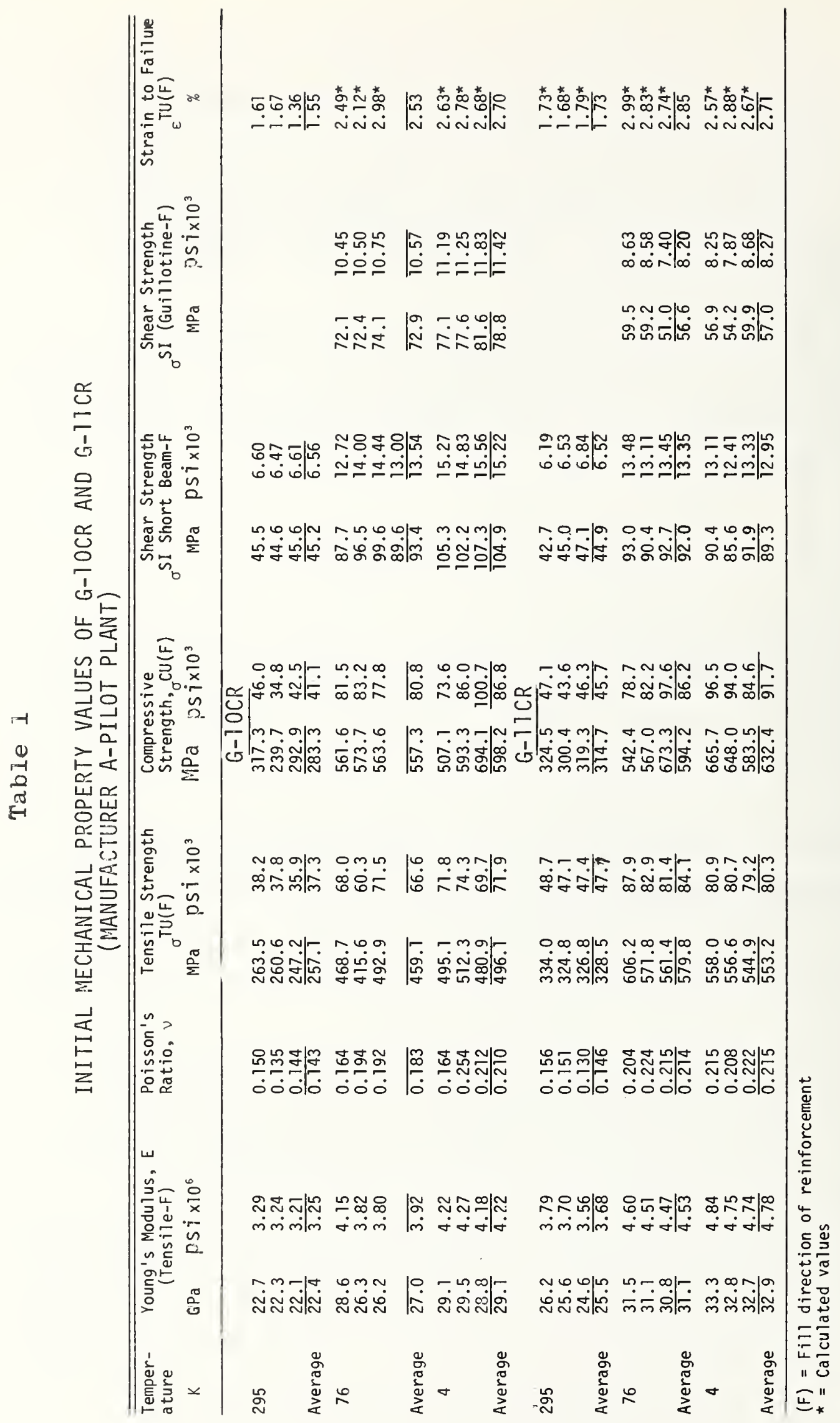




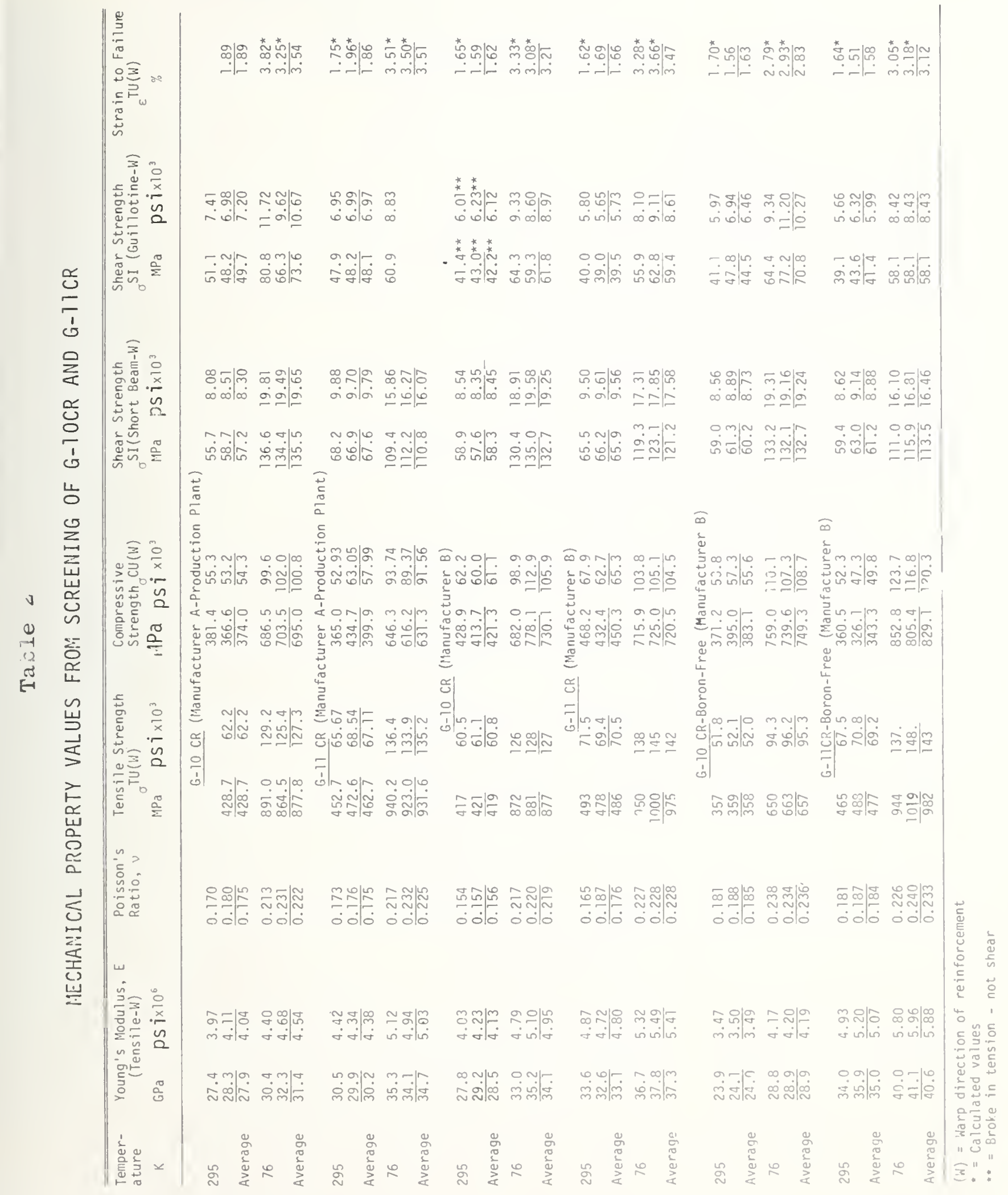



MECHANICAL, ELECTRICAL, AND THERMAL CHARACTERIZATION OF

G-10CR AND G-11CR GLASS CLOTH/EPOXY LAMINATES

BETWEEN ROOM TEMPERATURE AND $4 \mathrm{~K}$

National Bureau of Standards 

MECHANICAL, ELECTRICAL, AND THERMAL CHARACTERIZATION OF

G-1OCR AND G-11CR GLASS CLOTH/EPOXY LAMINATES

BETWEEN ROOM TEMPERATURE AND $4 \mathrm{~K}$ *

M. B. Kasen, G. R. MacDonald, D. H. Beekman, and R. E. Schramm Fracture and Deformation Division

National Bureau of Standards

Boulder, CO 80303

\section{ABSTRACT}

The magnetic fusion energy program of the U.S. Department of Energy will require large-scale use of industrial high-pressure fiberglass/ epoxy laminates for structural support and electrical and thermal insulation. In response to the need for commercially available and predictable materials, the National Bureau of Standards and industrial suppliers have cooperated with the National Electrical Manufacturers' Association (NEMA) to establish specifications for cryogenic grades of G-10 and G-11 glass-cloth laminates. These materials, designated G-10CR and G-11CR, differ from conventional laminates in that they are produced to the same material and process specifications by all commercial 1 aminators. Both products meet existing NEMA, federal, and miltary specifications. We have characterized the 295, 76, and $4 \mathrm{~K}$ mechanical properties of G-10CR and G-11CR produced by two manufacturers. Properties studied include tensile strength, elongation, modulus, Poisson's ratio, and compressive strength. Interlaminar shear strength was characterized by both guillotine and short beam methods. The effect of orientation was examined. The data indicate that both laminate types are excellent cryogenic materials. Additionally, we have screened the mechanical properties of the same laminates produced with boron-free E glass reinforcement in anticipation of improved radiation resistance of this variant.

*Supported by the Office of Fusion Energy, U.S. Department of Energy. 
The U.S. magnetic fusion energy program will require large-scale use of industrial high-pressure glass-reinforced epoxy laminates for structural supports and for electrical and thermal insulation in superconducting magnets. This choice is based on such factors as availability, cost, machinability, high strength-to-weight ratio, and low electrical and thermal conductivities. There is an immediate need for a commercial supply of such materials having predictable cryogenic performance. NBS, therefore, has cooperated with the U.S. laminating industry and the National Electrical Manufacturers' Association (NEMA) to establish specifications for cryogenic grades of NEMA G-10 and G-11 glass cloth reinforced epoxy laminates. These materials, designated G-10CR and G$11 C R$, meet existing NEMA, as well as federal and military, specifications for G-10 and G-11 products. The component and manufacturing specifications have been distributed to all U.S. manufacturers through the NEMA organization. The products are currently available from one manufacturer, and others have shown an interest in their production.

NBS is currently undertaking an electrical, thermal, and mechanical property characterization of the CR-grade materials over the 295 to $4 \mathrm{~K}$ temperature range. Contributions to the characterization have also been made by universities, national laboratories, and a private corporation. In this paper, we present the data base obtained on G-10CR and G-11CR produced for NBS by two manufacturers. For comparison, we screened the mechanical properties of CR-grade laminates produced with boron-free glass reinforcement in anticipation of improved radiation resistance of this variant. 
The basis for both G-10CR and G-11CR is the same glass fabric of silane-finished $E$ glass. Its plain weave is produced on a conventional loom by interlacing warp (1ength) threads (16.9 \pm 1.2 per $\mathrm{cm}$ or $43 \pm 3$ per inch) and fill (width) threads (12.6 \pm 0.8 per $\mathrm{cm}$ or $32 \pm 2$ per inch). The specially made boron-free $E$ glass is similarly configured.

The G-10CR matrix is a conventional heat-activated, amine-catalyzed bisphenol A solid-type epoxy resin chosen for proven performance at cryogenic temperature. The G-IICR matrix is an aromatic-amine hardened bisphenol A liquid-type epoxy resin expected to provide improved resistance to radiation damage. The finished products are a natural beige color. Resin weight fraction is 32 to $36 \%$ for G-1OCR and 28 to $33 \%$ for G-11CR. Production details are presented in another paper [1].

Two producers, designated manufacturers $A$ and $B$, supplied sheets of G-10CR and G-11CR in nominal thicknesses of $0.127 \mathrm{~cm}(0.050 \mathrm{in}), 0.0381 \mathrm{~cm}$ (0.150 in) and $2.54 \mathrm{~cm}$ (1 in). Additionally, manufacturer B provided similar panels in the boron-free variant. Manufacturer A produced the materials as a pilot plant run. Although pilot plant procedures closely parallel production conditions, the manufacturer subsequently provided additional actual production panels for additonal testing.

The mechanical tests performed on these materials are summarized in Tables I and II. As noted on Table I and Figures 1 through 3, the pilot plant production of manufacturer $A$ was used to establish base mechanical properties for tension (warp, fill), compression (warp, fill, normal) and shear (warp, fill). Results of the screening tests on the mechanical performance of material from manufacturer $B$ appear in Table II. 



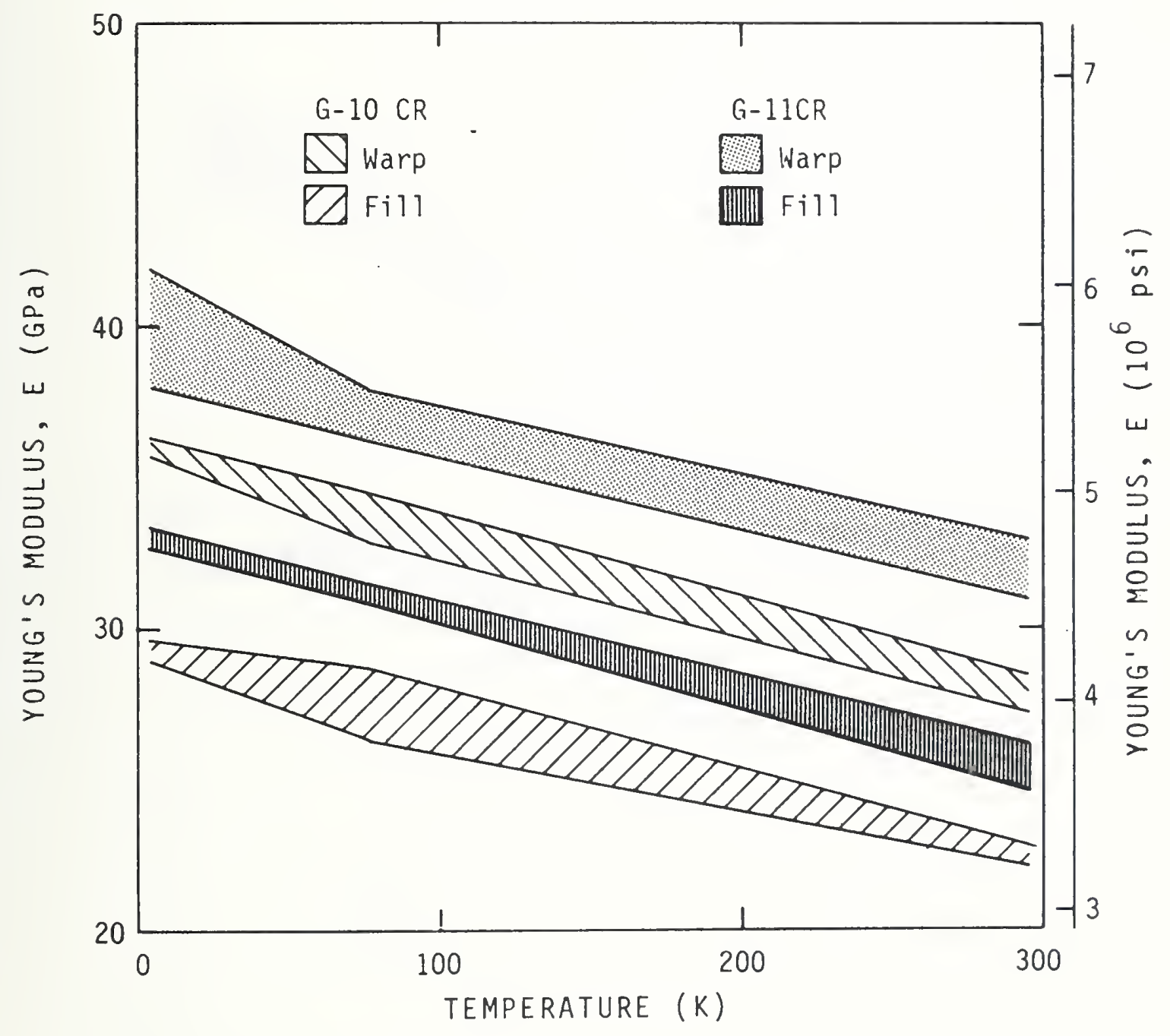

Figure 1. Young's modulus versus temperature for G-1OCR and G-11CR (Manufacturer A, Pilot Plant). Error bands show upper and lower data spreads. 



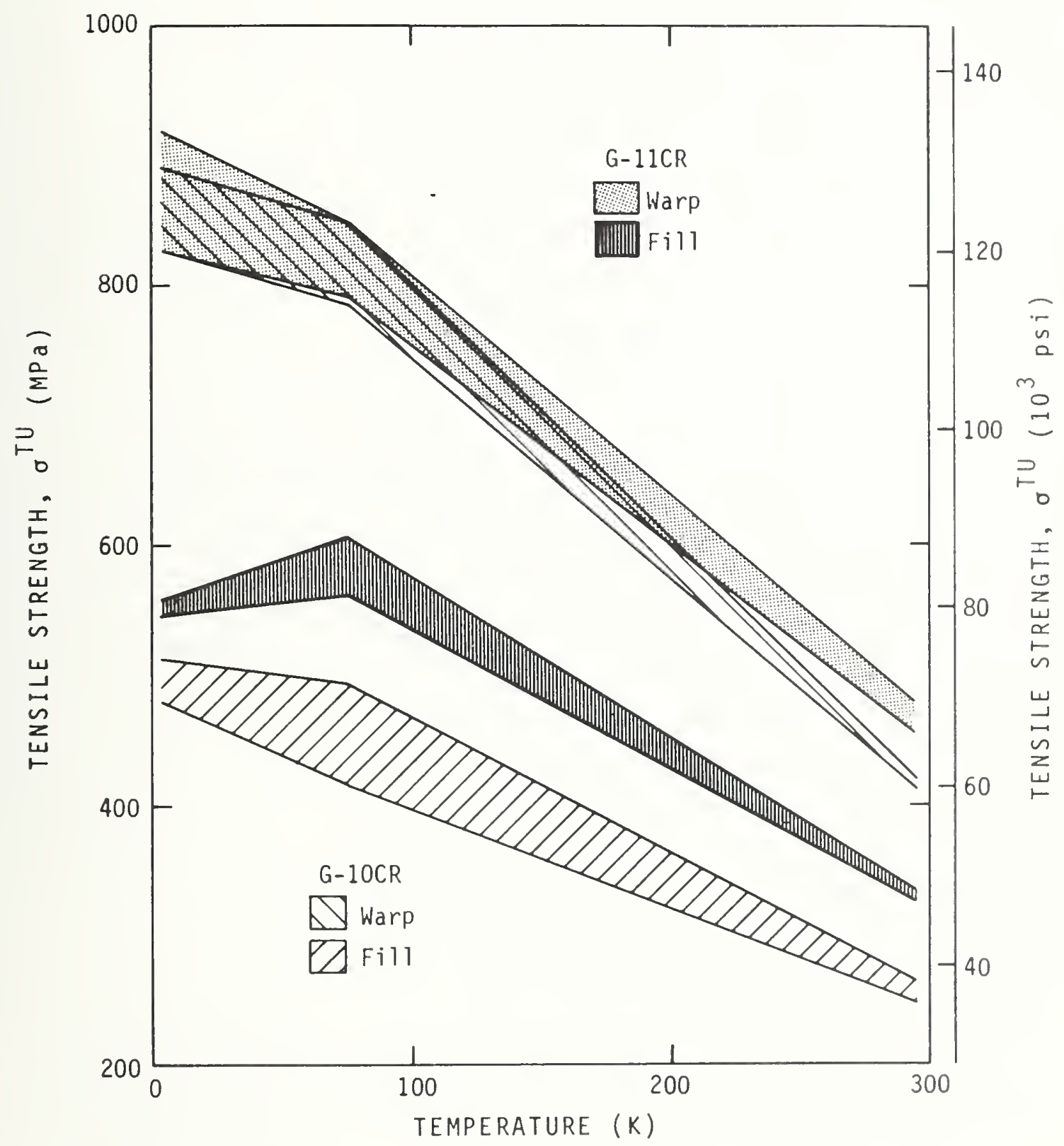

Figure 2. Tensile strength versus temperature for $F_{2}-10 C R$ and $F_{2}-11 C R$ (Manufacturer A, Pilot Plant). Error bands show upper and lower data spreads. 



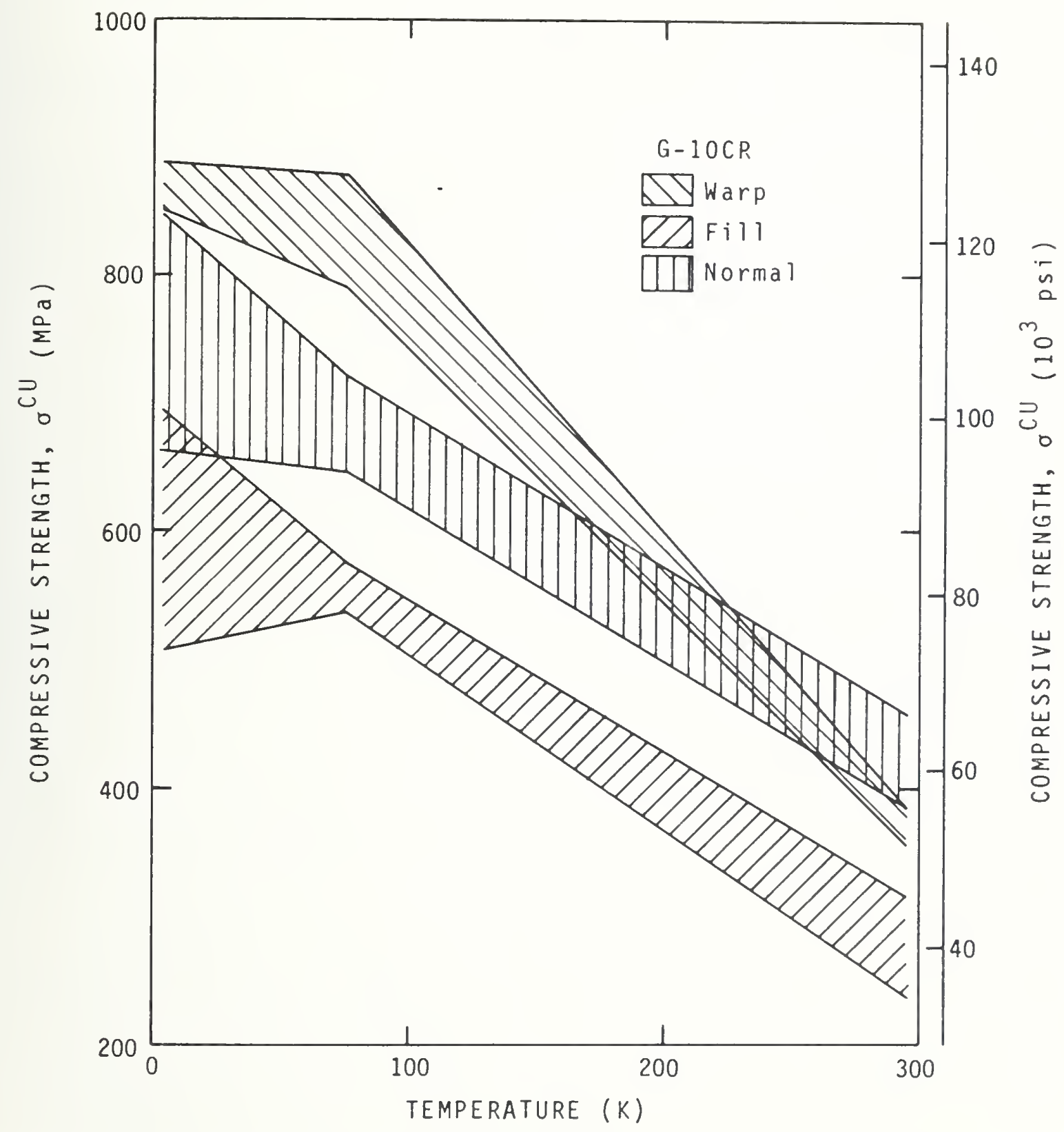

Figure 3. Compressive strength versus temperature for G-10CR (:1anufacturer A, Pilot Plant). Error bands show upper and lower data spreads. G-IICR displayed similar data spreads. 

These tests were performed only in the warp direction. The pilot plant production of manufacturer $A$ was also used in the study of electrical performance (Table III), thermal conductivity (Figure 4), and thermal expansion (Figure 5).

\section{METHODS}

\section{MECHANICAL TESTS}

Tensile specimens cut from the $0.127-\mathrm{cm}$ sheets were a modified version of the MIL-HDBK 17A specification. The gage 1ength was 5.4-cm (2.125-in) 1ong and $1.27-\mathrm{cm}(0.5-\mathrm{in})$ wide. The specimen width tapered to $2.54 \mathrm{~cm}$ ( $1 \mathrm{in}$ ) in the grip area. Resistance strain gages cemented directly to the surface in longitudinal and transverse orientations allowed measurement of Young's modulus and Poisson's ratio. The ultimate strength and elongation were also determined.

Warp and fill compression strength specimens from the $0.381 \mathrm{~cm}$ sheets were $6.99-\mathrm{cm}(2.75-\mathrm{in})$ long and $0.794-\mathrm{cm}(0.313-\mathrm{in})$ wide; specimens tested normal to the glass cloth had about the same cross-section but were only $2.54-\mathrm{cm}$ (1-in) 1ong. With end caps cemented in place, the gage length was $1.91-\mathrm{cm}(0.75-\mathrm{in})$. The compression method and fixture were described el sewhere [2].

Interlaminar shear strength tests followed two methods. Threepoint bending (ASTM D 2344-72) was the simplest and good for comparison or quality checks but provided no real engineering data, since tensile and compressive stresses were also present. The specimens were 2.54$\mathrm{cm}$ (1 in) long by $0.64-\mathrm{cm}(0.25-i n)$ wide and came from the $0.381 \mathrm{~cm}$ thick sheets. The guillotine shear method (ASTM D 2733-70) can provide more meaningful values of strength, but it, too, is subject to considerable inaccuracy unless care is used in its application. Data appearing 


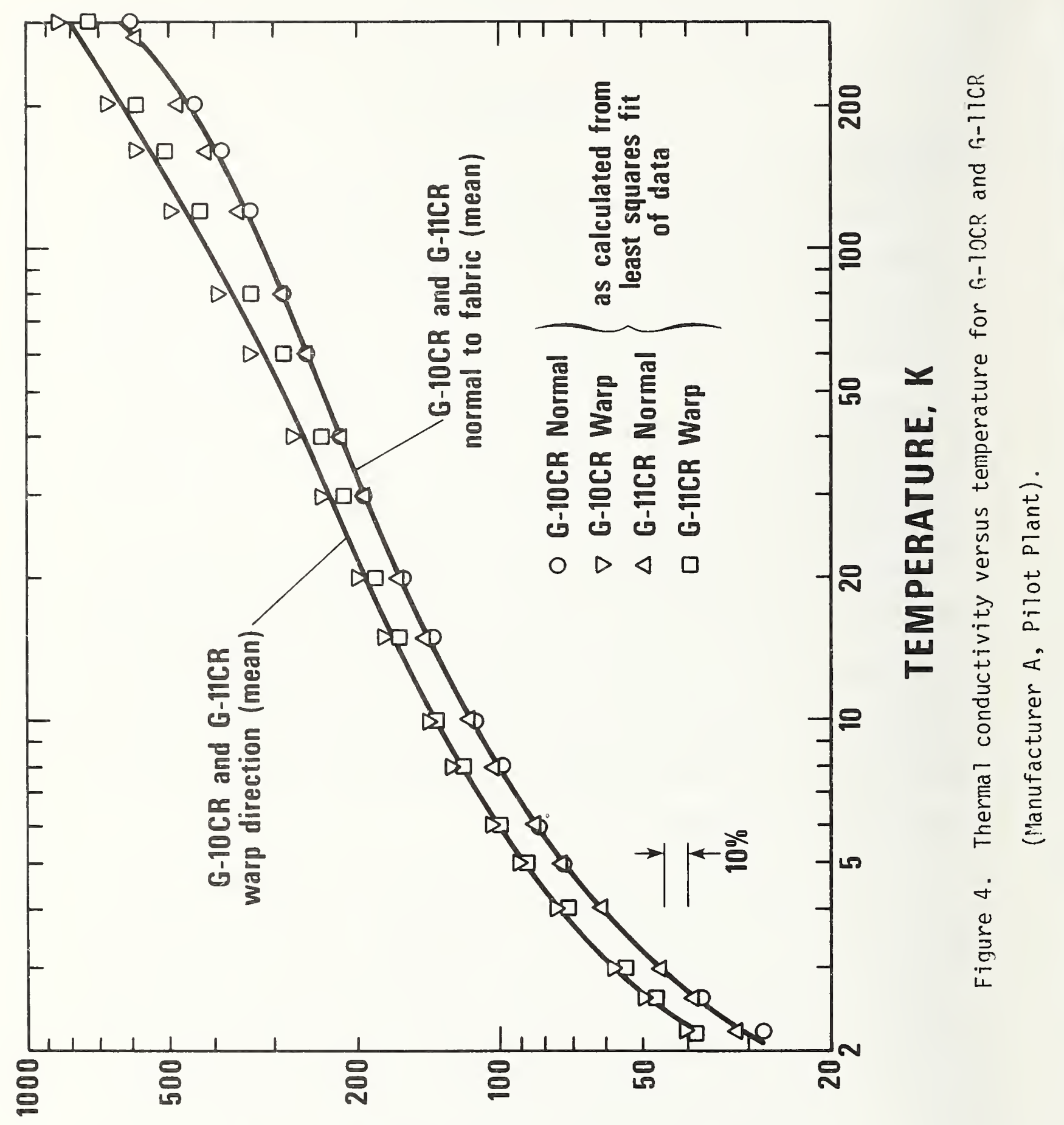

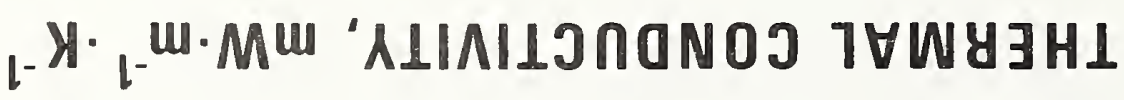




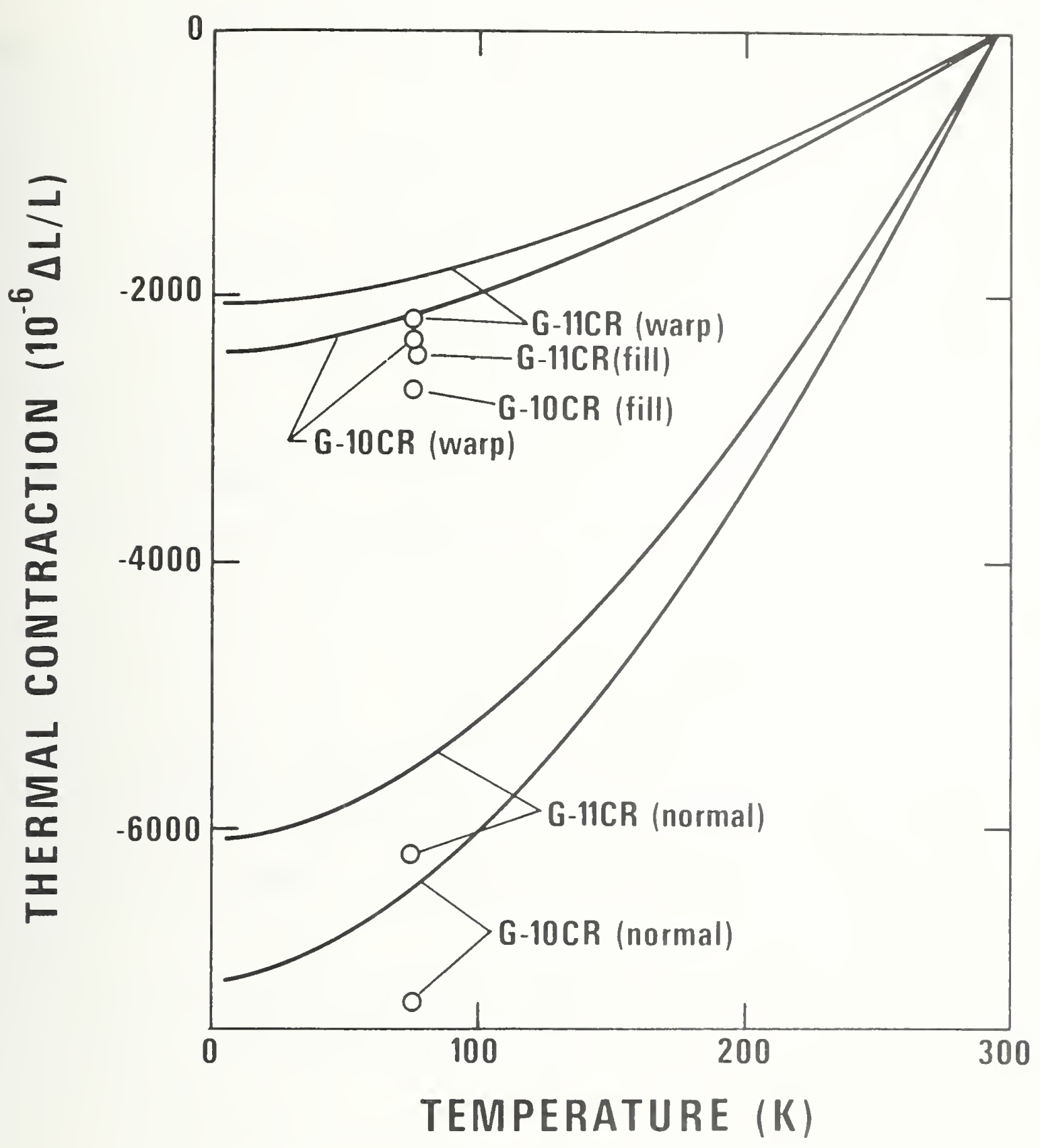

Figure 5. Thermal contraction of G-IOCR and G-1ICR. The discrete points were from the preliminary tests done at LASL while the continuous curves were measured at NBS. (lanufacturer A, Pilot Plant). 
on Tables I and II were obtained with a modified ASTM specimen (saw cuts on opposite surfaces were $0.953 \mathrm{~cm}$ (0.375 in) apart with side support established at a level yielding consistent results regardless of specimen thickness. Without this support, an apparent peeling of each side from the shear plane reduced the measured strength by $50 \%$.

Conditioning of all specimens prior to testing (ASTM D 3039-71) was $\geq 40 \mathrm{~h}$ at $22 \pm 2^{\circ} \mathrm{C}$ and $50 \pm 10 \%$ relative humidity.

\section{ELECTRICAL TESTS}

Volume resistivity tests conducted by the subcontractor were in accord with ASTM D 257 with $1000 \mathrm{Vdc}$ and $7.62 \mathrm{~cm}$ (3 in) diameter electrodes with a $0.64-\mathrm{cm}$ (0.25 in) guard gap. For the electric strength, $60 \mathrm{~Hz}$ was applied at $0.5 \mathrm{kV} / \mathrm{s}$ rise with $1.27-\mathrm{cm} \times 3.81 \mathrm{~cm}(0.5-$ in $\mathrm{x}$ 1.5-painted electrodes.

\section{THERMAL TESTS}

Thermal conductivity measurements were conducted by the longitudinal heat flow method at closely spaced temperature [3]. The specimens were $1.91 \mathrm{~cm}(0.75 \mathrm{in})$ cubes with a density of $1.904 \mathrm{~g} / \mathrm{cm}^{3}$ for G-10CR and $1.956 \mathrm{~g} / \mathrm{cm}^{3}$ for G-11CR.

A preliminary test of total contraction between room temperature and $75 \mathrm{~K}$ was conducted at the Los Alamos Scientific Laboratory. Later measurements as a continuous function of temperature were performed at NBS with a quartz dilatometer.

\section{RESULTS AND DISCUSSION}

\section{MECHANICAL TESTS}

The mechanical data in Table 1 are a characterization of the pilot plant G-10CR and G-11CR from manufacturer $A$ at all three temperatures and in both fiber directions (also normal direction for compressive 
strength). These are averages of three or four specimens. The standard deviations among individual tests were about $4 \%$ of the average value for the Young's modulus, tensile strength, and shear strengths, and about $9 \%$ for the Poisson's ratio, compressive strength, and strain-to-failure. Overall, there was no noticeable change in data scatter with temperature. In Figures 1 through 3, the shaded areas indicate the extent of upper and lower data spread among tests.

Only two parameters showed any significant temperature related material differences. G-11CR had a higher modulus in both directions and a higher tensile strength in the fill direction. The guillotine shear strength may indicate some superiority in the G-10CR.

Cooling both materials from room to cryogenic temperatures increased the value of all parameters: Young's modulus about $30 \%$, Poisson's ratio 35 to $40 \%$, tensile and compressive strengths 70 through $130 \%$, ultimate strain about $100 \%$ in the warp direction and $60 \%$ in the $f i 11$ direction, short-beam shear strength about 100\%, and guillotine shear strength in the range of 50\%. G-11CR appears to be slightly less temperature dependent than G-10CR. The elastic properties, modulus, and Poisson's ratio showed somewhat greater change with temperature for fill than warp directions, while the opposite occurred for the ultimate strength and elongation.

Since the fill direction yarn count is approximately 0.75 of the warp direction count, it would seem likely to find the fiber-dependent parameters occurring in roughly this ratio. Fill/warp was about 0.80 for the modulus and ultimate strain, 0.65 for tensile and compressive strengths, and 1.00 for Poisson's ratio. Shear strength is largely a function of matrix and matrix-fiber honding, so it should be directionally 


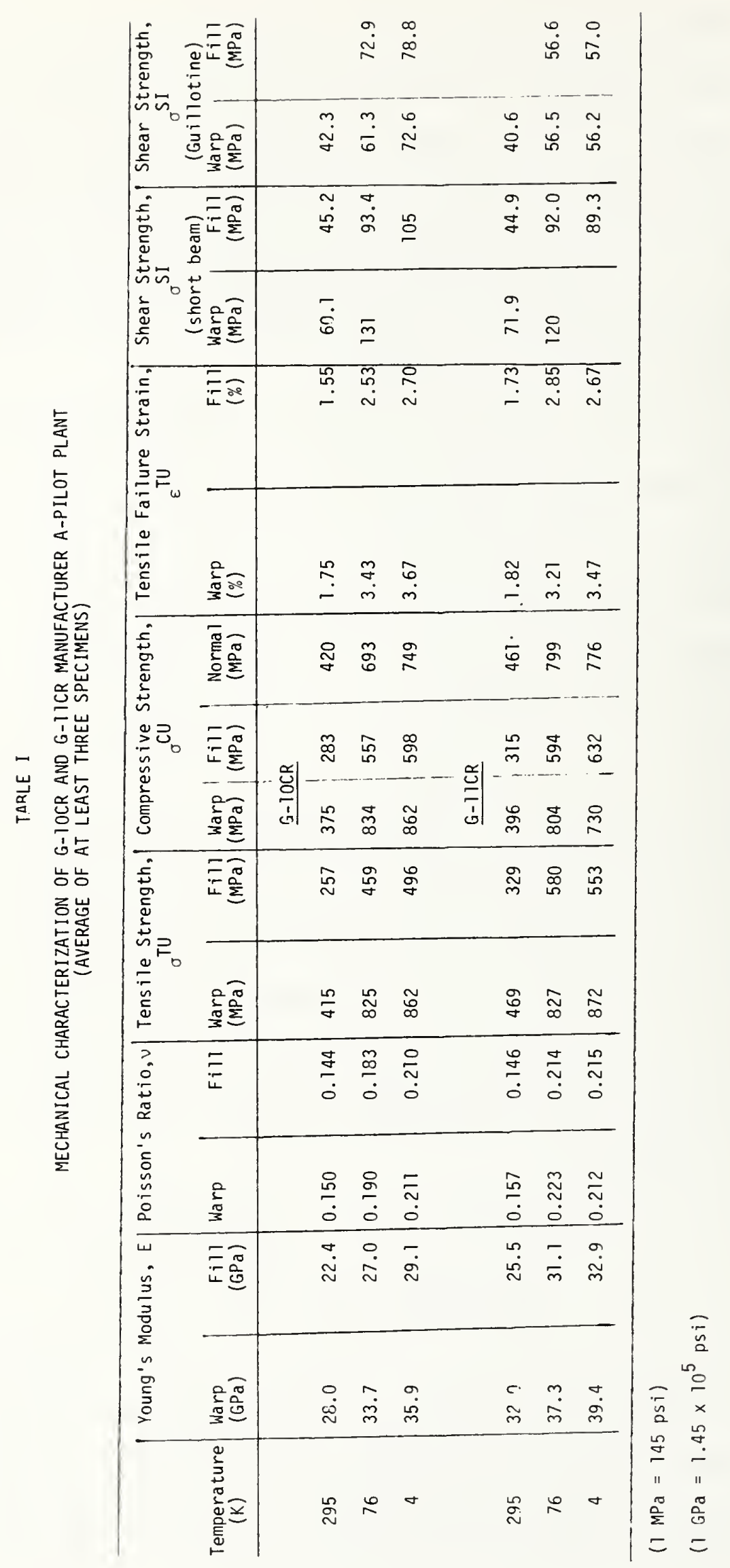


independent. The guillotine tests showed no real difference between orientations, but the short-beam tests yielded a fill/warp property ratio of 0.70 ; this is indicative of flexure-producing tensile and compressive as well as shear forces. Some material dependence with the fill/warp ratio did appear in the tensile and compressive strengths, where it was somewhat higher for G-1TCR than for G-10CR. The only parameter to display a temperature dependence was the failure strain, the ratio of fill/warp properties decreasing in the cryogenic region.

The compressive strengths normal to the cloth plane are valuable data for high-pressure laminates, since these materials are likely to be thus loaded in many weight-bearing applications. In general, the values seem to be comparable to those in the warp direction and show the same temperature dependence.

The screening data in Table II include only two temperatures and only the warp direction; they do, however, cover composite lots from manufacturer $A$ and $B^{\prime}$ 's production plants as well as the boron-free product from manufacturer $B$.

Some differences exist between values in the two tables. All comparisons here are to the complete characterization data in Table I for manufacturer A--pilot plant. For G-10CR, manufacturer A--production plant, Poisson's ratio runs about $15 \%$ high while the compressive strength at $76 \mathrm{~K}$ is $15 \%$ 10w. For G-11CR, manufacturer B--production plant, the tensile strength at $76 \mathrm{~K}$ is $18 \%$ high.

The majority of differences, however, occur in the boron-free products. In G-10CR the modulus is $1.5 \% 10 \mathrm{w}$, Poisson's ratio is $23 \%$ high, tensile strength is $14-20 \%$ low, and failure strain at $76 \mathrm{~K}$ is $17 \%$ low. The differences in G-11CR are a $9 \%$ high modulus, and the $76 \mathrm{~K}$ 


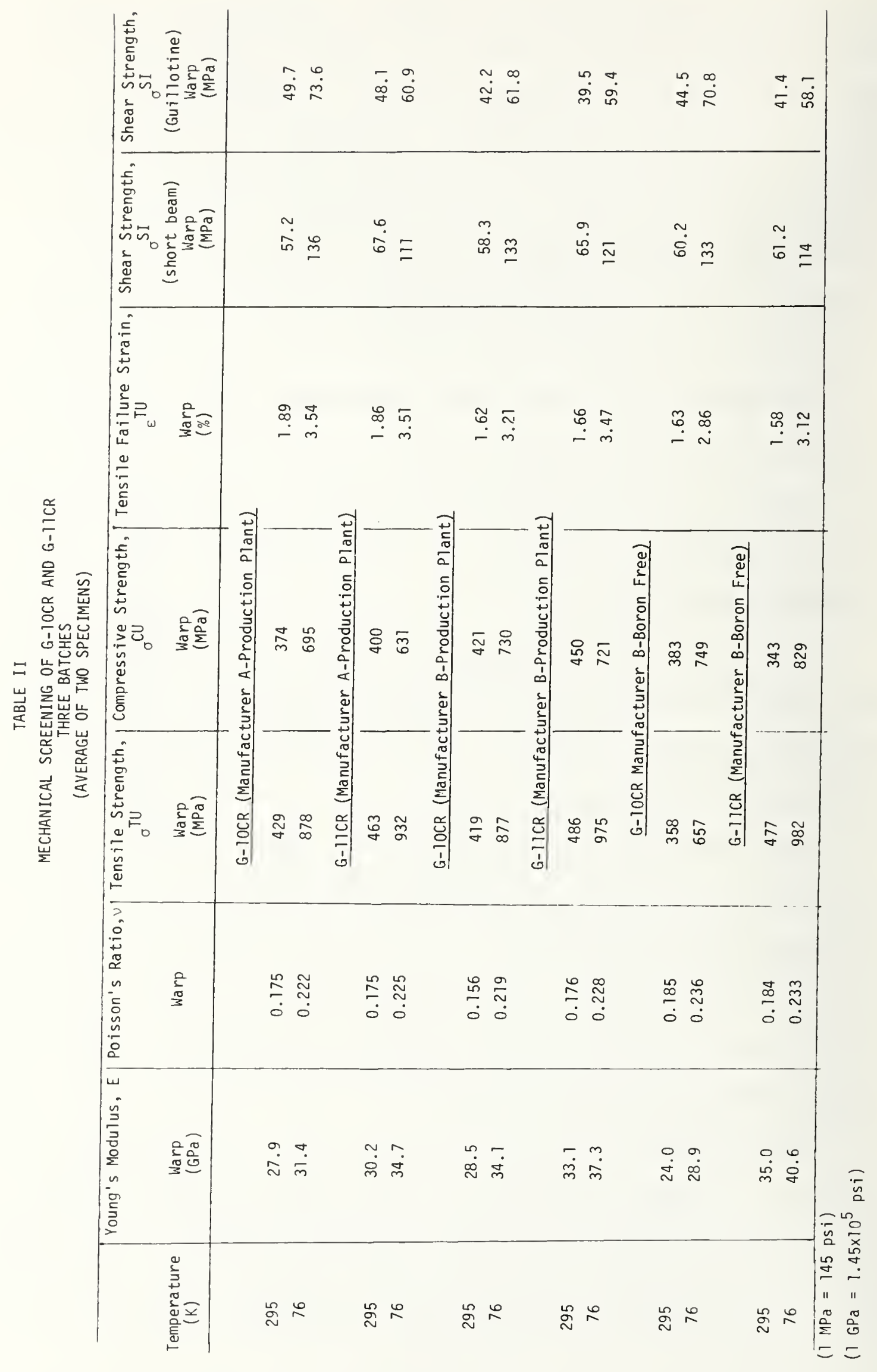


tensile strength is $19 \%$ high. None of these differences are really dramatic, and they could be the result of normal experimental scatter and the allowable variations in yarn count and resin content.

Limited data, particularly at cryogenic temperatures, are available for comparison, and they deal mostly with $S$ glass cloth $[4,5]$. In general, they show that the present materials display a higher modulus and tensile strength by a factor of about $1 / 3$ and a somewhat higher compressive strength and lower failure strain. Direct comparison of shear strengths is very difficult because of the many experimental variables.

\section{ELECTRICAL TESTS}

Volume resistivity (Table III) showed 1.5 to 2 orders of magnitude increase on cooling to $4 \mathrm{~K}$. Electric strength, however, displayed no temperature dependence and no difference between composite types. THERMAL TESTS

Thermal conductivities (Fig. 4) were nearly identical for both materials. Data were about 10\% higher for the warp direction than normal to the reinforcement. Fill direction measurements would likely yield values similar to present results. Uncertainties in measurement are about $\pm 5 \%$. Complete details and analysis will be published later [6].

The thermal contraction data (Fig. 5) show a directional dependence possibly indicating that the epoxy was a dominating factor. A detailed analysis of the continuous data is now in preparation for publication elsewhere [7]. A preliminary measurement of total contraction between room temperature and $75 \mathrm{~K}$ conducted at LASL indicated approximately $10 \%$ greater $\Delta L / L$. 
TABLE II I

ELECTRICAL PROPERTIES OF G-1OCR AND G-11CR

MANUFACTURER A-PILOT PLANT

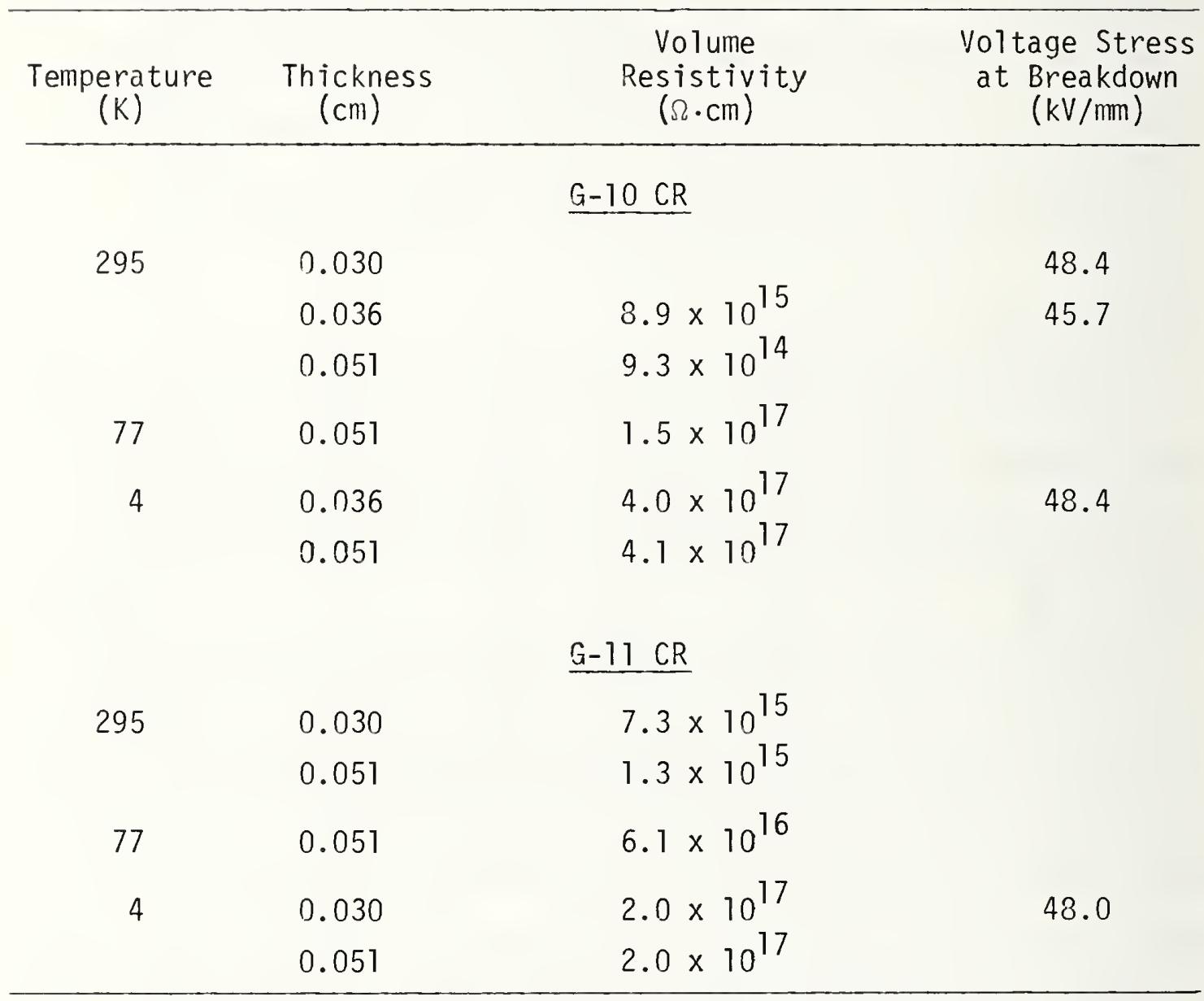


CONCLUSIONS

The CR grade glass-epoxy laminates should prove useful in those applications that require a structural or insulating material of predictable performance that is commercially available. These composites do have good mechanical properties at room temperature and below. In this and other laboratories, work continues on mechanical, electrical, and thermal characterization as well as resistance to radiation damage. -ACKNOWLEDGMENT

We are grateful to the Office of Fusion Energy, U.S. Department of Energy for sponsoring this work. Members of the NBS Thermophysical Properties Division performed the thermal conductivity studies (J.G. Hust) and thermal contraction measurements (A. F. Clark and M. A. Ranney). We also wish to thank G. A. Mullen of the Westinghouse R\&D Center, Pittsburgh, for the electrical data and J. Harlow and R. I. Schermer of the Los Alamos Scientific Laboratory for the preliminary thermal contraction data. 
1. J. R. Benzinger, in Advances in Cryogenic Engineering -- Materials, Vol. 26 Plenum Press, New York (1980), in press.

2. R. E. Schramm and M. B. Kasen, Mat. Sci. Eng. 30:197 (1977).

3. J. G. Hust and J. M. Arvidson, "Thermal Conductivity of Glass

Fiber/Epoxy Composite Support Bands for Cryogenic Dewars," Unpublished report 275.03-78-2, National Bureau of Standards, Boulder, Colorado.

4. M. B. Kasen, Cryogenics 15:327 (1975).

5. M. B. Kasen, in Composite Reliability, ASTM STP 580, American Society for Testing and Materials, Philadelphia, PA (1975), p. 586.

6. J. G. Hust, private communication, NBS, Thermophysical Properties Division Boulder, Colo. 80303.

7. A. F. Clark, private communication, NBS, Thermophysical Properties Division, Boulder, Colo. 80303. 


\section{LIST OF TABLES}

Table I. Mechanical Characterization of G-10CR and G-11CR, Manufacturer APilot Plant (Average of at Least Three Specimens).

Table II. Mechanical Screening of G-10CR and G-11CR, Three Batches (Average of Two Specimens).

Table III. Electrical Properties of G-10CR and G-11CR, Manufacturer A- Pilot Plant.

\section{LIST OF FIGURES}

Figure 1. Young's modulus versus temperature for G-10CR and G-11CR (Manufacturer A, Pilot Plant). Error bands show upper and lower data spreads.

Figure 2. Tensile strength versus temperature for G-10CR and G-11CR (Manufacturer A, Pilot Plant). Error bands show upper and lower data spreads.

Figure 3. Compressive strength versus temperature for G-10CR (Manufacturer A, Pilot Plant). Error bands show upper and lower data spreads. G-11CR displayed similar data spreads.

Figure 4. Thermal conductivity versus temperature for G-10CR and G-11CR (Manufacturer A, Pilot Plant).

Figure 5. Thermal contraction of G-10CR and G-11CR. The discrete points were from the preliminary tests done at LASL while the continuous curves were measured at NBS. (Manufacturer A, Pilot Plant). 
TEMPERATURE DEPENDENCE OF YOUNG'S MODULUS AND INTERNAL FRICTION OF G-10CR AND G-11CR EPOXY RESINS

National Bureau of Standards 

TEMPERATURE DEPENDENCE OF YOUNG'S MODULUS AND INTERNAL FRICTION OF G-10CR AND G-11CR EPOXY RESINS*

H. M. Ledbetter and G. Maerz

Fracture and Deformation Division, NBS, Boulder, Colorado 80303

Abstract

The Young's moduli of the epoxy-resin matrix material used in NEMAdesignation G-10CR and G-11CR fiberglass-cloth-reinforced composites were measured dynamically and semicontinuously between ambient and liquid-nitrogen temperatures. Both materials exhibit regular temperature behavior, showing large Young's-modulus changes, about 125 and 50 percent, respectively. Internal friction decreased about 80 percent during cooling to liquid-nitrogen temperature $(76 \mathrm{~K})$. The different thermoelastic coefficients of the two materials indicate a different internal structure.

Key words: Composites; elastic constants; epoxy resin; internal friction; low temperatures; Young's modulus. 
Large quantities of low-cost, high-pressure industrial laminates are now used as structural members and as electrical insulators. The National Electrical Manufacturers Association (NEMA) has established composite-material grades G-10 and G-11 for these purposes. These materials consist of glass-cloth-fiber reinforcement in an epoxy-resin matrix. Cryogenic grades of these materials are designated G-10CR and G- IICR.

Previously, Ledbetter ${ }^{1}$ summarized the importance of elastic-constant information for composite materials; and he reported Young's modulus and internal friction for both G $10 C R$ and G-11CR composites between room temperature and liquid-nitrogen temperature for three principal directions in the composite: warp, fill, and normal.

The present study focused on the epoxy-resin matrix materials used in these two composites. Young's modulus was determined semicontinuously between ambient and 1 iquid-nitrogen temperatures, and internal friction was determined at the two end-point temperatures.

Physical properties of a composite's constituents are essential to understanding the composite's behavior based on micromechanical models. Indeed, prediction of macroscopic properties from constituent properties is one of the few really fundamental problems in the theory of composite materials. And it remains the only such problem on which significant progress has been made. ${ }^{2}$

\section{Experimental}

\section{a. Materials}

Samples of each epoxy resin were obtained from a commercial source that also produces the composite materials. These samples were processed 
in terms of temperature, pressure, and time as though they were being fabricated into a composite. Both materials were translucent, the G-10 form being light-amber colored and the G-11 form dark-amber. Mass densities determined hydrostatically were 1.183 and $1.234 \mathrm{~g} / \mathrm{cm}^{3}$, respectively.

\section{b. Methods}

Methods used to measure Young's modulus and internal friction were described previously by Ledbetter. 1 Briefly, cylindrical specimens $5 \mathrm{~mm}$ in diameter and about $2 \mathrm{~cm}$ long formed one component of a a threecomponent (Marx) oscillator. The other two components were identical x-cut quartz piezoelectric crystals with fundamental resonance frequencies near $45 \mathrm{kHz}$. Young's modulus, E, is determined from

$$
E=4 \rho f_{s}^{2} e^{2}
$$

where $\rho$ denotes mass density, f frequency, \& length, and subscript-s specimen. The specimen's resonance frequency derives from

$$
f_{s}^{2}=f_{0}^{2}+\left(f_{0}^{2}-f_{q}^{2}\right) m_{q} / m_{s}
$$

where m denotes mass, subscript-o total oscillator, and subscript-q quartz.

Internal friction, $\mathrm{Q}^{-1}$, is determined by

$$
Q^{-1}=\left(f_{2}-f_{1}\right) / f_{0}
$$


the resonance-peak width at $1 / \sqrt{2}$ of maximum in a strain-versus-frequency curve. Similar to Eq. (2),

$$
Q_{S}^{-1}=Q_{0}^{-1}+\left(Q_{0}^{-1}-Q_{q}^{-1}\right) m_{q} / m_{s}
$$

\section{Results}

Room-temperature and liquid-nitrogen-temperature $E$ and $Q^{-1}$ values are given in Table 1. Young's-moduli-versus-temperature results are given in Table 2 and shown in Figs. 1 and 2.

Table 1. Young's modulus and internal friction at room temperature and liquid-nitrogen temperature for two epoxy resins.

\begin{tabular}{lcccc}
\hline & \multicolumn{2}{c}{ Young's ModuTus } & \multicolumn{2}{c}{ Internat Friction } \\
& $295 \mathrm{~K}^{(\mathrm{GPa})} 76 \mathrm{~K}$ & $295 \mathrm{~K}$ & $76 \mathrm{~K}$ \\
\hline $\mathrm{G}-10 \mathrm{CR}$ & 3.80 & 8.37 & 0.0396 & 0.0057 \\
$\mathrm{G}-11 \mathrm{CR}$ & 4.49 & 6.55 & 0.0164 & 0.0032 \\
\hline
\end{tabular}


Table 2. Temperature dependence of Young's moduli of G-10CR and G-11CR epoxy resins, in units of $10^{11} \mathrm{~N} / \mathrm{m}^{2}$. (Preliminary results.)

$\begin{array}{lll}\frac{T(K)}{300} & \frac{G-10 C R}{.03640} & \frac{G-11 C R}{.04319} \\ 290 & .03972 & .04454 \\ 280 & .04300 & .04588 \\ 270 & .04623 & .04720 \\ 260 & .04940 & .04850 \\ 250 & .05251 & .04977 \\ 240 & .05555 & .05102 \\ 230 & .05852 & .05224 \\ 220 & .06140 & .05343 \\ 210 & .06419 & .05458 \\ 200 & .06688 & .05570 \\ 190 & .06945 & .05677 \\ 180 & .07191 & .05780 \\ 170 & .07423 & .05878 \\ 160 & .07639 & .05970 \\ 150 & .07839 & .06055 \\ 140 & .08022 & .06134 \\ 130 & .08184 & .06205 \\ 120 & .08325 & .06267 \\ 110 & .08444 & .06320 \\ 100 & .08539 & .06364 \\ 90 & .08611 & .06397 \\ 80 & .08661 & .06421 \\ 76 & .08676 & .06429\end{array}$



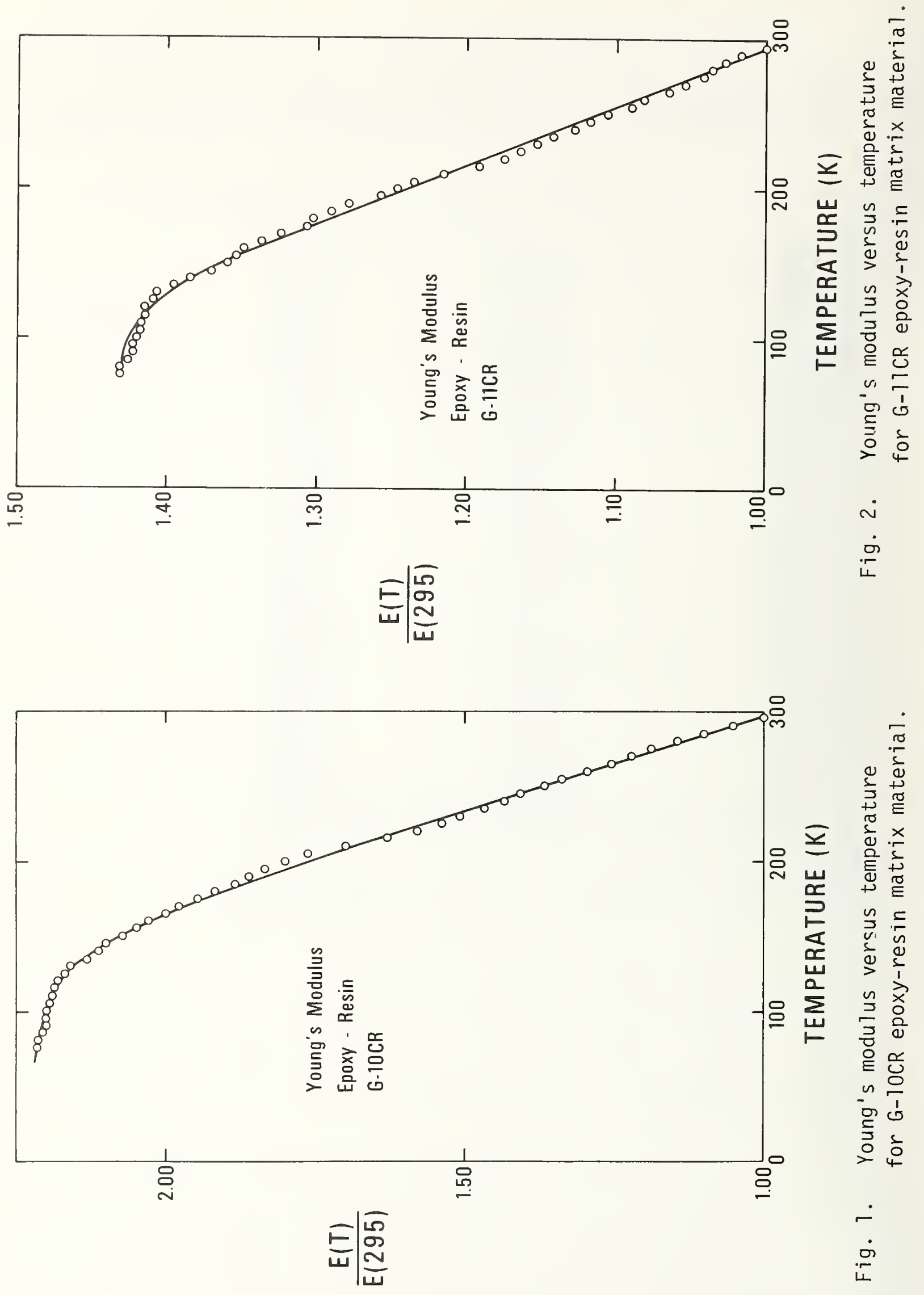


\section{Discussion}

As shown in Figs. 1 and 2, the Young's moduli of the epoxy resins change regularly with temperature: linear at high temperature; negative slope, decreasing with decreasing temperature; approaching zero slope at zero temperature. Such regular behavior indicates the absence of phase transitions or other abrupt changes in the internal structure of the material. Such behavior can be described by various models that have a theoretical basis. Varshni ${ }^{3}$ proposed that elastic-stiffness constants, $C$, change with temperature according to

$$
C(T)=C(0)-s /[\exp (t / T-1)]
$$

where $\mathrm{C}(\mathrm{o}), \mathrm{s}$, and $\mathrm{t}$ are the three adjustable parameters, and $\mathrm{T}$ is absolute temperature. Physically, $C(0)$ is the zero-temperature elastic constant; t corresponds to a characteristic vibration temperature such as the Einstein temperature; and $-s / t$ is the high-temperature limit of the thermoelastic coefficient $d C / d T$, the slope of the $C(T)$ curve.

Parameters determined by fitting the observations to Eq. (5) are given in Table 3. Consistent with a higher $\mathrm{dC} / \mathrm{dT}$, the G-10CR epoxyresin shows a higher value of $s$, despite having a similar $t$. This irregularity suggests that the two materials are structurally dissimilar. Some study may be appropriate to determine the physical meaning of $s$, which determines the relative temperature behavior of these two materials, a behavior usually determined by $t$.

The quantitatively different temperature behavior of the two materials is dramatic. Expressed as $-(1 / E)(d E / d T)$ at room temperature, 
Table 3. Parameters in equation (5).

\begin{tabular}{cccc}
\hline & $\begin{array}{c}C(0) \\
\left(10^{11} \mathrm{~N} / \mathrm{m}^{2}\right)\end{array}$ & $\begin{array}{c}\mathrm{s} \\
\left(10^{11} \mathrm{~N} / \mathrm{m}^{2}\right)\end{array}$ & $\begin{array}{c}\mathrm{t} \\
(\mathrm{K})\end{array}$ \\
\hline G-10CR & 0.0872 & 0.1926 & 470 \\
G-11CR & 0.0645 & 0.0726 & 445 \\
\hline
\end{tabular}

the values are 0.0087 for the G-10CR resin and 0.0031 for the G-11CR resin, a difference of a factor of three! In terms of a linear-chain model of solids and the temperature dependence of the elastic constant $c_{11}$ is $^{5}$

$$
d C_{11} / d T=-g^{2} k / 2 f^{2} a
$$

where $k$ denotes Boltzmann's constant, a the lattice parameter, and $f$ and $g$ the second-order and third-order force constants. Since the similar values of $E$ show that $f$ is about the same for the two materials, g must be much higher for the G-10CR case. This higher anharmonicity implies that properties such as thermal expansivity and specific heat will be higher also.

The dissimilarity of the two materials manifests itself also in the internal friction, where the G-10CR value is approximately double that of the G-11CR case. For a large number of composite materials, Ledbetter 4 established an approximately hyperbolic inverse relationship between $E$ and $Q^{-1}$. The result results suggest that this relationship may be more valid at ambient temperatures than at lower temperatures. 


\section{$\underline{\text { References }}$}

1. H. M. Ledbetter, Dynamic elastic modulus and internal friction in G-10CR and G-11CR fiberglass-cloth-epoxy composites, in Material Studies for Magnetic Fusion Energy Applications at Low Temperature-II, NBSIR 79-1609 (1979), pp. 437-451.

2. Z. Hashin, Theory of composite materials, in Mechanics of Composite Materials (Pergamon, New York, 1970), pp. 201-242.

3. Y. P. Varshni, Temperature dependence of the elastic constants, Phys. Rev. B2, 3952-3958 (1970).

4. H. M. Ledbetter, Dynamic modulus and damping in fiber-reinforced composites, to be published.

5. G. Leibfried, Gittertheorie der mechanischen and thermischen Eigenschaften der Kristalle, in Handbuch der Physik, Volume 7, Part 1 (Springer-Verlag, Berlin, 1955), pp. 104-324. 


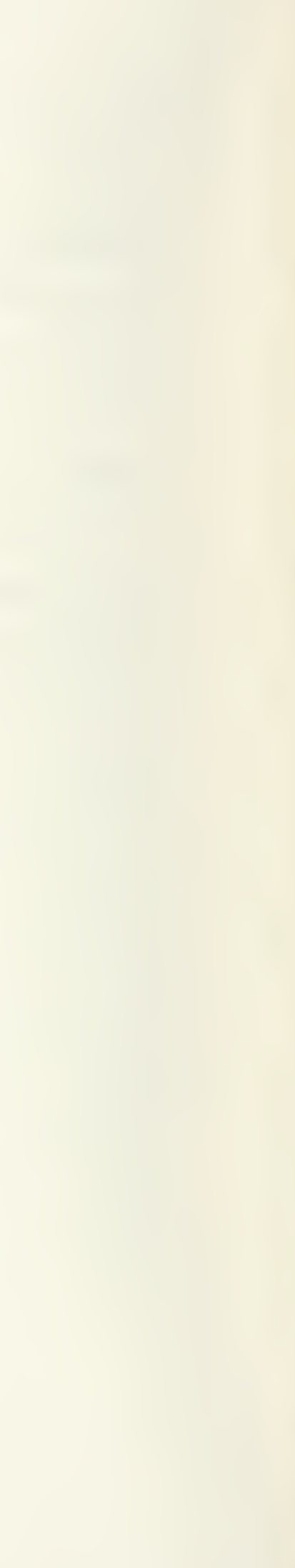


DIRECTIONAL VARIATION OF YOUNG'S MODULUS AND INTERNAL FRICTION IN TWO FIBERGLASS-CLOTH-EPOXY COMPOSITES National Bureau of Standards 

DIRECTIONAL VARIATION OF YOUNG'S MODULUS AND INTERNAL FRICTION IN TWO FIBERGLASS-CLOTH-EPOXY COMPOSITES

H. M. Ledbetter

Fracture and Deformation Division, NBS, Boulder, Colorado 80303

\section{Abstract}

Young's modulus was measured dynamically (near $50 \mathrm{kHz}$ ) for various directions in the warp-fill pTane and in the warp-normal plane of laminated fiberglass-cloth-epoxy composites. Results are interpreted using an anisotropic elasticity model. Directional dependence of internal friction was determined on the same specimens. Directions of high modulus are directions of low internal friction, and vice versa.

Key Words: Composites; elastic constants; glass-epoxy; internal friction; Young's modulus. 


\section{Introduction}

Stimulated largely by aerospace applications, interest in composite materials has skyrocketed during recent decades. The longstanding interest in lightweight, high-strength, low-cost materials has also intensified. For many structural applications, fiberglass-cloth-epoxy composites provide these desired properties. These considerations combined with electrical-property requirements led the National Electrical Manufacturers Association (NEMA) to develop specifications for two materials: G-10 and G-11, with the corresponding cryogenic grades G-10CR and G-11CR.

A principal characteristic of composites is the directional variation of most of their properties, mechanical and physical. Indeed, the primary theoretical problem for composites is to predict their direction-dependent properties from the (usually isotropic) properties of their constituents.

The macroscopic-microscopic elastic constants of composites have been studied extensively for fiber-reinforced materials. This subject has been reviewed by Bert ${ }^{1}$ from an experimental viewpoint and by Sendeckyj ${ }^{2}$ from a theoretical viewpoint.

The present study determined the directional variation of both Young's modulus and internal friction in two fiberglass-cloth-epoxy composites: NEMA grades G-10CR and G-11CR.

\section{Experimental}

a. Materials

Table 1 summarizes the properties of the materials, which were received from a commercial source in the form of plates 2.5 to $5.0 \mathrm{~cm}$ thick. Specimen lengths varied from 2 to $5 \mathrm{~cm}$ depending on material, 
fiber orientation, and resonance frequency. Three or more specimens were studied for each material and orientation.

\section{b. Young's-modulus measurements}

Experimental methods were described previously in detail elsewhere ${ }^{3}$. Briefly, the specimen formed one component of a three-component (Marx) oscillator. The other two components were identical x-cut quartz piezoelectric crystals with fundamental resonance frequencies near $45 \mathrm{kHz}$. Young's modulus, E, wàs determined from

$$
E=4 \rho f^{2} l^{2} s
$$

where, $\rho$ denotes mass density, f frequency, l length, and subscript-s specimen. The specimen's resonance frequency was derived from

$$
f_{s}^{2}=f_{0}^{2}+\left(f_{0}^{2}-f_{q}^{2}\right) m_{q} / m_{s}
$$

where m denotes mass, subscript-o total oscillator, and subscript-q quartz.

c. Interna]-friction measurement

Internal friction, $\mathrm{Q}^{-1}$, was determined by

$$
Q^{-1}=\left(f_{2}-f_{1}\right) / f_{0}
$$

the resonance-peak width at $1 / \sqrt{2}$ of maximum in a strain-versus-frequency curve. Similar to Eq. (2),

$$
Q_{S}^{-1}=Q_{0}^{-1}+\left(Q_{0}^{-1}-Q_{q}^{-1}\right) m_{q} / m_{s}
$$

\section{Results}

Figures 1-4 and Table 2 show the principal results of the study: the directional variation of Young's modulus and internal friction for 
two fiberglass-cloth-epoxy composites. Because of the similarity of the two composites, complete sets of measurements were not made on both materials. G-10CR was studied in the warp-fill plane and $F_{x}$ llCR was studied in the warp-normal plane. Samples were not available for studying the fill-normal plane; but because the fiber density does not differ markedly in the warp and fill directions, the warp-normal plane should not differ markedly from the fill-normal plane.

\section{Discussion}

It is attractive to interpret the strong dependence of Young's modulus on direction (Figs. 1 and 2) by invoking well-known anisotropicelasticity relationships 4 . We assume tetragonal elastic symmetry, that is, the equivalence of the warp and fill directions. Of course the composites actually have orthorhombic elastic symmetry; but this means nine independent elastic constants and a more complicated analys is with less useful results. Results in Table 2 and previously reported results ${ }^{3}$ for the temperature dependence of Young's modulus show that the fillwarp equivalence is not too bad an assumption for present purposes.

Tetragonal-symmetry materials have six independent elastic constants. For the elastic compliances, the $S_{i j}{ }^{\prime} s$, these are usually taken to be: $S_{11}=S_{22}, S_{33}, S_{12}, S_{13}=S_{23}, S_{44}=S_{55}$, and $S_{66}$. Young's modulus along the $x_{1}$ axis is $s_{11}^{-1}$, along $x_{2}$ it is $s_{22}^{-1}$, and along $x_{3}$ it is $s_{33}^{-1}$. Herein, $x_{1}, x_{2}$, and $x_{3}$ correspond to the warp, fill, and normal directions, respectively.

For an arbitrary direction in a material, Young's modulus is

$$
1 / E^{\prime}=S_{11}^{\prime}=S_{1111}^{\prime}=\alpha_{1 j^{\alpha}}{ }_{1 j}^{\alpha}{ }_{1 k^{\alpha}}{ }_{1 l} S_{i j k \ell}
$$


where primes denote a coordinate system rotated away from $x_{y}, x_{2}, x_{3}$; the four indices on $S$ are the ful1-tensor form necessary for tensor transformations; and the $\alpha_{1 j}$ 's are the direction cosines between the primed and unprimed coordinate sjstems. For tetraconal symmetry,

Eq. (5) becomes

$$
\begin{aligned}
& S_{11}^{1}=\left(\alpha_{1}^{4}+\alpha_{2}^{4}\right) S_{11}+\alpha_{3}^{4} S_{33}+2 \alpha_{1}^{2} \alpha_{2}^{2} S_{12}+2\left(\alpha_{1}^{2} \alpha_{3}^{2}+\alpha_{2}^{2} \alpha_{3}^{2}\right) S_{13} \\
& +\left(\alpha_{2}^{2} \alpha_{3}^{2}+\alpha_{1}^{2} \alpha_{3}^{2}\right) s_{44}+\alpha_{1}^{2} \alpha_{2}^{2} S_{66}
\end{aligned}
$$

For directions in the $x_{1}-x_{2}$ plane, Eq. (5) becomes

$$
S_{11}^{\prime}=\left(\alpha_{1}^{4}+\alpha_{2}^{4}\right) S_{11}+\alpha_{1}^{2} \alpha_{2}^{2}\left(2 S_{12}+S_{66}\right)
$$

For directions in the $x_{1}-x_{3}$ plane, Eq. (5) becomes

$$
S_{11}^{1}=\alpha_{1}^{4} S_{11}+\alpha_{3}^{4} S_{33}+\alpha_{1}^{2} \alpha_{3}^{2}\left(2 S_{13}+S_{44}\right)
$$

which is by symmetry the same as for the $x_{2}-x_{3}$ plane when $\alpha_{2}$ is substituted for $\alpha_{1}$.

From Eqs. (7) and (8) and the present experimental results, leastsquares values of $2 S_{12}+S_{66}$ and $2 S_{13}+S_{44}$ can be computed. The results are 16.05 and 16.37 , respectively. From the relationship

$$
S_{12}=-v_{12} S_{11}
$$

assuming $v_{12}=0.165^{5}, S_{12}$ is -0.5593 . Thus, $S_{66}$ is 17.17 and $c_{66}=s_{66}^{-1}=0.058 . \quad C_{66}$ represents the resistance on the $x_{2}$ or $x_{1}$ plane to a shear stress directed along either $x_{1}$ or $x_{2}$. Consistent with the results in Fig. 1, this result indicates the lower rigidity of the composite to any deformation not directed uniaxially along either $x_{1}$ or $x_{2}$. 


$$
S_{13}=-v_{13} S_{11}
$$

and the assumption that $\nu_{13}=0.333$, a typical value for an epoxy resin, which constitutes the matrix, which largely determines the $v_{13}$ value, it results that $S_{13}=-0.105$ and that $S_{44}=16.58$. Thus $C_{44}=S_{44}^{-1}=0.060$ is the resistance on the $x_{3}$ or $x_{2}$ plane to a shear stress along either $x_{2}$ or $x_{3}$. As for the case of a $C_{66}$-type shear, this deformation strongly reflects matrix properties and has a low value.

Thus, assuming tetragonal symmetry, from measurements of the Young'smodulus directional dependence and two assumptions concerning Poisson's ratio, we have deduced the complete set of six elastic constants of a fiberglass-cloth-epoxy composite. These are listed in Table 3. At the same time, the seemingly irregular directional dependence of Young's modulus is explained as resulting from contributions from elastic constants such as $\mathrm{S}_{44}$ and $\mathrm{S}_{66}$. Interestingly, for this material, the elastic constants $\mathrm{S}_{12}$ and $\mathrm{S}_{13}$ affect Young's modulus only negligibly.

Internal friction shows an inverse relationship to Young's modulus, as shown by comparing Figs. 3 and 4 with Figs. 1 and 2. This relationship holds for a wide variety of composites, as shown by Ledbetter ${ }^{6}$. While one intuitively associates higher damping with softer elastic stiffness, the author knows no model that shows this explicitly. Similarly, the author knows no model for interpreting anisotropic internal friction. 


\section{Conclusions}

The following principal results and conclusions emerge from the present study:

1. Young's modulus, $E\left(\alpha_{j}\right)$, varies strongly with direction, both in the warp-fill plane and in the warp-normal plane.

2. This directional variation can be interpreted using an anisotropic elasticity model.

3. Alternatively, by making two assumptions concerning Poisson's ratio, the complete set of elastic compliances, the $S_{i j}$ 's can be determined from the $E\left(\alpha_{j}\right)$ results.

4. Internal friction varies inversely with $E\left(\alpha_{i}\right)$. This result, while not unexpected, cannot be interpreted or explained by any simple model known to the author.

Acknowledgment

Both R. E. Schramm and M. B. Kasen of NBS provided information and materials required for this study. 


\section{References}

1. C. W. Bert, Experimental determination of composites, in Composite Materials, Volume 8 (Academic, New York, 1975).

2. G. P. Sendeckyj, Elastic behavior of composites, in Composite Materials, Volume 2 (Academic, New York, 1974), pp. 45-83.

3. H. M. Ledbetter, Dynamic elastic modulus and internal friction in fibrous composites, in Nonmetallic Materials and Composites at Low Temperatures (Plenum, New York, 1979), pp. 267-281.

4. J. F. Nye, Physical Properties of Crystals (Oxford Clarendon, London, 1960), p. 131-149.

5. R. E. Schramm and M. B. Kasen, Fracture and Deformation Division, NBS, Boulder, Colorado, personal communication (1979).

6. H. M. Ledbetter, Dynamic elastic modulus and damping in fiberreinforced composites, to be published. 
Table 1. Properties of studied materials.

\begin{tabular}{lcccc} 
Material & Fiber & Matrix & $\left(\mathrm{g} / \mathrm{cm}^{3}\right)$ & Fraction \\
\hline G-10CR & 7628 E-glass cloth bisphenol epoxy & 1.90 & $0.64-0.68$ \\
G-11CR & 7628 E-glass cloth bisphenol A, aromatic amine & 1.95 & $0.64-0.68$
\end{tabular}

Table 2. Dynamic Young's moduli, E, and internal friction, $Q^{-1}$, of $G-10 C R$ and $G-T 1 C R$.

\begin{tabular}{|c|c|c|c|c|c|}
\hline $\begin{array}{l}\text { Temp } \\
(\mathrm{K})\end{array}$ & irection & $E(G P a)$ & $Q^{-1}\left(10^{-4}\right)$ & $E(G P a)$ & $Q^{-1}\left(10^{-4}\right)$ \\
\hline 295 & $\begin{array}{c}\text { warp } \\
\text { fil1 } \\
\text { normal }\end{array}$ & $\begin{array}{l}29.4 \pm 1.0 \\
26.3 \pm 1.0 \\
14.0\end{array}$ & $\begin{array}{l}68.3 \pm 6.6 \\
114.0 \pm 7.8 \\
228.6\end{array}$ & $\begin{array}{l}31.4 \pm 0.4 \\
27.7 \\
15.6 \pm 0.6\end{array}$ & $\begin{array}{l}147.0 \pm 34.9 \\
161.3 \\
406.5\end{array}$ \\
\hline 76 & $\begin{array}{c}\text { warp } \\
\text { fi11 } \\
\text { normal }\end{array}$ & $\begin{array}{l}34.4 \\
32.9 \\
21.8\end{array}$ & $\begin{array}{l}14.6 \\
17.3 \\
19.6\end{array}$ & $\begin{array}{l}37.6 \\
33.6 \\
22.8\end{array}$ & $\begin{array}{c}33.4 \\
-- \\
--\end{array}$ \\
\hline $\begin{array}{l}76 / 295 \\
\text { dimensionles } \\
\text { ratios }\end{array}$ & $\begin{array}{l}\text { warp } \\
\text { ss } \\
\text { fill } \\
\text { normal }\end{array}$ & $\begin{array}{l}1.17 \\
1.25 \\
1.56\end{array}$ & $\begin{array}{l}0.21 \\
0.15 \\
0.09\end{array}$ & $\begin{array}{l}1.20 \\
1.21 \\
1.46\end{array}$ & $\begin{array}{c}0.23 \\
-- \\
--\end{array}$ \\
\hline
\end{tabular}


Table 3. Elastic compliances, the $S_{i j}{ }^{\prime} s$, and elastic stiffnesses, and elastic stiffnesses, the $C_{i j}{ }^{\prime} s$, reduced as described in text for G-10CR case.

\begin{tabular}{rcc}
\multicolumn{1}{c}{$i j$} & $\begin{array}{c}\mathrm{S}_{\mathrm{ij}} \\
\left(10^{\left.-11 \mathrm{~m}^{2} / \mathrm{N}\right)}\right.\end{array}$ & $\begin{array}{c}\mathrm{C}_{\mathrm{ij}} \\
\left(10^{11} \mathrm{~N} / \mathrm{m}^{2}\right)\end{array}$ \\
\hline 11,22 & 3.67 & 0.279 \\
33 & 6.41 & 0.156 \\
44,55 & 16.58 & 0.060 \\
66 & 17.77 & 0.058 \\
12 & -0.56 & 0.043 \\
13,23 & -0.11 & 0.005 \\
\hline
\end{tabular}




\section{Figure Captions}

1. Directional variation of Young's modulus of G-1OCR composite in warp-fill plane, in units of GPa.

2. Directional variation of Young's modulus of G-llCR composite in warp-normal plane, in units of GPa.

3. Directional variation of internal friction, $Q^{-1}$, of G-10CR composite in warp-fill plane.

4. Directional variation of internal friction, $Q^{-1}$, of G-1 ICR composite in warp-normal plane. Two points at $15^{\circ}$ and $30^{\circ}$ represent specimens from different samples of composite. Dashed line indicates that the exact directional variation remains uncertain in this region. 

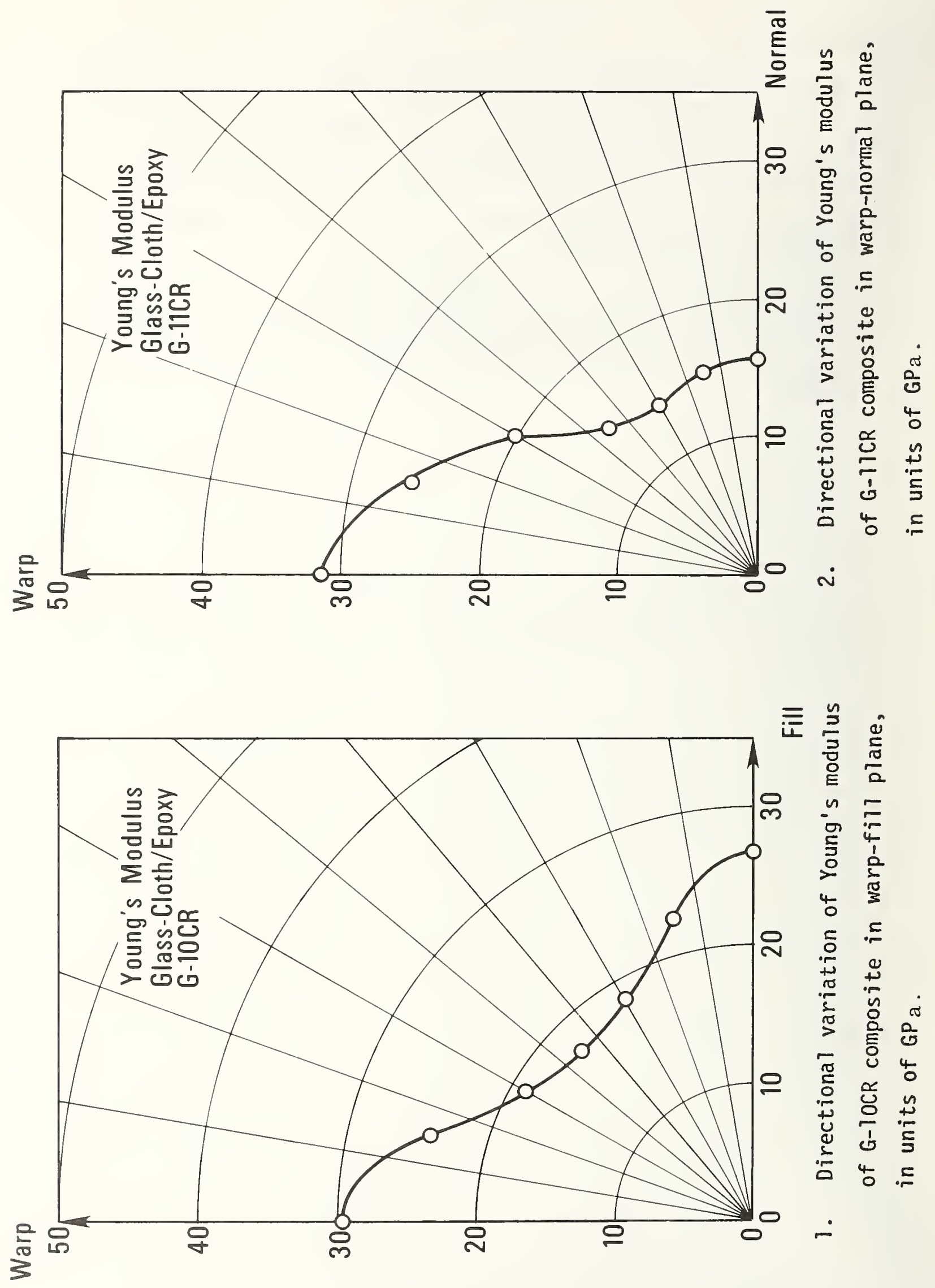


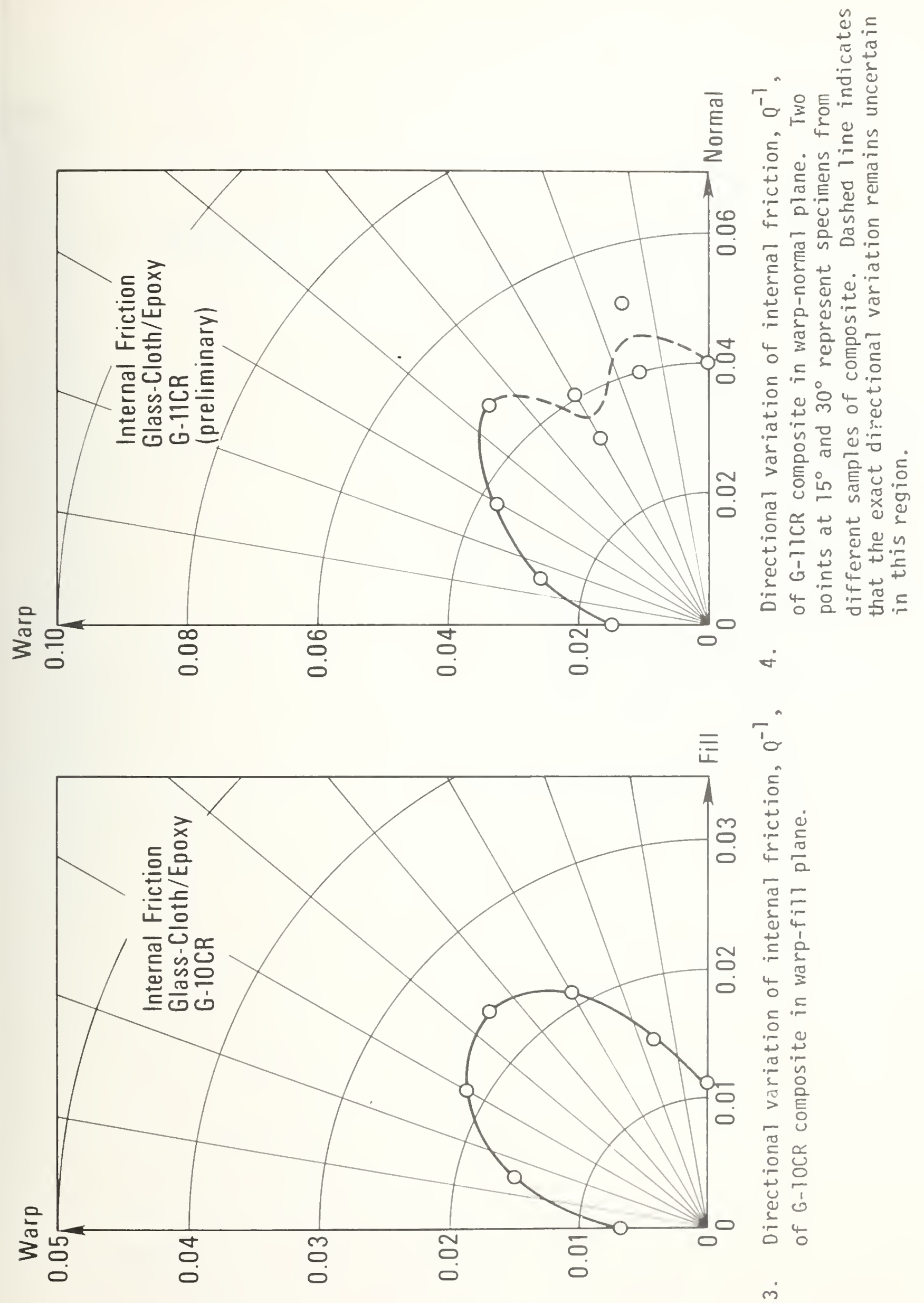


THERMAL CONDUCTIVITY OF G-10CR AND G-11CR INDUSTRIAL

LAMINATES AT LOW TEMPERATURES (PART II)

National Bureau of Standards 

THERMAL CONDUCTIVITY OF G-1OCR AND G-11CR INDUSTRIAL

LAMINATES AT LOW TEMPERATURES (PART II)

J. G. Hust

ABSTRACT

Experimental thermal conductivity results are reported for G-10CR composite specimens from two suppliers and at strains up to $90 \%$ of ultimate at temperatures from 2 to $300 \mathrm{~K}$. The results indicate considerable differences between the two manufacturers but essentially no effect due to strain. Data are also reported on the resins used in G-10CR and G-11CR. These results are difficult to understand and further measurements are scheduled to define their properties more clearly.

\section{INTRODUCTION}

NBS is performing extensive low-temperature electrical, thermal, and mechanical properties characterization of cryogenic grades of G-10 and G-11 fiberglass-epoxy composites. These special laminate grades, referred to as G-10CR and G-11CR, meet NEMA Grades G-10 and G-11, MIL-P-18177C, and federal specification LP-509.

In a previous report (Part I) [1], thermal conductivity data were presented for G-10CR and G-11CR at temperatures from 2 to $300 \mathrm{~K}$ for heat flow in both the normal and warp directions. These data indicated that the two laminates, produced by a single manufacturer (manufacturer $A$ ), had the same conductivity to within about 10\%. Also, it was found that the warp direction conductivity was about $20 \%$ higher than that in the normal direction.

The purpose of the present work is to investigate the difference in thermal conductivity on specimens obtained from another manufacturer (manufacturer B), to investigate the effect of large strain, and to determine the thermal conductivity of the pure epoxy resin used in these laminates. The latter results will aid the analysis and interpretation of the composite data. 


\section{MATERIAL AND SPECIMEN CHARACTERIZATION}

Both G-10CR and G-11CR are woven glass-epoxy composites. G-10CR is a heatactivated amine-catalyzed bisphenol $A$, solid-type, epoxy resin laminate reinforced with continuous filament E-glass fiber fabric, silane finished. G-11CR is an aromatic amine bisphenol A liquid-type epoxy resin laminate, reinforced with the same fabric. The fabric thread count is $17 \pm 1$ per $\mathrm{cm}(43 \pm 3$ per in) for warp and $12 \pm 1$ per $\mathrm{cm}(32 \pm 2$ per in) for fill. The threads are composed of 75 filaments each of $0.00046-\mathrm{cm}$ diameter $(0.00018-\mathrm{in})$. The direction referred to as normal in these measurements is perpendicular to the cloth plane.

The density of $E \mathrm{glass}$ is $2.4 \mathrm{~g} / \mathrm{cm}^{3}$. The resin used in $\mathrm{G}-10 C R$ has an uncured density of $1.10 \pm 0.01 \mathrm{~g} / \mathrm{cm}^{3}$, and the G-11CR resin has an uncured density of $1.04 \pm 0.01 \mathrm{~g} / \mathrm{cm}^{3}$. The G-10CR composite contains 33 to 35 weight percent resin, and the G-1ICR contains 27 to 31 weight percent resin. The typical density of G-1TCR is given by the manufacturer as $1.97 \mathrm{~g} / \mathrm{cm}^{3}$.

The thermal conductivity specimens of G-10CR and G-11CR lamintes are formed by cutting approximately $2-\mathrm{cm}$ squares from a laminate sheet $4-\mathrm{mm}$ thick and cementing these squares together to form a cube. The squares were cemented using a strain-gage adhesive under pressure at $150^{\circ} \mathrm{C}$ to obtain a thin glue line. The cured blocks were then machined to the dimensions shown in Table 1. The specimen masses and calculated densities are also given.

The resin specimens were cut from 1 arger blocks supplied by the manufacturer. The dimensions, masses, and calculated densities are given in Table 1. 
TABLE 1

DIMENSIONS, VOLUMES, WEIGHTS, AND DENSITIES

OF THE THERMAL CONDUCTIVITY SPECIMENS

\begin{tabular}{|c|c|c|c|c|c|c|}
\hline \multirow[b]{2}{*}{ SPEC IMEN } & \multicolumn{3}{|c|}{$\begin{array}{l}\text { DIMENSIONS } \\
(\mathrm{cm})^{-}\end{array}$} & \multirow[b]{2}{*}{$\begin{array}{l}\text { VOLUME } \\
\qquad(\mathrm{cm})^{3}\end{array}$} & \multirow[b]{2}{*}{$\begin{array}{l}\text { WEIGHT } \\
(\mathrm{g})\end{array}$} & \multirow[b]{2}{*}{$\begin{array}{r}\text { DENSITY } \\
(\mathrm{g} / \mathrm{cm})\end{array}$} \\
\hline & $x_{1}^{a}$ & $x_{2}^{b}$ & $x_{3}^{c}$ & & & \\
\hline G-10CR/WARP (78) & 1.910 & 1.890 & 1.919 & 6.93 & 13.188 & 1.904 \\
\hline G-11CR/WARP (78) & 1.915 & 1.913 & 1.910 & 7.00 & 13.684 & 1.956 \\
\hline $\begin{array}{l}\text { G-10CR }(6) \\
\text { WARP }(90 \text { PCT })\end{array}$ & 1.913 & 1.911 & 1.916 & 7.00 & 12.767 & 1.824 \\
\hline $\begin{array}{l}\text { G-10CR (1) } \\
\text { WARP (AS Rec.) }\end{array}$ & 1.916 & 1.819 & 1.824 & 6.36 & 11.608 & 1.825 \\
\hline G-10(GW) NORM & 1.882 & 1.908 & 1.873 & 6.73 & 11.717 & 1.741 \\
\hline G-10CR RESIN & 1.915 & 1.913 & 1.781 & 6.52 & 7.698 & 1.181 \\
\hline G-11CR RESIN & 1.915 & 1.915 & 1.915 & 7.02 & 8.620 & 1.228 \\
\hline
\end{tabular}
a - $X_{1}$ is normal to the fabric for the composite specimens
b - $x_{2}$ is the warp direction for the composite specimens
$c-X_{3}$ is the fill direction for the composite specimens 
Using the measured density of each specimen, the given density of $E$ glass, and the weight fractions of the resins in the composite specimens, the resin densities can be calculated with the equations below:

$$
\rho_{C}=\rho_{r} W F_{r}+\rho_{g} W F_{g}
$$

$$
\begin{aligned}
\rho_{\mathrm{C}} & =\text { density of composite } \\
\rho_{\mathrm{r}} & =\text { density of resin } \\
\rho_{\mathrm{g}} & =\text { density of glass } \\
W F_{r} & =\text { weight fraction of resin } \\
W F_{g} & =\text { weight fraction of glass }
\end{aligned}
$$

This resulted in a resin density of $1.25 \pm 0.01 \mathrm{~g} / \mathrm{cm}^{3}$ for both resins. Note that the measured densities of the two resin specimens are $1.181 \mathrm{~g} / \mathrm{cm}^{3}$ for G-10CR and $1.228 \mathrm{~g} / \mathrm{cm}^{3}$ for $\mathrm{G}-11 \mathrm{CR}$ resin. By using the equation

$$
v_{c}=V_{r} V F_{r}+V_{g} V F_{g}
$$

where $V$ is specific volume $(V=1 / \rho)$ and $V F$ is volume fraction, the volume fiber content was calculated to be $53 \%$ for G-10CR and $58 \%$ for G-11CR.

\section{EXPERIMENTAL PROCEDURE AND DATA ANALYSIS}

The thermal conductivity of the test specimens is determined using a thermal conductivity integral apparatus. This apparatus is described in detail by Hust and Arvidson [2]. The estimated uncertainty of the results is less than $10 \%$, unless otherwise noted, as verified by measurements on NBS standard reference material, SRM 735 . 


\section{RESULTS AND DISCUSSION}

The specimen designated as G-10CR(6) WARP (90 PCT) was prepared by first cutting a 2-cm strip from a sheet of material that was room-temperature strained in the warp direction to $90 \%$ of ultimate. This strained strip was then cut into pieces and glued together to form a block, as previously described. Seventeen data points (thermal conductivity-integrals) were obtained at temperatures from 4 to $304 \mathrm{~K}$. Heat flow was in the warp direction. These logarithmically spaced data were represented by the thermal conductivity integral method (see Hust and Arvidson [2]) to yield the parameters of the following equation:

$$
K(T)=\sum_{i=1}^{n} A[\ln (T+1)]^{i}
$$

The rms relative deviation of the experimental values of thermal conductivity integral from the least squares fit is $1.0 \%$ with a maximum deviation of $3.6 \%$. Values of $K(T)$ are $i 11$ ustrated in Figure 1.

It is noted that these values of $K(T)$ differed significantly from the data reported in 1978 for an unstrained specimen of G-10CR/WARP. The data for G-10CR/WARP (78) and G-11CR/WARP(78) are repeated in Figure 1 for comparison. To determine if this difference was caused by material variability (the two sets of specimens were prepared from sheets of materials supplied by different manufacturers) or by the strain, another specimen was prepared from the same unstrained sheet as the above strained specimen. This unstrained specimen is identified as G-10CR(1) WARP (as rec.). It was measured only at 281 and $88 \mathrm{~K}$. These data are plotted on Figure 1 and reveal that the effect of strain is undetectable. 


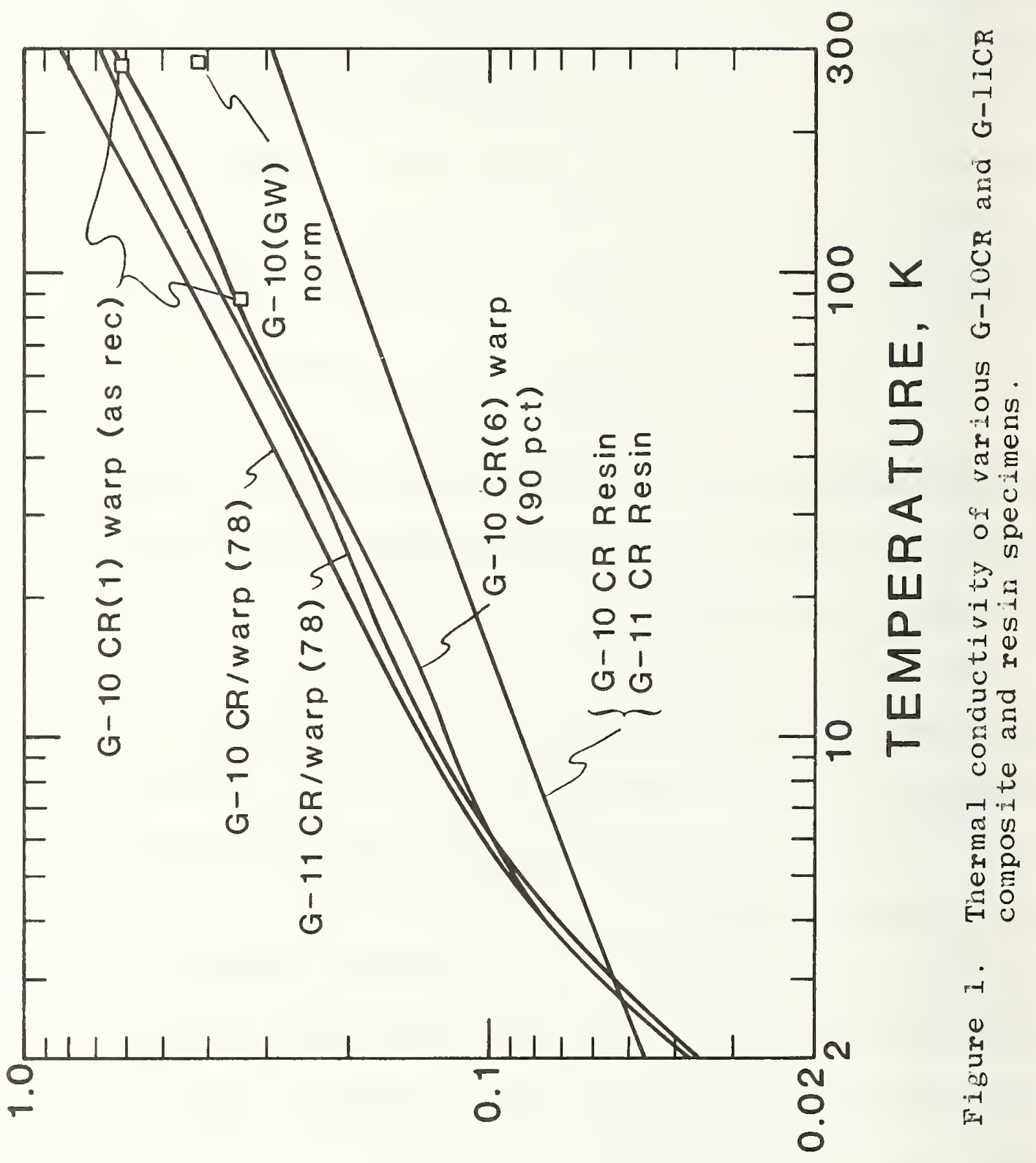

เ_H. LU.M ' 
Because of the large material variability suggested by the results of the 1978 and 1979 measurements, as well as by unpublished data on similar materials, further measurements on stock G-10 were undertaken. A specimen was fabricated from off-the-shelf $0.95-\mathrm{cm}$ thick G-10 sheet. This specimen, referred to as G-10(GW) NORM, was fabricated as described above and measured at $287 \mathrm{~K}$ with heat flow normal to the fabric. The thermal conductivity is 10 er by $19 \%$ than the value obtained in 1978 on G-10CR(NORM). It appears from this limited data that the $C R$ grade of G-10 has a higher conductivity than the standard G-10 material.

To facilitate future analysis of these and other composite data, measurements were performed on specimens fabricated from the pure resins used in G-10CR and G-11CR. These specimens were prepared from larger cured pieces supplied by manufacturer A. Twenty-one data points between 2 and $304 \mathrm{~K}$ were obtained on G-10CR Resin and sixteen data points were obtained from 4 to $304 \mathrm{~K}$ on G-11CR Resin. The results, identical within the imprecision of the data $(+3 \%)$ for both resins, are illustrated in Figure 1. These values are more uncertain than the previous results because the specimen thicknesses were too large for optimum accuracy. The presence of heat transfer by radiation through the specimen is also potentially a problem in defining unique values of thermal conductivity. That is, there may be a measurable thickness effect. Further work has been scheduled to define the resin values more clearly. The present estimated uncertainty for the smoothed resin data is $\pm 15 \%$. 


\section{REFERENCES}

1. M. B. Kasen, J. G. Hust, and H. M. Ledbetter, "Nonmetallics for Magnet Systems," NBSIR 79-1609, pp. 405-451 (1979).

2. J. G. Hust and J. Arvidson, "Thermal Conductivity of Glass Fiber/Epoxy Composites Support Bands for Cryogenic Dewars," Unpublished report 275.03-78-2. 
THERMAL EXPANSION OF CRYOGENIC-GRADE GLASS-EPOXY LAMINATES

National Bureau of Standards 

THERMAL EXPANSION OF CRYOGENIC-GRADE GLASS-EPOXY LAMINATES

M. A. Ranney and A. F. Clark

\section{ABSTRACT}

Thermal expansion measurements for special grades of NEMA-type G-10 and G-11 glass-epoxy laminates were carried out in a quartz-tube dilatometer over a temperature range 4 to $300 \mathrm{~K}$. It was found that expansions in the warp direction were comparable to those of the samples' reinforcement fabric, whereas expansions in the normal direction were characteristic of the samples' epoxy resins.

\section{INTRODUCTION}

Special grades of NEMA-type G-10 and G-11 glass-epoxy laminates (G-10CR and G-IICR) were measured for thermal expansion to investigate further their use in cryogenic properties.

These laminates are commercial products meeting current NEMA G-10 and G-11, MIL-P-18177C, and federal LP-509 specifications. G-10CR is a heat-activated, amine-catalyzed bisphenol A solid-type epoxy resin laminate reinforced with continuous-filament E-glass fabric, silane finished. G-llCR is an aromatic-amine hardened bisphenol A liquid-type epoxy resin laminate reinforced in the same manner.

Both laminates are woven glass cloth composites. The warp fibers are those which emerge from the 10om, and fill fibers are those woven across them at right angles. Each composite has a yarn count of $17 \pm 1$ per $\mathrm{cm}(43 \pm 3$ per in) for warp and $12.6 \pm 0.8$ per $\mathrm{cm}(32 \pm 2$ per in) for fill. The composites' nomal direction is perpendicular to the cloth ply plane.

Our measurements for G-1OCR and G-1ICR are in the warp and nomal directions. 


\section{SAMPLE PREPARATION}

For measurements in the normal direction, samples were prepared using eight pieces of each laminate, which were bonded end-to-end by a commercially available epoxy resin adhesive. This adhesive has special low expansion properties and was used to minimize our experimental error. The G-10CR sample dimensions were $6.5 \mathrm{~mm} \times 6.5 \mathrm{~mm} \times 19.92 \mathrm{~mm}$, and the G-11CR sample dimensions were $6.5 \mathrm{~mm} \times$ $6.5 \mathrm{~mm} \times 19.76 \mathrm{~mm}$.

The samples for warp direction measurement were both directly machined to the dimensions $4.2 \mathrm{~mm} \times 4.2 \mathrm{~mm} \times 20.32 \mathrm{~mm}$.

\section{APPARATUS}

Measurements were made in a quartz tube dilatometer [1], schematically shown in Figure 1. The differential contraction is transmitted to a room temperature mechanical dial gauge (sensitivity $0.5 \mu \mathrm{m}$ ) by concentric quartz tubes (1abeled quartz support tube and quartz rider in Figure 1). All samples were kept vertical by a copper heat shield, which also inhibited thermal gradients from interfering with the measurement accuracy.

Samples were each cooled at a rate of $2.5 \mathrm{~K} \mathrm{~min}^{-1}$ from 300 to $4 \mathrm{~K}$, and the temperature was determined by a chromel-constantan thermocouple attached directly to the samples at midpoint. The helium gas temperature and the sample temperature were assumed to be the same.

The apparatus was calibrated by measuring the thermal expansion of a polycrystalline OFHC copper bar. The difference between the average measured data and the standard reference material (SRM) data for OFHC copper [2] was used as an absolute correction factor. Measurement accuracy was estimated at $\pm 0.005 \%$. 


\section{RESULTS}

Figure 2 shows the relationship of the four samples tested (G-10CR warp and normal, G-11CR warp and normal), graphically depicted in terms of thermal expansion.* A computer curve fitting program was developed to fit the experimental data, $[L(293)-L(T)] / L(293)$, and to approximate expansion coefficients, $[1 / L(293)](d L / d T) K^{-1}$, from the data. The form of the function was

$$
\frac{L(293)-L(T)}{L(293)}=a+\frac{T^{4}}{b+c T^{2}+d T^{3}} .
$$

Table 1 summarizes the data for the four samples.

\section{CONCLUSIONS}

The data obtained indicate that thermal expansion in the warp direction is comparable to that of the composites' E-glass reinforcement fabric, while expansion in the normal direction is characteristic of the bisphenol $A$ epoxy resin. Aside from the present study, only one other reference of G-10CR and G-11CR expansion data was located. These data on the same material, independently provided by the Los Alamos Scientific Laboratory, R. I. Schermer [3], gave the total contraction from $295 \mathrm{~K}$ to $75 \mathrm{~K}$ using a fixed-point apparatus. The Los Alamos data is found to be consistently $\sim 10 \%$ greater in total contraction than the data in the present study, vet the difference is within the accuracy limits of the two sets of measurements.

*The SRM 736 Copper Standard is included as a scaling reference.

\section{REFERENCES}

1. A. F. Clark, Cryogenics 8,282 (1968).

2. T. A. Hahn, J. Appl. Phys. 41,5096 (1970).

3. M. B. Kasen, J.G. Hust, and H. M. Ledbetter, "Nonmetallics for Magnet Systems," in Materials Study for Magnetic Fusion Energy Applications at Low Temperatures-II, NBSIR 79-1609 (1979), p. 405. 


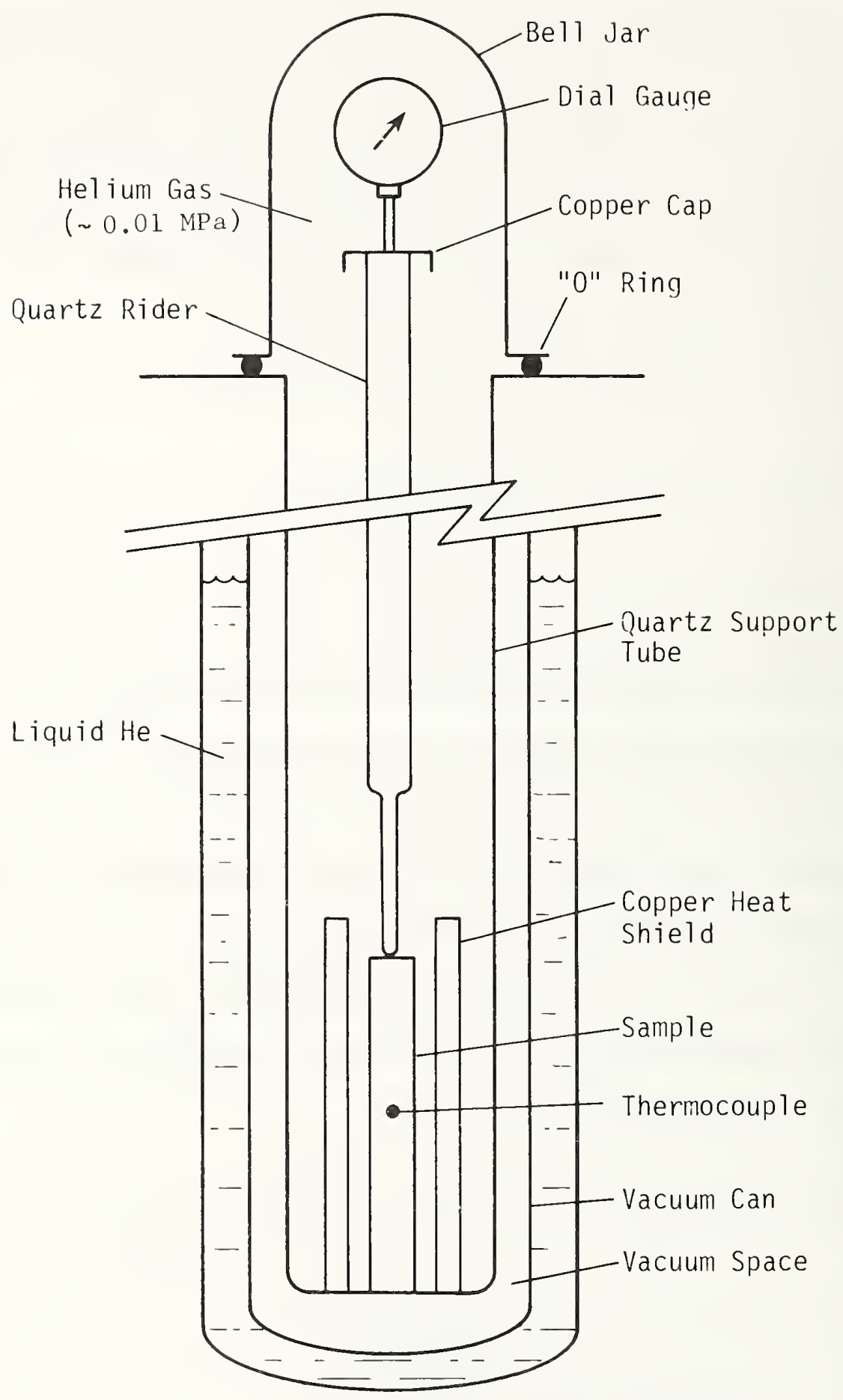

Figure 1. Schematic representation of quartz tube dilatometer. 


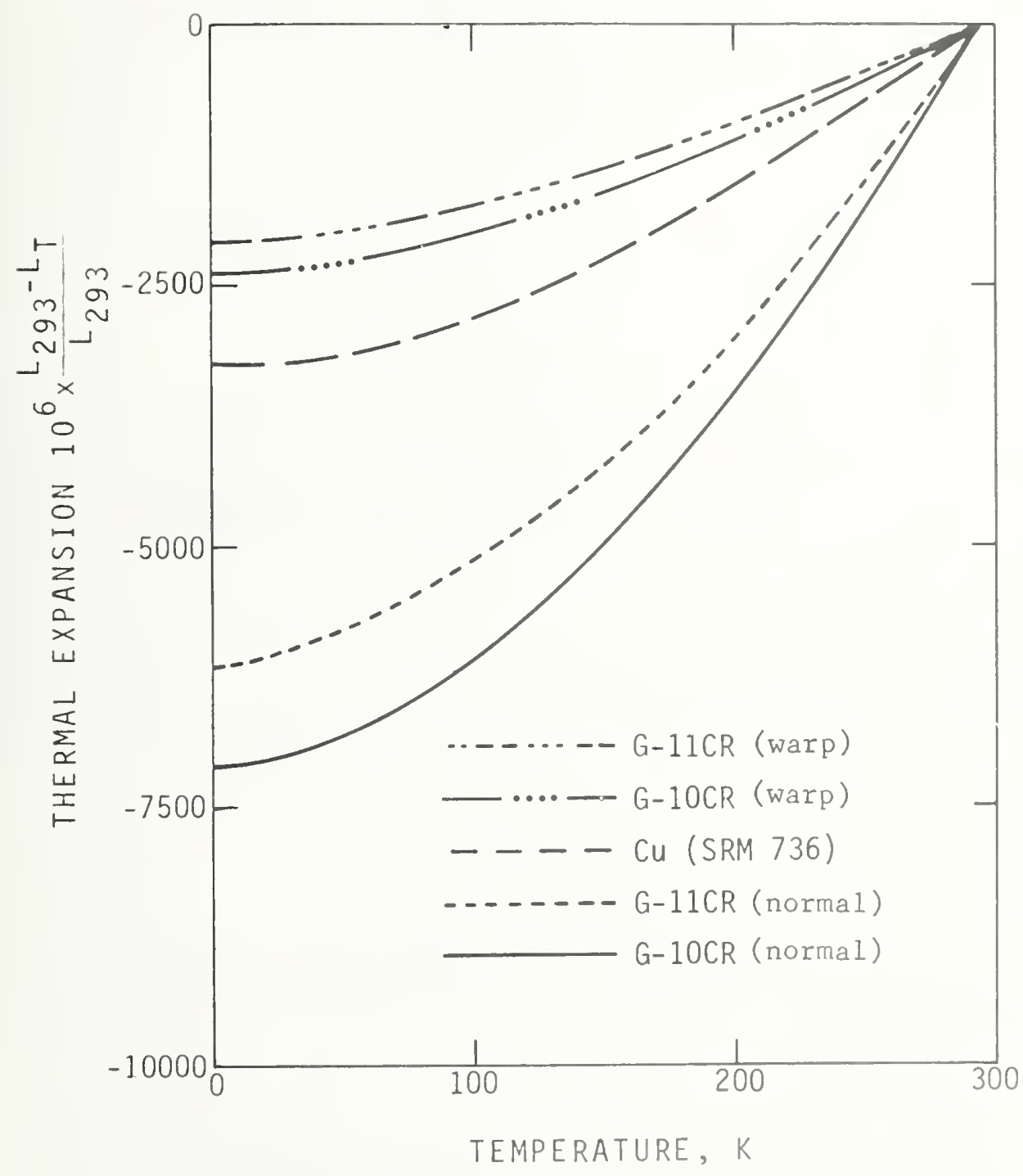

Figure 2. Thermal expansion of G-IOCR and G-lICR in both warp and normal directions. 


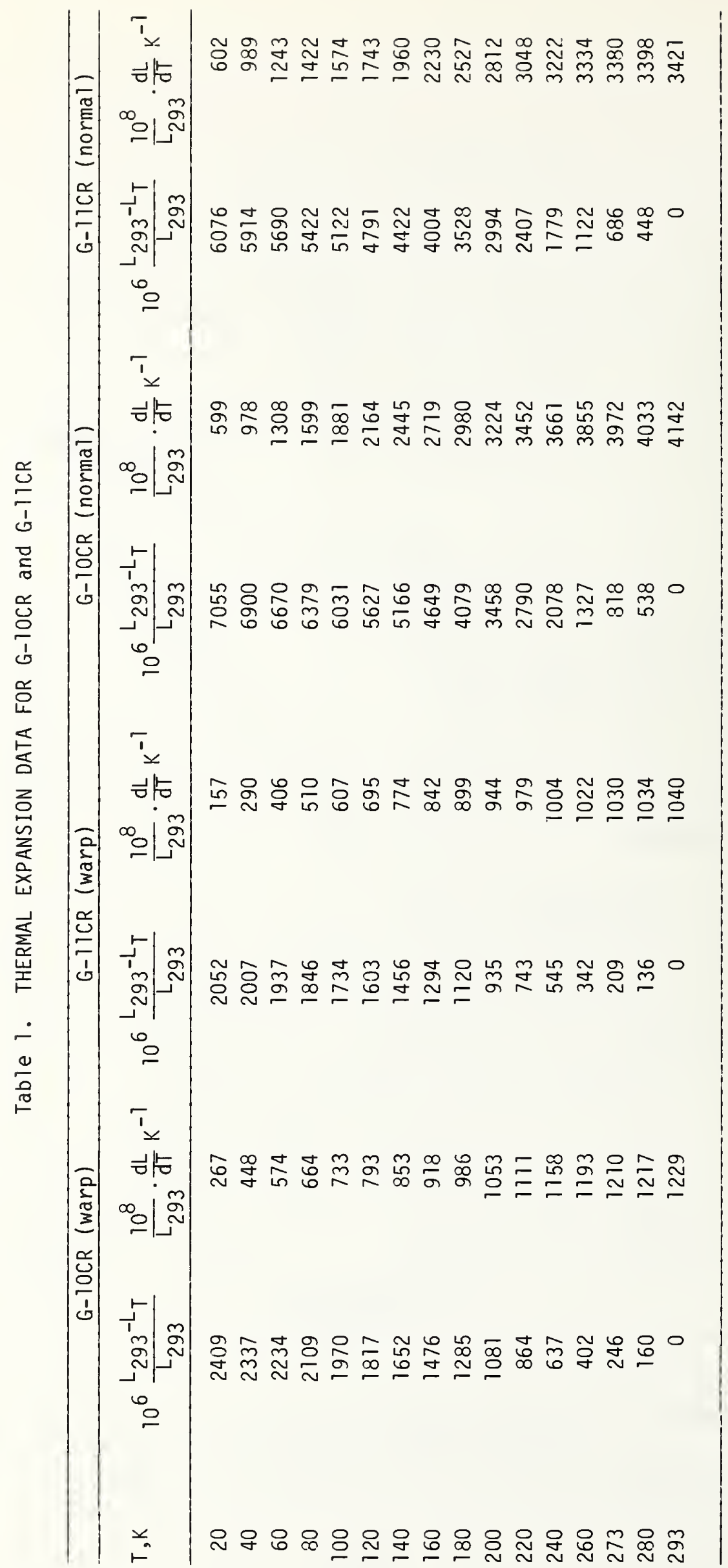




\section{Technology Transfer}



STRUCTURES, INSULATORS AND CONDUCTORS

FOR LARGE SUPERCONDUCTING MAGNETS

National Bureau of Standards

U. S. Department of Energy 

F. R. FICKETT and R. P. REED

National Bureau of Standards, Boulder, CO 80302

and

E. N. C. DALDER

Department of Energy, Washington, D. C. 20545

As the size of superconducting magnet systems increases, the structural aspects become of of Increasing importance. Because the stresses increase rapidly with size and field, magnets of the type proposed for new devices will be largely structure. We are engaged in a program to acquire low temperature mechanical and physical property data on a wide range of mater1als. The present status of this data base is reviewed and results from our test program are described. We have placed emphasis on the austenitic stainless steels as the primary structural material, although data have also been acquired on a few aluminum alloys. Particular stress has been placed on the fracture characteristics of both the base metal and weldments where appropriate. Achieving a good match between weld and base metal at $4 \mathrm{~K} 1 \mathrm{~s}$ proving to be a difficult task. Several industrial fiberglass-epoxy laminates of fixed composition have been produced as a result of this program. These materials, GIO CR, GII CR and GII CR(BF) have been tested at $4 \mathrm{~K}$ and the results are presented. Recent measurements on the effect of stress and fatigue on matrix materials for superconductor stabilization are also briefly reviewed. A new handbook of data on the properties of structural materials for superconducting magnet systems is described.

\section{INTRODUCTION}

It now seems nearly certain that economical fusion reactors relying on magnetic confinement will require superconducting magnets, at least for the toroidal field colls and probably for other coll systems as well. Such magnets operate well below $20 \mathrm{~K}$ and most often very near to 4.2 $K$, the temperature of liquid hellum at one atmosphere. There is essentially no chance that a superconductor capable of operation at significantly higher temperatures will be developed and brought to the commercial stage in time to do us any good. The question of which of the existing superconductors will be adequate for fusion energy applications remains to be answered. NbT1 is certainly the most preferable since it is a ductile alloy and, thus, easily fabricated and quite strain tolerant, but such magnets are restricted to maximum fields of about 8 tesla. The intermetallics $\mathrm{Nb}_{3} \mathrm{Sn}$ and $\mathrm{V}_{3} \mathrm{Ga}$ will handle much higher fields, but are expensive to produce and very sensitive to strain.

Regardless of the superconducting material finally chosen, the magnets will be large by present-day standards. Most of the magnet will be structure necessary to confine the large forces generated by the field. At the same time, problems of access to the plasma region severely limit the total amount of structure which can be tolerated in a working device. Alloys with relatively high strength are a clear choice here. Furthermore, the structure must be at cryogenic temperatures near $4 \mathrm{~K}$, a region

« Sponsored by the Office of Fusion Energy, Department of Energy, Washington, D.C. 20545 where little information exists on material properties. This lack of data is especially serious in the case of welded joints between large structural members.

Working superconducting magnets also require large amounts of nonmetallics as electrical insulation and as thermal standoffs. Where rapidly changing magnetic fields are encountered, it is frequently desirable to make the entre structure from nonmetallics in order to avold heat input due to eddy current generation. Furthermore, the multilayer "superinsulation" now favored for dewar construction is a metallized polymer f1lm also subject to eddy current heating. The propertles of many of these materlals are not well characterized for low temperature service. Unlike alloys, they are not often of standard composition and, even when they are, material variability is high. The neutron and gamma radiation which will be found in working reactors introduces a further complication in the use of nonmetallics. It is not at all certaln what the useful lifetimes of materials will bo under the combined influence of low temperature and radiation.

The final major magnet component is the conductor composite. The superconducting material is just one part of it. The composte also contalns a large amount of pure met.al, wsullly copper, to protect the superconductor in thr event of an excursion out of the superconductins. state by carrying the current for a time long

Presented at the First Topical Meeting on Fusion Reactor Materials, Jan. 1979, to be published in Journal of Nuclear liaterials 1979. 
enough to allow the superconducting state to be reestablished. The resistivity of this stabilizing material at the operating temperature is a critical parameter and one which may be strongly influenced by stress, fatigue and radiation.

Most of the problems outlined here were recognized a long time ago, but only recently has there been a concerted effort toward their solution. In this paper, we attempt to outline the progress of that effort and to summarize the present status. For many readers, this world of low temperature material behavior is somewhat new, and thus, our presentation will be, in part, tutorial. The detalls will be found in the references and the actual data in the various handbooks and monographs described here.

A comment should be made as to how the low temperature materials problems encountered in fusion energy applications differ from those which occurred in earlier applications, such as the space program. Here very long term rellabil1ty will be required. The use of large sections of materlal at low temperatures is new. The need to weld these large pleces occurred only rarely in the past. The projected amount of material is very large and, thus, necessitates production by conventional mill techniques. On- site construction may be necessary. Complex NDE may be needed. Economics is a large factor in the materlals choices.

\section{STATUS OF THE LOW TEMPERATURE DATA BASE}

The avallability of a substantial data base covering the mechanical and physical properties of all materials used in magnets for fuston energy should be a matter of prime concern. It is Important to stress that many materials behave much differently at very low temperatures than they do at room temperature. Extrapolation of room temperature properties data can lead to very serlous errors with often catastrophic consequences.

The data base as 1 t exists today is barely adequate in a few instances and totally inadequate in most others. In no case does a sufficlent data base exist to allow preparation of a code. Seldom is there enough to even permit a good assessment of the effect of material variability which, again, may be significantly different at low temperatures than at room temperature. It is fair to say that nearly no data exist on the properties of alloy welds and of nonmetallics to $4 \mathrm{~K}$. Data on fracture and crack growth are fust now being developed for most alloys of interest. Nevertheless, a few general handbooks exist, as do monographs treating specific properties and reports from experimental test programs. Here we will describe the most common of these.

\subsection{Data handbooks}

The handbooks described here usually treat a large number of materials and present many properties. Most often data points are not shown, and in many instances, the curves displayed are drawn with only limited data. Usually mechanical properties data are taken at only a few discrete temperatures $(4,20,77,295 \mathrm{~K})$ and a complete curve is drawn. The most often used handbooks which concentrate on low temperature data are (NTIS order numbers are in parentheses):

a. A Compendium of the Properties of Materials at Low Temperatures, Part II, Properties of Solids (1960). V. J. Johnson, ed. (SS/PB 171619). Physical properties (thermal) of metallic and nonmetallic materials.

b. Cryogenic Materials Data Handbook (1968). F. R. Schwartzberg, ed. (AD 713619 and $A D 713$ 620). Mechanical and physical properties of ferrous and nonferrous alloys as well as plastics and nonmetallic composites.

c. Handbook on Materials for Superconducting Machinery (1977). (ADA002-698 or Metals and Ceramics Information Center MCIC-HB-04). Mechanical and physical properties of pure metals, ferrous and nonferrous alloys, polymers and composites.

d. LNG Materials and Fluids (1977). D. B. Mann, ed. (Cryogenic Data Center, NBS). Mechanical and physical properties of ferrous and aluminum alloys and thermal insulation for tankage. Thermodynamic properties of LNG components and nitrogen.

e. Materials for Superconducting Magnet Systems (1979). (In preparation by NBS and Mechanical Properties Data Center). Mechanical and physical properties of selected stainless steels and aluminum alloys.

In addition to these, many handbooks of data at room temperature and above often carry some curves to the cryogenic temperature range.

\subsection{Monographs}

Several monographs are avallable which treat a specific low temperature property or present data for a limited number of materials. Some of the more useful are:

a. R. J. Corruccint and J. J. Gniewek, "Specific Heats and Enthalpies of Technical Sollds at Low Temperatures," NBS, Monograph 21 (1960) (PB 172161).

b. R. J. Corruccini and J. J. Gniewek, "Thermal Expansion of Technical Solids at Low Temperatures," NBS, Monograph 29 (1961) (PB 172178). 
c. R. P. Reed and R. P. Mikesell, "Low Ternperature Mechanical Properties of Copper and Selected Copper Alloys," NBS, Monograph 101 (1967).

d. G. E. Childs, L. J. Ericks and R. L. Powe11, "Thermal Conductivity of Sollds at Low Temperatures. A Review of the Literature," NBS Monograph 131 (1973).

e. R. E. Schramm, A. F. Clark and R. P. Reed, "A Compilation of Mechanical, Thermal and Electrical Properties of Selected Polymers," NBS Monograph 132 (1973).

\subsection{Project reports}

Two projects in recent years have attempted to acquire a wide range of data on structural materlals at temperatures down to $4 \mathrm{~K}$. The first was performed by NBS and industrial contractors for the Defense Advanced Research Projects Agency (DARPA) and completed in 1977. It resulted in the handbook described above in Section 2.1(C). The six semi-annual reports describe measurements on a number of alloys and a few nonmetallics. They include all the details of apparatus and procedure. The six volumes are available under the title "Materials Research for Superconducting Machinery" (AD780596, ADA 004586, ADA012365, ADA019230, ADA030170,. ADA036919). The second project, also by NBS, is for the office of Fusion Energy of DOE and is currently in its third year. It will be described in more detall shortly, but is essentially a program to develop a low temperature data base for selected materials which have promise for use in superconducting magnets for fusion. The annual reports are titled "Materials Studies for Magnetic Fusion Energy Applications at Low Temperatures." Two are avallable from the authors of this paper.

\subsection{Current awareness documents}

The NBS Cryogenic Data Center publishes a biweekly listing of titles from the current literature dealing with cryogenic research and engineering. The title is "Current Awareness Service." The same organization publishes a quarterly, "Superconducting Devices and Materlals." The Metal Properties Council and Battelle publish a "Review of the Low-Temperature Properties of Metals" on a regular basis which contains actual data extracted from the literature.

\subsection{MATERIAL BEHAVIOR AT LOW TEMPERATURES}

As the temperature is lowered, all mechanical and physical properties of materials undergo significant changes. Here we will look at the general behavior of these properties for some classes of materials. All of the discussions will refer to Figure 1 , in which we show schematic curves illustrating the effect of termperature. The actual curves are typical of austenitic stainless steels, but we will also be discussing the behavior of pure metals and nonmetallics. We want to stress that the figures are only schematic. The behavior of any actual material should be checked in one of the handbooks described earlier.

\subsection{Tensile properties (Figure l a,b,c,d)}

The ultimate tensile strength of nearly all materials increases as the temperature is lowered and the increase is usually quite large. It is not greatly affected by alloying additions such as nitrogen in the stainless steels.

The tensile yield strength also increases but not as much. In the stainless steels the amount of increase is strongly dependent on nitrogen content with'high nitrogen giving a much larger increase. For the nonmetallic composites the yield strength is about the same as the ultimate strength. Polymers show a varied behavior and no generalization is possible.

The Young's modulus also increases with decreasing temperature for most materials. The increases are not particularly large but are significant for engineering design.

The elongation does not always decrease un $1-$ formly as one might expect, even for the polymers. Under the combined influence of temperature and stress, many materials undergo transformations (e.g., martensite formation in stainless steels) which have a strong influence on elongation. Changes in elongation are seldom a problem in actual applications, since structures are never taken that close to fallure.

\subsection{Fracture and fatigue (Figure 1 e,f,g)}

These properties are very significant ones for fusion applications, particularly where pulsed field operations are encountered. They are strongly affected by temperature and by material composition. Little low temperature data exists for efther pure metals or nonmetallics.

The fracture toughness may elther increase or decrease with decreasing temperature. The desireable situation is to have an increase, but the opposite is usually the case. There ls an inverse correlation with the amount of increase in yield strength, and thus, for example, nitrogen additions to stainless steel result in a fracture toughness decrease at low temperatures. The low values found at $4 k$ may make many alloys unacceptable for service.

The fatigue crack growth rale is another important property which can exhibit a varlety of behavior depending on the material. This pard- 
meter is not well correlated with any other, although it is obviously related to both yield strength and toughess, but in a very complex way. Again, the low temperature crack growth properties may make material with promising properties at room temperature completely unacceptable.

Fatigue strength is a somewhat more well-behaved property. The high-cycle fatigue strength of alloys and pure metals generally increases with decreasing temperature. In stainless steels a decrease is seen under conditions of low-cycle fatigue (high stress levels). Nonmetallic composites show an increased fatigue strength as the temperature is lowered, but this may be followed by a decrease below $77 \mathrm{~K}$.

\subsection{Thermal properties (F1gure $1 \mathrm{~h}, 1, j$, )}

In general, the physical properties are better behaved than those already discussed although wide variations are found, particularly in "pure" metals, depending on the exact makeup of the metal.

(a)

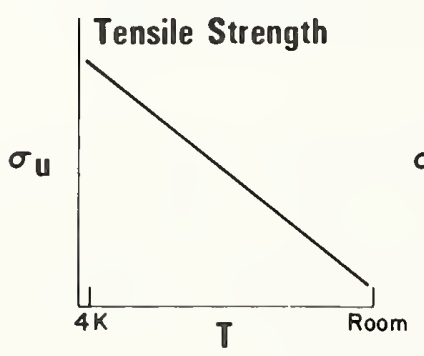

(e)

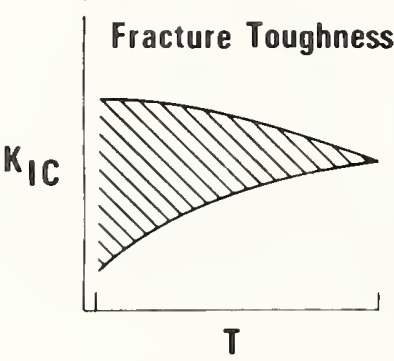

(i)

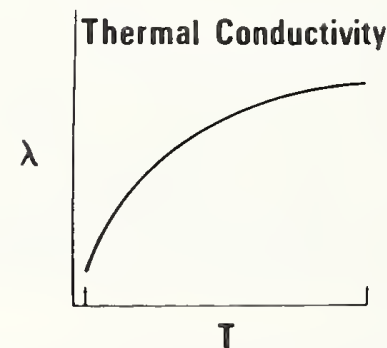

(b)

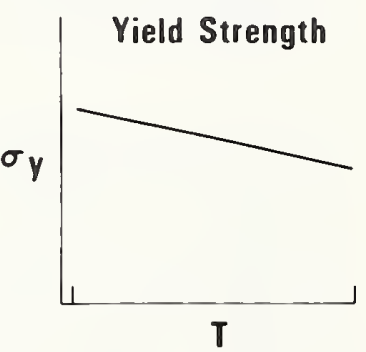

(f)

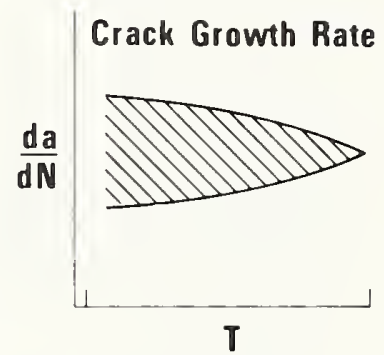

(j)

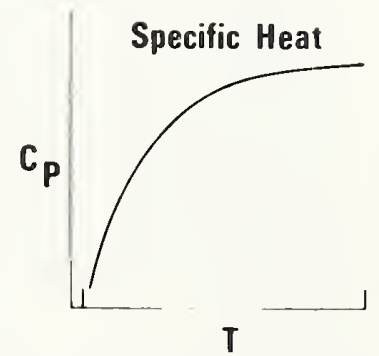

The thermal expansion of essentially all structural materials is negative, 1.e., they contract as they cool. The rate of contraction decreases toward lower temperatures leading to a strong decrease in the thermal expansion coefficlent, a parameter not shown on the graph.

The thermal conductivity of most materials decreases rapidly with lowering temperature. Very pure metals and some dielectrics may show a large peak in the conductivity at low temperatures, but in all cases, the value at $4 \mathrm{~K}$ is well below that at room temperature.

The specific heat of materials also decreases very rapidly at low temperatures, usually dropping several orders of magnitude to $4 \mathrm{~K}$. Unlike the conductivity this property is quite insensitive to material composition. For example, the specific heat behavior of nearly all austenitic stainless steels is about the same. The very low value of this parameter at $4 \mathrm{~K}$ can lead to serious problems of component heating, since a very small energy input can cause a large rise in temperature.

(c)

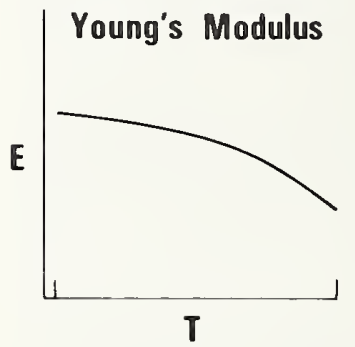

(g)

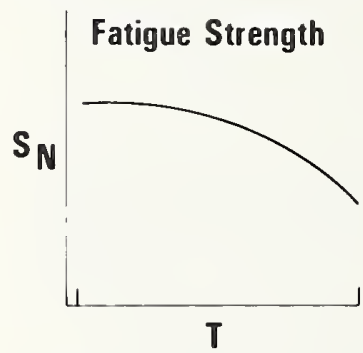

(k)

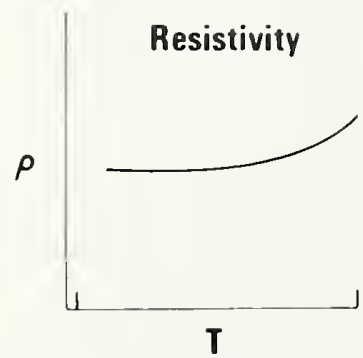

(d)

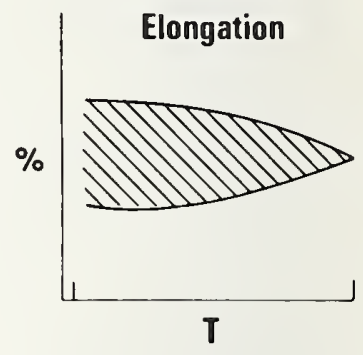

(h)

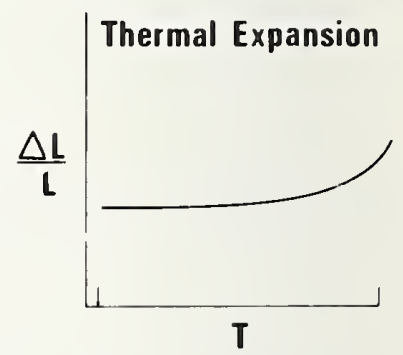

(I)

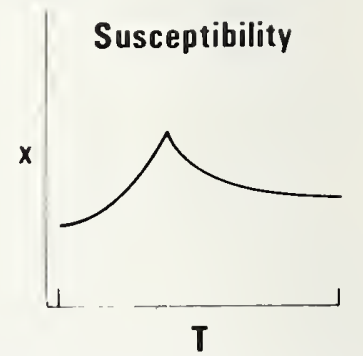

Figure 1. The behavior of the mechanical and physical properties of materials as a function of temperature. The graphs are general schematics most representative of the austenitic stainless steels. 
3.4 Electrical and magnet1c properties (F1gure $1 k, 1$ )

The electrical resistivity of metals always decreases with decreasing temperature. The total change observed in highly alloyed metals is quite small, usually less than a factor of flve. Pure metals, on the other hand, may show decreases of several orders of magnitude. The resistivity change tends to level out at the lowest temperatures. For organic nonmetallics $11 m i t e d$ data indicate that the volume resistivity increases significantly and the dielectric breakdown strength increases slightly to $4 \mathrm{~K}$.

The magnetic properties of most structural materfals are not much affected by low temperatures. The ferrous alloys are an exception. In particular, the susceptibility of the austenit1c (nonmagnet1c) stalnless steels exhib1ts a cusp presently thought to indicate a spin glass transition. The behavior of magnetization with field at low temperatures is nonlinear and shows a tendency to saturation. Magnetic steels show pretty much the same behavior as at room temperature, except that the saturation magnetization may be increased a bit.

This discussion has been very brief of necessity. A more extensive treatment with many speciflc examples is provided by several earlier reviews $[1,2,3]$. In addition, a tutorial book covering all aspects of materlals behavior at low temperatures is now in preparation [4].

\section{THE NBS/DOE MATERIALS RESEARCH PROGRAM}

Two years ago the NBS Cryogenics Division started a program for DOE (then ERDA) which had as 1ts goals: a. the evaluation of proposed fusion devices to determine the materials problems untque to the low temperature magnet systems; b. development of a research program to Insure that the necessary properties data would be avallable; and, $c$. the rapid dissemination of the data to the fusion community. As with all programs, the avallable funding was limited and, thus, it was necessary to assign rather strict priorities to the tasks. Furthermore, when the program started, there were no actual superconducting fusion magnets or models under construction, so many of our decisions were based on Iimited information. The advent of the Large Coll Program and the MFTF (M1rror Fusion Test Faclifty) profect has resulted in some redirection of the research, but our inftial cholces have proven to be quite reasonable and the data developed to date by NBS and 1ts contractors has already been used extensively by the projects. Here we will point out some of the more interesting results and their implications. The total program is described in the reports mentioned in Section 2.3. Our survey of fusion device designs and the research program proposals which resulted are an appendix to the first report. This program specifically excluded research on the superconducting composite itself. Other NBS profects have measured propertles of some relatively small wires, however, and some results will be discussed in the next section. The actual conductors to be used for fusion magnets are very large and carry very high currents ( $\geq 10 \mathrm{kA}$ at full fleld) and, thus, can only be tested in the few laboratorles with large magnet facilities.

The materials which we decided should be tested first were the austenitic stainless steels with emphasis on those with nitrogen strengthening, a few aluminum alloys, and the fiberglassepoxy industrial laminates. The behavior of welds made in the stainless steels also appeared to be a matter of concern.

\section{々.l Structural alloys}

Considerations of strength, avallability, and the requirement for a nonmagnetic alloy with an expansion behavior close to that of the conductor led us to consider the austenitic stainless steels as the primary alloys for low temperature service. The nitrogen strengthened versions are particularly appealing because of their increased low temperature yield strength. For example the yleld strength at $76 \mathrm{~K}$ of AISI 304 (a Cr- $\$ 1$ alloy) is increased by a factor of three by the nitrogen additions which give $304 \mathrm{~N}$. The ultimate strength remains about the same. Other nitrogen strengthened stainless steels of the composition $\mathrm{Cr}-\mathrm{N} 1-\mathrm{Mn}-\mathrm{N}$, such as the 21-6-9 alloy, have also been investigated. They have somewhat higher yleld strengths. Our measurements on these steels indicate a decreased, but sat 1sfactory, toughness at $4 \mathrm{~K}$. The low temperature fatigue crack growth behavior of $21-6-9$ and $316 \mathrm{LN}$ is satisfactory, but recent data indicate a signfficant acceleration of crack growth in $304 \mathrm{~N}$. Data comparing $1 t$ to 304 are given in Figure 2 from [5]. This much of an 1ncrease in crack growth could be a serious problem in cyclic operation. The 21-6-9 alloy has a good comblnation of properties, but a matching filler metal for welding is needed. To date, $316 \mathrm{LN}$ appears to be the most appealing structural alloy except for the minor matter of price, but again we need more measurements to make a reasonable evaluation.

Aluminum alloys are good candidates for structural applications at low temperatures. Their strength is close to that of stalnless steel, but welded sections require strengthening heat treatments which are 1mpractical in most appl1cations. However, bolted construction may be possible. The alloys tend to have low modul 11 and high thermal expansion, both of which can occastonally present problems. We have measured the fracture toughness and crack growth behavior of 2219-T87 alloy at $4 K$ and found it to be acceptable in all respects.

\subsection{Welds}

One of our goals for this profect, obvlously. is to find an alloy which not only has acceptable base metal propertles, but also can be 
Ing the mechanical, thermal, and electrical properties of GlOCR and GllCR samples from several manufacturers. The laminates are anisotropic in most properties because of the layup method of manufacture, so that a number of measurements are reaulred to characterize them completely.

Typical compressive strength data are shown in Figure 4 and the behavior of the thermal conduct1vity in Figure 5. Both flgures are from the NBS report on this program described earlier. In general, cooling to cryogenic temperatures is beneficlal to all of the properties of interest. We have not yet done sufficlent work to dependably evaluate the varlability between manufacturers, but the preliminary results are promising.

है
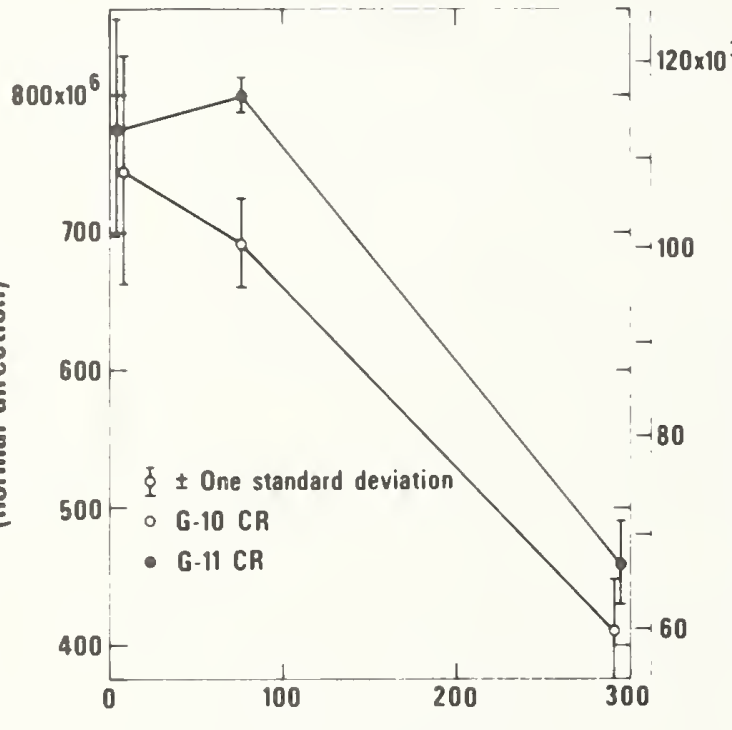

TEMPERATURE,T(K)

Figure 4. Temperature dependence of the ultimate compressive strength for industrial fiberglass epoxy laminates.

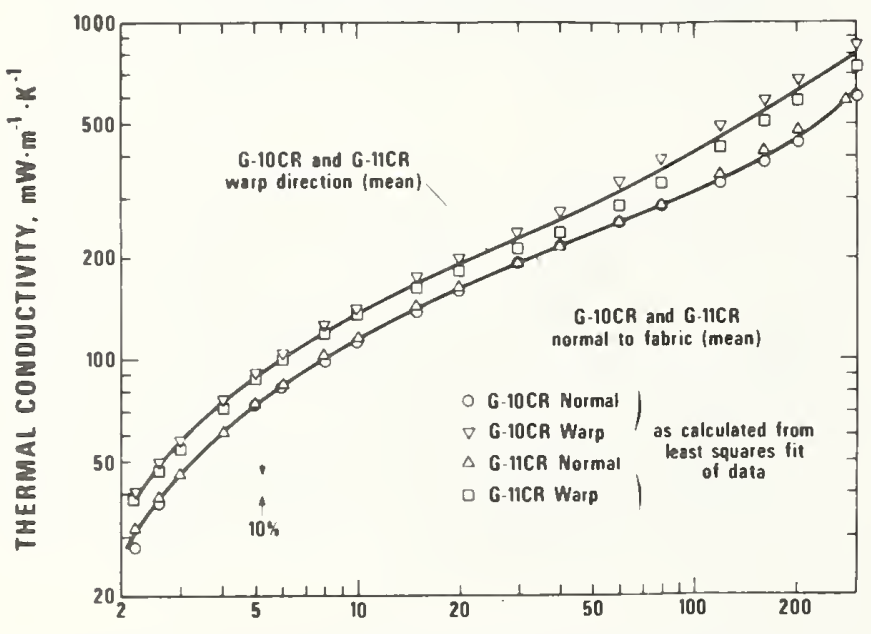

TEMPERATURE, $K$

Figure 5. Thermal conductivity of fiberglass epoxy laminates as a function of temperature.

\section{STRESS AND FATIGUE IN CONDUCTORS}

Whenever real structures are subjected to stress, they expand or contract to accommodate 1t. In large superconducting magnets these strains can serfously affect the superconducting properties of the current-carrying conductors. This degradation is especially serious for the high fleld superconductors, which are brittle materials, and it is this parameter which ultimately determines the amount of structure required for the magnet. A number of papers on this topic were presented at the latest International Cryogenic Materials Conference [7]. Figure 6, from the review paper by Ekin, summarizes the effect of strain on the superconducting critical current of nioblum-tin conductors. Clearly, a relatively small strain can cause a significant decrease in the current.

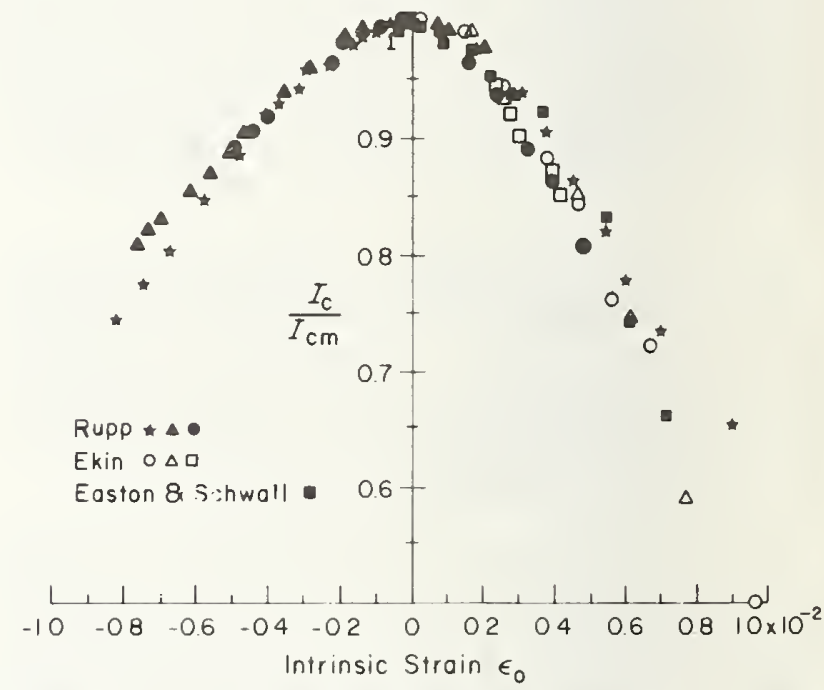

Figure 6. Critical current as a function of 1ntrinsic strain in nioblum-tin superconductor. Current values have been normalized to the maximum in each case.

A further difficulty arises when conductors are subject to fatigue, even at relatively low stress levels. The pure copper stabilizer described earlier requrles a low electrical resistvity in order to properly perform its function of protecting the superconductor. Fatigue can cause the resistivity to increase significantly. Figure 7, from the paper just mentloned, shows this effect for copper on a nioblum-titanium superconductor. This ductile superconducting alloy is not serfously affected by the strain levels shown, but the resisitivity of the protective copper increases very rapidly with cycling, and it may well be this effect which will determine the allowable strain limits for the conductor composite in many applications. 


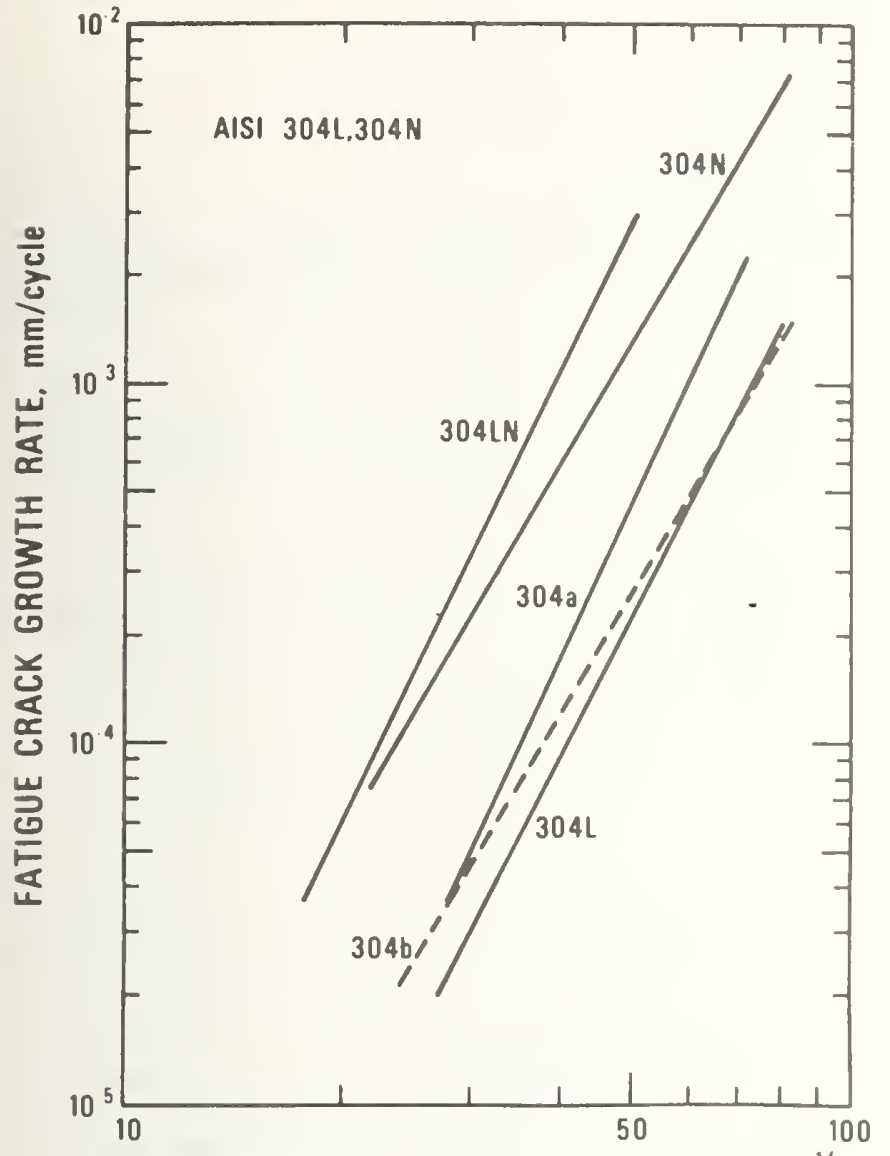

STRESS INTENSITY FACTOR RANGE, MPa $\cdot \mathrm{m}^{1 / 2}$

P1gure 2. Low temperature crack growth rate data comparing nitrogen strengtened AISI 304 stainless steel with the standard alloy.

jolned successfully. Th1s means that the jolnt should have properties approximating those of the base metal. While this condition occurs frequently at room temperature, significant differences arise as the temperature 18 lowered. Our measurements have shown, for example, that the toughness of stalnless steel welds is marginal at $4 \mathrm{~K}$ in all cases investigated to date. We have been 1nvestigating the metallurglcal factors which cause this reduction in toughness. We have found that one of the most deleterious factors is the ferrite content of the welds as indicated in pigure 3 for 316 L [6]. The ferrite not only degrades toughness but makes the welds ferromagnet1c. Sensitization (grain boundary precipitation of carbides) also serfously degrades the toughness. Part of our program has been to attempt to develop a new filler metal for welding the 21-6-9 alloy which has very nice properties in the base metal. A number of promising candidates have been evaluated but none has proven to be acceptable yet. We are now evaluating the effect of varlous welding processes on the properties of the final weld; preliminary results show significant variat1ons.

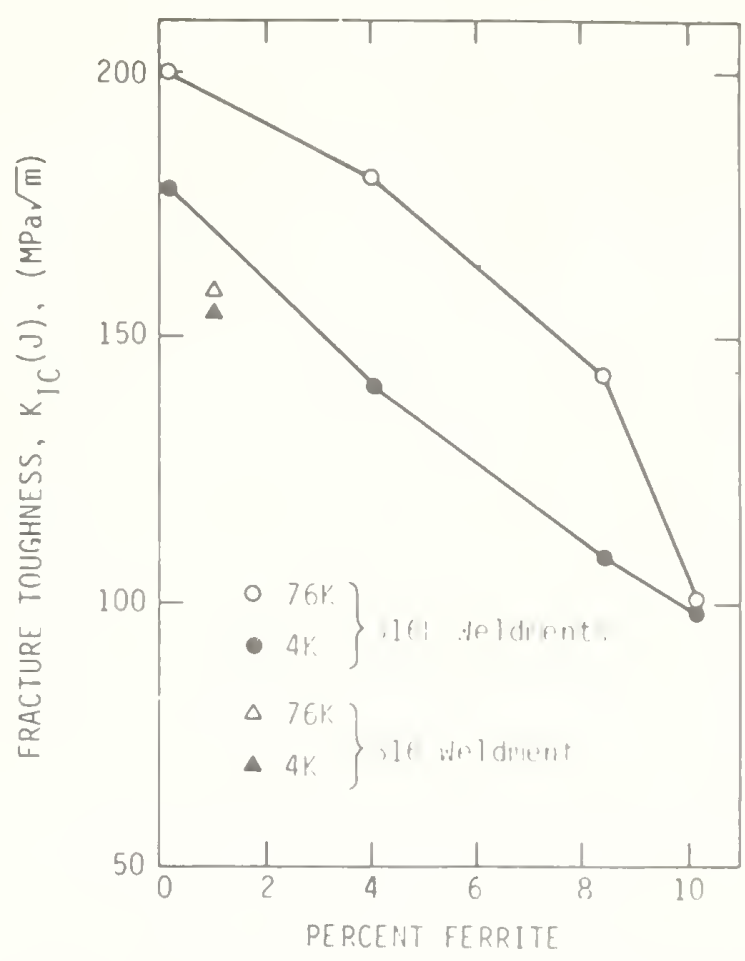

Figure 3. The effect of ferrite content on weld toughness in AISI 316 stainless ateel at cryogenic temperatures.

\subsection{Industrial laminates}

Flberglass epoxy industrial laminates are extensively used in magnet construction, primar1ly as electrical insulation, but occasionally as thermal standoffs and for dewars. The most common are the NEMA (National Electrical Manufacturers Association) GIO and GIl laminates. There are a number of problems whth these mater1als: their compositions tend to be proprletary and the NEMA specifications, which are primarlly electrical, do not require any speciflc composition which can lead to large variations in the mechantcal properties; the low temperature data base 18 very $11 \mathrm{~m} 1 \mathrm{ted}$, and because of materlal variability, the existing data may not be applicable to a particular materlal; the effects of radiation at low temperatures are not known, but It is thought that they may be particularly susceptible to damage to the extent of limiting the magnet $11 \mathrm{fet} 1 \mathrm{me}$. Our program has addressed the flrst two of these concerns directly and oak Ridge National Laboratory is now carrying out a program to evaluate the extent of the radiation damage problom.

In cooperation with NEMA and several manufacturers, we have reached agreement on specific formulations and preparation procedures for materials for cryogentc applications. These are termed $G 10 C R$ and $G 11 C R$. There 18 also a GIICR(BF) grade wh1ch uses a boron-free glass and, thus, may be more radiation resistant. These materlals should have unfform properties regardless of thelr source. We are now evaluat- 


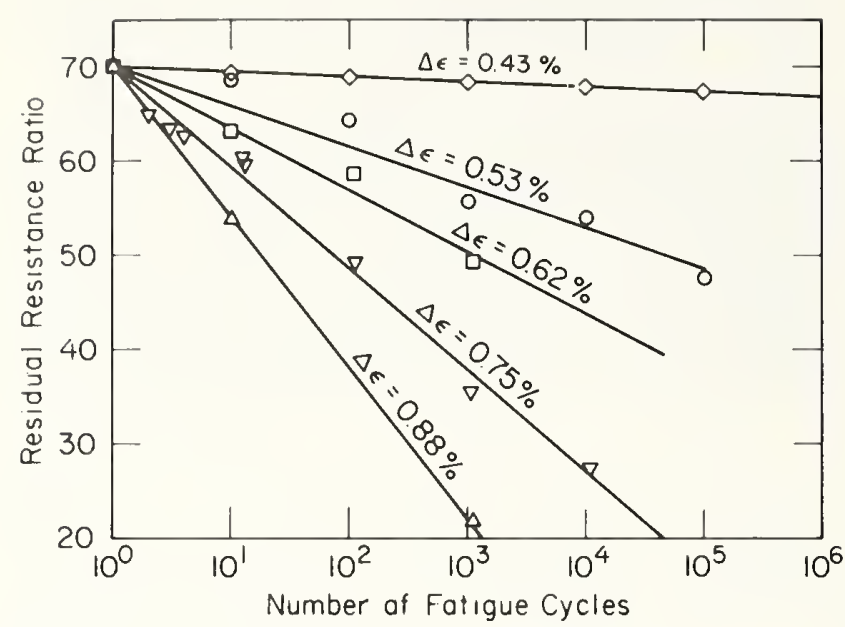

Figure 7. Degradation of the residual resistance ratio, $R(295 \mathrm{~K}) / \mathrm{R}(9 \mathrm{~K})$, of the copper stabilizer on a commercial nioblum-titanium conductor. The strain range is indicated on each curve.

\section{CONCLUSIONS}

Much remains to be learned about the properties of materials at low temperatures as they relate to fusion magnet applications. Large, expensive structures, especially those involved in base-load power supply, require a rellability which can only be ensured by an adequate low temperature data base. Such a data base does not exist at present. In the realm of fusion energy, so many problems arise due to the very high temperatures involved that we often tend to lose sight of the fact that there are significant problems at the other end of the temperature scale also.

\section{REFERE NCES}

[1] F. R. Fickett, Proc. Fourth Int. Conf. on Magnet Tech. (1972), USAEC CONF-72098 p. 498.

[2] F. R. Fickett, Proc. Fifth Int. Conf. on Magnet Tech. (1975). N. Sacchett1, M. Spadoni and S. Stipcich, eds. Laboratori Nazionali del CNEN, Frascat1, Italy, p. 659 .

[3] F. R. Fickett, Proc. Sixth Int. Cryo. Eng. Conf. IPC Business Press, Sussex, England (1977), p. 20 .

[4] Materials at Low Temperatures, R. P. Reed and A. F. Clark, eds, In preparation.

[5] R. L. Tobler and H. I. McHenry, ibid Ch. 8.

[6] R. P. Reed, H. I. Mchenry and P. Steinmeyer, Nuclear Englneering and Design, To be pub11shed.

[7] Advances in Cryogenic Engineering, Vol. 24, K. D. Timmerhaus, R. P. Reed and A. F. Clark, eds. Plenum Press, New York (1978). 
VAIL WORKSHOP 

VAIL WORKSHOP

R. P. Reed

Fracture and Deformation Division

National Bureau of Standards

A major aspect of the technology transfer part of the program is the workshop. These meetings are held each year with the goal of bringing together representatives from all parts of the materials community who are involved with low temperature applications. The attendees at this year's workshop, held at Vail, Colorado, October 16-18, 1979, represented just such a diverse group including representatives of industry, national labs, MFE projects, and universities. The following pages give the attendance list and the program for the workshop. No proceedings are published, but extended abstracts of the presentations were provided to the attendees. 
NBS/DoE Workshop on Materials at Low Temperatures

October 16-18, 1979

Vail, Colorado

Tuesday, October 16

Session 1 (9:00-12:00): Large Magnet Programs

R. P. Reed, Chairman

DoE Office of Fusion Energy - Overview

E. N. C. Dalder, LLL

NBS Program

Large Coil Project (LCP)

R. P. Reed, NBS

MHD

C. J. Long, ORNL

Energy Storage

P. G. Marston, MIT

MFTF Magnets

$H$. Boenig, LASL

A. J. Hodges, LLL

Session 2 (2:00-5:00): Design, Materials and Fabrication

E. N. C. Dalder, Chairman

General Dynamics' Designs for Fusion and MHD

General Electric's Design for Fusion and MHD

Westinghouse's Design for the LCP

Argonne's MHD Magnet Program

Airborne MHD Magnet

Pulsed Coils

J. L. Christian, GD

C. L. Linkinhoker, GE

T. R. Leax, W

L. Genens, ANL

R. K. Miller, GD

S. K. Singh, $W$

Wednesday, October 17

Session 3 (9:00-12:00): Structural Alloys

D. T. Read, Chairman

Structural Alloys for Liquid Helium Service

Ferritic Alloys for $4 \mathrm{~K}$ Service

Stainless Steel Alloy Development

Interstitial Strengthening of Stainless Steel

Phase Transformations and Magnetic Transitions

H. I. McHenry, NBS

J.W. Morris, Jr., LBL

R. H. Espy, Armco

R. L. Tobler, NBS

H. W. King, Dalhousie U.

Session $4(2: 00-5: 00)$ : Welding

H. I. McHenry, Chairman

Aluminum Welding

Stainless Steel Welding-Filler Metals

Stainless Steel Welding-Methods

Stainless Steel Welding-Properties

US/USSR Exchange Program

R. A. Kelsey, Alcoa

D. J. Kotecki, McKay

D. M. Parker, GE

T. A. Whipple, NBS

R. P. Reed, NBS

Thursday, October 18

Session 5 (9:00-12:00): Composites and Nonmetallics

M. B. Kasen, Chairman

Cryogenic Grade Glass Fabric Epoxy Laminate

Cryogenic Grade Glass Mat Epoxy Laminate

Composite Resin Matrix Selection

Radiation Effects

Interlaminar Shear Strength

R. E. Schramm, NBS

J. L. 01 inger, Owens Corning

R. L. Kolek, $W$

C. J. Long, ORNL

H. Becker, MIT 
NBS/DoE Workshop

October 16-18, 1979

Vail, Colorado

Name

Don Beard

Herb Becker

J. R. Benzinger

Dick Blaugher

J. G. Y. Chow

Jack Christian

George D. Covington

George Cypher

Ed Dalder

Mike Dew

John Elmer

R. H. Espy

Fred R. Fickett

Lyle Genens

C. Goodzeit

Don Harwell

George Heim

Jeff Hodges

J. Horvath

Jess W. Hurt

M. B. Kasen

Ron A. Kelsey

S. H. Kim

Hubert W. King

C. Klamut

Robert Kolek

D. J. Kotecki

J. Kotora

David C. Larbalestier

T. R. Leax

A. L. Liby

C. Linkinhoker

Joe Long
Affiliation

U.S. Department of Energy

M.I.T.

Spaulding Fibre

Westinghouse

Brookhaven National Lab General Dynamics Convair CTI-Cryogenics.

INCRA

Lawrence Livermore Lab

Intermagnetics

NBS

Armco

NBS

Argonne

Brookhaven National Lab

Cryogenic Energy Company Fermi Lab

Lawrence Livermore Lab

General Dynamics

CVI

NBS

Alcoa

Argonne

Dalhousie University

Brookhaven National Lab

Westinghouse

Teledyne

Argonne

University of Wisconsin

Westinghouse

Rockwell

General Electric

Oak Ridge National Lab 
Name

Kim W. Mahin

Peter Marston

H. I. McHenry

John Mikurak

Ron Miller

Gerald Mordhorst

J. W. Morris, Jr.

J. L. 01 inger

Dave Parker

Clyde V. Prestowitz

Jeffrey $V$. Prose

David T. Read

Richard P. Reed

H. Reid

Bill Roden

M. Rosen

Robert E. Rowlands

Ron Scanlan

Ray Schramm

Robert Schermer

Oscar W. Seth

John Shepic

S. K. Singh

F. Spinella

E. R. Szumachowski

Ralph L. Tobler

T. A. Whipple

Dick Wolgast
Affiliation

Lawrence Berkeley Lab

M.I.T.

NBS

Sandvik, Inc.

General Dynamics Convair

Cryogenic Energy Company

University of California

Owens/Corning

General Electric

Arcos

CVI Corporation

NBS

NBS

Teledyne

General Dynamics

Lawrence Berkeley Lab

University of Wisconsin

Arcos

NBS

Los Alamos Scientific Lab Chicago Bridge and Iron

Martin Marietta

Westinghouse

General Dynamics

Teledyne

NBS

NBS

Lawrence Berkeley Lab 


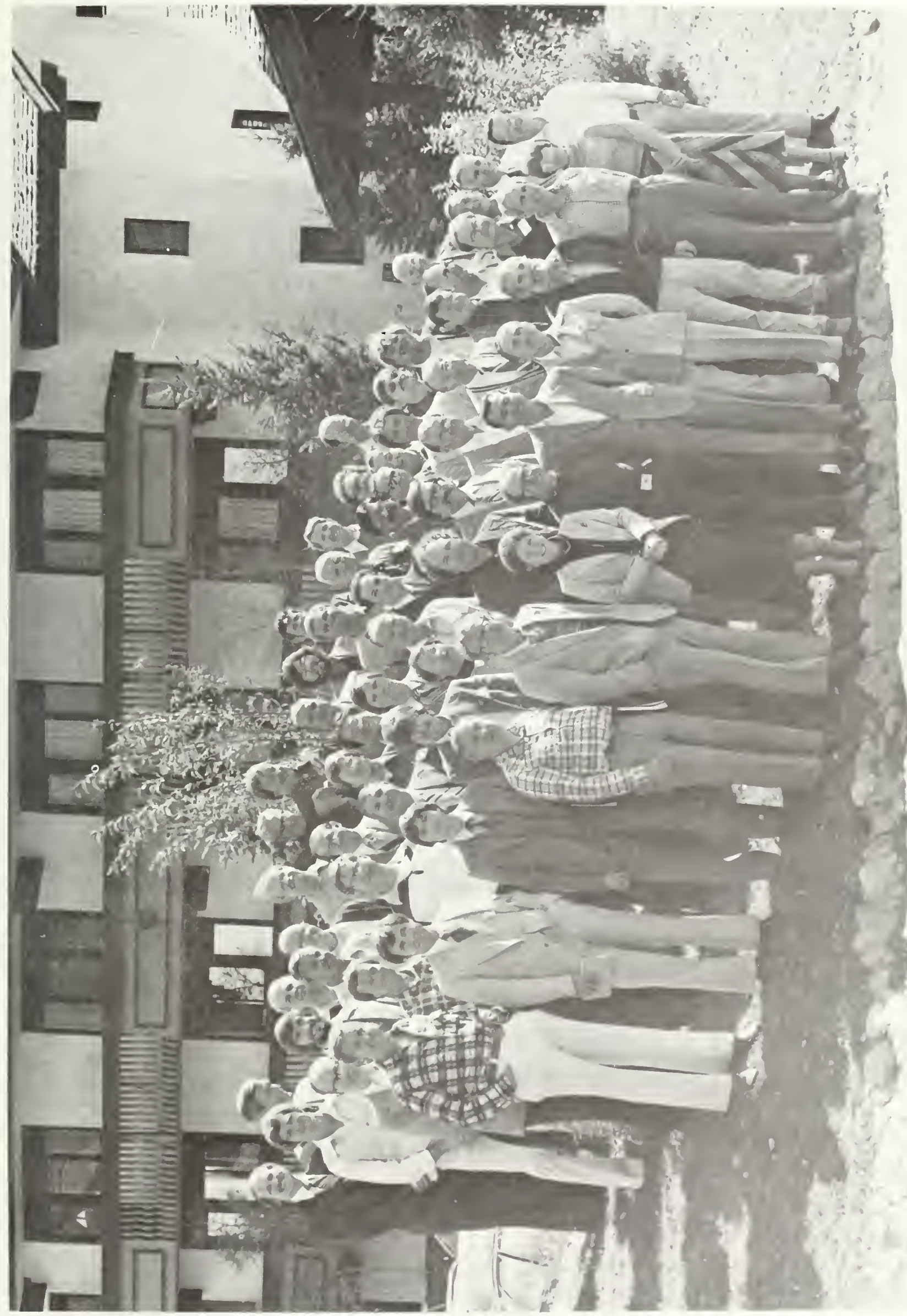

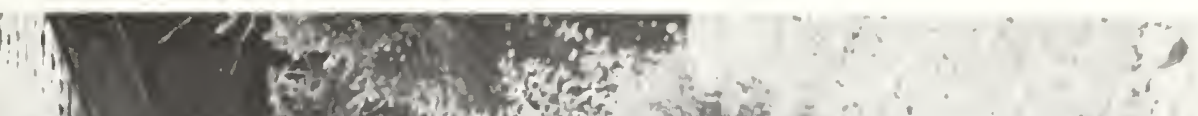



The overall objective of the program is to assist in the design, construction, and safe operation of low temperature magnetic fusion energy (MFE) systems, especially superconducting magnets, through effective materials research and materials technology transfer. The specific steps taken to achieve this objective are: (1) evaluation of low temperature materials research needs specific to MFE devices; (2) development and monitoring of a research program to acquire the necessary data; and (3) insuring rapid dissemination of the data to potential users through personal contacts, publications, and workshops.

Accomplishment of the first specific objective started with the publication of the Survey of Low Temperature Materials for Magnetic Fusion Energy in March 1977. By continuing interactions with all low temperature design, construction, and measurement programs, such as the Large Coil Project, we keep in touch with new problems as they arise. This year's contribution to accomplishment of the second objective is described here in Table 1 in the form of an outline of the research projects. The results are contained later in this report. The third objective is satisfied in part by these annual reports and by the series of NBS-DoE Workshops on Materials at Low Temperatures, which are held each fall in Vail, Colorado. 

Table 1. Outline of the NBS/DoE program on materials studies for magnetic fusion energy applications at low temperatures.

Program Area

1. Characterization

2. Effects of $C$ and $N$ on strength and toughness $\underline{\text { Organization }}$

Program Description

A. Alloys for Low Temperature Service

NBS

NBS

3. Effects of temperature NBS on strength
Fracture toughness, fatigue crack growth rates, and tensile tests at 295,76 , and $4 \mathrm{~K}$ on AISI 304,376 , $304 \mathrm{LN}$, and $316 \mathrm{LN}$.

Tensile, fracture toughness, and fatigue crack growth rate tests conducted on three carbon concentrations, each with three nitrogen concentrations of 304 base alloy.

Tensile tests of AISI $316 \mathrm{~L}$ conducted at some 20 different temperatures between 4 and $295 \mathrm{~K}$. Empirical formulation of temperature dependence of yield strength, using high temperature ORNL data.

\section{B. Physical Properties of Stainless Steels}

1. Elastic properties NBS

Measurement of the elastic properties of AISI 310 and 316 and nitrogenstrengthened stainless steels to determine temperature dependence to $4 \mathrm{~K}$.

C. Welding

1. Toughness NBS

2. Aluminum welding

Alcoa
Evaluate the toughness at $4 \mathrm{~K}$ of austenitic stainless steel welds for LCP and MFTF and of experimental welds supplied by filler metal producers. Relate toughness values to metallurgical characteristics, such as grain size, nitrogen content, and ferrite.

Determine the tensile and notch tensile properties at room temperature and $4 \mathrm{~K}$ of welds in 5083-0 plate. GMA welds using 5183 electrode in $51 \mathrm{~mm}$ thick plate were provided for evaluation by six aluminum producers and fabricators. 
3. Multi-process study Teledyne-McKay

A series of test weldments were prepared using three welding processes: gas tungsten-arc, gas metal-arc and submerged arc. Al1 welds were in 25-mm thick 304L stainless steel with $316 \mathrm{~L}$ filler wire. Tests were conducted to determine room temperature tensile properties, $76 \mathrm{~K}$ Charpy toughness, and microfissuring susceptibility.

\section{Nonmetallics for Magnet Structures}

1. Characterization NBS

Analyze the sources of cryogenic property variability in G-10CR and G-11CR industrial glass-epoxy laminates including a correlation of fracture mode with mechanical properties under tension, compression, and shear. Cooperate with national laboratories in assessing radiation resistance of the $C R$ grades including variants containing boron-free E glass. Establish the lower bound of cryogenic mechanical properties for cottonphenolic industrial laminates. Review literature to establish state of knowledge of polymer film properties at cryogenic temperatures.

\section{E. Technology Transfer}

1. NBS/DoE Workshop NBS
An annual workshop to present research results to the fusion community, to discuss new problems, and to promote interaction between interested parties. 
Listed here are the people responsible for the various major aspects of the program so that those with specific technical questions may contact the individual directly. Late in the contract year responsibility for program monitoring was transferred to D. Beard after E. Dalder left OFE to work at Lawrence Livermore Laboratories.

Department of Energy, Office of Fusion Energy, Washington, D.C. 20545
Program Monitor
D. Beard
(301) $353-4958$
(FTS) $233-4958$

National Bureau of Standards, Boulder, Colorado 80303
Program Manager
R. P. Reed
Welding
Elastic Properties
H. I. McHenry, T. A. Whipple
H. M. Ledbetter
Nonmetallics
M. B. Kasen
Structural Alloys
R. P. Reed, R. L. Tobler

(303) $499-1000, \times 3870$

(FTS) $323-3870$

Mechanical Properties Data Center, 13919 West Bay Shore Drive, Traverse City, Michigan 49684
Program Manager
R. C. Braden
(616) $947-4500$

Teledyne McKay, 850 Grantley Road, York, Pennsylvania 17405 Program Manager D. Kotecki

(717) $845-7581$

Aluminum Company of America, Alcoa Center, Pennsylvania 15069 Program Manager

R. A. Kelsey 
NBS-1ILA (REV. 0.70)

U.S. DEPT. OF COMM.

BIBLIOGRAPHIC DATA SHEET

1. PUBLICATION OR REPORT NO.

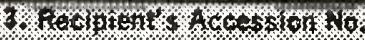

NBSIR $80-1627$

4. TITLE AND SUBTITLE

Materials Studies for Magnetic Fusion Energy Applications at Low Temperatures - III

5. Publication Date

June 1980

6. Performing Organization Code

8. Performing Organ. Report No.

7. $\operatorname{AUTHOR}(S)$

R. P. Reed, Editor

9. PERFORMING ORGANIZATION NAME AND ADDRESS

NATIONAL BUREAU OF STANDARDS

DEPARTMENT OF COMMERCE

WASHINGTON, DC 20234

12. SPONSORING ORGANIZATION NAME AND COMPLETE ADDRESS (Street, City, state, zIP)

13. Type of Report \& Period Covered

Department of Energy

Office of Fusion Energy

Washington, DC 20545

Fr. Sonsoring Asency Code

15. SUPPLEMENTARY NOTES

Document describes a computer program; SF-185, FIPS Software Summary, is attached.

16. ABSTRACT (A 200-word or less factual summary of most significant information. If document includes a significant bibliography or literature survey, mention it here.)

The reports presented here summarize the work of the low temperature materials research project for the third year of the program. The various projects are outlined and the research results are presented. The major thrust of the measurements has been the evaluation of the low temperature mechanical and physical properties of stainless steel base metal and welds, with particular emphasis on the nitrogenstrengthened stainless steels. Aluminum alloys have received some consideration also. Work has also been done on the production and standardization of nonmetallics, primarily industrial laminates, for low temperature applications and on the measurement of their properties at cryogenic temperatures. The third NBS/DOE Vail workshop was held in October 1979. A brief description is given of that program.

17. KEY WORDS (six to twelve entries; alphabetical order; capitalize only the first letter of the first key word unless a proper name; separated by semicolons)

Composites; low temperature; mechanical and physical properties; structural alloys; welding

18. AVAILABILITY

\$. Unlimited

For Official Distribution. Do Not Release to NTIS

Order From Sup. of Doc., U.S. Government Printing Office, Washington, DC 20402, SD Stock No. SNO03-003-

$[\mathrm{X}]$ Order From National Technical Information Service (NTIS), Springfield, VA. 22161

\begin{tabular}{|l|c|}
\hline $\begin{array}{l}\text { 19. SECURITY CLASS } \\
\text { (THIS REPORT) }\end{array}$ & $\begin{array}{c}\text { 21. NO. OF } \\
\text { PRINTED PAGES }\end{array}$ \\
UNCLASSIFIED & 396 \\
\hline $\begin{array}{l}\text { 20. SECURITY CLASS } \\
\text { (THIS PAGE) }\end{array}$ & 22. Price \\
UNCLASSIFIED & $\$ 20.00$ \\
\hline
\end{tabular}

USCOMM-DC 
- 
